\title{
An affordance lens on the influence of incubators on firms' strategy development
}

\author{
By Jenny Patricia Douché
}

A thesis submitted to Victoria University of Wellington in fulfilment of the requirements for the degree of Doctor of Philosophy.

Victoria University of Wellington

2016 



\section{Abstract}

Business incubators provide resources to help create successful new ventures (Hackett \& Dilts, 2004b). However little is known about how the strategies of the incubated firms develop and the specific role of incubators in this process. While incubators have received increased attention in academic literature in recent years, most of this research has focused on the economic benefits of incubators, the firms' survival rates, and on the incubators' provisions to firms. There has been minimal attention on how incubators influence what firms actually do and about strategy development in new entrepreneurial firms.

This thesis explores how incubators influence firms' strategy developments. The theory of affordances (TOA) recognises that objects allow for varying opportunities for action (Gibson, 1977) and provides the theoretical lens for this study. This lens was chosen due to its inherent acknowledgement of the complexity of relationships between objects, actors and the environment.

First the TOA, incubator, and strategy development literature are examined. This examination concludes with the development of a conceptual model to operationalise incubators' provisions and firms' strategy developments. The conceptual model highlights that the relationship between incubators' provisions and firms' strategy developments may not simply be one of cause and effect; it takes into account how the affordances of the provisions are perceived and realised, and how this is related to the incubators' influence on the firms' strategy development. The conceptual model also identifies contextual factors that could impact this process.

A mixed methodology approach was employed which involved in-depth interviews and a survey. The participants were from all six incubators that were in the New Zealand Government's incubator support programme and included both the incubators and their firms, enabling a triangulated analysis of this primarily qualitative data.

The application of the TOA aided the contribution to incubator knowledge. It was found that firms' judged the value of provisions differently depending on use, and the affordances arising from the provisions varied in scope and changed over time. The firm's product type, governance structure, duration-factors and the breadth of focus of the incubators, may be associated with how the firms perceived and realised affordances from the incubators' provisions and, in turn, how their strategies were influenced. In the process of applying the TOA in organisational studies three underlying themes emerged regarding its application; the 
specificity of affordances, the substitutability of objects and path dependency. Based on these three themes, contributions to the TOA are also proposed.

Knowledge gained from this study could inspire further use of the TOA to gain a greater understanding of its application, particularly in organisational settings. From a practice standpoint, knowledge gained should lead to enhancements and greater efficiencies in the incubation sector.

\section{Key words}

Theory of affordances, business incubators, incubator firms, new entrepreneurial firms, strategy development. 


\section{Acknowledgements}

I would like to acknowledge everyone who has supported and encouraged me on my journey to complete this doctoral thesis.

Firstly, thank you to my supervisors, Urs Daellenbach and Sally Davenport, for their enthusiasm, wisdom and time. I could not have imagined better supervisors and mentors. I truly appreciate you believing in me and taking me on as a student, for guiding me on possible directions, for encouraging me to see things from all angles, for challenging my ideas, and for reading many drafts.

Secondly, thank you to fellow students, academic and administration staff in the School of Management at Victoria University of Wellington, many of whom have provided much needed and appreciated moral support and practical assistance.

Thirdly, thank you to all the research participants, that is, the incubator managers and the entrepreneurs in the firms that were part of the New Zealand Incubator Support Programme. Without their involvement my research would not have been possible.

Thank you also to my three anonymous reviewers for taking the time to examine my thesis and provide feedback, and to Sue Beguely who proofread this document.

Finally, thank you to my husband, mother, parents-in-law, children, wider family and friends for your encouragement and for allowing me the time to pursue my doctoral ambitions. 



\section{Table of contents}

An affordance lens on the influence of incubators on firms' strategy development................... i

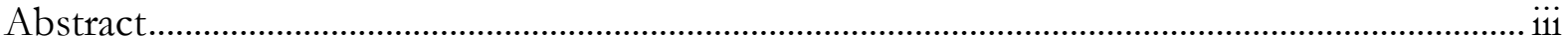

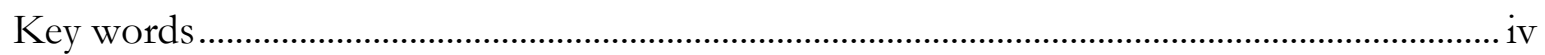

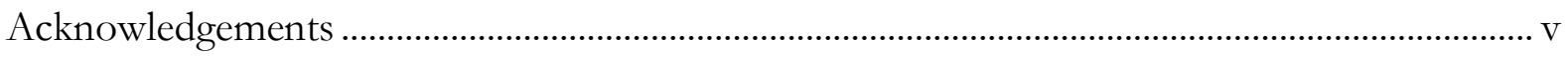

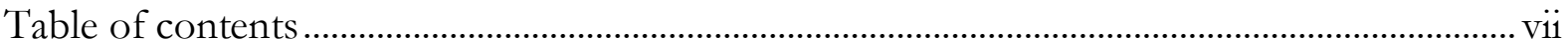

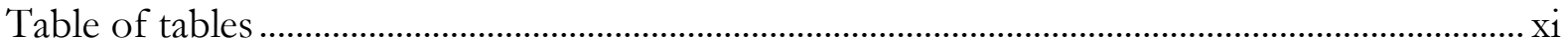

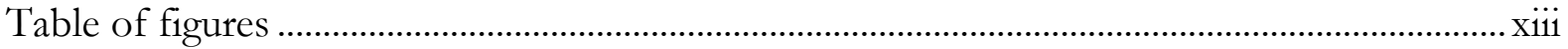

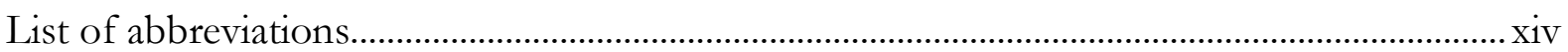

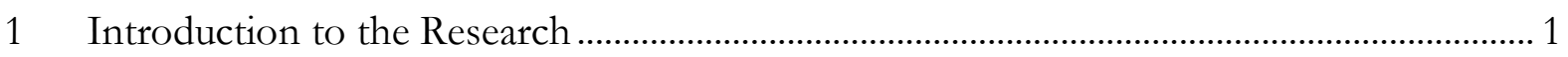

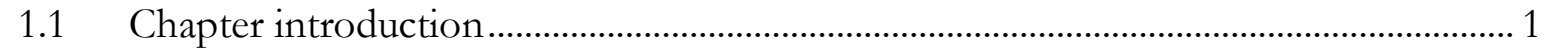

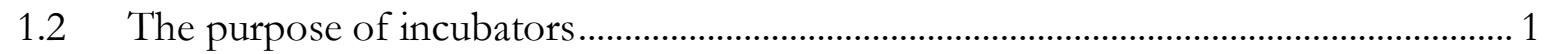

1.3 The history of business incubation ................................................................................... 3

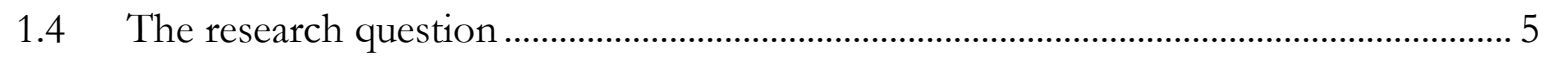

1.5 Rationale for the topic and background of the researcher........................................... 6

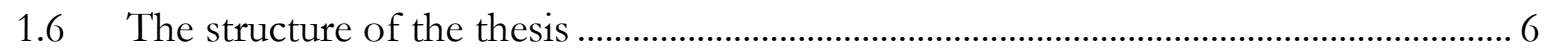

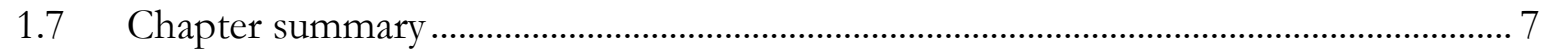

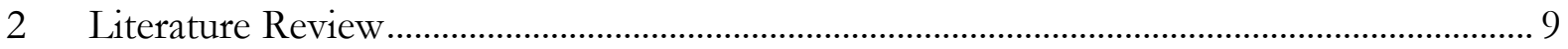

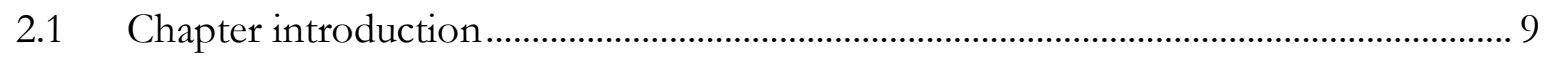

2.2 The selection of a theoretical framework ...................................................................... 9

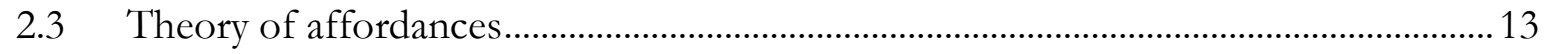

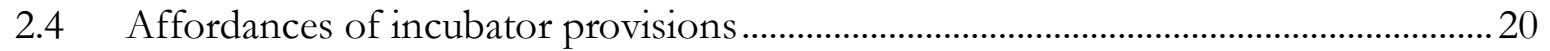

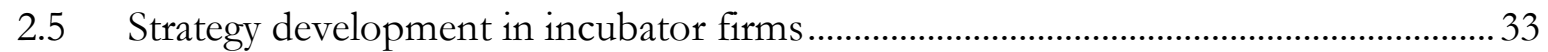

2.6 Strategy development in new entrepreneurial firms ......................................................... 34

2.7 Defining the scope of strategy development ....................................................................... 35

2.8 Dimensions of strategy development to observe ................................................................ 36

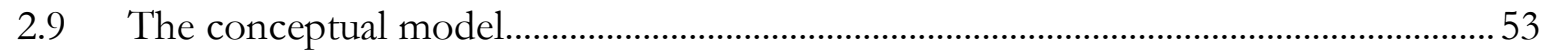

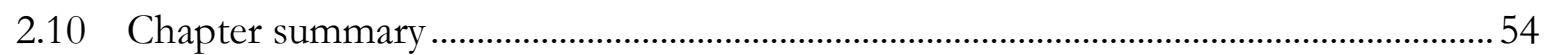

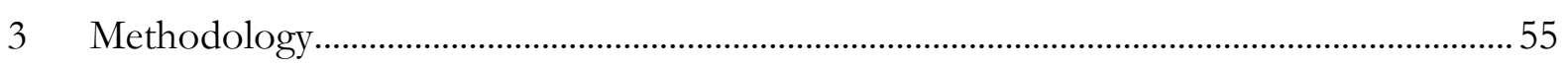

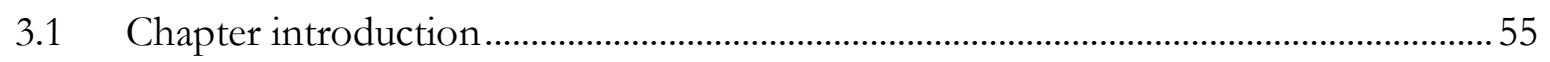

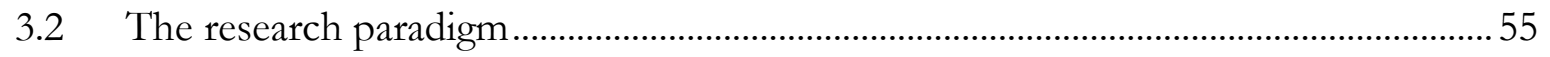

3.3 Comparison of research methods in similar empirical research ....................................57

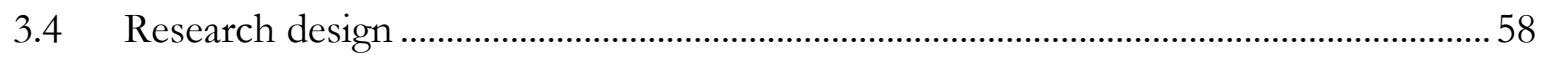




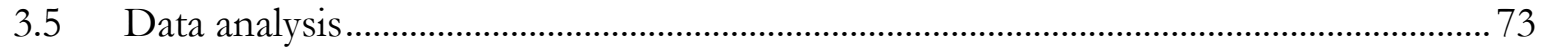

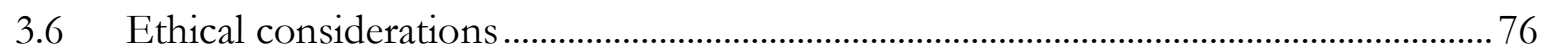

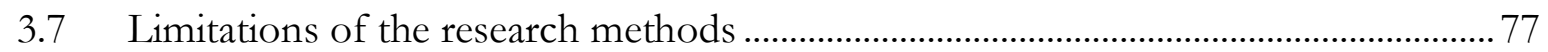

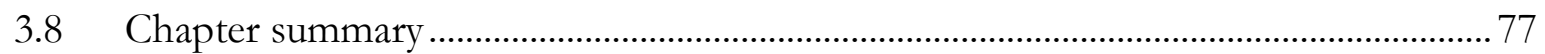

4 Findings and analysis - The affordances of incubators' provisions ...................................... 79

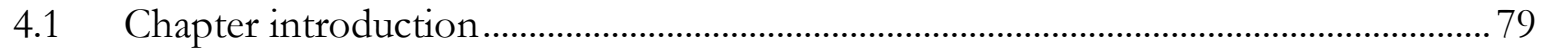

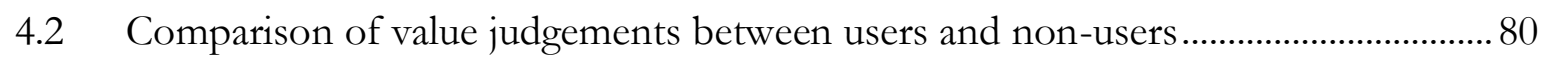

4.3 Comparison of value judgements and usage frequency ................................................ 83

4.4 Differences in awareness of provision availability and usage ………………………...... 86

4.5 The nature of the affordances from the provisions ........................................................ 87

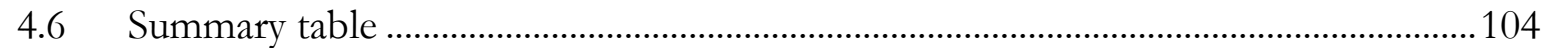

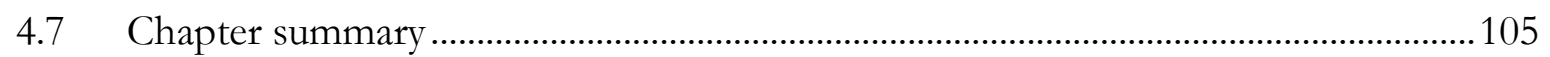

$5 \quad$ Findings and analysis - Influence of affordances on strategy development ....................107

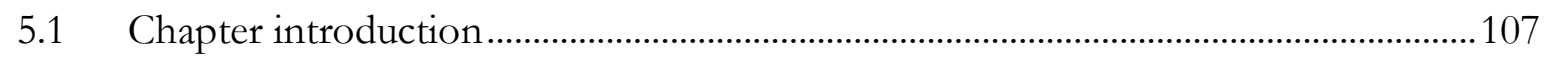

5.2 Summary counts of instances where affordances from provisions influence strategy development.

5.3 Exploration of strategy development orientations and the affordances of influence 110

5.4 Summary table 133

5.5 Chapter summary 134

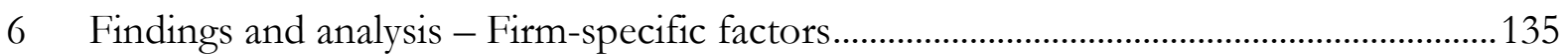

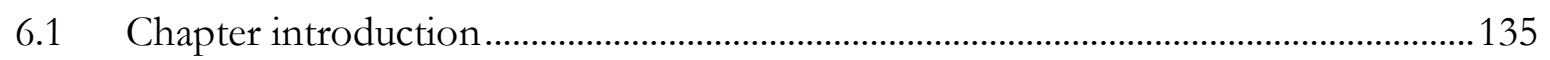

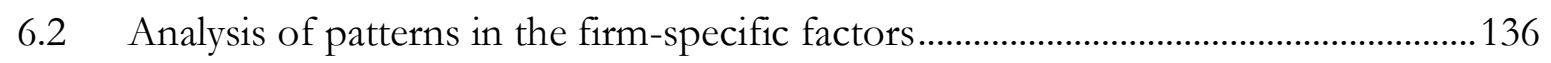

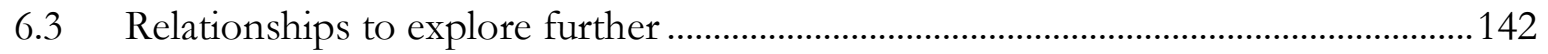

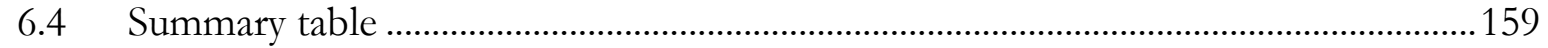

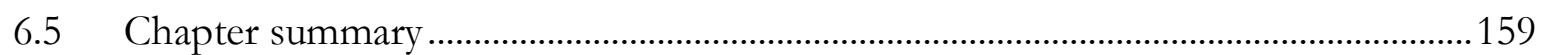

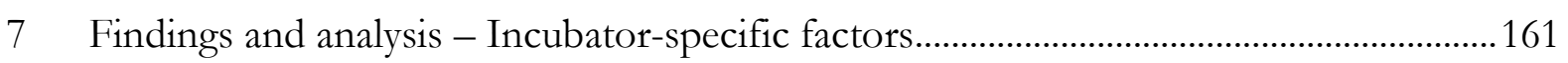

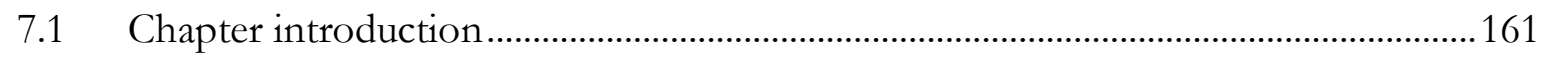

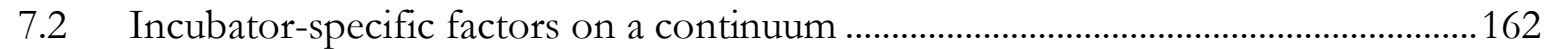

7.3 The influence of individual incubators: A triangulated perspective..............................165

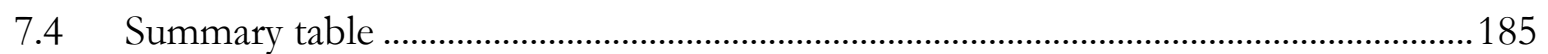

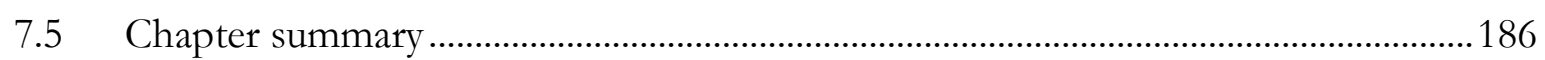

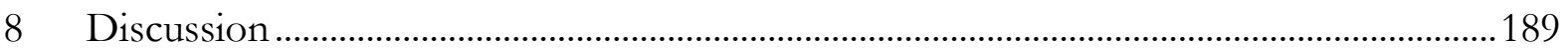




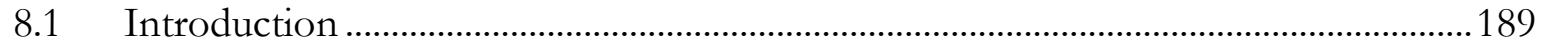

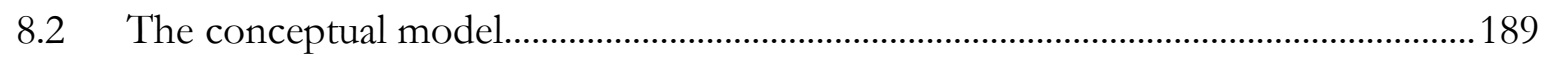

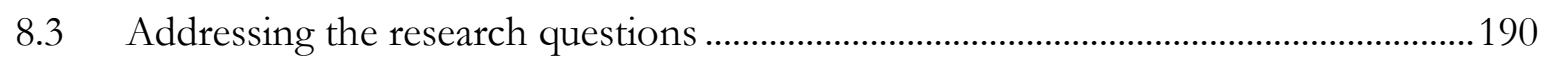

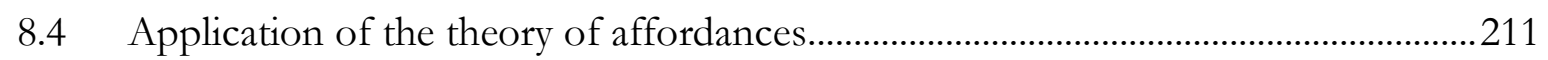

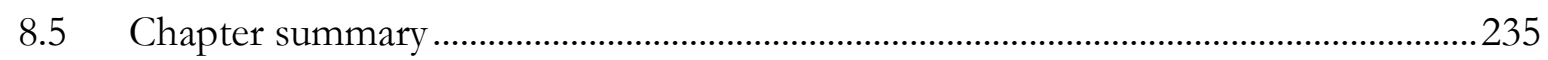

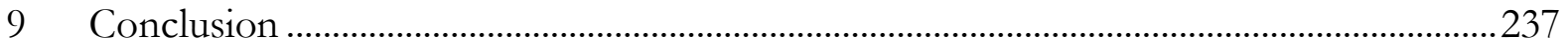

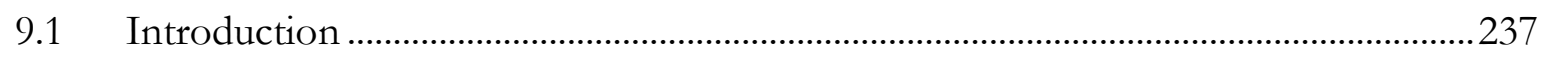

9.2 Contribution to the theory of affordances as applied in organisational studies ......238

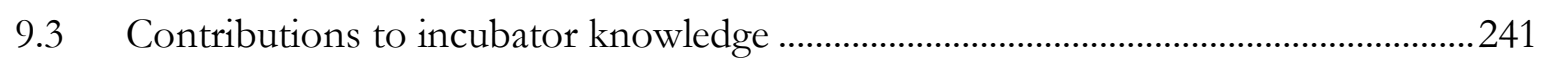

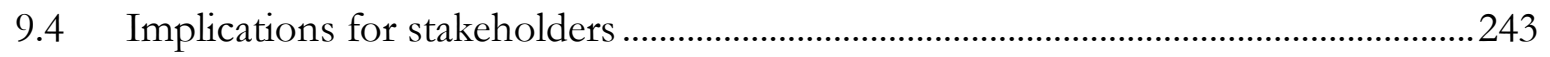

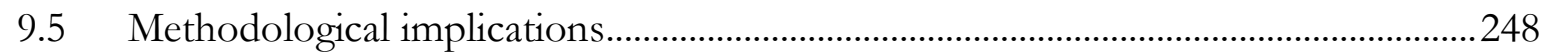

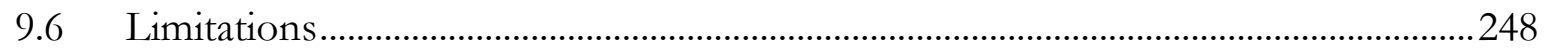

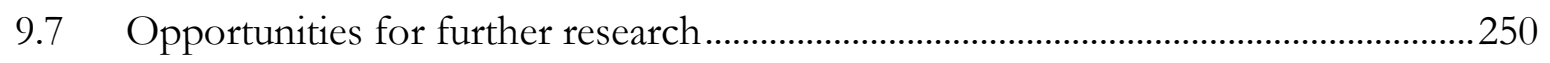

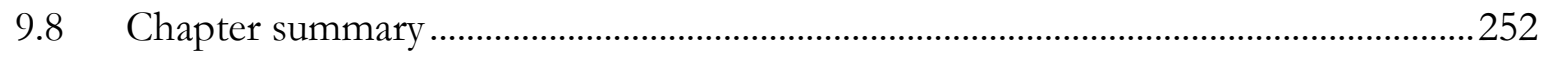

Appendix A: Information sheet for incubators (Phase One) .....................................................253

Appendix B: Interview consent form (Phases One and Three) ................................................255

Appendix C: Interview schedule (Phase One) ………………………………………………....256

Appendix D: Online survey (Phase Two) …………………….................................................257

Appendix E: Information sheet for firms (Phase Three) ...............................................................264

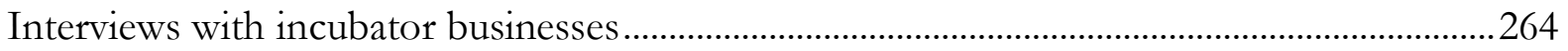

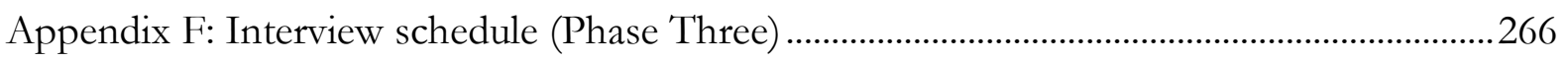

Appendix G: Firms' characteristics comparison tables .................................................................26

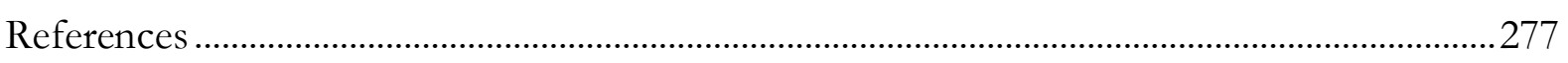





\section{Table of tables}

1 Summary of Theory of Affordances 19

2 Summary of Incubator Provisions 28

3 Summary of Empirical Studies on Provision Value and Usage 30

4 Comparison of Typology Components with Respect to Strategy Development Content 46

5 Summary of Strategy Development Continuums 53

6 Relationship Between the Research Questions and the Strands of Data Collection 60

7 Justification for the Selection of Provisions to be Operationalised 69

8 Coding Sample for Affordances of Provisions E to H 75

9 Coding Sample for Type of Change on the Product Scope Continuum 75

10 Comparison of Availability and Value Judgements of Provisions 81

11 Summary of the Characteristics of the Affordances of the Provisions 104

12 The Number of Instances Where Each Provision Influenced Strategy Development 109

13 Direction of Goal Orientation Changes and the Provisions of Influence 111

14 Direction of Change on the Deliberate to Emergent Continuum and the Provisions of 114 Influence

15 Direction of Planning Continuum Changes and the Provisions of Influence 117

16 Where the Content Orientation Strategy Developments May Fall on the Core-Periphery 119 Continuum

17 Direction of Partnership Status Changes and the Provisions of Influence 120

18 Product Scope Changes and the Provisions of Influence 123

19 Competitive Emphasis Changes and the Provisions of Influence 127

20 Direction of Time Allocation Changes and Provisions of Influence 130

21 Summary of the Nature of the Affordances of the Provisions That Influenced Strategy 133 Development

22 Key to Characteristics of Firms 136

23 Characteristics of Firms' Ordered by Number of Provisions Used 138

24 Characteristics of Firms Ordered by the Number of Strategy Developments Made 141

25 Key to the Provision Codes 142

26 Key for the Provision Awareness and Usage Tables 143

27 Provision Awareness and Usage by ITFs 144

28 Provision Awareness and Usage by HTFs 144

29 Provision Awareness and Usage by LTFs 145

30 Goal Orientation Changes According to Firms' Product Type 145

31 Deliberate to Emergent Continuum Changes According to Firms' Product Type 146

32 Planning Continuum Changes According to Firms' Product Type 146

33 Product Scope Changes According to Firms' Product Type 147

34 Competitive Emphasis Changes According to Firms' Product Type 148

35 Provision Awareness and Usage by WGFs 149

36 Provision Awareness and Usage by NGFs 149

37 Deliberate to emergent Continuum Changes According to Firms' Governance Structure 150

38 Planning Continuum Changes According to Firms' Governance Structure 151

39 Partnership Status Changes According to Firms' Governance Structure 151

40 Provision Awareness and Usage by Firms Which Had Been in the Incubator Less Than 153 One Year

41 Provision Awareness and Usage by Firms Which Had Been in the Incubator More Than 153 One Year

42 Provision Awareness and Usage by Firms Which Were Less Than One Year Old on Entry into the Incubator 
43 Provision Awareness and Usage by Firms Which Were More Than One Year Old on Entry into the Incubator

44 Planning Continuum Changes According to Firms' Duration in Incubator

45 Planning Continuum Changes According to Firms' Duration of Existence before Entry into the Incubator

46 Partnership Status Changes According to Firms' Duration in Incubator

47 Comparison of Age of Firm on Entry with Type of Product

8 Comparison of Age of Firm on Entry into the Incubator with Stage of Development

49 Summary of the Nature of the Affordances of the Provisions That Influenced Strategy Development

50 Summary of Incubator Characteristics Ordered According to its Focus of Activities and Equity in Firms

51 Summary of the Provisions Viewed as Important as Anticipated by the Incubators

52 Summary of the Strategy Developments Emphasised by the Incubators

53 Comparison of Percentage of Changes along Each Continuum According to Incubator Type

54 Comparison of the Provisions Viewed as Important by Incubator E and Used by its Firms

55 Comparison of Strategy Developments Anticipated by Incubator E and Undertaken by its Firms

56 Comparison of the Provisions Viewed as Important by Incubator A and Used by its Firms

57 Comparison of Strategy Developments Anticipated by Incubator A and Undertaken by its Firms

58 Comparison of the Provisions Viewed as Important by Incubator $\mathrm{C}$ and Used by its Firms

59 Comparison of Strategy Developments Anticipated by Incubator $C$ and Undertaken by its Firms

60 Comparison of the Provisions Viewed as Important by Incubator B and Used by its Firms

61 Comparison of Strategy Developments Anticipated by Incubator B and Undertaken by its Firms

62 Comparison of the Provisions Viewed as Important by Incubator D and Used by its Firms

63 Comparison of Strategy Developments Anticipated by Incubator D and Undertaken by its Firms

64 Comparison of the Provisions Viewed as Important by Incubator F and Used by its Firms

65 Comparison of Strategy Developments Anticipated by Incubator F and Undertaken by its Firms

66 Summary of the Nature of the Affordances of the Provisions That Influenced Strategy Development

67 Summary of the Incubator Attributes on a Continuum According to Range of Provisions

68 Summary of Key TOA Themes Extracted From the Answers to the Research Questions

69 Type of Product Compared to Types of Strategy Developments

70 Governance Structure Compared to Types of Strategy Developments

71 Time in Incubator Compared to Types of Strategy Developments

72 Age of Firm Before Entering Compared to Types of Strategy Developments

$\begin{array}{lll}74 & \text { Stage of Development on Entry Compared to Types of Strategy Developments } & 272 \\ 75 & \text { Locerteraction with Advisor Compared to Types of Strategy Developments } & 273\end{array}$

75 Location of Head Office Compared to Types of Strategy Developments 275

76 Background of Participant Compared to Types of Strategy Developments 276 


\section{Table of figures}

1 Typology of incubator provisions 20

2 Typology of strategy development orientations 37

3 Conceptual model showing the relationships between the key constructs and contextual 53 factors and how each

4 The research strands adapted from the multistrand design in Creswell and Clark (2011) 59

5 The conceptual model with the focus of Chapter Four highlighted 79

6 Value judgements and usage frequency of provisions if used 84

7 Summary of awareness of availability and the usage of the internal-tangible provisions $\quad 87$

8 The conceptual model with the focus of Chapter Five highlighted. 107

9 Summary of the categories of provisions that influenced strategy development 108

10 The conceptual model with the focus of Chapter Six highlighted. 135

11 The conceptual model with the focus of Chapter Seven highlighted. 161

12 Proportion of firms that used provisions in incubator E and the influence on strategy 168 development

13 Proportion of firms that used provisions in incubator A and the influence on strategy 171 development

14 Proportion of firms that used provisions in incubator C and the influence on strategy 174 development

15 Proportion of firms that used provisions in incubator B and the influence on strategy 177 development

16 Proportion of firms that used provisions in incubator D and the influence on strategy 180 development

17 Proportion of firms that used provisions in incubator $\mathrm{F}$ and the influence on strategy development

18 Conceptual model showing the relationships between the key constructs and contextual factors

19 Example of 10C's repeated use of a provision due to the ability to extract ongoing value

20 Proposed continuum of provisions according to their frequency of use and scope of affordances

21 Example of ITF firm 7D showing how their product was flexible and why it changed substantially

22 Example of HTF firm 24B showing how prior investment in product development constrained development

23 Example of WGF firm 18C showing how and why the advice from the incubator decreased

24 Example of firm 22D showing how and why their level of planning decreased

25 How the three specificity concepts are related to the conceptual model

27 Comparative example of clustering of affordances from provisions

28 Comparative example of how the environment may be related to affordances 219

29 How the three substitutability concepts are related to conceptual model 222

30 Comparative example of how the ease of substitution depends on the object and the actor 223

31 Comparative example of how the substitution of some objects can maximise the 227 affordances of others

32 The conceptual model showing that affordance perception and realisation is path dependent

33 Example of how firms may engage with incubators' provisions over time

34 Factors influencing future realisation 


\section{List of abbreviations}

Throughout this thesis a number of abbreviations are introduced and applied. Some of these abbreviated terms are new, and are introduced accordingly in the text. These relate to either categories of firms or incubators that have been identified as being relevant.

\begin{tabular}{|l|l|}
\hline BFI & Broad-focused incubators \\
\hline HTF & High-technology firm \\
\hline ISP & Incubator Support Programme (Callaghan Innovation) \\
\hline ITF & Information-technology firm \\
\hline LTF & Low-technology firm \\
\hline NEF & New entrepreneurial firms \\
\hline NFI & Narrow-focused incubators \\
\hline NGF & No external governance firms \\
\hline TOA & Theory of Affordances \\
\hline WGF & With external governance firms \\
\hline
\end{tabular}




\section{Introduction to the Research}

\subsection{Chapter introduction}

This study seeks to address the overarching question: How may incubators influence firms' strategy development? The theory of affordances (TOA) was used as a theoretical lens to explore this question. The use of this lens is a recognition that the affordances of incubators' provisions may vary and therefore produce various strategy development outcomes that do not necessarily follow a simple cause and effect relationship. Knowledge gained from this study is expected to generate further discussion on the application of the TOA, particularly in the organisational context. The new knowledge should also contribute to incubator literature and practice. While this study explores incubators in the New Zealand context, it is anticipated it may have application to other geographic regions.

Chapter One introduces the history and purpose of business incubators, the overarching question that this study is addressing, and the rationale for the choice of topic and, finally, the structure of the thesis.

\subsection{The purpose of incubators}

Business incubators provide resources to help create successful new ventures (Hackett \& Dilts, 2004b) and some researchers believe that business incubators play a substantial role in economic development (NBIA, 2013d; Sherman \& Chappell, 1998). The literature also reflects widespread support for the notion that the incubation process reduces the risk of new firms failing and increases their growth, job creation and survival rates (Al-Mubaraki \& Busler, 2012; Gstraunthaler, 2010; Sherman, 1999; Sherman \& Chappell, 1998) and that, overall, incubators are an effective tool when it comes to helping firms (Al-Mubaraki \& Hamad, 2013; Grimaldi \& Grandi, 2005).

Incubators are defined by Al-Mubaraki and Busler (2013) as "an economic and social development entity designed to advise potential start-up companies, help them establish, and accelerate their growth and success through a comprehensive business assistance program" (p. 368). Peters, Rice, and Sundararajan (2004) defined an incubator more succinctly as "a support environment for start-up and fledgling companies" (p. 83). 
There appears to be widespread agreement in the literature on the general classification criteria of business incubators. In an extensive review of the literature Bergek and Norrman (2008) concluded that there are four recurring criteria an organisation must meet in order to be classified as a business incubator. These criteria include the provision of shared office space that is normally flexible and subsidised; shared support services; professional business support and advice; and internal and external networks. The holistic nature of incubator support is unlike that which is provided individually by professional service providers such as banks, lawyers and accountants or by shared accommodation facilities such as business parks.

Incubators achieve favourable outcomes firstly by promoting the concept of entrepreneurship (Al-Mubaraki and Busler, 2012; Madichie, 2010) followed by enabling and facilitating innovative ideas to be transformed into an opportunity (Al-Mubaraki and Busler, 2012; NBIA, 2013d; Savescu, 2010). However, it is not just the ideas that need nurturing; the firm itself needs to be developed and its growth accelerated utilising the incubator's resources (Al-Mubaraki \& Hamad, 2013). Importantly, incubation appears to not only accelerate a firm's success, but also help reduce the cost of potential failure, as costs are kept to what is rationally minimal and contained within the incubator (Hackett \& Dilts, 2004b). These authors considered that the incubator achieves this cost containment by functioning like a laboratory for entrepreneurial firms, staging the investment of the resources in the incubator firm to the appropriate level of development that the firm has reached. Incubators provide these targeted resources and services (provisions), which are coordinated by incubator management (Erlwine \& Gerl, 2004).

While all incubators generally have a commonality in their provisions, their overall purpose can vary from country to country and can depend on the key objectives of their governments. This situation results in differences in the types and intensity of their provisions. For example, in New Zealand start-ups are seen as a critical component of the innovation system (Callaghan, 2015) and assist the innovation process though nurturing the business as a whole (Incubators New Zealand, 2011c). New Zealand's Ministry of Business Innovation and Employment has recognised that business incubators can help stimulate entrepreneurship (MBIE, 2012), and therefore there is value in supporting them. 


\subsection{The history of business incubation}

Business incubation is a relatively new concept with the Batavia Industrial Center (BIC) being widely recognised as the first incubator, according to the National Business Incubator Association in the United States (NBIA, 2013c). BIC was formed in 1959 in Batavia, New York, as a result of a real estate developer acquiring a large building space and not being able to find a suitable tenant that was capable of leasing the whole building space (Adkins, 2001). Instead the developer sublet the building to multiple tenants, some of which sought business- and capital-raising, advice. BIC is still in existence (BIC, 2013). The concept of what would now be loosely defined as business incubation was underway, and in 1963 the University City Science Center (UCSC) was developed in Pennsylvania (UCSC, 2015). The UCSC remains the oldest and largest urban research park in the United States and it has incubated over 350 organisations since its inception. The UCSC was a collaboration between universities, federal laboratories, non-profit research and development institutions and private companies, as many modern incubators are today.

During the 1960s and 1970s the number of incubation programmes grew slowly. Most of these were government-sponsored initiatives representing an effort to revitalise the economy. However, the concept of using business incubators to stimulate and institutionalise best practices for evaluating and commercialising inventions was not introduced until the 1970s with the formation of the United States National Science Foundation's Innovation Centres Program (Bowman-Upton, Scheirer, 1985; Seaman \& Sexton 1989). This development was followed by strong growth in the number of business incubators in the 1980s in the U.S. The U.S. Small Business Administration was formed in 1985 to help promote incubator development (Hackett \& Dilts, 2004b). This resulted in an increase in new incubator openings from about 20 annually in 1984 to more than 70 annually in 1987 (NBIA, 2013c). The USSBA had strong support from the United States Government. It was also during this time that academic incubation studies began in earnest (Hackett \& Dilts, 2004b).

The incubator concept has spread quickly since the 1980s, and to many regions around the world including Europe (Al-Mubaraki \& Busler, 2013; Schwartz, 2011), and China (Xu, 2010). Incubation has also become an important strategy for enterprise development in both developed and newly developing countries (Economic Commission for Europe, 2001; OECD, 1999). Most countries now boast a thriving incubation sector (Hannon, 2005). As at 
October 2012 there were about 1,250 incubators in the United States and about 7,000 business incubators worldwide (NBIA, 2013a).

\subsubsection{Incubation in New Zealand}

In New Zealand business incubation is a relatively new concept. The government-funded Incubator Support Programme (ISP) has been in operation since 2001 (NZTE, 2013b). There were six incubators within this programme at the time of data collection in mid-2014. The purpose of the ISP is to provide financial and other assistance to incubators, enabling them to effectively help firms with high-growth potential through "technology and market validation, business planning and development, capability development, investment preparation, governance and advisory board advice, and shared working space. Some incubators also provide investment capital" (Callaghan Innovation, 2014). The New Zealand Government has provided funding for incubators through the ISP, an incentive which has had a positive impact on business development. This positive impact was evident in 2011 when the Chair of Incubators New Zealand, Steve Corbett, said, "We have achieved a huge amount in the last ten years, and I'm confident and optimistic about what the next ten years hold for incubators, and for start-ups, in New Zealand” (NZTE, 2011). NZTE (2011) reported, "Over the past 10 years, more than 250 ventures have graduated from an incubator; 69 per cent of these have raised external investment, 71 per cent are still trading, and 57 per cent are exporting. Along the way over 1100 high value jobs have been created." It appears that incubation in New Zealand is a successful undertaking.

In 2001 two incubators formed in Auckland: the Icehouse, and Massey University's ecentre; and powerHouse Ventures was established in Christchurch. In 2003 Creative HQ opened in Wellington, Upstart opened in Dunedin in 2004 - it later merged with powerHouse Ventures - the Bio-Commerce Centre (BCC) opened in Palmerston North in 2004 and, most recently, SODA opened in Hamilton in 2009. Since 2001 other incubators have come and gone. The focus of this study however is on incubators that are part of the ISP because they are considered to fit the business incubator classification criteria as identified by Bergek and Norrman (2008).

In addition to the incubators already in the ISP, up to four new technology incubators are planned at a cost of NZ\$31.3m over four years. Under the scheme’s Repayable Grants 
Programme, grants of up to $\$ 450,000$ each will be available to firms, a scheme which is based on the successful Israeli model of incubation (Joyce, 2013).

Incubators come in a range of shapes and sizes depending on their constituent elements as Al-Mubaraki and Hamad (2013) found in their international study into the value of incubation as an economic development tool. The situation is no different in New Zealand, where the incubators concentrate on developing entrepreneurs that come into the incubator with pre-formed ideas or firms or the incubators focus on investing in complex technology that is generally derived from publically-funded research organisations (Joyce, 2014).

\subsection{The research question}

Incubators appear to be successful in supporting the development of NEFs through their extensive provisions to these firms. Research to date has not expressly focussed on how incubators' provisions influence firms' strategic development. The existing research has explored how valuable the provisions of incubators are and how this value changes with use, but not the relationship between the provisions and how the firms actually change what they do as a result. Notable incubator researchers such as Hackett and Dilts (2004b) have also concluded that very little attention has been paid to the incubators themselves and to their innovations and resulting outcomes; rather, the focus has been on the facilities and services that incubators provide to the firms. Hackett and Dilts recommended that further research is needed on the incubation process to draw attention to the factors influencing the development of new firms within the incubator environment (Hackett and Dilts (2004b). Further, Bergek and Norrman (2008) concluded that the issue of whether incubator business models are aligned effectively with the firms' performance also requires further investigation to ascertain the effectiveness of incubators' provisions. It is for this reason that this study will specifically seek to address the influence of incubators' provisions on firms' strategy development, thus going some way to address these important knowledge gaps. The overarching research question is:

How may incubators influence firms' strategy development?

This research question is further divided into four sub-questions, which are explained following the presentation of the conceptual model at the conclusion of the literature review. 
While it is not well known how incubators influence strategy development, there has been research into firms' use and perceptions of incubator provisions. Some of these studies showed that provisions relating to the incubators' physical infrastructure were valued and used the most, with provisions relating to advice generally not being as useful as the firms initially perceived.

\subsection{Rationale for the topic and background of the researcher}

Strategy development was chosen as the focus of this study because the purpose of incubators is to apply their resources to successfully develop NEFs. It is therefore anticipated that the strategies of the firms may also develop. This expectation was based on the researcher's experience in creating and managing a graduate firm in Wellington's incubator Creative HQ and, later, as an employee of that same incubator's management team. During this time the researcher noted that the influence of the incubator on the firms' strategy development appeared substantial in many cases. This study presented an opportunity to study empirically this largely unexplored relationship.

\subsection{The structure of the thesis}

Chapter Two is the literature review, which comprises an investigation of the literature and which resulted in the selection of the TOA as the theoretical lens, a determination of how to operationalise the provisions of business incubators and strategy development, and a discussion of the contextual factors that need to be acknowledged. This chapter concludes with the proposed conceptual model to address the research question.

Chapter Three describes the methodology. This chapter explains the rationale for the research philosophy, compares the research methods of related empirical studies, and then explains the research design, the research participants, the design of the research tools, the data collection process, the analysis methodology and, finally, the ethical considerations.

Chapters Four to Seven present the findings and analysis. Chapter Four discovers what the nature of the affordances of provisions are. Chapter Five uncovers how the incubators' affordances influence strategy development in order to understand both the cause of the strategy developments and the direction in which they developed. Chapter Six examines how the firms' contextual factors are related to the incubators' influence on strategy development. Chapter Seven explores how the incubators' contextual factors are related to the incubators' influence on strategy development. The purpose of analysing contextual factors is to help 
understand how these variances are related to the influence of the affordances on strategy developments, and the direction in which strategies developed.

Chapter Eight presents the discussion. This commences with an in-depth discussion of the findings relating to the sub-questions and the ensuing key discoveries that were apparent from the findings and analysis chapters. This covers how the findings compare to existing knowledge and how the various circumstances may have occurred. Based on these key discoveries, specific themes emerged about the application of the TOA and these are explored in detail.

Chapter Nine concludes with the contribution of this study to the application of the TOA in organisational studies, and the implications for incubators and firms. The limitations and the opportunities for further research are also described.

\subsection{Chapter summary}

Chapter One provided context to the rationale for the research and a background to the literature on incubators both internationally and in New Zealand. The purpose of the research and the research question were presented. A more in-depth examination of the literature is addressed in Chapter Two. 


\section{Literature Review}

\subsection{Chapter introduction}

In Chapter Two the rationale is explained for selecting the theory of affordances (TOA) as an appropriate theoretical framework in the context of other possible theories. What is known about incubators' provisions is reviewed, along with their possible affordances. The nature of strategy development in NEFs is discussed and three broad orientations for exploring the firm's strategy developments are identified. Contextual factors that are likely to impact the incubator's influence on strategy development are explored.

The chapter concludes with the presentation of the conceptual model, which brings together the key components that formulate the four specific research questions within the overarching research question.

\subsection{The selection of a theoretical framework}

The selected theory needed to adequately address the research question: How may incubators influence firms' strategy development? The key premise of this question is: If incubators provide common provisions to their firms, how and why do firms develop their strategies differently? Addressing the nuances of the relationship between the incubators' provisions and the firm's strategy development was therefore deemed critical.

When reviewing the literature it became evident that a range of theories were commonly used in studies of business incubators and strategy development. These were resourceorientated theories such as the internally-focussed Resource-Based View and the externallyfocused Resource-Dependency Theory, socially-orientated theories such as Stakeholder Theory, Network Theory, Actor-Network Theory and Co-evolution Theory, and practiceorientated theories such as Strategy-as-Practice, and a sub-set of which, TOA. Next these theories are reviewed with particular attention paid to their characteristics, why they were not selected as the theoretical lens for this research, and what additional insights they may have provided if they had been applied.

\subsubsection{Resource-Based View (RBV)}

RBV considers that strategy is formulated by looking at resources that are available to the firm, which are different for each firm and are not perfectly mobile (Wernerfelt, 1984). This 
heterogeneity of resources between firms and immobility is said to impact a firm's ability to deliver sustained competitive advantage (Barney, 1991).

In the context of this research the resources in question (incubator provisions) are generally homogenous to all firms in the incubator, and are quite mobile in that they can be utilised as required. Therefore immobile and unique-to-firm resources are not necessarily constraining the firms in the incubator context, and so using RBV may have de-emphasised the key issue being explored, which is why firms are influenced differently when the resources are relatively common to all firms.

However, if used in this research, RBV would have ensured the consideration of all resources available to the firm and not just resources available from the incubator. Attention would have been paid to things such as the firm's capital, staffing and intellectual property in considering how these factors may have had a moderating effect on the incubators' influence on strategy development.

\subsubsection{Resource dependency theory (RDT)}

RDT looks at organisations as open systems that are dependent on the possibilities enabled by the context of the external environment (Pfeffer \& Salancik, 2003). Managers of organisations seek to gain the power to control the external environment in order to reduce uncertainty, and to gain power over others. However, start-ups, by their very nature, are not considered to be actively seeking to reduce uncertainty, rather they are about exploration of new opportunities (Kiss, 2010; Nicholls-Nixon et al., 2000). Consequently, while a role of incubators could somewhat be considered to be about uncertainty reduction (for example, incubators generally offer firms office space on a month-by-month basis and they appear to mandate that firms validate their markets) their main focus is arguably on identifying opportunities for high growth, which is inherently risky.

If used, RDT would focus the research on the influence of incubators on their role in uncertainty reduction and control-based activities, as opposed to opportunity discoveryrelated activities. However, potentially the application of TOA meant that risk mitigation was largely ignored in this research due to the inherently growth focused nature of incubator firms. 


\subsubsection{Stakeholder theory (ST)}

ST addresses morality and values in organisational management (Freeman, 1984). Freeman identified and recognised the importance of considering a variety of stakeholders beyond just the shareholders, which had traditionally been viewed as most important. These stakeholder groups include employees, customers, government organisations and even competitors.

However, this research focusses on the influence from just one stakeholder group, the incubator. Adopting a ST lens would potentially have diluted the strength of the research question due to the sheer number of stakeholders that firms may have. Additionally the influence of interest in this research is just one-directional, in that it doesn't consider the influence that the firms may have on the incubator, here the incubator is considered a resource, not a party whose views and needs have to be considered.

Adopting a ST lens could have enabled greater insights into other sources of influence on firms' strategy development, beyond just those of the incubator. It could have explored if and how the firms had consideration for the incubator itself, and for the firm's relationship with the incubator, when making strategy development decisions.

\subsubsection{Co-evolution theory (CT)}

Similar to ST, CT considers the two-way relationship between entities. Phan, Siegel and Wright (2005) suggest that there is a need to explore the coevolution of incubators and their tenant firms, which is that firms and incubators evolve together and are dependent on each other.

If applied to this research CT could have provided insights into how the incubators developed along with the firms, and importantly, what they individually and collectively learned and how they adapted during this process. However, as this research is just exploring the influence of incubators on the firms, and not the other way around, CT was deemed to offer too broad a perspective. Although, if used, CT would potentially have revealed more about why incubators operate in the way that they do, and if and how this is due to coevolving with the firms.

\subsubsection{Network theory (NT)}

O'Donnell, Gilmore, Cummins, and Carson (2001) attest that researchers have appeared to adopt two different definitions of networks as they apply to the process of entrepreneurship, inter-organisational networks and personal networks. These authors discuss that the premise 
of the inter-organisational networks is orientated towards successful strategic adaptations and could encompass vertical and horizontal networks and industrial networks. NT, in an interorganisational context, is about obtaining resources to improve competitive advantage and therefore, in this regard, has similarities with the resource-orientated theories. In contrast the term personal network is viewed by O'Donnell et al. (2001) as being somewhat interchangeable with the term social network or personal contact network, and encompasses the relationship of an individual with other individuals.

NT has relevance to this research because a key premise of incubators is their extensive networks which arguably could be both inter-organisational and personal. There are a multitude of ways that these networks help firms, from providing professional advice, to connections to sources of capital.

While NT may address the purpose of the network connections it doesn't specifically address the process of the influence and why the use of similar networks and other provisions of the incubator and how they may result in different strategy development outcomes for the firms. However, if applied to this research NT could have provided insights into the purpose of the wider networks of the firm, as opposed to just focusing on the networks provided by the incubator (the external-intangible provisions). This would have enabled a more balanced and contextual perspective on the incubator's influence.

\subsubsection{Actor Network Theory (ANT)}

In contrast to studies on social networks (e.g. NT above), which are concerned with the social relations of humans, ANT describes the nature of societies and incorporates nonhuman and non-individual entities, and explores the possibilities that they offer (Latour, 1996) and what motivates human actors to align with non-human actors (Gao, 2005).

Applying ANT to this research would have ensured a focus on the relationship that firms have with the incubator's tangible provisions, such as office space, as well as with the social networks. However, while ANT considers why these relationships occur it does not explicitly consider the relationships between the objects (provisions) themselves and how they may cluster together resulting in different kinds of opportunities.

\subsubsection{Strategy-as-Practice (SAP) and theories of affordances (TOA)}

The SAP perspective focuses on the actual tools and practical activities involved in strategy planning (Chia \& MacKay, 2007). It also considers that strategy is a situated activity, one that 
is continually under construction, and is both distributed and collective (Jarzabkowski, 2004). The pragmatic nature of SAP research is further evidenced in that it seeks to explain and solve problems, as opposed to the research being defined by the specific theories that are being adopted (Jarzabkowski, Balogun \& Seidl, 2007). Therefore, as Vaara and Whittington (2012) attest, SAP has broadened the strategy literature beyond just economic performance, which is arguably the emphasis in RBV and RBT due to their focus on manipulating resources to obtain competitive advantage, as discussed above.

Given the process-orientation of SAP and its emphasis on how strategy practitioners think and interact (Whittington, 1996) it was deemed to be an appropriate "umbrella" lens for exploring the relationship between the firms and the provisions of the incubators, and the resulting influence on firms' strategy development.

In the organisational context TOA is a sub-set of SAP. As viewed by Norman (1999) TOA emphasises the variances in perceptions (thinking) and realisations (interactions) resulting from objects. Affordances are about the naturally occurring and actionable relationships between the world and an actor, or in this case the incubator and the firms. The key principle is that actors see what an object enables them to achieve as opposed to the object's physical properties (Gibson, 1979). Critically, these perceptions vary depending on the user (Sadler \& Given, 2007) and affordances of an object (provisions) and the ensuing opportunities for action (strategy developments) are not a simple one-to-one relationship, they may also be one-to-many and many-to-one. TOA therefore addresses the complexity of the influence of the incubator on the firm and allows for an in-depth understanding of the complex nature of the incubator's influence on firms' strategy development, within the wider SAP framework. For the reasons above the TOA was selected as an appropriate lens to explore the research question despite limited application in organisational studies. The discussion that follows explores the development of the TOA since its inception. Propositions are included as to how the TOA could apply to incubator firms.

\subsection{Theory of affordances}

A perceptual psychologist, J. J. Gibson, was among the first to develop the TOA (Gibson, 1979). From his observations he concluded that affordances were about the naturally occurring and actionable relationships between the world and an actor. Affordances, in his view, were based on the actor's visual perception of the natural world. He claimed that when someone looks at an environment they perceive the opportunities for action as opposed to 
perceiving just its physical properties, and that while aspects of the object can be described such as its shape, colour and substance - people don't usually pay attention to this; rather, they focus on what that environment or object enables them to achieve. The concept of affordances is explained simply by Zhao et al. (2013) using an example of a chair with four legs. When a person sees a chair they recognise it instantly as an object that they can sit on, as opposed to seeing just its physical properties. Similarly a doorknob is recognised as an object that will enable a person to open a door. The affordance phenomenon is therefore about the actions that occur as a result of an object and an actor coming together. Following Zhao et al, for example, when an entrepreneur looks at their office space in the incubator, they may see beyond objects such as desks, computers and filing cabinets, and see instead an environment that can help them develop a more robust strategy.

In their study of how graduate students engage with libraries, Sadler and Given (2007) concluded that opportunities for action can also be perceived differently depending on the actor. These authors gave the example of a rock as the object. To a lizard the rock may afford a hiding place or something on which to sunbathe, but to a person the rock may afford a weapon or a building material. The perceptions of use vary, and therefore there is no single or correct use of the rock. The affordance is therefore relative to the individual actors, as Gibson (1979) noted, and thus the environment or object could mean different things to different people based on their experience, knowledge or culture (Norman, 1999). For example, one incubator firm may see the provision of market validation from the incubator as a way to determine what features their product needs, whereas another firm may see the same affordance as a way to find an entirely new market. Therefore in this current research it was considered important to compare how different firms perceive the affordances of the same provision in terms of both its existence and of its value.

Maier (2008) expanded the concept of affordances by arguing that single objects may also have multiple affordances with respect to the same actor. Maier used the example of windows, which both afford views outside and, when opened, afford fresh air. In business the types of affordances of an object can be diverse and, as Maier also identified, an object such as a manufacturing plant can have multiple affordances to a firm such as ease of manufacture, assembly and maintenance. Maier also reported that while affordances are generally positive, they are not always desirable or intended; there are positive affordances, such as the operations of a motor, and negative affordances such as the excess heat 
generated by that same motor. Therefore it cannot be assumed that all affordances of objects have a positive influence, and that all incubators' affordances may benefit the firms.

Further, affordances occur not only as a result of interactions between single actors and objects, but also they are the result of complex interactions between multiple actors and objects as van Osch and Mendelson (2011) demonstrated in their study of sociomaterial interactions between developers, users and artefacts. Given the potential for an extensive variety of uses of the incubator provisions, and the wide range of potential needs of the firms, this complexity of interaction is somewhat inevitable. For example, the provision of pitching practice sessions may offer some firms the affordance of building their confidence, whereas for others it may be a way to directly connect with potential investors.

According to Letiche and Lissack (2009) "affordances are a dynamic reciprocal relationship between animate persons and their environments" (p. 61). Fayard and Weeks (2007) demonstrated how TOA can help understand the relationship between environments and actors, namely the physical and social elements. They did this by showing that photocopier rooms can afford informal interaction by bringing people together, giving them privacy through providing physical barriers, and through giving them a reason to stay together. Thus the actor's behaviour is roughly shaped with respect to an environment and its physical and social characteristics. For incubator firms the affordances of social interactions within the incubator environment may be critical, given the frequently close physical proximity of the firms.

Building on the notion of social interaction in the social media interaction design setting, Zhao et al. (2013) concluded that affordances are not static, rather they have dynamic attributes and that affordances can also take into account more than just 'objects', that is, they also incorporate the wider concept of 'environment', and include the corresponding contexts and culture (Zhao et al., 2013). Therefore affordances are neither specific attributes of a person or the environment; rather they are about the relations between the person's abilities and the features of the environment. This focus on the wider environment, and not just on a single object, makes the view of Zhao et al. especially relevant to incubators as it is likely that some affordances cannot be isolated to a single object. For example, the affordance of assistance with market validation may not come from just the incubator's staff, but also from its networks. 
In notable contrast to Gibson's (1979) view of affordances as being about the possibility of an actual action between the actor and the object, Norman (1999), through his research on affordances as they relate to design, emphasised that the perception of affordances can be manipulated. Norman identified the differences between real and perceived affordances, that is, that a real affordance is about the actions that actually occur, whereas a perceived affordance is about the actions that are perceived as possible by the user. The real and perceived affordances of an object may not be the same, and the perceived affordances may not actually even exist. Norman argued that it is the perceived affordances or their value, not the real affordances that determine the object's usability, although there is often substantial overlap. Further, the perceived affordances depend on the individual perception of each perceiver (Zhao et al., 2013). This is potentially critical in the incubator environment as incubator management could potentially manipulate information about possible affordances. Therefore it is important to compare the perceptions of affordances by incubator management with those of the firms.

Given Norman's emphasis on design and its role in influencing perceptions, it is not surprising that Gibson and Norman have fundamental differences in their definitions of affordances. Norman himself made these distinctions clear (Norman, 1999). For Gibson, affordance is about the possibility or perception of the actual action between the actor and the object, whereas Norman is much more concerned with the portrayal of the possibility of the action to the actor and how this portrayal can be manipulated, thus presenting different opportunities for action to the actor.

The perception of these affordances can rely on learning (Nye, 2013) and they can be hidden, that is, the actor is not yet aware of the affordances so they are not perceived at all (Gaver, 1991). Once actors are aware of the affordances only then can the opportunities for action be perceived. Zhao et al. (2013) also found that actors may not be aware of affordances and the detection of which depends on the actor's abilities to detect them. Incubator affordances may be similar to multi-media affordances identified by Zhao et al. in that they are not immediately apparent, and their detection depends to some extent on the firm's relationship with the incubator.

It is not only the wider environment that impacts the perception of the affordance, it is also influenced by the prospective control of affordances. That is, in order to be able to realise the goal that a particular action affords, the person must be able to perceive whether it is 
indeed possible to complete the whole action, and the required sub-actions (Turvey, 1992). Turvey used an example of a person walking across a cluttered room and needing to navigate the furniture in their way. An entrepreneur in an incubator firm may perceive an affordance of financial investment from venture capitalists. However the possibility of successfully achieving this may be remote, and therefore the action may not be attempted.

McGrenere and Ho (2000) discussed the notion of varying degrees and stages of affordances as they relate to software design. The authors highlighted the need to clearly distinguish between two aspects: usability and usefulness. Usability relates to the user interface and to the portrayal of information about the affordance, and usefulness is the functionality of the affordance. This concept of stages of affordance was furthered by Hartson (2003). Following Norman's (1999) pioneering essay Affordance, Conventions, and Design, Hartson wrote a conceptual paper that expanded on the usefulness of the affordance concepts in terms of how they could be applied to interaction design and evaluation. Hartson identified four levels of engagement with affordances: cognitive, sensory, physical and functional. He looked at how an object's design features could support and facilitate thoughts or actions with respect to these four aspects of affordances. Hartson's specific focus was on the affordances of human-computer interaction. He recognised that when a user interacts with an object they perform cognitive, physical and sensory actions that lead to the affordance. The four terms are not mutually exclusive and are all part of the process of perceiving and realising an affordance. That is, first the user perceives the affordances, for example by seeing, hearing or feeling the possibility offered. Next the user interprets that perception cognitively using information provided about the object or environment. The user may then execute an action or sequence of actions, a physical affordance. The result is that the user accomplishes the opportunity for action that the affordance offered (Hartson, 2003). Therefore, the four concepts of affordance mostly occur for any single affordance, as they are part of the cycle of realising the affordance, as opposed to a difference in types of affordances. Hartson's concepts therefore built on Norman's notion that realising an affordance is a process, starting at perception and potentially leading to realisation.

Given the large variety of possible affordances available and the uniqueness of each firm it is anticipated that there may be differences in the way that affordances are perceived and realised by incubator firms. 


\subsubsection{Application of the TOA in empirical research}

Since its inception, the concept of affordances has been applied to many fields, as noted by Maier (2008). Applications include workplace learning and innovation, childhood psychology, ecological psychology, the design of graphical-user and control-room interfaces and mobile robots. No empirical studies were found that apply the TOA to the field of business incubation. A summary of aspects of TOA as concluded in the literature are provided in Table 1.

Given the complexity of incubators, the TOA is the chosen theoretical lens as it has the potential to provide insight into the largely unexplored field of the influence of incubators on firms' strategy development. Incubators offer high-intervention environments, which at a macro level, have the purpose of influencing strategy development. Specifically, the infrastructure, advice and network provisions enable affordances designed to aid in the development of the incubator firms during their two- to three-year period of incubation. The potential affordances are vast in number and scope. However, the way in which these provisions are perceived and used can vary depending on the firms and on the wider environment (the incubator), and this perception and usage potentially changes over time. The affordances may not even be perceived by the firm at all, and then, if they are perceived, they may not actually be used in the way anticipated by the incubator. The extent to which affordances are perceived versus realised is therefore of particular interest in this study. Letiche and Lissack (2009) reflected on the value of applying the TOA as a theoretical lens in organisational studies attesting that "[traditionally] management studies are geared around the retrospective reduction of what was to a set of rules" (p. 71) and that this is done in retrospect. Affordances, on the other hand enable a less constrained analysis. As they went on to explain "The logic of affordances is a logic of relationship and possibility. Affordances are about the could be and not the IS" (p. 71).

Table 1 provides a summary of the key conclusions drawn from applications of the TOA. 
Table 1

Summary of Theory of Affordances

\begin{tabular}{|c|c|}
\hline Theory of Affordances & Reference \\
\hline $\begin{array}{l}\text { When someone looks at an environment they focus on what that environment or } \\
\text { object enables them to achieve as opposed to perceiving just its physical } \\
\text { properties. }\end{array}$ & Gibson (1979) \\
\hline $\begin{array}{l}\text { Affordances can be hidden so the actor is not aware of them. It is only once the } \\
\text { actor is aware of the affordances that the opportunities for action are perceived. }\end{array}$ & Gaver (1991) \\
\hline $\begin{array}{l}\text { In order to be able to realise the goal that a particular action affords the person } \\
\text { must be able to perceive whether it is indeed possible to complete the whole action } \\
\text { and the required sub-actions. }\end{array}$ & Turvey (1992) \\
\hline $\begin{array}{l}\text { A real affordance is about the actions that actually occur, whereas a perceived } \\
\text { affordance is about the actions that are perceived to be possible by the user. The } \\
\text { real and perceived affordances of an object may not be the same, and the } \\
\text { perceived affordances may not actually even exist. }\end{array}$ & Norman (1999) \\
\hline $\begin{array}{l}\text { There is a need to distinguish clearly between two aspects: usability and usefulness. } \\
\text { Usability relates to the user interface and to the portrayal of information about the } \\
\text { affordance and usefulness is functionality of the affordance. }\end{array}$ & $\begin{array}{l}\text { McGrenere \& Ho } \\
(2000)\end{array}$ \\
\hline $\begin{array}{l}\text { Affordances therefore are neither specific attributes of a person or of the } \\
\text { environment, rather they are about the relations between the person's abilities and } \\
\text { the features of the environment and, as a result, are both real and perceivable. }\end{array}$ & Chemero (2003) \\
\hline $\begin{array}{l}\text { There are four levels of engagement with affordances: cognitive, sensory, physical } \\
\text { and functional. An object's design features could help, aid, support and facilitate } \\
\text { thoughts or actions with respect to these four aspects of affordances. Specific } \\
\text { focus was on the affordances of human-computer interaction. }\end{array}$ & Hartson (2003) \\
\hline $\begin{array}{l}\text { The perceptions of affordances can only occur when the environment meets the } \\
\text { actor. }\end{array}$ & Yang et al. (2004) \\
\hline $\begin{array}{l}\text { Opportunities for action may be different depending on the relationship of the } \\
\text { actor to the environment. }\end{array}$ & Bryson et al. (2006) \\
\hline $\begin{array}{l}\text { Informal interaction amongst people can also enable a range of affordances. The } \\
\text { affordances from an environment not only arise from its physical properties they } \\
\text { also come out of its social meaning and how it is normally used. }\end{array}$ & $\begin{array}{l}\text { Fayard \& Weeks } \\
(2007)\end{array}$ \\
\hline $\begin{array}{l}\text { Opportunities for action can be perceived differently depending on the actor, for } \\
\text { example, to a lizard the rock may afford a hiding place or something on which to } \\
\text { sunbathe, but to a person the rock may afford a weapon or a building material. }\end{array}$ & Sadler \& Given (2007) \\
\hline Single objects may have multiple affordances with respect to the same actor. & Maier (2008) \\
\hline $\begin{array}{l}\text { Affordances are about the logic of relationship and possibility, and are therefore } \\
\text { about the future rather than a constrained analysis of the past. }\end{array}$ & $\begin{array}{l}\text { Letiche \& Lissack } \\
(2009)\end{array}$ \\
\hline $\begin{array}{l}\text { Affordances can be designed in that they were intended, improvised from an } \\
\text { intended object, or emergent in that they were neither designed nor intended. }\end{array}$ & $\begin{array}{l}\text { van Osch \& } \\
\text { Mendelson (2011) }\end{array}$ \\
\hline $\begin{array}{l}\text { The actors' characteristics are related to the role of affordances and the lack of } \\
\text { heterogeneity of an affordance can result in greater opportunities for action. }\end{array}$ & $\begin{array}{l}\text { van Dijk, Berends, } \\
\text { Jelinek, Rommer \& } \\
\text { Weggeman (2011) }\end{array}$ \\
\hline $\begin{array}{l}\text { The capacity of the actor can impact how affordances are realised in the same } \\
\text { environment. }\end{array}$ & $\begin{array}{l}\text { Gram-Hansson \& } \\
\text { Bech-Danielson } \\
\text { (2012) }\end{array}$ \\
\hline $\begin{array}{l}\text { Affordances are not static, rather they have dynamic attributes that occur during } \\
\text { interactions between organisms and the environment. Perceived affordances are } \\
\text { multi-faceted in nature and are thus detected differently depending on the actor's } \\
\text { abilities to detect them. }\end{array}$ & Zhao et al. (2013) \\
\hline
\end{tabular}




\subsection{Affordances of incubator provisions}

As stated earlier in the chapter, the TOA imply that a variety of opportunities for action (affordance) may arise from the provisions of incubators. An examination of the literature resulted in the development of a typology of incubator provisions. First the incubator provisions are categorised. A common differentiation is whether the provisions are tangible such as infrastructure-related services, or intangible such as counselling and business assistance services, and incubator networks, as concluded by Abduh, D’Souza, Quazi, and Burley (2007). Further, these services and infrastructure may be provided internally or externally to the incubator (Erlwine \& Gerl, 2004; Hackett \& Dilts, 2004b). These two basic categorisations were combined to form the basis of a typology of incubator provisions (see Figure 1). The number of provisions and the associated affordances vary greatly between the four categories, as reflected in the size of the discussion on each category.

\begin{tabular}{c|l|l|}
\cline { 2 - 3 } Internal & Internal-tangible & Internal-intangible \\
\cline { 2 - 3 } External & External-tangible & External-intangible \\
\cline { 2 - 2 } & Tangible & Intangible
\end{tabular}

Figure 1. Typology of incubator provisions

The reason for categorising the provisions as either tangible or intangible, and internal or external, was to enable analysis and pattern identification of affordances within groupings of provisions.

The word internal, according to Oxford Dictionaries (2013), means "of or situated on the inside". This word, so defined, will be used with reference to incubator provisions that are provided within an incubator's premises, and include services and facilities that are provided by the incubator's staff, such as mentoring and office space. By contrast, the most applicable meaning of external is "coming or derived from a source outside the subject affected" (Oxford, 2013). An incubator's external provisions therefore include those provided by an incubator's external stakeholders such as professional advisory partners.

The word tangible means "a thing that is perceptible by touch" (Oxford, 2013). This definition will be used with reference to incubator provisions related to infrastructure, including provisions that, while not being tangible in themselves, are connected to tangible 
objects, such as internet, phone services and finances. Again, by contrast, intangible means "unable to be touched; not having physical presence" (Oxford, 2013). Intangible incubator provisions are defined here primarily as services such as advisory meetings and connections to networks.

Examination of the literature revealed specific provisions that may be relevant to this study. The results of the NBIA's research into developing a best-practice model for incubation (Lewis, Harper-Anderson and Molnar, 2011) are worthy of consideration. The research by Lewis et al. (2011) determined the most pertinent incubator provisions with respect to positive firm performance and involved surveying 111 incubation programmes throughout the US. The authors found that the incubator services that aligned best with positive firm performance included training entrepreneurs in business basics and new firm management, access to investment capital, facilitation of relationships with local tertiary institutions, production assistance from prototyping to manufacturing and the development of strong mentoring programmes. The incubation programmes that were most successful had similar management practices. These included having written mission statements, staff selection criteria that prioritised cultural fit, facilitation of the showcasing of incubators to the community and to potential funders, along with robust rent and service fee payment plans.

Due to the limited number of empirical studies that apply the TOA, and the dearth of studies on affordance-related concepts with regards to incubator firms, little is known about the specific affordances of the incubator provisions. This thesis addresses this gap in knowledge.

\subsubsection{The internal-tangible provisions}

The internal-tangible provisions arise from the infrastructure services and meet many of the incubator firms' physical office-based requirements. Rice (2002, p. 173) referred to this group of provisions as "passive environmental intervention" which includes office space, internet access, and office and specialised equipment (Abduh et al., 2007; Al-Mubaraki \& Busler, 2012). Peters et al. (2004) expanded on these provisions to include labs and conference facilities. The office space provided to incubator firms is normally charged at below market rates $(\mathrm{Xu}, 2010)$ enabling cost savings.

The office space is often flexible, as Tornatzky, McCrea and Lewis (1996) contended, with the size varying depending on the needs of the incubator firm, and often has flexible rental payment terms. This flexibility gives a firm the affordance of capacity to hire temporary employees, without having to commit to office space that would potentially be unused. Also 
typically included within the greater incubator environment are meeting and conference rooms, a kitchen or cafeteria, and lunchrooms (Tornatzky et al., 1996). Other internaltangible provisions include shared office services, such as secretarial, reception and mailhandling services (Xu, 2010) and building security (Tornatzky et al., 1996). These provisions could enable substantial cost savings, and infrastructure support.

Incubators sometimes provide financing from their own internal sources (Webb, 2012). In the US, financing is provided through the provision and management of revolving and microloans (NBIA, 2013a).

\subsubsection{The internal-intangible provisions}

While internal-tangible provisions potentially offer affordances relating to cost savings and infrastructure support, they do not necessarily build the firms' value (Mitra, 2013). Mitra argued that the true value of a new firm is created by having a validated product or service that has endorsement from its customers. In Mitra's view there are two critical things that determine the success of a new firm: a validated market and the right products or services to fit the opportunity. It is the role of the incubator to help a firm achieve these outcomes. Provisions that come under the umbrella of internal-intangible provisions come from the incubators' staff, advisory board and the various incubator firms and their staff (Hackett \& Dilts, 2004b). The provisions are primarily service-based, and include advice by incubator management to help the firm develop and orchestrate their business, marketing and management resources (Al-Mubaraki \& Busler, 2013). Provisions also provide support with the development of a sound business model (Rubens, Jackson, \& Andrews, 2011), as well as strategic planning (Abduh, D’Souza, Fry, 1987; Quazi \& Burley, 2007b; Webb 2012). Specifically, advice that is offered by an incubator's management often includes aspects such as business management, market development, manufacturing, commercialisation, presentation skills, human resources, personal development and business etiquette (AlMubaraki \& Busler, 2012). Advice is therefore an important element of support that incubators provide, and is something that sets them apart from other organisations that offer business infrastructure support such as industrial parks and small business hubs (Xu, 2010). In addition to providing firm-specific advice, Xu has suggested that an incubator's management team also forms a point of contact between the incubator firm and resources and, as Peters et al. (2004) noted, provides educational workshops and seminars. 
The provisions are generally no different in New Zealand, with incubators providing incubator firms with mentoring, advice and training on practical topics such as technology, business management skills and on fundraising (NZTE, 2013). New Zealand incubators emphasise a requirement that firms first rigorously test business opportunities to determine their likelihood of success (Incubators New Zealand, 2011c). Specific market validation methodologies have been adapted and developed to test these opportunities, and are also utilised at the pre-incubation screening stages to determine the likely market for ideas, thus reducing the risk of firm failure (Webb, 2012). Assistance with market validation is therefore potentially a critical component of incubation in New Zealand. The ensuing affordances could thus include the identification of viable market opportunities and the products or services that will fill that need.

This study proposes that a prerequisite of being able to effectively analyse the firms' internal and external environment depends on a firms' ability to gather data about its internal and external environment through the process of product validation and market validation. Data gathering is viewed as an important function of all firms and is critical if firms are to adjust their strategies (Nicholls-Nixon, Cooper, \& Woo 2000). According to Woo, Daellenbach, and Nicholls-Nixon (1994) every activity that a firm undertakes is a consequence of a decision resulting from their interpretation of data. The interpretations made by the entrepreneur are imperative in effectively defining the firms' environment. Woo et al. (2004) concluded that, in contrast to larger, more mature firms that have established data collection systems, NEFs tend to rely mainly on their own environmental scanning abilities, which may be a far less objective method. This is especially the case with new innovations as there is no prior environmental data to use as a benchmark. This view is backed up by van Gelderen (2012) who has asserted that information needed by new firms can be hard to get, unreliable, lacking in specificity, or irrelevant. It is not just the early developmental stages where data availability is an issue. Sometimes, if a firm is in a state of rapid growth, any feedback about the state of the market may go undetected, before it is too late (Garnsey \& Heffernan, 2005). The notion that NEFs need to have a constant and recurrent feedback loop between the challenge faced, the firms' innovative response and the predicted outcome was discussed by Oliver and Garnsey (2005). Moreover, West and Meyer (1997) found that technology-based firms should focus on identifying, embracing and then communicating ideas that challenge their present strategy, thus resulting in reinvigoration through new and proactive growth opportunities. 
Incubator management also generally helps with the overall financial education of incubator firms, including with the important aspect of helping the firm establish the real need for capital (Aaboen, Lofsten, \& Bengtsson, 2011). However, it is also equally important to educate firms on what is not fundable (Mitra, 2013). Once the need for funding has been established, incubator management can assist firms with the creation of appropriate investment-ready presentations and business plans (McAdam \& Marlow, 2011; NBIA, 2013b). These services offer important affordances to the firm as the capital markets have very specific requirements of what information is required from firms and how it is to be presented.

Given that a key function of incubator management is to give advice, knowledge sharing is considered an important internal-intangible provision of incubators (Patton \& Marlow, 2011; Warren, Patton \& Bream, 2009), affording the firm with targeted and timely learning. This view has been supported by Rice (2002) who attested that the purpose of the incubator environment is to allow the incubator firms to benefit from the superior knowledge of the incubator managers. Rice found that while incubator firms had strong knowledge regarding development and production specific to their product or service, they had less knowledge regarding business development topics such as financial management, sales, marketing, distribution, and the development and management of a team. As Hughes, Hughes, and Morgan (2007) concluded, knowledge sharing is not only two-way but there is an expectation that the more knowledge that is shared, the higher the performance outcomes. These authors found that in the United Kingdom the government supported incubation by investing over $£, 125 \mathrm{~m}$ in the five years to 2007 , with the view of maximising this knowledge sharing. This high level of expenditure is therefore considered testament to the belief held by the UK government that knowledge sharing enables positive outcomes within incubators. This view of maximising knowledge sharing in incubators was furthered by Boschma (2005), who found that for knowledge sharing to be most effective, and for this interactive learning to occur, firms need to have just the right amount of what the author referred to as cognitive proximity, which is the ability of an actor to take in new ideas. Too little cognitive proximity can result in misunderstandings and too much can result in a reduced level of novelty.

Vital affordances could also arise as a result of interaction between the incubator firms themselves, as networking occurs due to the physical nature of incubator firms being under one roof $(\mathrm{Xu}, 2010)$. In their study of networking within a university business incubator, 
Cooper et al. (2012) found that face-to-face interaction with the other incubator firms was the dominant networking occurrence in the incubator, with the physical proximity of the firms influencing who is spoken to most. This firm-to-firm networking affords incubator firms the ability to get social support, as Cooper, Hamel, and Connaughton (2012) found, with the support helping entrepreneurs manage stress and to feel like they were part of an 'in-group'. Further, Bøllingtoft (2012) found that internal networking helped further embed the incubator firms within entrepreneurial networks. Ziemer and Long (2009) concluded that internal networking enabled an increased impetus to the launch of a new venture. Jack and Anderson (2002) found that it assisted with the creation of opportunities and improved performance, and Xu (2010) found that sometimes business was conducted between firms. In a study of two incubators in the US, Lichtenstein (1992) found that the most important contribution to entrepreneurship that incubators made was that they enabled entrepreneurs to easily interact and to form relationships with others in the incubator, which can result in instrumental benefits such as revenue and capability gains, and psychological and developmental benefits. Schwartz and Hornych (2012) found that internal networking between the incubator firms was much more advantageous in specialised incubators than in diversified incubators, but there were drawbacks in that there was a degree of distrust amongst the incubator firms, and a greater tendency to towards keeping information secret.

\subsubsection{The external-tangible provisions}

Following on from the critical step of becoming investment-ready, incubator management can help the incubator firm actually apply for capital as Aaboen et al. (2011) noted, by facilitating connections with angel investors and venture capitalists, with assistance in the preparation of the presentations, and by helping incubator firms apply for loans (NBIA, 2013a). During this investment preparation process professional client advisors can act as sense-makers between the organisations with the capital and the firms (McAdam \& Marlow, 2011).

Connections to financial institutions increase the access and availability of needed capital for incubator firms. This capital-raising function is a critical aspect of incubation because, as Armstrong and Mullin (1983) noted, obtaining financing can be a significant problem for incubator firms, given that they often have, among other things, little managerial experience. Little appears to have changed in this regard since Armstong and Mullin's early empirical study of new US firms, so it is not surprising therefore that helping incubator firms secure 
capital is a key service provided by incubator management, as identified by the NBIA (2013b). Incubators assist with obtaining necessary finance for business growth (Al-Mubaraki $\&$ Busler, 2013). To deliver effectively on this function there are a range of external networks designed to facilitate incubator firms obtaining finance from public and private sources.

Financing is a priority for New Zealand incubators. Incubators New Zealand (2011a) showed that New Zealand incubators are viewed as "key players in the New Zealand investment community" and have developed vehicles, such as angel networks and seed funders, to connect incubator firms with the investment community. In addition, NZTE provides funding to the incubator firms in the form of research and development grants of up to $50 \%$ of project costs, with the remaining contribution made by the firm (NZTE, 2013a). Capital can also be obtained through grants provided by local and national economic development agencies such the science and innovation grants provided by TechNZ (NZTE, 2013c). Not surprisingly then, as McAdam and Marlow (2011) noted, just being in an incubator increases the opportunities for incubator firms to come into contact with potential investors. This view is supported by Aaboen et al. (2011) who found that incubator firms are more successful at obtaining capital than are non-incubator firms, and that they are more successful at obtaining capital from public investors as opposed to private investors.

\subsubsection{The external-intangible provisions}

Affordances of the external-intangible provisions relate to an incubator's external networks. Strong networks are critical for incubator firms to create competitive capabilities (Muniz, Morales-Gutiérrez \& Ariza-Montes, 2013). Incubator firms generally have substantial resource and funding gaps due to their newness, which can limit their development potential. An incubator's wider networks can help fill some of these gaps (Rice, 2002). Access to external people and organisations is therefore a key, intangible function of incubation.

The overall benefits of incubation were investigated by (Xu, 2010), who researched 61 incubator firms in Shanghai, China. Xu found that incubators were very effective in enhancing the credibility and visibility of incubator firms. These positive image effects were also confirmed by the findings of Schwartz and Hornych (2012), with the most favourable image effects made possible by associations with business partners in the incubator's external networks. A lack of credibility in NEFs can prevent them from outsourcing to larger firms, because NEFs do not have, among other things, a significant history of operations (Murphy, Wu, Welsch, Heiser, Young \& Jiang, 2012). An incubator's external networks could therefore 
afford substantial credibility, helping to counter this negative effect (Rice, 2002). This concept of newness being a liability for firms was notably explored by Stinchcombe (1965) who argued that new organisations are more likely to fail than older organisations largely due to their high dependence on others, and to their frequent inability to compete against incumbent organisations.

External networks of incubators can be vast, and may include local universities and industry contacts (Hackett \& Dilts, 2004b); advisory and board members, business training, banks and other loan sources, strategic partners and legal services such as intellectual property management (Al-Mubaraki \& Busler, 2012); innovation communities and industries (Hackett \& Dilts, 2004a); providers of professional services such as lawyers, accountants and marketing experts (Hackett and Dilts, 2004a; UCF, 2013); insurance services, website development, government contracting, human resources, office supplies and services, telecommunications (UCF, 2013) and funders such as angel investors and venture capitalists (Hackett \& Dilts, 2004b). Therefore the range of networking opportunities is generally immense, but many of these affordances may not actually be realised. As Rice, (2002) found, the most frequently used provisions of the external networks were, in descending order, assistance to gain outside equity financing or investment banking, access to laboratories and equipment, shops, computer processing, libraries and legal services. Given that many of the professional services provided by these networks are available at a subsidised cost, they are potentially more likely to be utilised, thus affording the firm cost savings and the benefits gained from the use of the services.

Table 2 provides a summary of the main provisions of incubators as identified in the literature. 
Table 2

Summary of Incubator Provisions

\begin{tabular}{|c|c|c|}
\hline $\begin{array}{l}\text { Provision } \\
\text { category }\end{array}$ & $\begin{array}{l}\text { Broad provision } \\
\text { grouping }\end{array}$ & Specific provisions and references \\
\hline \multirow{3}{*}{$\begin{array}{l}\text { Internal- } \\
\text { tangible }\end{array}$} & \multirow{3}{*}{$\begin{array}{l}\text { Shared office } \\
\text { space and support } \\
\text { services (Bergek \& } \\
\text { Norrman, 2007) }\end{array}$} & Subsidised office space and internet access (Abduh et al., 2007; Xu, 2010) \\
\hline & & Shared office services (Xu, 2010) \\
\hline & & Capital from incubator's funds (Webb, 2012) \\
\hline \multirow{9}{*}{$\begin{array}{l}\text { Internal- } \\
\text { intangible }\end{array}$} & \multirow{7}{*}{$\begin{array}{l}\text { Professional } \\
\text { business support } \\
\text { and advice (Bergek } \\
\text { \& Norrman, 2007) }\end{array}$} & $\begin{array}{l}\text { Business planning and growth advice (Abduh et al., 2007; Fry, 1987; Incubators } \\
\text { New Zealand, 2011b; Webb, 2012) }\end{array}$ \\
\hline & & $\begin{array}{l}\text { General business management advice (Al-Mubaraki \& Busler, 2012; Lewis, } \\
\text { Harper-Anderson \& Molnar, 2011) }\end{array}$ \\
\hline & & Educational workshops (Peters et al., 2004) \\
\hline & & Fundraising support (Aaboen et al., 2011; McAdam \& Marlow, 2011) \\
\hline & & Market validation advice (Incubators New Zealand, 2011b; Webb, 2012) \\
\hline & & Knowledge sharing (Rice, 2002; Warren et al., 2009) \\
\hline & & Development of exit strategies (Patton, Warren \& Bream, 2009) \\
\hline & \multirow{2}{*}{$\begin{array}{l}\text { Internal networks } \\
\text { (Bergek \& } \\
\text { Norrman, 2007; } \\
\text { Patton, Warren \& } \\
\text { Bream, 2009) }\end{array}$} & $\begin{array}{l}\text { Social support and feeling like they are part of an in-group (Cooper et al., } \\
\text { 2012) }\end{array}$ \\
\hline & & Embed firms with entrepreneurial networks (Bøllingtoft, 2012) \\
\hline $\begin{array}{l}\text { External- } \\
\text { tangible }\end{array}$ & External financing & $\begin{array}{l}\text { Capital from grants by local and national economic development agencies } \\
\text { (NZTE, 2013c) }\end{array}$ \\
\hline \multirow{6}{*}{$\begin{array}{l}\text { External- } \\
\text { intangible }\end{array}$} & \multirow{6}{*}{$\begin{array}{l}\text { Connections to } \\
\text { external networks } \\
\text { (Bergek \& } \\
\text { Norrman, 2007; } \\
\text { Patton et al., 2009) }\end{array}$} & $\begin{array}{l}\text { Connections to local universities and industry (Hackett \& Dilts, 2004a; Lewis et } \\
\text { al., 2011) }\end{array}$ \\
\hline & & Connections to advisory and board members (Al-Mubaraki \& Busler, 2012) \\
\hline & & $\begin{array}{l}\text { Connections to providers of professional services often at subsidised rates } \\
\text { (Hackett \& Dilts, 2004b) }\end{array}$ \\
\hline & & $\begin{array}{l}\text { Connections to funders including angel investors and venture capitalists } \\
\text { (Hackett \& Dilts, 2004a; Incubators New Zealand, 2011a; Lewis et al., 2011) }\end{array}$ \\
\hline & & Credibility from being connected to incubator's networks (Rice, 2002) \\
\hline & & Credibility from being connected to incubator (Xu, 2010) \\
\hline
\end{tabular}

\subsubsection{What is known about availability and usage of provisions?}

Just because provisions are available it does not mean that the potential affordances of that provision are perceived as being the same by all firms. For example, the affordances available through the planning and advisory provisions may fall short of incubator firms' expectations - this is despite these affordances being in demand from incubator firms from the outset of incubation. Rice (2002) found that these differences depend on the initiator of, and the 
purpose of the interaction, and categorised them accordingly as reactive and episodic, proactive and episodic, and continual and proactive. Reactive and episodic counselling occurs when the incubator firm initiates the support to help them deal with a specific situation or problem and the time and focus on the issue by incubator management is generally limited. This may happen when the incubator considers that the process should be primarily managed by the incubator firms and that the managers are merely external facilitators, as discussed by Bergek and Norrman (2008). Proactive and episodic counselling is generally enabled by the affordance of the co-location of incubator management and the incubator firm and, as Rice (2002) noted, happens as a result of fairly informal interactions such as those that occur around the coffee pot (p. 175). Continual and proactive counselling is undertaken to assist with the ongoing and active development of the incubator firm. This may occur when the incubator sees itself as manager of the incubation process and has a major involvement in the firm, in which case the incubator may hold shares and/or be on the firm's board (Bergek \& Norrman, 2008). Rice (2002) concluded that for the monitoring and business assistance to be most effective it should be provided to the firm proactively and immediately in order to reduce costly mistakes.

Another major provision of incubators is their extensive networks. However, just because access to networks is provided, it does not necessarily mean that the affordances that they offer will be utilised by the incubator firm. Hughes, Ireland, and Morgan (2007) suggested that value extracted from the networks depends on how the incubator firms actually behave with respect to the networking opportunities provided. This behaviour could be influenced by the incubator firms' lack of readiness, and the time or skills required to utilise the network effectively, as (Rice, 2002) noted. This means that while firms may perceive an affordance it is not actually realised.

The value extracted from the incubator's provisions can also vary according to a firm's evolution with the incubator and as the relationship between the incubator and the incubator firm develops. Rice (2002) called this an "interdependent co-production relationship", with the purpose being to help fill gaps in the incubator firms' knowledge, competencies and resources. Rice concluded that, in the short-term, incubator management helps a firm to cope with unexpected issues and problems and, in the long-term, it enables the firm to develop the required knowledge, competencies, and resources to enable it to be autonomous and to be a sustainable economic entity and to identify developmental stages that may 
necessitate changes in the firm's strategy. This understanding that the incubator provides support where is it most needed is confirmed by Erlewine and Gerl (2004), whose study noted that a supportive environment is provided through targeted resources and services which are coordinated by incubator management.

A summary of empirical studies on the usage and value judgements of incubator provisions is shown in Table 3.

Table 3

Summary of Empirical Studies on Provision V alue and Usage

\begin{tabular}{|c|c|c|c|c|}
\hline Reference & Method & Provision value and usage & Findings & Analysis formats \\
\hline $\begin{array}{l}\text { Kilcrease } \\
(2011)\end{array}$ & $\begin{array}{l}\text { Survey of } \\
196 \text { non- } \\
\text { profit } \\
\text { government } \\
\text { supported } \\
\text { incubator } \\
\text { firms in US }\end{array}$ & $\begin{array}{l}\text { Looked at degree of satisfaction } \\
\text { of services provided. Used a 5- } \\
\text { point scale, 'very poor' to 'very } \\
\text { good'. } \\
\text { Measured if provision was used } \\
\text { and gave number and percentage } \\
\text { of users. }\end{array}$ & $\begin{array}{l}\text { Highest satisfaction was with } \\
\text { networking-related services } \\
\text { (relationships with co-tenants, } \\
\text { external businesses, strategic } \\
\text { partners, advisory board and } \\
\text { mentors, and higher } \\
\text { education), followed by } \\
\text { technology-related services. }\end{array}$ & $\begin{array}{l}\text { Grouped into the } \\
\text { categories of } \\
\text { 'organisational' } \\
\text { 'networking' and } \\
\text { 'financial and } \\
\text { technology'. } \\
\text { Compared means of } \\
\text { degree of satisfaction } \\
\text { only. }\end{array}$ \\
\hline $\begin{array}{l}\text { Meru and } \\
\text { Struwig } \\
(2011)\end{array}$ & $\begin{array}{l}\text { Survey of } \\
124 \\
\text { incubator } \\
\text { firms in } \\
\text { Kenya }\end{array}$ & $\begin{array}{l}\text { Expected perception of } \\
\text { importance of provision. Used a } \\
\text { Likert scale from "very } \\
\text { applicable" to "not applicable". } \\
\text { Perception of performance. } \\
\text { provision once used. Used a } \\
\text { Likert scale from "well above" } \\
\text { to "poor performance". }\end{array}$ & $\begin{array}{l}\text { Most important perception was } \\
\text { training, followed by facilities, } \\
\text { then infrastructure. But ratings } \\
\text { after realisation revealed the } \\
\text { biggest value gap was for } \\
\text { training and financial support. } \\
\text { The most closely aligned values } \\
\text { were for facilities and } \\
\text { infrastructure. }\end{array}$ & $\begin{array}{l}\text { Compared the } \\
\text { differences in means } \\
\text { between the expected } \\
\text { value of the provision } \\
\text { and the value of } \\
\text { provision once used. }\end{array}$ \\
\hline $\mathrm{Xu}(2011)$ & $\begin{array}{l}\text { Survey of } 61 \\
\text { incubator } \\
\text { firms in } \\
\text { Shanghai, } \\
\text { China }\end{array}$ & $\begin{array}{l}\text { Value judgement of provision } \\
\text { once used. Used a Likert scale } \\
\text { from "no value to "great value". } \\
\text { Measured if provision was used } \\
\text { and gave number and percentage } \\
\text { of users. }\end{array}$ & $\begin{array}{l}\text { Highest value was for financial } \\
\text { management, but usage was } \\
\text { low. This was followed by } \\
\text { employment assistance, legal, } \\
\text { patent and IP assistance, then } \\
\text { sales and marketing. The } \\
\text { highest usage was for sales and } \\
\text { marketing, and employment } \\
\text { assistance. The remainder was } \\
\text { below } 26 \% \text { usage. }\end{array}$ & $\begin{array}{l}\text { Used a table to } \\
\text { compare the } \\
\text { perceived value of } \\
\text { used provisions and } \\
\text { the number of firms } \\
\text { that had used them. }\end{array}$ \\
\hline $\begin{array}{l}\text { Abduh et al. } \\
(2007)\end{array}$ & $\begin{array}{l}\text { Survey of } \\
111 \text { firms } \\
\text { from } 24 \\
\text { incubators in } \\
\text { Australia }\end{array}$ & $\begin{array}{l}\text { Expected value of provision. } \\
\text { Used a } 4 \text { point scale, from "not } \\
\text { at all" to "very important". } \\
\text { Used effectiveness / } \\
\text { performance. Used a } 4 \text { point } \\
\text { scale from "not at all" to "very } \\
\text { effective". }\end{array}$ & $\begin{array}{l}\text { The highest effectiveness } \\
\text { (usage) and the highest } \\
\text { expectations (value) were } \\
\text { office equipment, shared office } \\
\text { services, training and } \\
\text { education, information sharing } \\
\text { through peer networks, } \\
\text { credibility and visibility and } \\
\text { space and building facilities. }\end{array}$ & $\begin{array}{l}\text { Developed a } 4 \times 4 \\
\text { matrix incorporating } \\
\text { effectiveness and } \\
\text { importance. The four } \\
\text { resulting quadrants } \\
\text { were labelled from } \\
\text { higher level of } \\
\text { dissatisfaction to the } \\
\text { higher level of } \\
\text { satisfaction. }\end{array}$ \\
\hline Rice (2002) & $\begin{array}{l}\text { Surveys and } \\
\text { interviews } \\
\text { managers of } \\
\text { eight } \\
\text { incubators } \\
\text { and } 32 \text { firms } \\
\text { in the US }\end{array}$ & $\begin{array}{l}\text { Rated the impact of the business } \\
\text { assistance ranging from little to } \\
\text { critical assistance. } \\
\text { Measured if provision used, but } \\
\text { not frequency. }\end{array}$ & $\begin{array}{l}\text { The value of the co-production } \\
\text { relationship depended on the } \\
\text { time available, the intensity, } \\
\text { and range of co-production } \\
\text { modalities employed. }\end{array}$ & $\begin{array}{l}\text { Used a table to } \\
\text { compare the co- } \\
\text { production impact of } \\
\text { the incubator } \\
\text { managers and a } \\
\text { schematic to illustrate } \\
\text { relationships. }\end{array}$ \\
\hline
\end{tabular}


The emphasis on providing targeted resources is further emphasised by Hackett and Dilts (2004a) who viewed these interventions as needing to be strategic and value-added. The situation is comparable in New Zealand, where Incubators New Zealand (2011b) specified that incubators need to determine what action and resources will be required to make the individual firms successful and how the incubators themselves can assist the efforts of the entrepreneurs. Therefore, the realisation of affordances can depend on the firms' developmental requirements.

In their large Australian study of firms' satisfaction with incubator provisions, Abduh et al. (2007a) discussed the notion that differences exist in the availability and quality of the internal-intangible provisions. These authors found that there was a significant difference between the perceived value of provisions and their resulting effectiveness. Specifically, the provisions that performed the most poorly - although perceived as being most important to the incubator firms - were generally related to the internal-intangible provisions of counselling and business assistance and to the external-intangible provisions of the incubator networks. The satisfaction levels were generally greater with services related to internaltangible provisions such as office equipment, shared office services and space, and building infrastructure. Specifically, the poor-performing provisions included government grants and loans, referrals, sales and marketing, business planning, general counselling and mentoring, access to external information and resources, and access to business people and peer networks. It was concluded that while the incubator firms viewed most of these services as being useful, they thought that the actual performance of the incubators in effective delivery of the services was poor (Abduh et al., 2007). These findings were supported by Xu (2010) who found that the weakest services were those related to skill development and, while it was thought that incubator managers should have a good understanding of the needs of the incubator firms and provide them with "quality counselling and mentoring", those who utilised this service saw it as having either no value, or negligible value at best.

This disparity in perceived versus realised affordances was also backed up in the findings of Meru and Struwig (2011) who conducted a study of 124 entrepreneurs in Kenyan incubators. These researchers found that while the incubator firms viewed incubation services as being very important, the actual services received were below expectations. The services identified as being of greatest importance to an incubator firm were training, infrastructure, business support, networking and mentoring. Further, although the performance of the internal- 
tangible provisions services was rated the highest by the incubator firms it was still well below the relative importance rating. Almost all of the 12 incubators in the Meru and Struwig study were profit-driven, meaning that the drive for profit may have overridden the need to deliver excellent service. These authors concluded that being profit-driven may explain the focus on delivering services which give a fixed return, in the form of rent, as opposed to the delivery of services, such as mentoring and training that have uncertain returns for the incubator thus negatively impacting on the potential affordances of these services. Later, Kilcrease (2011) concluded, based on the results of a survey of 478 firms in the US, that the overall perception of services provided by incubators was that they were just "done in a tepid manner" (p. 92). This was particularly the case for organisational and financial services in academic incubators, which were seen by firms to offer little more than office space. This author also found that for-profit seed capital incubators were the best-performing in terms of client satisfaction for services overall - a finding which is at odds with those of Meru and Struwig (2011) - and that non-profit private incubators were identified as the most deficient in services relating to technology and networking.

In addition, while benefits can be gained from close physical proximity - such as the facilitation of learning and of innovation (Boschma, 2005) - the incubation environment itself can also present obstacles to internal networking. Cooper et al. (2012) noted that the incubator firms can be under severe time limitations, there can be a lack of regular information provided about other residents, and a lack of trust in the other residents with regards to sensitive information. Concerns about intellectual property is an example of this (McAdam \& Marlow, 2008). Further, when the proximity is too close, it can also be detrimental as it results in a lack of geographical openness (Boschma, 2005). This may cause a problem in the incubator environment if the firms are housed too closely together.

The value that can be derived from the incubator's networks may also be less than expected. Experts often provide services in expectation that the incubator firms will exit from the incubator as established, standard fee-paying firms that will remain loyal to the experts that supported them during incubation, as Rice (2002) attested. These experts may have a low expectation of this outcome eventuating, which means that, potentially, they are not fully committed to the engagement with the incubator firm during incubation. Further, as Rice concluded, incubator management can also be at fault as it may fail to evaluate and manage the network experts properly by not doing an initial assessment of the expert's suitability, by 
not assisting the incubator firms to engage successfully in the incubation process, and by not adequately facilitating the networking relationships.

Despite its shortcomings, incubation was, generally, perceived as being valuable by the incubator firms and by the wider incubation network. In this early study, Sherman (1999) found that two-thirds of firms perceived incubation as being 'important' or 'very important'. However, incubator firms in Portugal viewed having the support of an incubator as even more critical (Gaspar, 2009) with 87\% of the entrepreneurs saying that they could not have created their firms without this support.

While the affordances of incubators are potentially diverse, based on the above discussion, the affordances related to the provisions in the internal-intangible and the external-intangible categories may be perceived as being most important.

It is also important to consider that affordances may also arise from the firm's networks outside of the incubator and within the firm itself. Shahidi (1998) proposed a typology of entrepreneurial networks, consisting of seven groups: board of directors, customers, suppliers, trade organisations, financial sources, consultants and advisors, and strategic partners. All these individuals and organisations therefore may have an important impact on strategy development and need to be acknowledged, even though they may not be directly connected to the incubator.

\subsection{Strategy development in incubator firms}

As discussed in Chapter One it is widely accepted that the purpose of incubators is to assist with the development and growth of incubator firms. While there has been research on what incubators actually do, there has been little focus on how the incubators' provisions influence the incubator firms, and particularly their strategy development practices. The purpose of this discussion is to review what is known about strategy development in NEFs and then to determine the most appropriate dimensions with which to observe strategy developments in incubator firms.

Incubator firms are considered to be NEFs, given they are both new and entrepreneurial, as defined in Chapter One. Miller (1983) concluded that firms that are conceptualised as entrepreneurial are engaging in proactive product-market innovations, are somewhat risky, and are ahead of the competition. While Miller's study applied to a vast range of sizes and ages of firms, incubator firms are considered to be inherently entrepreneurial and therefore 
these characteristics can generally apply across the spectrum of incubator firms. Entrepreneurial firms can be somewhat distinct from the majority of start-ups, many of which enter well-established markets in a moderately competitive fashion, with the goal of generating only modest, but sustainable, growth. These characteristics could imply that the strategies of NEFs are quite fluid, and consequently somewhat unstructured, whereas incubators are arguably about enforcing structure. Therefore, how these two seemingly opposing forces combine is of particular interest to the current study.

\subsection{Strategy development in new entrepreneurial firms}

While it is frequently argued in the literature that new firms are a source of dynamism in economies, there have been few empirical studies examining how new firms change (Garnsey \& Hefferman, 2005; Nicholls-Nixon et al., 2000) or on how elements of NEFs' strategies combine to effect change as opposed to being viewed in isolation (Deligianni \& Voudouris, 2011), and as these later authors' contest, most of the literature on strategic change is focussed on large firms, leaving substantial gaps in knowledge about the strategy developments made in NEFs and the rationale behind their development. In order to determine the most appropriate dimensions on which to observe strategy development in incubator firms it is necessary to first establish these firms' distinguishing characteristics.

In the literature concerning strategic change, the notion of fast adaptation is at odds with the prevailing concept of the punctuated equilibrium model, as presented by Nicholls-Nixon et al. (2000) whereby most firms transition from one steady state to another. This punctuated equilibrium model emphasises that changes are made along various dimensions of strategy in incremental stages over long periods of time. However, it can also be punctuated by infrequent, deep-seated reorientations (Gersick, 1994). Given that the focus of the punctuated equilibrium model is longitudinal change in established, large, and well-known firms, the theory is less suited to NEFs, as these firms are not necessarily seeking to change from one steady state to another. Rather NEFs are seeking to find what is likely to be their first steady strategic state (Kiss, 2010; Nicholls-Nixon et al., 2000). Strategic experimentation is therefore a common occurrence in NEFs. According to Nicholls-Nixon et al. (2000, p. 496), strategic experimentation is about seeking to create a new and reasoned competitive strategy, and is defined as "a series of trial and error changes pursued along various dimensions of strategy, over a relatively short period of time, in an effort to identify and establish a viable basis for competing." New strategic dimensions are constantly explored 
and evaluated in an effort to determine their fit with the firms' competitive advantage. Woo et al (1994) earlier found that twists and turns can therefore dominate the activities of NEFs, often occurring as a result of unexpected one-off events. Nicholls-Nixon et al. (2000) argued that while this environmental responsiveness is necessary for all firms, and at all stages of their lifecycles, new firms have untested strategies and are consequently under greater pressures to experiment across their various strategy dimensions.

This frequent strategic experimentation however can be moderated by the firms' somewhat meagre human, technical and financial resources, which are usually narrowly focused on a specific market opportunity (Woo et al., 1994). Further, there can be considerable risk if the entrepreneur was to make poor decisions, as the firm might not be able to endure the consequences due to their limited resources (Covin \& Slevin, 1989). This risk of poor decision-making in NEFs is mirrored in their poor survival rates, estimations of which vary widely. Some researchers estimated that twenty per cent of firms do not survive beyond their first year of operation (Christie \& Sjoquist, 2012). It has also been estimated that the failure rate for all new products is five out of six (Marcouse, 2005). Small firms are particularly at risk due to their limited resources and therefore their relative inability to endure the consequences of entrepreneurs' poor decisions (Covin \& Slevin, 1989). Furthermore, firms can face challenges in the form of a lack of funding, failed technological developments, problematic suppliers and hostile market conditions all of which can have disastrous outcomes (Oliver \& Garnsey, 2005).

\subsection{Defining the scope of strategy development}

As argued thus far there are notable gaps in knowledge about strategy development in NEFs, particularly within incubator firms. The purpose of the following literature review is to explore how strategy development could be defined and operationalised in incubator firms based on what is known about strategy development in NEFs.

The term strategy in the context of business and management was introduced in the 1960s, and Chandler was one of the first to use the term as a descriptive concept (Snow \& Hambrick, 1980). Chandler defined strategy as "the determination of the basic long-term goals and objectives of an enterprise, and the adoption of courses of action and the allocation of resources necessary for carrying out these goals" (Chandler, 1962, p. 13). This definition, as Snow and Hambrick noted, encompasses the firms' goals and the process of their achievement. Strategic management is a widely accepted term for the process of developing 
and managing strategy, but there appears to be no common definition. Following their largescale survey of strategic management scholars Nag, Hambrick, and Chen (2007) determined the content of strategic management, and concluded that it comprises seven conceptual elements: strategic initiatives, internal organisation, managers and owners, resources, performance, firms and environment. The notion that strategic management was a process was clarified by Gupta and Pandit (2012) when they described it as involving "a set of decisions, commitments, and actions that result in the formulation and implementation of plans designed to achieve firms' objectives and produce a competitive advantage" (p. 89). In the study by Hsiu-Li (2005, p. 366) strategic management is defined as a series of four phases: situation analysis, strategy planning, strategy implementation and strategy evaluation. Together they result in the creation of a firms' competitive strategy.

From the discussion in Section 2.5 it appears that NEFs' strategies may generally be driven by a central and passionate entrepreneur who has a strong vision. NEFs are also small and therefore inherently flexible, enabling them to respond quickly to opportunities and to adverse events. NEFs may be frequently in a state of strategic experimentation with the goal of enabling the firm to reach a steady strategic state for the first time, a goal which can be very difficult to obtain due to the high probability of their experiencing adversity and failure. This could be one of the reasons why it is commonly held that smallness is a liability for NEFs (Strotmann, 2007). There seems to be a notable gap in the literature about the concept of strategic development in NEFs. However, Oliver and Garnsey (2005) viewed the formation of NEFs as involving dynamic internal and external processes, and a focus of this study is on exploring these dynamic processes.

\subsection{Dimensions of strategy development to observe}

Based on the definition of strategy and on the characteristics of NEFs discussed in Section 2.6, it is concluded that the most appropriate way to observe strategy is along three orientations; goal, process and content.

Goal orientation is discussed next in Section 2.7.1. Given that the purpose of incubators is to develop firms with high growth potential, it was expected that firms' goals were likely to change. This continuum is considered foremost as it is predicted that the effect of a firm's goal change on the other strategy development orientations will be substantial, and that this effect will be apparent soon after entry into the incubator. 
Process orientation is discussed in Section 2.7.2. Process orientation is considered important because there appears to be contention in the literature as to what mode may be more prevalent in incubator firms. Some researchers (Abduh et al., 2007; Fry, 1987; Incubators New Zealand, 2011b; Webb, 2012) consider that incubators encourage planning; however, it is proposed here that there is a move towards a strategic experimentation approach within incubators. Therefore, long-term planning may be increasingly redundant in incubator firms, with strategic experimentation becoming more common.

Content orientation as discussed in Section 2.7.3. Given the strong emphasis of incubators on growing a firm, and the holistic nature of the incubator environment, it is expected that substantial changes may be made to the content of the firms' strategy.

Based on what is known about strategy development in NEFs and what is known about incubators and their affordances, goal orientation, process orientation, and content orientation appear to encompass the most pertinent aspects to define and operationalise incubator firms' strategy development as set out in Figure 2.

\section{Firms' strategy developments \\ Goal orientation \\ Process orientation \\ Content orientation}

Figure 2. Typology of strategy development orientations

Next, these three dimensions will be explored with specific attention to how the strategy developments may be observed along each dimension.

\subsubsection{Goal orientation}

Goal is defined as "the object of a person's ambition or effort; an aim or desired result" (Oxford, 2013).

The discussion below explores the possible factors influencing strategy development goals for incubator firms. This is followed by a discussion on how the goals could broadly be operationalised. 
This study proposes that incubators emphasise the need for formalised governance, as they offer affordances of advice on governance and fundraising, and affordances of connections to their extensive external networks. Individuals in the incubator's networks may become directors or advisors to the firm. Individuals or organisations that are external to the incubator may also take a shareholding in the firm, and the incubator helps facilitate this by offering affordances of connections to angel investors and to venture capitalists. While these people may or may not take on a formal governance role, they are likely to have influence over the control, and subsequently goals, of the firm.

The increased availability of financial resources has the potential to increase goals. Financial resources can increase substantially during incubation as incubators offer a large number of finance-related affordances to incubator firms (see Section 2.3.3). Affordances from the incubator include advice on fundraising - including education on what is not fundable - help with the preparation of investment-ready business plans and loan applications. The firm's advisor can act as a sense-maker between fund managers and the firm. Network-related financial affordances include connections to angel investors and venture capitalists, to local and national economic development agencies who may provide grants, and to professional advisors such as lawyers and accountants who may assist with transactions. The firms can also gain much-needed exposure and credibility from being part of an incubator, meaning that they are more likely to get funds. Given the potentially large number of affordances, it is proposed that during incubation, firms gain additional funding in the form of debt or equity, thus increasing their goals.

Mintzberg (1973) developed three modes of strategy-making in his efforts to categorise the overarching characteristics of the different ways that firms go about the strategy-making process. They were the entrepreneurial mode, the adaptive mode and the planning mode. While the strategy-making modes are not about goals per se, they do have implications for how goals may change. The goals of firms in the entrepreneurial mode may increase or decrease substantially or change direction entirely; in the adaptive mode and the planning mode the changes may be more subtle.

The idea that strategy development can be on a continuum of goals also appears evident in the strategy typology developed by Wissema, van der Pol, and Messer (1980). The typology comprised the explosion strategy, the expansion strategy, the continuous growth strategy, and the slip strategy. The explosion strategy depicts a plan for increased goals with the ability to take 
considerable risks. The expansion strategy implies some risk-taking and good planning capacity. The continuous growth strategy implies a sustainable maintenance-focused competitive vision. The slip strategy implies no growth and essentially the abandonment of maintenance of the firm and its market share. This typology, like that of Mintzberg, lies along a continuum from increasing goals to reducing or radically changed goals. This is how goal orientation changes were elected to be observed in this study.

Given the role of incubators in growing firms, it is pertinent to observe how incubator firms' goals may change during incubation.

\subsubsection{Process orientation}

Process is defined "a series of actions or steps taken in order to achieve a particular end" (Oxford, 2013).

Incubators are expected to influence the level of strategy development in firms due to their high level of intervention (see Section 2.3). However there appears to be contention in the literature as to the level of planning that may occur. On the one hand many authors acknowledge that incubators encourage long-range detailed planning (Abduh et al., 2007; Fry, 1987; Webb, 2012). On the other hand, there may be a move towards more of a shortrange strategic experimentation approach. One such strategy development methodology is the 'Lean Start-up' approach to commercialisation as developed by Ries (2011). This approach results in continuous validation of the market, continuous development and shorter product development life-cycles. Therefore, long-term planning may be becoming a thing of the past in incubator firms, with strategic experimentation becoming more common. Hence the actual process of strategy development is worth exploring.

A number of notable strategy researchers have proposed various dimensions and typologies in an attempt to categorise the process of strategy development. Before determining how to observe the process of strategy development in incubator firms the relevant literature was reviewed. This included exploring how strategies could be created in a more deliberate or a more emergent fashion and how planning or doing activities were prioritised.

\subsubsection{Deliberate or emergent strategies}

The concept of a firm's strategy being either set from the start or evolving over time was explored by Mintzberg and Waters (1985); they recognised that strategies can range from being entirely deliberate to entirely emergent. These authors considered that traditionally a firm's 
strategy was seen as something that its leaders planned to do with the organisation in the future, with the emphasis being on strategy development as an analytical process, followed by the detailed formation of action plans in order to achieve the stated goals. Mintzberg and Waters argued that this view is gravely limited in that it does not cover the true realities and scope of how strategies are shaped in practice, and concluded that strategies can be either deliberate or emergent. They considered that for a strategy to be deliberate its intentions must be precise, the intentions of all the actors must be aligned to the strategy and the strategy must be realised exactly as intended. For a strategy to be emergent there must be no intention or order. In reality however, it would be rare to find a perfectly deliberate or emergent strategy and most strategies fall on a continuum between two. Mintzberg and Waters identified eight types of strategies that fall along this continuum. The planned strategy is one end of the continuum, where the intentions are formulated by leaders and recorded in a detailed plan, and then implemented with the goal of having as few surprises as possible. At the other end of the continuum is the entrepreneurial strategy where the intentions are less precise and are built around one person who has control and a strong vision. The market opportunity is normally focused on a niche environment, but this can change easily. Related to this is the ideological strategy where the vision can come from one person or many and this strategy arises when a firm's members identify strongly with the vision leading to the formation of a clear strategy. Other types of strategies identified by Mintzberg and Waters were more commonly seen in larger firms where decision-making was more complex, such as the tightly-controlled umbrella strategy, and the imposed strategy. While incubator firms potentially have entrepreneurial strategies or ideological strategies it is important to assume that not all firms have this type of strategy.

Later, Whittington (2000) furthered the notion that there are different styles of strategymaking in an effort to typify the various strategy development processes. Whittington identified four main planning approaches: the classical approach, the evolutionary approach, the processual approach and the systemic approach.

1. The classical approach offers a traditional view of strategy. This approach views strategy as a rational and deliberate planning process.

2. The evolutionary approach takes its rules from the laws of the jungle. The strategy's driving forces are creating efficiencies and survival, in an emergent fashion. 
3. The processual approach takes an informal view of strategy, seeing it as something that is emerging but is shaped by making sense of past experience and the market. It is driven by multiple goals.

4. The systemic approach views strategy as being deliberate and embedded in the cultures and local systems where it is located.

Like the typology of Mintzberg and Waters (1985), there appears to be a common continuum in these approaches that ranges from deliberate to emergent.

Given that incubator firms operate in a volatile environment, the deliberate to emergent continuum is considered a valuable tool to observe the mode of strategy development employed and if and how it changes during incubation. In the typologies of both Mintzberg and Waters (1985), and Whittington (2000) the strategies may not have initially been deliberately deliberate or deliberately emergent; instead they may have simply evolved. That is, the firm may have chosen one approach at the outset and this approach may have changed along the deliberate to emergent continuum. This is expected to apply to incubator firms as they are flexible and generally operate in a volatile environment.

\subsubsection{The planning continuum}

Frequent strategic experimentation, environmental responsiveness and high risk in NEFs could imply that their strategic planning is minimal. However, there has been little research on this topic. Burke and Jarratt (2004) concluded that the planning process in NEFs is not generally a result of exhaustive strategic analysis by multiple people, as it is in larger firms. Rather, it is driven by personalities, opportunities and instincts, and it is channelled through an evolving planning process. In fact, Harris, Forbes, and Fletcher (2000) have argued that the process of planning in NEFs actually "dampens the realisation of entrepreneurial vision." These authors found that the formation of strategy by entrepreneurs relies more on emergent approaches as opposed to deliberate planning approaches, as discussed previously.

The actual activities of incubator firms could vary, ranging from planning-focused activities to doing-focused activities. Planning is considered an important function in New Zealand incubators (see Section 1.3.1). It is expected that each firm is assigned a dedicated advisor who is an incubator staff member and who works closely with the firm during the incubation period. As discussed in Section 2.3.2, an expected affordance arises from the incubator advisor actively assisting the firm with the development of a sound business model and with business planning. Educational workshops and seminars are also expected to play an 
important, but lesser role, in educating the entrepreneurs about strategy planning. Therefore it is expected that, initially, planning may become more formalised and detailed and that doing becomes secondary. An important component of planning includes the analysis of a firm's internal and external environment (Cohn, 1981; Weihrich, 1982). It is suggested that minimal internal analysis was potentially done by the firm prior to entry into the incubator, and that it was done in an informal way due to the lack of a formalised process. However, it is expected that more formal internal analysis will be required by the incubator. Incubators also provide firms with subsidised access to professional advisors such as accountants and banks through their external networks, enabling affordances such as advice on financial forecasting and budgeting, thus assisting with analysis and planning. Like the internal analysis, the level of external environmental analysis is also expected to be minimal prior to entry into the incubator. Prior analysis may just have involved the entrepreneur looking at their own industry experience, and at the products and services of their competitors. No particular reference was found in the literature as to how incubators assist firms with external environmental analysis, with the exception of the related function of product and market validation. However, it is expected that the firm's advisor will require the firm to analyse their external environment extensively. Therefore it is proposed that during incubation, firms substantially increase the amount of external and internal environmental analysis undertaken; this will then inform their planning, as opposed to undertaking planning without this information.

As mentioned earlier, Mintzberg (1973) recognised that firms can be in different strategy development states, and these states can be segmented on the planning or doing continuum. In an effort to observe changes in the strategy development process in firms, Mintzberg developed three modes of strategy-making as an attempt to categorise the overarching characteristics of the different ways that firms go about the strategy-making process. The modes were the entrepreneurial mode, the adaptive mode and the planning mode. The entrepreneurial mode is where there is one dominant leader who takes charge and takes somewhat bold and risky actions in order to find and pursue new opportunities. Solving problems becomes secondary. The environment can be uncertain; however, there are dramatic leaps forward in the pursuit of strong growth and there are clear goals. The adaptive mode is where strategy is viewed as an adaptive process where small reactive and disjointed steps are made as a response to difficult environments. In contrast to the entrepreneurial mode, uncertainty is something to be avoided and the focus can be on 
problem-solving as opposed to seeking out opportunities. Decision-making is complex and goals do not exist. The planning mode is where strategies are made as a result of formal data analysis that results in clear and integrated strategies. For firms operating in this mode, planning is rationally and systematically done, with the goals being precise and measurable. Planning is the key activity in the planning mode and doing is the key activity in the entrepreneurial and the adaptive modes. While Mintzberg's research was based on all sizes of firms, it is proposed that the range of states is applicable to incubator firms. Although it could be assumed that incubator firms just operate in the entrepreneurial state, this may not be the case. Due to the pressure on the incubator firm to plan and validate markets, it is considered likely that incubator firms may move somewhat frequently and fluidly between these three states.

Therefore, given the potential influence of the incubator on the strategy development activities of the firm, it is considered pertinent to observe how the actual activities of the firm change on the planning continuum during incubation.

In the discussion above the strategy development process is explored from a range of theoretical perspectives. While doing this it became apparent that some of these categories would benefit from being combined or modified due to their similarities. Planning was found to be an important element of the strategy development process. It was decided that it was most appropriate to analyse just the planning activities and not the doing activities and to view the process of strategy development on the deliberate to emergent continuum.

\subsubsection{Content orientation}

The word content means "the things that are held or included in something" (Oxford, 2013).

Before determining how the content orientation should be operationalised, the literature on how researchers defined the content of strategy was first reviewed.

\subsubsection{Determining content orientation}

Miles and Snow (1978) developed a typology to categorise the content of strategy. This consisted of three dimensions: entrepreneurial, administrative and technical. The entrepreneurial continuum concerns how a firm is positioned in the market, that is, what products and services it is offering and to whom. The administrative continuum is about the internal functions that a firm needs to deliver the strategies. The technical continuum is about the processes and technology that a firm requires to create the products and services. While this 
typology was developed in the context of large firms, it is considered to potentially apply equally to NEFs as changes are likely to occur across all three dimensions in these firms. Later, in an effort to research how strategy components evolve, and specifically the strategy developments that occur in order to achieve a strategic turnaround, O’Shaughnessy (1986) identified four components that are impacted: organisational, technology, strategic and input. The organisational continuum relates to internal growth, to the internal structure, and to the available resources to manage that growth. The technology continuum relates to the technological advantage that the firm has. The strategic continuum relates to the conservation and consolidation of the core thrust of the firm, particularly the unique and critical competitive advantages that are required for success in the market. The input continuum relates to the elements within the firm such as people, finance, raw materials and information and the social and logistical systems within which they all interact. Again, while this typology was developed in the context of large firms, the four elements are also considered applicable to NEFs, specifically the emphasis of the strategic continuum on the consolidation of the core thrust of the firm. This is considered relevant to NEFs given that their core thrust is potentially underdeveloped and therefore subject to change. However neither typology is considered to present the most suitable tool for operationalising the content orientation changes made because they do not specifically address the magnitude of the change in the firm's strategy, which can substantially affect its ownership, financing and operations.

Few researchers have concentrated on strategy development in NEFs. Deligianni and Voudouris are an exception, they published a study in (2011) which formulated a threedimensional conceptual framework of the dimensions along which NEFs develop their strategies. These authors recognised that strategies can be developed by product/service diversification, by geographic diversification and by the degree of innovativeness (p. 733). While this typology is considered applicable to NEFs, it just focuses on a firm's marketing strategy and omits addressing the firm's internal workings or the extent of the strategy changes made. Another study on strategy developments in NEFs by Nicholls-Nixon et al. (2000) undertook an extensive quantitative study and focused on both the extent of the changes and on their content. These authors determined that changes could be made at the core and at the periphery of the firm. Core changes are those made to the product scope or partnership status. Changing the product scope was considered core because it can impose 
major constraints on the firm as often substantial investments have been made in fixed assets to support the production of the products. Changing people impacted the core of the firm as this can alter the ownership structure and the decision-making resulting in changes to organisational goals. Changes may also occur to the firms' capital structure, increasing or reducing paid-up capital or debt. Peripheral changes are those made to the firm's competitive emphasis or to time allocation (Nicholls-Nixon et al., 2000). Competitive emphasis changes were considered peripheral because they required fewer changes to skills and to physical assets than core changes do, making changes easier. Prices can be altered, advertising can be used, and the service levels can be varied, all with the intent of testing the market's reaction. Time allocation changes refer to the amount of time that the entrepreneur dedicates to the initiative. A key influence on this time allocation is their personal interest in doing the required task, and if the tasks can be delegated to employees. Nicholls-Nixon et al. (2000) found that the peripheral aspects of a firm's strategies are more likely to alter than the core aspects, most likely due to the fact that it is harder to alter core aspects.

The typologies of strategy content discussed thus far are compared in Table 4. The purpose of this exercise is to establish the most inclusive and relevant typology to apply in order to observe strategy content changes. Five broad groups of strategy content are identified in the table: market offering, internal functions, technology, financial resources and stakeholders. Establishing these strategy content groups helped ensure that the chosen typology adequately covered the most pertinent strategy development content dimensions to observe.

It was concluded that the most appropriate typology through which to view changes to strategy development content is the one developed by Nicholls-Nixon et al. (2000). This typology covers all the strategy-development content areas that are considered relevant but, most importantly, it addresses the degree to which the changes may impact the firm, that is, changes impact a firm's core, or its periphery. The four dimensions of the typology developed by Nicholls-Nixon et al. (2000) are explored in detail next. Given that there is a notable gap in the literature about how incubator firms develop the content of their strategies, much of the discussion is about strategy content development in NEFs, coupled with propositions as to how this may apply to incubator firms.

Table 4 shows a summary of how the strategy researchers, discussed above, have defined strategy content. 
Table 4

Comparison of Typology Components with Respect to Strategy Development Content

\begin{tabular}{|c|c|c|c|c|c|}
\hline & $\begin{array}{l}\text { Strategy development } \\
\text { content }\end{array}$ & $\begin{array}{l}\text { Miles \& Snow } \\
\quad(1978)\end{array}$ & $\begin{array}{c}\text { O'Shaughnessy } \\
\text { (1986) }\end{array}$ & $\begin{array}{l}\text { Nicholls- } \\
\text { Nixon et al. } \\
(2000)\end{array}$ & $\begin{array}{l}\text { Deligianni \& } \\
\text { Voudouris } \\
\text { (2011) }\end{array}$ \\
\hline \multirow{2}{*}{ 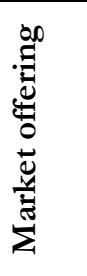 } & $\begin{array}{c}\text { Competitive advantage in } \\
\text { market }\end{array}$ & $\begin{array}{l}\text { Entrepreneurial } \\
\text { dimension }\end{array}$ & $\begin{array}{l}\text { Strategic } \\
\text { dimension }\end{array}$ & $\begin{array}{l}\text { Peripheral } \\
\text { changes to } \\
\text { competitive } \\
\text { emphasis }\end{array}$ & $\begin{array}{l}\text { Geographical } \\
\text { diversification }\end{array}$ \\
\hline & $\begin{array}{c}\text { Products and services } \\
\text { offered }\end{array}$ & $\begin{array}{l}\text { Entrepreneurial } \\
\text { dimension }\end{array}$ & $\begin{array}{l}\text { Strategic } \\
\text { dimension }\end{array}$ & $\begin{array}{l}\text { Core changes } \\
\text { to product } \\
\text { scope } \\
\end{array}$ & $\begin{array}{c}\text { Product and } \\
\text { service } \\
\text { diversification } \\
\end{array}$ \\
\hline \multirow{2}{*}{ 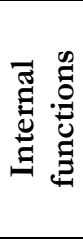 } & $\begin{array}{l}\text { Internal functions of the } \\
\text { firm }\end{array}$ & $\begin{array}{l}\text { Administrative } \\
\text { dimension }\end{array}$ & Input dimension & $\begin{array}{c}\text { Peripheral } \\
\text { changes to } \\
\text { time allocation }\end{array}$ & \\
\hline & Manufacturing processes & $\begin{array}{l}\text { Technical } \\
\text { dimension }\end{array}$ & Input dimension & $\begin{array}{l}\text { Core changes } \\
\text { to product } \\
\text { scope }\end{array}$ & \\
\hline 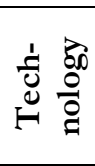 & $\begin{array}{l}\text { Technology to create } \\
\text { products and services }\end{array}$ & $\begin{array}{l}\text { Technical } \\
\text { dimension }\end{array}$ & $\begin{array}{l}\text { Technology } \\
\text { dimension }\end{array}$ & $\begin{array}{l}\text { Core changes } \\
\text { to product } \\
\text { scope }\end{array}$ & $\begin{array}{l}\text { Innovations } \\
\text { made to } \\
\text { product and } \\
\text { service offering. }\end{array}$ \\
\hline 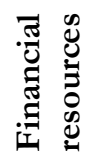 & $\begin{array}{l}\text { Finance and other } \\
\text { resources to produce } \\
\text { products and services }\end{array}$ & & $\begin{array}{l}\text { Organisational } \\
\text { dimension }\end{array}$ & $\begin{array}{l}\text { Peripheral } \\
\text { changes to } \\
\text { time allocation }\end{array}$ & \\
\hline \multirow{3}{*}{$\begin{array}{l}\frac{0}{d} \\
\frac{0}{0} \\
\frac{0}{0} \\
\frac{c}{0} \\
\frac{n}{\pi}\end{array}$} & Staff & & Input dimension & $\begin{array}{c}\text { Peripheral } \\
\text { changes to } \\
\text { time allocation } \\
\end{array}$ & \\
\hline & $\begin{array}{l}\text { Partnership and } \\
\text { ownership status }\end{array}$ & & & $\begin{array}{l}\text { Core changes } \\
\text { to partnership } \\
\text { status } \\
\end{array}$ & \\
\hline & Empirical focus & Large firms & Large firms & NEFs & NEFs \\
\hline
\end{tabular}

\subsubsection{Core changes - product scope}

As Nicholls-Nixon et al. (2000) concluded, changes to NEFs' scope of products may occur. These authors classified these changes as a core continuum because they related to the identity of the firm. Changes to the product scope may have a notable impact on the firms' market offering, on technology, and on financing, as discussed below.

A firm's products and services form a major component of its strategy and are potentially subject to change as the firm evolves. The main problem that NEFs face, as concluded by Marcouse (2005), is that they are generally completely dependent on just one uncertain income stream and this can create financial problems. Therefore the key to success is to "identify a market niche and then fill it compassionately, flexibly and efficiently" (p. 32). Thus, niche market strategies are commonly employed and, as Cooper (1981) noted, are done in order to avoid direct competition with much larger firms. Once a firm's initial products become well established, further innovation of product lines can be introduced. 
This flexible niche market approach of NEFs is expected to be comparable for incubator firms. This could be due to various contemporary strategy-development tools becoming increasingly popular within incubators nationally and internationally. One of these is the Lean Start-up approach to commercialisation as made popular by Ries (2011). This approach employs a continuous and short cycle of product development and validation of the market. The Lean Canvas concept - or Business Model Canvas as it is also known - was developed from the Lean Start-up approach as a way of concisely documenting a firm's agile business model on a one-page document that is based around the firm's value proposition as its central focus. Considered central to this is the concept of the Minimum Viable Product (MVP) which is "a concise summary of the smallest possible group of features that will work as a stand-alone product while still solving at least the 'core' problem and demonstrating the product's value" (Blank \& Dorf, 2012, p. 80). This concept enables agile planning and increased speed to market; however, it may be at odds with incubators' traditional approach to planning, which is more formalised strategic planning (Abduh et al, 2007; Fry, 1987; Incubators New Zealand, 2011b). Therefore it is interesting to observe how strategy development tools are employed in incubators and the resulting influence on a firm's product scope changes.

The success of a NEF's strategy may be dependent on its ability to determine the right products and services, and the right niche. Product and market validation is frequently conducted in New Zealand incubators (BCC, 2013; Callaghan Innovation, 2014; Creative HQ, 2013; ecentre, 2013) in order to establish the most appropriate strategy. New Zealand incubators emphasise the need for market validation to ensure that ideas are well-tested (Webb, 2012). During the product and market validation process it may become apparent that a firm's products and services do not meet the anticipated market need. Unforeseen opportunities for new products, services and markets may also come into the fore.

Incubators also offer provisions of connections to relevant industry people and universities. This could help a firm with the creation of specific technologies and may enable existing, and sometimes previously unknown, technologies to be leveraged. In addition, incubator staff and other incubator firms may have experience with similar technology and may therefore be able to offer the affordance of sharing this knowledge. Therefore, it is proposed that during incubation, firms may be able to make major advancements in their technological 
developments over and above what they could achieve if they were outside the incubator environment.

Once NEFs enter the commercialisation phase, market forces may further influence their product scope. Zahra and Neubaum (1998) have attested that NEFs can be frequently at the mercy of adverse conditions, relating to the industry's supply and demand conditions which can reduce profit and growth potential. These conditions could include a market where the needs of customers change frequently or become more unpredictable, where the loyalty of customers is decreasing, and where the failure rate of new firms is high. In his empirical research on new-firm survival rates in Germany, Strotmann (2007) found that some industry sectors have increased probability of firm failures, especially where there is a higher threshold in order to achieve economies of scale, lower price-cost-margins which demand conditions, and high entry rates. High regional agglomeration was also found to be positively correlated with firm failure. Whole industries can also go into a state of decline, which can be experienced in the form of economic slowdown, increased competition and changes in the social and technological environment (O’Shaughnessy, 1986). The target market can even dry up altogether (Miller \& Friesen, 1983). The result is that there can be few exploitable growth opportunities in these hostile environments (Covin \& Slevin, 1989), which may consequently result in a reduction or even the entire removal of revenues for the firm, as shown by Woo et al. (1994).

It is not unusual for incubator firms to have a strong technology component, especially as technology firms are increasingly becoming the focus of the Incubator Support Programme (Callaghan Innovation, 2014). Incubators offer many affordances to assist firms with technological developments and these can come from the incubator's connections to industry people, universities and other incubator firms. The result is that incubator firms may be able to make major advancements in their technological developments, over and above what they could achieve if they were outside of the incubator environment. Technology is considered important because it can be at the core of a firm's product scope since one of a firm's most viable competitive strategies is the creation and successful commercialisation of technology (Zahra, Nash, \& Bickford 1995). However, as these authors noted, in order for technology-based strategies to succeed, management needs to be skilled and resourceful as markets can be quite unforgiving if technology is poorly executed. Also, problems can arise from radical shifts in technological resources and capabilities in an industry. This can result 
in challenges such as a high rate of product innovation, technological change and product obsolescence and, where innovation occurs quickly, so does innovation in manufacturing (Zahra \& Neubaum, 1998). These problems can undermine a firm's competitive standing, sometimes leading to their demise (Anderson \& Tushman, 1990). Firms can also experience unexpected and increased costs for production and costs incurred in solving technical problems (Woo et al., 1994). In order to overcome these problems, the firm's resources can also be mobilised in new ways, used more economically, leveraged, or new resources can be created (Oliver \& Garnsey, 2005). Similarly, in their study of 59 Swedish mobile internet firms, Boccardelli and Magnusson (2006) found that when firms change their focus in response to a market opportunity these changes can occur without changes actually being made to firms' technological resources; rather, the change is made to the way those measures are employed. Therefore, while technology is considered to be at a firm's core, major technological challenges can sometimes be addressed at the firm's periphery.

\subsubsection{Core changes - partnership status}

As Nicholls-Nixon et al. (2000) found, changes to a firm's partnership status are considered core because they affect the number of full-time partners that join or leave the firm, thus impacting the firm's available resources such as skills and financing. For the purpose of this study, the definition formulated by Nicholls-Nixon et al. (2000) will be expanded to include changes to a firm's governance structure.

Nicholls-Nixon et al. (2000) concluded that financial resources can be substantially impacted by changes in partnership status. It is argued that incubator firms acquire increased financial resources which, in turn, change their partnership status. The affordances that lead to this increase can come from the firm's advisor, venture capitalists, local and national economic development agencies, or professional advisors such as lawyers and accountants. Garnsey and Hefferman (2005) concluded that external funding enables a firm to achieve growth from inputs, such as resources and assets before achieving growth from outputs such as revenues which means that the firm is then likely to be in a more favourable position to grow than firms that rely on their own internal funds and revenue to fund growth. Therefore, as these authors noted, when firms are growing they require a specific mix of resources and the timing of the availability of these resources is critical, with the pace of growth needing to be synchronised with resource availability, which can be unlike the challenges of larger firms as Yang (2012) found in her study of small-medium enterprises. 
Despite its importance, the acquisition of funding may be more difficult, expensive or timeconsuming than planned (van Gelderen, 2012). Financial investments in start-ups are risky, especially given that it is widely known that the failure rates of new firms is high, and in recent times accessing credit has become especially difficult due to the financial crisis (Yang, 2012). In their research into 140 internet-based firms Mahto and Khanin (2013) found that the speed and ability to obtain financing is a major commercialisation hurdle for technologybased entrepreneurial firms in particular, and is worse in cases where the technology firm is new because the founders generally do not have strong reputations in the financial services industry. Obtaining financing can be made even more difficult by the fact that firms that have new technology may not have sufficient information on the environment, and investors in these firms may not have sufficient information about the firm as found by Garnsey and Hefferman (2005). However, these authors concluded that new firms with good prospects are well placed to obtain funds from external investors although, while it is generally beneficial, obtaining funding from external sources can make the firm vulnerable. Investors may become dissatisfied if the firm fails to meet expected targets and can withdraw their capital, potentially resulting in the firm having to be sold in a trade sale or being made bankrupt.

It is anticipated that, generally, incubator firms have just one or two entrepreneurs who are the sole owners. Given the small size of NEFs, and their anticipated fast pace of growth, they potentially undergo many stakeholder developments because, as Garnsey and Hefferman (2005) have attested, as firms grow they become more complex, detail-orientated and routinized. Helping firms structure for growth is a key affordance offered by advisors, which is inextricably linked to a major goal of incubators which is to create employment, as discussed by Al-Mubaraki and Busler (2012). One of the ways to enable this growth is to acquire external resources in the form of skills, connections and funding, which can be achieved by bringing additional shareholders into the firm. These shareholders may also take on the roles of directors or employees. Another way these resources can be acquired is through creating a governance structure. Many NEFs have external governance in the form of a board of directors or an advisory board; however, little research has been done on this topic (Machold, Huse, Minichilli, \& Nordqvist, 2011; Minichilli \& Hansen, 2007). Incubators offer the affordance of advice about governance, and connections through their extensive networks to potential advisory and board members and to potential investors. To help assess and formalise these new stakeholders, incubators also offer provisions of professional legal 
advice through the incubators' connections to legal firms. One of the few researchers who has focussed on governance in small firms is Cowling (2003) who found that boards provide value to small firms by increasing their productivity, especially when there is the addition of a non-executive board member. Further, Minichilli and Hansen (2007) found that this increased diversity can be beneficial in times of crises too, as the NEF will have access to greater experience and competencies. It therefore seems pertinent to observe how incubator firms might change their governance during incubation.

It is proposed here that due to the affordances of the incubator, the number of stakeholders that a firm has increases substantially through increased staffing, the creation of a governance structure and investors. With the exception of the above discussion, there is little in the literature about the nature of partnerships and stakeholder developments in NEFs. It would therefore be interesting to observe changes that are made to a firm's stakeholders during incubation.

\subsubsection{Peripheral changes - competitive emphasis}

As Nicholls-Nixon et al. (2000) concluded, changes in competitive emphasis relate to changes in the strategic positioning of a firm's products and services.

It is anticipated that advice on competitor analysis and market validation is a key provision offered by the firms' advisors. This may result in changes in a firm's competitive emphasis and consequently its strategic positioning. The concept of strategic positioning was explored by Porter (1985), who developed a typology of generic strategies as they relate to the competitive positioning of a firm: differentiation, cost leadership, focus and combination. A differentiation strategy refers to a focus on providing a unique product or service. A cost leadership strategy implies having a lowest-cost model for the industry. A focus strategy implies targeting a narrow market segment. A combination strategy is a mix of the above strategies. These generic strategies have had wide acceptance as a strategic typology (Allen \& Helms, 2006). It is not known if NEFs, and specifically incubator firms, have a typical strategic positioning; it is also not known how this may change during incubation, given the lack of empirical studies about the nature of strategy development in incubator firms. But the strategic positioning of a firm is not a focus of this study. However, given that Porter's strategies are not necessarily related to the life-stage or to the entrepreneurial focus of a firm, it is likely that the strategies of incubator firms may be any one of these four strategies. 
While this type of strategic positioning is interesting, this study just explores the level of change in competitive emphasis, not the type of change with respect to a firm's strategic positioning.

\subsubsection{Peripheral changes - time allocation}

As Nicholls-Nixon et al. (2000) concluded, changes to time allocation are peripheral because they do not impact a firm's basic concepts or power structures.

Little knowledge can be garnered from the literature about what activities NEFs spend their time on. However, one aspect that is widely accepted is that small firms have more freedom than large firms to change their long-term goals, the customers they will target, and their resources (Bhide, 2000). Enhancing this freedom is the generally uncomplicated systems and procedures of NEFs allowing for flexibility and quick decision-making and response times to changing customer needs (Singh, Garg, \& Deshmukh, 2008). Therefore, it could be assumed that the time a firm allocates to different activities could change frequently in response to opportunities and challenges.

Time utilisation by the incubator firm may be under increased scrutiny by the firm's advisor due to the additional accountability that the firm has to its potentially growing number of stakeholders. This scrutiny may include the preparation of detailed action plans, helping ensure that time is used more efficiently. The use of time can also potentially be improved through the affordances of the incubator's kitchen, cafeteria and lunchrooms, as the entrepreneur and their staff will not need to leave the building as frequently. This may result in the entrepreneur's time being used more efficiently, with greater focus on specific activities that directly impact on the growth of the firm, and may, as (Xu, 2010) noted, potentially enable the firm to be started at a faster rate.

It is not known how the specific provisions of incubators influence incubator firms' strategy developments. Gaining that knowledge is a function of the empirical component of this study.

Table 5 presents a summary of the strategy development continuums. 
Table 5

Summary of Strategy Development Continuums

\begin{tabular}{|l|l|l|}
\hline $\begin{array}{l}\text { Broad } \\
\text { continuum }\end{array}$ & Specific continuum & Reference \\
\hline $\begin{array}{l}\text { Goal } \\
\text { orientation }\end{array}$ & Increased, decreased or more precise & $\begin{array}{l}\text { Adapted from Wissema et al. (1980), } \\
\text { and Mintzberg (1973) }\end{array}$ \\
\hline \multirow{2}{*}{$\begin{array}{l}\text { Process } \\
\text { orientation }\end{array}$} & Deliberate or emergent goals & $\begin{array}{l}\text { Whittington (2000); Mintzberg \& } \\
\text { Waters (1985) }\end{array}$ \\
\cline { 2 - 3 } & Planning & Adapted from Mintzberg (1973) \\
\hline \multirow{3}{*}{$\begin{array}{l}\text { Content } \\
\text { orientation }\end{array}$} & Core or peripheral product scope changes & \\
\cline { 2 - 2 } & Core or peripheral partnership status changes & \multirow{2}{*}{$\begin{array}{l}\text { Core or peripheral competitive emphasis } \\
\text { changes }\end{array}$} \\
\cline { 2 - 2 } & Core or peripheral time allocation changes & \\
\cline { 2 - 3 } & \multicolumn{2}{|l}{} \\
\hline
\end{tabular}

\subsection{The conceptual model}

The overarching question that this study is addressing is:

How may incubators influence firms' strategy development?

To address this question a conceptual model was developed (see Figure 3). The two main constructs in the conceptual framework are (a) the incubator provisions (at left), and (b) the firms' strategy developments that occur during incubation (at right). The arrow in the middle illustrates the affordances that may arise from the incubators' provisions.

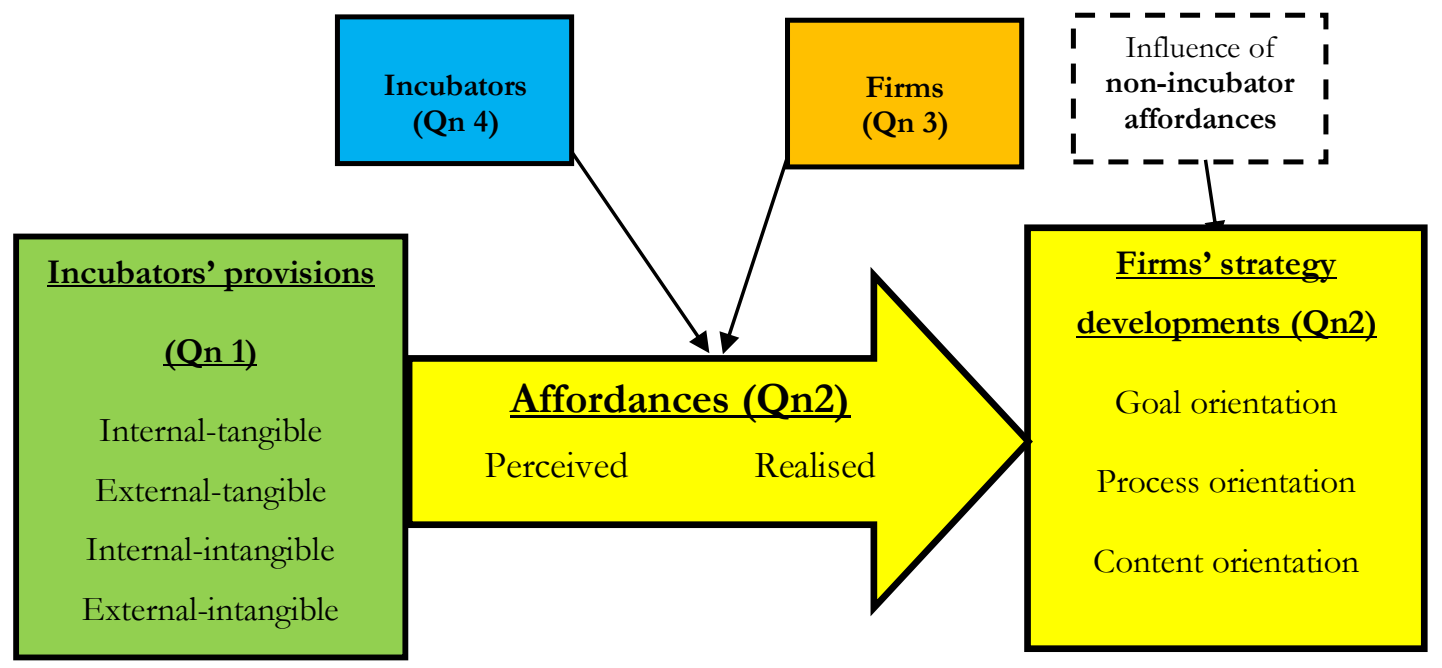

Figure 3. Conceptual model showing the relationships between the key constructs and contextual factors and how each part of the model is addressed by the sub-questions 
The central relationship of interest is the influence that the incubator affordances have on the firms' strategy developments, as depicted by the arrow. This arrow illustrates the affordances may influence firms' strategy developments. The model shows that there are two key contextual factors that may be important: the incubators and the firms. Differences may exist in the characteristics of both incubators and firms, thus impacting the degree to which the affordances are perceived and realised. Similarly, the firms' strategy developments may be influenced by factors distinct from the incubators such as customers, suppliers, competitors, shareholders and technology. These contextual factors need to be acknowledged because it cannot be assumed that all strategy developments are due to the incubators' affordances, that all affordances are the same, and that all firms are the same.

Accordingly, the overarching research question is segmented into four sub-questions to address these complexities. The sub-questions are presented here along with how they correspond to the colours in the conceptual model:

1. What are the affordances of the incubators' provisions? (Green)

2. How may the provisions' affordances influence strategy development? (Yellow)

3. How may the firm-specific factors be related to the provisions' influence on strategy development? (Orange)

4. How may the incubator-specific factors be related to the provisions' influence on strategy development? (Blue)

\subsection{Chapter summary}

The evidence in the literature points to the purpose of incubators being to aid the development of NEFs. However little is known about how incubator firms develop their strategies. In Chapter Two the TOA was identified as an appropriate lens through which to explore this relationship. The provisions of incubators and the firms' strategy developments were operationalised, research questions were formulated, and a conceptual model was developed. The process for addressing the research questions is the topic of Chapter Three, Methodology. 


\section{Methodology}

\subsection{Chapter introduction}

As Chapters One and Two have shown there has been increasing focus on business incubators in recent years. Incubators have been created to help grow economies through the successful development of NEFs. An examination of the literature revealed gaps in knowledge regarding the process of incubation and strategy development in NEFs, and among incubator firms in particular. The aim of this study was to explore the overarching question: How may incubators influence firms' strategy development? The theory of affordances (TOA) provided the theoretical lens from which a conceptual model was developed to frame the four sub-questions (see Figure 3).

Chapter Three discusses the methodology used to address the research questions. First, the research philosophy in the context of the theoretical lens is explained. The methodologies used in related empirical research are then reviewed; this review concludes with the rationale for the methodology for this study. The research design - which includes three strands of data collection - is explained, along with the selection of the research participants and the process of designing and piloting the interview schedule and survey instrument. This chapter concludes with a discussion of how the findings and analysis were presented, and how this information was used to address the research questions.

\subsection{The research paradigm}

Before considering the research methodology it is important to account for the philosophical underpinnings of the research paradigm as this guides the research process leading to the desired outcome (Crotty, 1998). Denzin and Lincoln (2005) defined a paradigm as "a set of beliefs that guide action" (p. 22). Davidson and Tolich (2003) were more specific defining paradigms as a "collection of ontological and epistemological assumptions about what the world is made of and how it works" (p. 26). Similarly, according to Easterby-Smith, Thorpe, and Lowe (2002), research paradigms concern the "philosophical assumptions about the nature of reality" (p. 60) and epistemology encompasses "a general set of assumptions about the best way of enquiring into the nature of the world" (p. 60).

Paradigms differ in the ontological and epistemological beliefs on which they are based. For example, a positivist paradigm assumes a realist ontology, which assumes a tangible reality that is independent of human consciousness and is awaiting discovery through empirical 
means (Denzin \& Lincoln, 2005). An interpretivist paradigm takes an alternative view to the positivist viewpoint (Bryman \& Bell, 2011) in that it "respects the differences between people and the objects of the natural sciences and therefore requires the social scientist to grasp the subjective meaning of social action" (p. 17).

The ontological perspective of this thesis is that of a relativist ontology that accepts that multiple realities exist as a result of social interactions. This perspective allows for diversity in interpreting the world (Crotty, 1998). This ontological viewpoint is important given that the central construct of the research is founded on the TOA, which acknowledges that perceptions of affordances vary depending on the individual user and the context (Zhao et al., 2013).

As with a relativist ontology an interpretive epistemology assumes that knowledge can be socially created, that is, the individual interprets meaning through their interaction with objects in the social world (Bryman \& Bell, 2011; Crotty, 1998; Davidson \& Tolich, 2003). The determination of what counts as legitimate knowledge is central to the research epistemology (Davidson \& Tolich, 2003, p. 24). In this study the perceptions of the individuals were considered to be legitimate and are indeed central to the TOA. The perceptions of individuals are also considered to represent those of the entity in which they exist which, in this case, is the firm or the incubator. An interpretative approach also suggests that components of a problem cannot be solved without understanding the context of its wider environment (Davidson \& Tolich, 2003), which is an important consideration for this study. In contrast, if a positivist epistemology were used it would assume that meanings are just in the objects (Crotty, 1998) in a reality that is "separate from our descriptions of it" (Bryman \& Bell, 2011, p. 17). TOA, on the other hand, acknowledges the validity of descriptions of meanings. Within a positivist empirical paradigm knowledge is objectively acquired proclaiming that "only knowledge gained through experience and the senses is acceptable” (Bryman \& Bell, 2011, p. 10).

This study seeks to explore the points of view from both the strategists in the firms and the managers of the incubators. However, not all aspects of this study were able to be triangulated in such a manner and, instead, just one viewpoint was relied upon in some instances. Therefore the ontology may in some cases lean more towards nominalism which views truth as something which "depends on who establishes it" (Easterby-Smith et al., 2002, p. 62). This approach was considered relevant because the 'reality' of the incubator's 
influence on strategy development requires a considerable degree of elucidation by the participants based on their lived experiences, as opposed to a deductively-focused, positivistic ontology. The firms' construction of meaning is especially important as they will be asked to reflect back on their experiences and their strategy at entry into the incubator and compare them with their current experience and strategy.

The theoretical lens and the research paradigm were guiding factors in the choice of research methods needed to facilitate the gathering of data in the appropriate form, thus allowing it to be analysed in a way that would address the research questions. However, before deciding on the most appropriate methods, it was necessary to consider prior empirical studies in the incubator and TOA fields.

\subsection{Comparison of research methods in similar empirical research}

As discussed in the introduction to the literature review, no prior studies were found on the impact of incubator provisions on strategy development, and just six studies were found about incubator firms' perceptions of incubator provisions. Four of the six studies took a solely quantitative approach, using survey questionnaires to broadly research the range of incubator provisions (Abduh et al. 2007; Kilcrease, 2011; Meru \& Struwig, 2011; Xu, 2010). The two studies that used a multi-method approach made use of questionnaires and in-depth interviews. The study by Rice (2002) sought to explore the nature of the co-production relationship between the firm and the incubator. The study by McAdam and Marlow (2011) used mixed-methods. Rather than a broad study of perceptions of incubator provisions, these authors sought to gain an in-depth understanding of the process of attaining venture capital. Given the in-depth data required in this proposed research, the multi-method approach is also relevant. The use of qualitative methods could also enable substantial insights into the incubation process which has, until now, predominantly been researched using survey methods.

TOA has had application in empirical research in various disciplines. Quantitative and qualitative approaches appear to have been used in equal measure, with methods including laboratory experiments, field studies, in-depth interviews, focus groups and surveys.

The TOA research contexts often related to learning and behaviour, and included workplace learning and interactions (Andres \& Shipps, 2010; Bryson et al., 2006; Fayard \& Weeks, 2007; Hetzner, Gartmeier, Heid \& Gruber, 2009), student behaviour (Sadler \& Given, 2007; Yang et al., 2011) virtual communications (Goel, Johnson, Junglas, \& Ives, 2013), and social housing 
(Gram-Hanssen \& Bech-Danielson, 2011). Of particular relevance to this study, more in terms of subject matter than methodology, is the study by van Dijk et al., (2011). These authors studied innovation trajectories in mature firms and the affordances of organisations that enable different strategic responses. The researchers used qualitative methods to allow for examination of the actors' interpretations and to gain an understanding of the affordances and the strategic responses. Two firms were used as case studies using interviews conducted with several stakeholders from a variety of disciplines within each organisation.

Another study of particular interest is that of Sadler and Given (2007) who sought to establish graduate students' perceptions and experiences of the affordances of a university library. These researchers interviewed both students and librarians, thus enabling comparison of the students' perceptions and behaviour with the librarians' expectations of students' behaviour. Qualitative in-depth interviews were used to help the researchers explore the actions and attitudes of the participants and to understand the broader context of behaviours. Sadler and Given's study sought to use a triangulated approach by gaining views from both the students and the librarians, who represented the 'views' and 'intentions' of the environment. Given the epistemological similarities with this study, that is, the desire to also triangulate the perceptions and realisations of affordances, in-depth interviews with both firm strategists and incubator managers were considered most appropriate because of the desire to compare the views of firms with their respective incubators.

\subsection{Research design}

This study uses a multiphase design that encompasses both qualitative and quantitative strands. Data can be effectively mixed during data collection and data analysis; however, as Creswell and Clark (2011) concluded, it is important to ensure that the level of mixing between the strands is appropriate.

Figure 4 presents a model of the research design for this study. It is an adaption of multiphase design in Creswell and Clark (2011, p. 70), which is one of their six prototypical versions and has been chosen for the current study because of its informing capabilities, rather than simply its complementary features. In this design each strand occurs in an interactive sequence with the objective that each strand informs the design of its sequential other. As shown in Figure 4, Strand One informs and operationalises variables in the quantitative component and Strand Two, in turn, facilitates the design of the interview schedule for Strand Three. Therefore some analysis occurred between the implementation of 
the strands. However, the main analysis occurred at the end of the data collection process, and as a result of iterating between the strands.

The other prototypical versions developed by Creswell and Clark involved the various strands complementing and building upon their respective data, but not informing it; this process occurred either sequentially or concurrently.

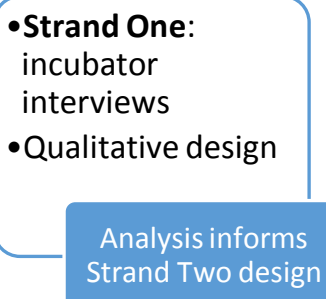

Analysis informs

Strand Three design

-Strand Two: firm

survey

-Quantitative

design

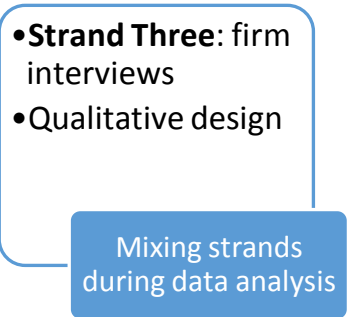

Figure 4. The research strands adapted from the multistrand design in Creswell and Clark (2011).

Figure 4 illustrates that there are two distinct types of research participants: incubators and firms. This approach allowed for both the triangulation of the data - that is, comparing the incubators' and the firms' views on the availability of provisions and the ensuing strategy development - and for informing the next phase of data collection. For example, in Strand One the incubator managers discussed what provisions were available and, in Strand Two, the discussion on which provisions were available informed the list of provisions to be included in the survey. Refer to Table 6 for detail on what information was collected and why.

\subsubsection{Data collection}

The central constructs of this study are the affordances that arise from the incubators' provisions and the influence of these affordances on firms' strategy development. In the qualitative phase of the study (Strand One), data were gathered on the incubators' influence on strategy development using interviews with key stakeholders from both firms and incubator management.

The data were collected in three distinct and sequential strands, as presented in Table 6. 
Table 6

Relationship Between the Research Questions and the Strands of Data Collection

\begin{tabular}{|c|c|c|c|}
\hline The research questions & $\begin{array}{l}\text { Strand One: Incubator } \\
\text { manager in-depth } \\
\text { interviews }\end{array}$ & $\begin{array}{l}\text { Strand Two: Firm } \\
\text { surveys }\end{array}$ & $\begin{array}{l}\text { Strand Three: Firm } \\
\text { strategist in-depth } \\
\text { interviews }\end{array}$ \\
\hline $\begin{array}{l}\text { What are the affordances of } \\
\text { the incubators' provisions? }\end{array}$ & $\begin{array}{l}\text { Perceptions of } \\
\text { affordances of } \\
\text { provisions }\end{array}$ & $\begin{array}{l}\text { Value judgments } \\
\text { awareness of, and usage } \\
\text { rates of incubator } \\
\text { provisions }\end{array}$ & $\begin{array}{l}\text { Perceptions of } \\
\text { affordances of provisions }\end{array}$ \\
\hline $\begin{array}{l}\text { How may the provisions' } \\
\text { affordances influence } \\
\text { strategy development? }\end{array}$ & $\begin{array}{l}\text { Potential influence of } \\
\text { affordances on strategy } \\
\text { development }\end{array}$ & Not assessed here & $\begin{array}{l}\text { Actual strategy } \\
\text { developments that } \\
\text { occurred and the } \\
\text { influence of the incubator } \\
\text { in the process }\end{array}$ \\
\hline $\begin{array}{l}\text { How may the firm-specific } \\
\text { factors be related to the } \\
\text { provisions' influence on } \\
\text { strategy development? }\end{array}$ & Not assessed here & Demographics of firms & Demographics of firms \\
\hline $\begin{array}{l}\text { How may the incubator- } \\
\text { specific factors be related to } \\
\text { the provisions' influence on } \\
\text { strategy development? }\end{array}$ & $\begin{array}{l}\text { Characteristics of the } \\
\text { incubator and of their } \\
\text { approach to strategy } \\
\text { development }\end{array}$ & Not assessed here & $\begin{array}{l}\text { Characteristics of the } \\
\text { incubator }\end{array}$ \\
\hline
\end{tabular}

\subsubsection{Strand One}

In Strand One, data were gathered using in-depth, face-to-face interviews with the managers of the incubators that were part of the New Zealand Incubator Support Programme. The interview schedule helped maintain consistency (refer Appendix C). The interviews generated data about the incubators' expectations around the provisions and the consequent affordances available to incubator firms, and about potential strategy development outcomes. Information about the incubators' purpose, selection criteria and other characteristics was also collected. Having these data gave context to the incubator environment, and enabled a triangulated comparison with the firms' awareness of availability, usage and value of the provisions (Strand Two) and with their strategy developments (Strand Three). This approach allowed for differences between the expectations and experiences of the two parties to be identified. The questions about the predicted strategy development outcomes did not relate to specific firms; they were generalised - given the desire to get the incubators' overall views - rather than obtaining comments about specific firms, which may have breached the firms' privacy. The data from these interviews about the incubator provisions informed the development of the list of provisions in the survey instrument in Strand Two. The data generated from Strand One informed the analysis for Question Two, 'How may the provisions' affordances influence strategy development?' and Question Four, 'How may the incubator-specific factors be related to the provisions' influence on strategy development?' 


\subsubsection{Strand Two}

Strand Two utilised a self-report and a primarily quantitative questionnaire which was administered to all firms. The purpose was to give a broad context to the research regarding the firms' value perceptions and usage rates of provisions, and to ask respondents if they would consider participating in an in-depth interview for Strand Three. The nature of the firms' strategy developments was not explored in this strand due to the need to obtain indepth data on strategy development and the inherent difficulties in achieving this with a survey instrument. Online surveys appear to have been used frequently in recent studies of incubator firms (Clausen \& Korneliussen, 2012; Kilcrease, 2011; Schwartz \& Hornych, 2012) as opposed to mailed questionnaires, reflecting the trend towards this convenient surveyadministration method, especially in incubator-based NEFs, which are potentially high-users of technology. The survey results helped inform the topics in the interview schedule for Strand Three by identifying the provisions that might be worthy of in-depth exploration. The data generated from Strand Two informed the analysis for Question One, 'What are the affordances of the incubators' provisions?' Question Three, 'How may the firm-specific factors be related to the provisions' influence on strategy development?' and Question Four, 'How may the incubator-specific factors be related to the provisions' influence on strategy development??

\subsubsection{Strand Three}

Strand Three utilised inductively-orientated qualitative interviews with 33 (42\%) of the estimated 80 firms to generate in-depth data about the firms' strategy developments, and the influence of the incubators' affordances on those developments, thus addressing the later research questions. The interview approach was chosen because it allows for the interviewees' points of view to come across more strongly than the researcher's, as could happen when using a questionnaire (Bryman \& Bell, 2011). The need to fully understand the firms' experiences and their interpretation of the influence of the incubator is important given the contextual and exploratory nature of the research question. The data generated from Strand Three informed the analysis for Question Two, 'How may the provisions' affordances influence strategy development?', Question Three, 'How may the firm-specific factors be related to the provisions' influence on strategy development?' and Question Four 'How may the incubator-specific factors be related to the provisions' influence on strategy development? 


\subsubsection{The research participants}

The target population consisted of two main groups: the incubators and the firms within them. Here the rationale and process for the selection of the research participants and their characteristics are discussed.

\subsubsection{The incubators}

All six of the incubators that were, at the time, part of the New Zealand Incubator Support Programme contributed to this study, which formed a census (O'Leary, 2010, p. 181). Sampling was not needed due to the relatively small size of the population, and to the desire to triangulate the data from the individual firms with their respective incubators. In this instance triangulation aided both verification of the data (Cavana, Delahaye \& Sekaran 2001, p. 136) and differences in the data to be identified, as these disparities formed a key part of the analysis to address Question Four, 'How may the incubator-specific factors be related to the provisions' influence on strategy development?' Triangulation was achieved by comparing the firms' awareness and usage of provisions and their strategy developments with the views of the incubators.

Strand One's individual participants within the incubators were selected on the basis of their expertise (Cavana et al., 2001, p. 267). Consequently the participants were the CEOs or managers of each incubator as they were considered to have the most knowledge about their incubators. One interview was conducted for each incubator; however, in two incubators there were two participants, as the first interview participants were not considered to have full historical knowledge due to their short tenure. All of the potential participants that were approached agreed to an interview. Eight incubator manager interviews were therefore conducted in Strand One.

As the research needed to preserve anonymity, the incubators were assigned a random code, from $\mathrm{A}$ to $\mathrm{F}$ and are referred to as such in this thesis. In addition, in the interest of conciseness, the comments from the incubator managers are cited as coming from, for example 'incubator A' as opposed to the grammatically correct, 'the manager from incubator A'.

The ecentre is based in Auckland and was established as the incubator for a university, from which it draws expert advice for its firms. Its funding includes contributions by a local government and private organisations (ecentre, 2013). 
The Icehouse is also based in Auckland and is a collaboration between the University of Auckland Business School and major corporations including Telecom NZ, Ernst \& Young, Microsoft and the Boston Consulting Group (Icehouse, 2013).

Soda Inc is based in Hamilton and is funded by the Waikato Institute of Technology, local government and a range of private organisations. Soda provided the full range of incubator services with open-plan offices that are "funky and buzzing with energy" (Soda Inc, 2013).

The Bio Commerce Centre (BCC) is based in Palmerston North and is funded by a wide range of government, education and private institutions (BCC, 2013).

Creative HQ is based in Wellington and was established in 2003. Its funders include Grow Wellington - the regional economic development agency, NZTE and commercial organisations (Creative HQ, 2013).

powerHouse Ventures is based in Christchurch and Dunedin and their partners include universities and Crown research institutes. powerHouse specialises in creating high-value academic spin-out firms (powerHouse Ventures, 2013).

\subsubsection{The firms}

The total population of incubator firms was estimated to be 80 , based on the estimates provided by the incubator managers during Strand One data collection. For Strand Two data collection a census was administered (O'Leary, 2010, p. 181). However, while this aimed to be a census, the response rate for the survey was actually $37(46 \%)$ of the 80 firms.

For Strand Three it was determined that logistically it would not be feasible to interview all the firms in the population due to time and cost considerations. Therefore a sampling approach was used. This started with the firms self-selecting, based on their indications on the survey questionnaire (Strand Two) that they would like to be interviewed. Just three said no and a further 4 were unable to be interviewed due to logistical challenges. This left 30 firms. Non-probability quota sampling followed. Non-probability quota sampling is when participants are chosen from specific groups in order to meet a pre-determined quota (Cavana et al., 2001, p. 267). This process was considered necessary because of the desire to get a proportionally representative number of firms from each incubator. In addition efforts were made to ensure there was an even spread in terms of the length of time that the firms had been in each incubator. The result was that an additional three firms were selected, bringing the total to 33 firms being interviewed for Phase Three. 
The participants from the firms were the founding $\mathrm{CEO}$, or an individual at an equivalent level of authority and knowledge as occurred with the selection of the participants in the incubators. This was considered to be a non-probability judgement sampling methodology (Cavana et al., 2001, p. 267).

The decision was made to include firms that were at all stages of their incubation term, rather than just firms that had been with the incubator for a specified time. This decision was made due to the relatively small population size and therefore the potential difficulty of getting enough interview participants. Also, selection of the participants was not based on the likelihood of the firms graduating as the focus of the study was to explore the influence of the incubator on firms' strategy development, and not on the firms' success. The inclusion of firms of all types and growth stages helped to ensure a more comprehensive picture of the incubator's influences on strategy development.

The use of a matched sample of non-incubator NEFs was considered but the decision was made not to do this due to the potential difficulties with finding appropriately matched firms, and of isolating any substitute mechanisms that these firms may use in lieu of incubator provisions. The effect was that it could not be ascertained whether substitute provisions led to equivalent affordances and strategy development.

As assurances to preserve anonymity were made to firms the names of the firms are not used. Instead the firms are differentiated by labels, which have two parts. The first part is an arbitrary number, from 1-33 and the second part is a letter representing which incubator the firm was from. Again, in the interest of conciseness, the comments from the firms' strategists are cited as coming from, for example, 'firm 32A', as opposed to the grammatically correct, 'the strategist from firm 32A'.

\subsubsection{Methods of data collection}

\subsubsection{Research tools and data collection process}

The three strands of data collection employed different, but complementary, approaches to content design, piloting, participant recruitment, deployment, and analysis. A key premise was that the data generated from Strands One and Two informed the development of the subsequent strand and that collectively the three strands would address the research question. In this section this iterative process of data collection for Strands One to Three is 
discussed. The section following this explains the methodology used to analyse the data in order to address the research question, thus informing the findings and analysis.

\subsubsection{Strand One: Incubator interviews}

Strand One involved in-depth interviews with the incubator managers. The first step was to create an interview schedule which was used as a guide to the type of questions to ask and how to prompt the participant, if needed. (See Appendix C).

The interviews were all held at the premises of the participants (Wellington, Palmerston North, Auckland and Hamilton), with two exceptions. In one case the interview was undertaken using Skype, while the interview with the Christchurch-based incubator was held in Wellington. The interview duration ranged from 44-62 minutes.

\subsection{The interview schedule for Strand One}

The first question asked what the incubators' overall approach was to the development of the firms and if they specialised in any particular type of firm. The participants were asked how many firms were in the incubator and if they were located on-site or off-site. The answers to this question helped contextualise the incubator's emphasis on infrastructure provisions, such as office space. Another question asked whether the incubator offered any other programmes to the wider business community apart from standard incubation. The purpose of this question was to establish the extent to which the incubators focused on incubation or on a broader range of services to the business community.

The next set of questions was about the incubators' provisions. Open and broad questions were deliberately used so as to not bias the responses. Participants were asked to list the provisions that were available to the firms which they thought were the most important, and why. Following this they were asked if they had any specific strategy development programmes or tools. The purpose of this question was to generate a list of provisions that the incubator managers perceived they were offering firms, which would later be compared to a list generated from the literature review and then assessed for use in the online survey in Strand Two. In addition, it would be useful to compare the provisions the incubator managers thought were most valuable to firms with the firms' perceptions of valuable provisions from Strands Two and Three.

The incubators' selection process for new firms was the focus of the next few questions. This included what they looked for and what stage of development the firms were generally 
at. The purpose of these questions was to help put in context the emphasis of the incubators' programmes in terms of the firms' characteristics.

The three strategy development orientations were then explored through questions about how the firms' goals may have changed (goal orientation); how the firms' approach to planning and strategic experimentation may have changed (process orientation); and about how the partnership status, product scope, competitive emphasis and time allocation (content orientation) may have changed. The purpose of these questions was to delve into detail about the strategy developments that the incubators perceive as occurring, using the pre-determined definitions of the various dimensions of strategy. There was limited prompting in this line of questions so as not to bias the responses unduly; there appeared to be a solid understanding of what was being asked.

The final question asked the incubator managers how they would address the overall research question: How may incubators influence firms' strategy development? This question had value for three reasons. The first was that it helped ensure that the incubators' views on the most important provisions of incubators were captured and could be included in the subsequent strands of the research. Secondly it provided a summary of what types of strategy developments the incubator managers thought occurred. Thirdly, this question sought to draw out any other aspects of incubation not already covered in the interview that the incubator deemed important.

Once the interview schedule for Strand One was written it was piloted to assess its suitability for gathering the required data. In April 2014 a pilot interview with the first participant from incubator B was conducted. The interview went well, but was potentially compromised by the fact that the participant had only been in their role for a few months. While the participant answered most of the questions on the interview schedule, it was decided to interview a second participant to generate a more comprehensive data set for this incubator.

Overall, the pilot interview was useful in testing the interview schedule and some minor changes were made as a result.

\subsection{Timing of the interviews in the context of incubator funding applications}

An important factor to acknowledge is that the interviews took place during a critical time period in the New Zealand incubator industry. Callaghan Innovation administers government funding of incubators in the Incubator Support Programme. In early 2014 
Callaghan Innovation issued a Request for Proposal (RFP) from incubators with an April deadline for written responses to be followed by a series of oral presentations from applicants. Incubators were accustomed to applying for this government funding every 2-3 years but this time it was especially important given that the funding was likely to decrease substantially. The incubators were notified of the outcomes of their funding proposals midJune, 2014. The incubator interviews were carried out from the end of April until early June. However, while these interviews occurred at a critical time for the incubators, it was not expected that it would have had any notable impact on the data collected, as the subjects were reflecting on prior experiences as opposed to future plans.

\subsubsection{Strand Two: Firm surveys}

Strand Two involved an electronic survey of all incubator firms (see Appendix D). The survey instrument was created for the purpose of gathering data about the firms' perceptions and usage rates of the incubators' provisions.

\subsection{Designing the survey instrument}

The survey comprised questions about the firms' characteristics and about their value judgements and usage of the incubators' provisions.

The survey started with a one-page introduction to the research and the survey. The purpose was to convey information about the researcher, about the nature of the research question, the survey process and the potential outcomes of the research. The information outlined who was to complete the survey, how their anonymity would be preserved, and the implied consent for the use of the data collected. Respondents were also informed about the next strand of the research and were asked to indicate if they would consider being interviewed. The ethics approval and the thesis publication process were explained. Finally contact information for the researcher and supervisors was provided.

\subsection{Scale measurements for the provisions}

Various scale measurements were used for the provisions. For the internal-intangible, external-tangible and the external-intangible provisions, respondents were asked about the availability, usage levels, and value judgements of the provisions. The first question in this series sought to establish if the respondent knew if a particular provision was available at their incubator or not. They were required to select 'yes', 'unsure' or 'no', with subsequent questions taking this answer into account. The reason for this technique was to avoid asking 
about, for example, usage levels of provisions that were not available. The purpose of asking about availability was to enable analysis of the scope of provisions that firms were aware of in each incubator. The respondents were then asked to indicate their frequency of usage, again ranging from 'never' to 'almost daily' on a 7-point Likert scale. The purpose of this question was to enable analysis of whether ongoing affordances could be extracted from additional usage of the provisions. The groups of questions were summed up with a question asking the respondent to judge the value of all the provisions using a 100-point rating scale, whether they were available at their incubator or not. The purpose of this question was to ascertain the respective value judgements of each provision. As with Strand One, respondents were also asked if they had anything else to add that they thought may be of interest to the wider study to ensure that the most important provisions of incubators were acknowledged.

\subsection{Operationalising the incubator provisions}

A list of provisions needed to be generated, or operationalised for the survey. In the literature review there were a number of incubator provisions that were identified (see Table 2) and in Strand One of the data collection the incubators discussed the provisions that they offered and viewed as being most important. Table 7 presents a comparison of these two groups of provisions and the ensuing rationale for the provisions included in the survey.

Table 7 shows that there was some mismatch, that is, some provisions identified in the literature review were not specifically highlighted in the data generated from Strand One, and vice versa. 
Table 7

Justification for the Selection of Provisions to be Operationalised

\begin{tabular}{|c|c|c|c|c|}
\hline $\begin{array}{l}\text { Provision } \\
\text { category }\end{array}$ & $\begin{array}{l}\text { Core provisions identified from } \\
\text { literature review (Table 2, Chapter 2) }\end{array}$ & $\begin{array}{l}\text { Core provisions identified by incubators } \\
\text { (Strand One) }\end{array}$ & $\begin{array}{l}\text { Provisions selected for inclusion in } \\
\text { the survey }\end{array}$ & $\begin{array}{l}\text { Rationale for inclusion or } \\
\text { exclusion of provisions in } \\
\text { the survey (Strand Two) }\end{array}$ \\
\hline \multirow{3}{*}{$\begin{array}{l}\text { Internal- } \\
\text { tangible }\end{array}$} & $\begin{array}{l}\text { Subsidised office space and internet } \\
\text { access }\end{array}$ & Dedicated desks and/or office space & Dedicated desks and/or office space & \multirow{3}{*}{$\begin{array}{l}\text { In literature review and } \\
\text { identified by incubators. }\end{array}$} \\
\hline & Shared office services & Board rooms or meeting rooms & Board rooms or meeting rooms & \\
\hline & Capital from incubator's funds & Funding from incubator itself & Not included & \\
\hline & & & & \\
\hline \multirow{2}{*}{$\begin{array}{l}\text { External- } \\
\text { tangible }\end{array}$} & $\begin{array}{l}\text { Capital from grants by local and national } \\
\text { economic development agencies }\end{array}$ & Government grants & Connections to government grants & \multirow{2}{*}{$\begin{array}{l}\text { In literature review and } \\
\text { identified by incubators. }\end{array}$} \\
\hline & $\begin{array}{l}\text { Connections to funders including angel } \\
\text { investors and venture capitalists }\end{array}$ & Angel investors and venture capitalists & $\begin{array}{l}\text { Connections to angel investors or } \\
\text { venture capitalists }\end{array}$ & \\
\hline & & & & \\
\hline \multirow{9}{*}{$\begin{array}{l}\text { Internal- } \\
\text { intangible }\end{array}$} & Business planning and growth advice & $\begin{array}{l}\text { Strategy development and planning } \\
\text { Growth management }\end{array}$ & $\begin{array}{l}\text { Assistance with strategy development } \\
\text { methodologies. Assistance with growth } \\
\text { management }\end{array}$ & \multirow{5}{*}{$\begin{array}{l}\text { In literature review and } \\
\text { identified by incubators. }\end{array}$} \\
\hline & General business management advice & $\begin{array}{l}\text { General business administration tasks and } \\
\text { advice }\end{array}$ & $\begin{array}{l}\text { Assistance with general business } \\
\text { administration tasks }\end{array}$ & \\
\hline & Educational workshops & Educational workshops & Educational workshops & \\
\hline & Fundraising support & $\begin{array}{l}\text { Financial planning and management } \\
\text { Assistance with getting investment ready }\end{array}$ & $\begin{array}{l}\text { Assistance with financial planning and } \\
\text { management }\end{array}$ & \\
\hline & Market validation advice & Market validation and development & $\begin{array}{l}\text { Assistance with market validation and } \\
\text { development }\end{array}$ & \\
\hline & Not mentioned in literature & Product validation and development & $\begin{array}{l}\text { Assistance with product validation and } \\
\text { development }\end{array}$ & \multirow{4}{*}{$\begin{array}{l}\text { Not mentioned in literature } \\
\text { review but highlighted as } \\
\text { important by incubators. }\end{array}$} \\
\hline & Not mentioned in literature & Pitching practice and development & $\begin{array}{l}\text { Assistance with pitching development } \\
\text { and practice }\end{array}$ & \\
\hline & Not mentioned in literature & Developing a team of people & $\begin{array}{l}\text { Assistance with developing a team of } \\
\text { people }\end{array}$ & \\
\hline & Not mentioned in literature & Developing a board of directors or advisors & $\begin{array}{l}\text { Assistance with developing a board of } \\
\text { directors or advisors }\end{array}$ & \\
\hline
\end{tabular}




\begin{tabular}{|c|c|c|c|c|}
\hline \multirow{6}{*}{$\begin{array}{l}\text { External- } \\
\text { intangible }\end{array}$} & Not mentioned in literature & Connections to subject matter experts & Connections to subject matter experts & $\begin{array}{l}\text { Not mentioned in literature } \\
\text { review but highlighted by } \\
\text { incubators. }\end{array}$ \\
\hline & $\begin{array}{l}\text { Connections to local universities and } \\
\text { industry }\end{array}$ & $\begin{array}{l}\text { Connections to universities and other } \\
\text { tertiary institutions } \\
\text { Connections to interns from tertiary } \\
\text { institutions }\end{array}$ & $\begin{array}{l}\text { Connections to universities and other } \\
\text { tertiary institutions } \\
\text { Connections to interns from tertiary } \\
\text { institutions }\end{array}$ & \multirow[t]{3}{*}{$\begin{array}{l}\text { In literature review and } \\
\text { identified by incubators. }\end{array}$} \\
\hline & $\begin{array}{l}\text { Connections to advisory and board } \\
\text { members }\end{array}$ & Connections to potential board members & $\begin{array}{l}\text { Connections to potential board } \\
\text { members }\end{array}$ & \\
\hline & $\begin{array}{l}\text { Connections to providers of professional } \\
\text { services often at subsidised rates }\end{array}$ & Connections to professional advisors & $\begin{array}{l}\text { Connections to professional services, } \\
\text { e.g. lawyers, accountants, sales trainers }\end{array}$ & \\
\hline & Not mentioned in literature & Connections to potential major customers & $\begin{array}{l}\text { Connections to potential major } \\
\text { customers }\end{array}$ & \multirow{2}{*}{$\begin{array}{l}\text { Not mentioned in literature } \\
\text { review but highlighted by } \\
\text { incubators. }\end{array}$} \\
\hline & Not mentioned in literature & $\begin{array}{l}\text { Connections to business mentors from } \\
\text { outside the incubator }\end{array}$ & $\begin{array}{l}\text { Business mentors from outside of } \\
\text { incubator }\end{array}$ & \\
\hline & & & & \\
\hline \multirow{4}{*}{$\begin{array}{l}\text { Firms' } \\
\text { relationship } \\
\text { with } \\
\text { incubator }\end{array}$} & $\begin{array}{l}\text { Credibility from being connected to } \\
\text { incubator's networks } \\
\text { Credibility from being associated with the } \\
\text { incubator }\end{array}$ & Not mentioned by incubators & $\begin{array}{l}\text { A sense of increased credibility from } \\
\text { being associated with the incubator }\end{array}$ & $\begin{array}{l}\text { Not mentioned by } \\
\text { incubators but highlighted in } \\
\text { literature review }\end{array}$ \\
\hline & $\begin{array}{l}\text { Get social support and feel like they are } \\
\text { part of an in-group }\end{array}$ & $\begin{array}{l}\text { Interaction with entrepreneurs in other } \\
\text { incubator companies }\end{array}$ & $\begin{array}{l}\text { Emotional support from other } \\
\text { incubator companies }\end{array}$ & $\begin{array}{l}\text { In literature review and } \\
\text { identified by incubators }\end{array}$ \\
\hline & $\begin{array}{l}\text { Embed firms with entrepreneurial } \\
\text { networks }\end{array}$ & Not mentioned by incubators & $\begin{array}{l}\text { A sense of being part of } \\
\text { entrepreneurial networks }\end{array}$ & \multirow{2}{*}{$\begin{array}{l}\text { Not mentioned by } \\
\text { incubators but highlighted in } \\
\text { literature review }\end{array}$} \\
\hline & $\begin{array}{l}\text { Knowledge sharing with other incubator } \\
\text { companies }\end{array}$ & Not mentioned by incubators & $\begin{array}{l}\text { Knowledge sharing with other } \\
\text { incubator companies }\end{array}$ & \\
\hline
\end{tabular}




\subsection{Piloting the survey}

The online survey was created using the online survey software Qualtrics. The piloting process was conducted online, and consisted of four stages of testing. The first stage was conducted with the researcher's supervisors. The second stage involved two incubator firms. One of these tests was conducted with the researcher sitting beside the participant, with the purpose being to directly observe how they responded to the questions. This approach also gave the researcher an opportunity to ask why the participant chose the answers they did, and to discuss any confusing questions as they arose. The third stage involved someone who had no connection to incubators whatsoever. The purpose was to establish how easy the questions were to understand from a layperson's point of view. This respondent reported that the survey was easy to follow and logical, with no changes recommended. The fourth stage of piloting the survey involved the managers of all six incubators. The purpose of this was to ensure that they understood the survey, and that they were happy with the nature of the questions being asked. No changes were recommended as a result.

\subsection{Administering the survey to firms}

During Strand One the incubators were informed of the desire to survey the firms and were asked if they would be prepared to supply the researcher with contact names and email addresses of the appropriate people with the firms. However they indicated that they would prefer not to, and were instead a central point for despatching the online and anonymous link to the survey. A URL link to the survey was sent to the firms via the managers of the incubators at varying times between May and August, 2014. Ideally the survey would have been despatched to firms at the same time, but this was not possible due to some of the incubator managers being on leave and having other priorities. The survey took participants on average 16 minutes to complete.

\subsubsection{Strand Three: Firm interviews}

The purpose of the third data collection strand was to generate in-depth data about the affordances that arose out the incubators' provisions, the actual strategy developments that occurred, and the influence of the affordances from the incubators' provisions on the strategy developments (see Table 6). 


\subsection{Design of the interview schedule for Strand Three}

The interview schedule was designed using three main sources of information: the literature review, the data from the interviews with the incubators from Strand One, and the data from the firms' surveys from Strand Two.

The first half of the interview focussed on the provisions of the incubator. To help reduce the potential for bias the participants were asked open questions rather than about specific provisions. Participants were questioned about their interactions with incubator staff and about what this interaction enabled; this was essentially about what affordances arose from the internal-intangible provisions. The next question asked about how they engaged with the incubators' networks - which relates to external-intangible provisions - then about how they had engaged with the infrastructure that the incubator provided, which relates to the internal-tangible provisions. Following this participants were asked about any capital investment that had been facilitated by the incubator, which relates to the external-tangible provisions. Questions relating to the intangible provisions were asked first because they were considered to have the greatest number of provisions and may therefore generate more discussion.

The second half of the interview focused on the firms' strategy developments and what influenced them. The questions were based on the three strategy development orientations: goals, process and content, as identified in the literature review. The questions about each orientation followed a set format. Firstly, they were asked about whether, for example, their goals had changed, and then about what had influenced that change. If they were unsure about what the influences were, they were prompted about whether the incubator had had any influence.

The interview concluded with the question, 'If you were to answer the research question, which is, how may incubators influence firms' strategy development, what would you say?' The purpose of asking this was to highlight the relative importance of the provisions and their influence on the firms' strategy development.

The initial interview schedule was piloted with one incubator firm in May 2014 at around the same time that the incubator manager interviews were being conducted. The interview schedule worked effectively and therefore no changes were made to it. 


\subsection{Conducting the interviews}

Strand Three interviews commenced in May 2014 with the pilot interview. The remaining 32 interviews were conducted between August and October 2014 as outlined earlier. As discussed in Section 3.4.3.2.2 it was anticipated that major changes would be imposed on the New Zealand incubators by their main funder, Callaghan Innovation. These changes occurred during data collection and, if the data collection strands had taken place over a longer period of time, this could have affected the relevance of the data from the earlier strands. Therefore it was decided to attempt to capture the data from all three strands within as short a time frame as possible, while still enabling the multiphase design.

All the Strand Three interviews were conducted in person, with the exception of three interviews that were conducted via Skype. The average duration of each interview was 55 minutes.

Prior to each interview the research process was explained to the participants, including the purpose of the research strands, ethical issues, and what the participants could expect after the interview. Participants were also required to read and sign a consent form.

The interviews were recorded and the transcript was provided to each participant within approximately four weeks of the interview taking place. Participants were then given four weeks from receipt of the transcript to withdraw from the research or to request any changes. The transcripts were not always full transcripts; that is, in some instances any discussions that were not deemed relevant to the research were omitted, such as the detail of the firms' products.

\subsection{Data analysis}

The data generated from the three strands were analysed in various ways according to the stage and purpose (refer Table 6). The discussion above indicates how the data from Strand One of the research informed the survey design, and how the data from Strands One and Two informed the interview schedule for Strand Three of the data collection. Next, the way the data were actually prepared for analysis is discussed along with the processes involved in extracting the findings and doing the analysis.

\subsubsection{Preparation and coding of the data}

The interviews were coded using NVivo, with parent nodes comprising the incubator provisions, strategy developments and sources of influence. The demographic data was also 
coded. During the coding process it became evident that the data did not always fit succinctly into the original list of provisions within the internal/external and tangible/intangible categories. For example, firms may have attributed strategy developments to the affordances resulting from multiple provisions. In these instances an effort was made to ensure that these statements were coded in multiple places to ensure that the richness of these occurrences was captured.

The extent to which the incubators influenced strategy development varied. To analyse this data effectively it also coded according to the magnitude of the influence. This was done by creating groups of nodes within these parent nodes with names such as 'perceived', 'not perceived', 'valued', 'not valued' for the provisions, and 'no change', 'moderate change', 'big change' for the strategy developments and 'no influence', 'moderate influence' and 'big influence' for the incubators' influence on these provisions. This additional layer of coding enabled further filtering of the data and viewing it from multiple angles. For example, it enabled coding queries that just looked at the quotes regarding specific strategy developments where the incubator had a big influence, and then in situations where it had no influence.

\subsubsection{Data analysis process}

The data analysis process involved combining the strands of data, that is, using the interview and survey data together, and from the two distinct groups of participants, enabling triangulation. The purpose was to address the four research sub-questions. There are four findings and analysis chapters_-Chapters Four to Seven.

Question One, 'What are the affordances of the incubators' provisions?' is addressed in Chapter Four, which takes an affordance-centric view using data from all three strands. First the provision availability, usage and value judgements were analysed to establish if and how they differ depending on whether the firms had used them or not, and how the frequency of use compared to the value judgements. Following this, the nature and characteristics of each provision was analysed in depth, from the point of view of both the firms (from Strand Three) and the incubators (from Strand One). This analysis led to the coding of the specific affordances from each provision, which was used for the purposes of the background analysis in subsequent research questions. For example, the coding for provisions E, F, G and $\mathrm{H}$ are listed in Table 8. 
Table 8

Coding Sample for Affordances of Provisions E to $H$

\begin{tabular}{|l|l|l|}
\hline Provision & Affordance & Code \\
\hline \multirow{3}{*}{$\begin{array}{l}\text { Strategy methodologies } \\
\text { E) }\end{array}$} & Provided structure and clarity of strategy & E1 \\
\cline { 2 - 3 } & Provided tools to develop strategies & $\mathrm{E} 2$ \\
\cline { 2 - 3 } & Challenged strategic decisions & $\mathrm{E} 3$ \\
\hline \multirow{2}{*}{$\begin{array}{l}\text { Product validation and } \\
\text { development }(\mathrm{F})\end{array}$} & Provided assistance with the product validation process & $\mathrm{F} 1$ \\
\cline { 2 - 3 } & Provided assistance with pivoting & $\mathrm{F} 2$ \\
\hline \multirow{2}{*}{$\begin{array}{l}\text { Pitching development } \\
\text { and practice }(\mathrm{G})\end{array}$} & Provided assistance with presentation format and content & $\mathrm{G} 1$ \\
\hline \multirow{2}{*}{$\begin{array}{l}\text { Market validation and } \\
\text { development }(\mathrm{H})\end{array}$} & Helped build skills and confidence & $\mathrm{G} 2$ \\
\cline { 2 - 3 } & Realised need for market validation & $\mathrm{H} 1$ \\
\cline { 2 - 3 } & Ensured market validation is done & $\mathrm{H} 2$ \\
\cline { 2 - 3 } & Helped with market validation process & $\mathrm{H} 3$ \\
\cline { 2 - 3 } & Provided introductions & $\mathrm{H} 4$ \\
\hline
\end{tabular}

Question Two, 'How may the provisions' affordances influence strategy development?' is addressed in Chapter Five, which takes a strategy development-centric view. The analysis explores the affordances that influenced strategy development, again from the perspective of both the firms (Strands Two and Three) and the incubators (Strand One). Based on this analysis, a determination was made about the strategy developments that occurred, the direction of the strategy developments on each continuum, and the specific affordances that were of influence. For example, the coding of the data for some of the firms on the product scope continuum is presented in Table 9.

Table 9

Coding Sample for Type of Change on the Product Scope Continuum

\begin{tabular}{|l|l|l|}
\hline Firm & Type of change on continuum & Affordance code \\
\hline $16 \mathrm{C}$ & Different (core) & E3 \\
\hline $21 \mathrm{C}$ & Scalable ICT (middle) & F2, H3 \\
\hline $7 \mathrm{D}$ & Evolution (middle) & E1, H1 \\
\hline 8D & Scope up (core) & E3 \\
\hline $11 \mathrm{D}$ & Evolution (middle) & E3, H1 \\
\hline $12 \mathrm{D}$ & No change & \\
\hline $14 \mathrm{D}$ & Evolution (middle) & E3 \\
\hline $17 \mathrm{D}$ & Scope up (core) & H3, E3 \\
\hline $19 \mathrm{D}$ & Scope down (core) & E3 \\
\hline $22 \mathrm{D}$ & Evolution (middle) & E3, H2 \\
\hline 31D & Different (core) & E2, H1 \\
\hline
\end{tabular}

Question Three, 'How may the firm-specific factors be related to the provisions' influence on strategy development?' is addressed in Chapter Six. This is done by comparing the quantitative data from Strand Two to the qualitative data in Strand Three using a series of comparison tables. The purpose is to explore whether the firms' contextual factors are related to the influence of the affordances on strategy developments, and the direction in which they developed. The contextual factors are determined and then plotted for each firm. 
Heat maps are included in Chapter Six and Seven and are used to graphically identify patterns in the data regarding provision usage and strategy development rates. Each contextual factor was then explored along each strategy development dimension using a comparison table to determine the respective relationships. The comparison tables are displayed only where a relationship was apparent; the tables that have not been displayed in this chapter are included in Appendix G.

Question Four, 'How may the incubator-specific factors be related to the provisions' influence on strategy development?' ' is addressed in Chapter Seven. The characteristics of the incubators are analysed with respect to their influence on their firms, which is done by comparing the qualitative data (Strand One) to the quantitative data (Strand Two) and qualitative data (Strand Three). The purpose is, again, to explore how the differences in the incubators may affect their influence on the firms' strategy developments and the direction in which they developed.

The findings and analysis are discussed in Chapter Eight, which commences with addressing the research questions. The research questions are discussed in terms of how the findings relate to the literature and the possible reasons why they may have occurred. Based on this, it was established that the TOA did not specifically allow for some factors that affected the influence the incubators had on the firms' strategy development. In Chapter Nine these factors are discussed in detail before any conclusions are drawn on the contribution of this thesis to the TOA in the context of organisational studies or the implications for incubators.

\subsection{Ethical considerations}

The ethical obligation of the researcher is to protect the participants' anonymity, privacy and confidentiality and protect them from emotional harm, discomfort and discrimination (O'Leary, 2010). In this study the participants' anonymity was protected as their name, the name of the incubators and the firms, and the specific nature of their products or services have not appeared in the final thesis. In instances where participants are quoted, codes were used to differentiate the firms. However, the relatively small number of incubators and firms in the research presented challenges with ensuring anonymity of the participants. By excluding any information that could identify the firms their anonymity was protected as much as was feasible. Issues regarding sensitivity of information were further alleviated by the fact that this study did not explore the performance outcomes of the firms. These ethical considerations are important because the data collected could be deemed commercially 
sensitive and having the potential to impact on the firms' relationship with the incubator. However this meant that the survey data could not be directly matched to the interview data. Privacy was protected by the questionnaires and interviews being conducted in private and by the questionnaire results, interview transcripts and any documentary data being kept in a secure environment. Access to this secure environment is restricted to the researcher and her supervisors throughout the duration of the research and for six years thereafter. Following this, the data will be either shredded if in hard copy, or erased if in electronic or audio form. Approval from the University of Victoria's Human Ethics Committee was obtained in March 2014, prior to data collection, thus ensuring that the research was constructed within the University's guidelines concerning human participants.

\subsection{Limitations of the research methods}

The research methodology has highlighted that there are some potential limitations, which are summarised here, and discussed more fully in the conclusion in Chapter Nine.

In summary, the limitations in Strand One involved interviewing two participants in two incubators respectively, instead of one, because of the relative newness of the first interview participants to their respective roles. In Strand Two the survey was self-reported and distributed anonymously, potentially resulting in some misreporting and self-selection bias. This self-selection bias may have also occurred in Strand Three, but was considered to be mitigated by actively approaching firms for interview in an effort to make the samples within each incubator more representative. Lastly, the effects of the firms' strategy developments on their performance were not explored as it was not the aim of the research.

\subsection{Chapter summary}

Chapter Three outlines the research methodology that was used to address the research questions. It included the research aims, paradigm, design, participants, and the methods of data collection and data analysis. This process had an explicit pathway for ensuring reliability of the methods used. The findings and analysis of this study are presented in Chapters Four to Seven. 


\section{Findings and analysis - The affordances of incubators' provisions}

\subsection{Chapter introduction}

Chapter Four addresses the first sub-question: What are the affordances of the incubators' provisions? The purpose of this sub-question is to explore the nature of the affordances and to gain an understanding of why firms engage with them. The focus of this chapter is highlighted in green in the conceptual model.

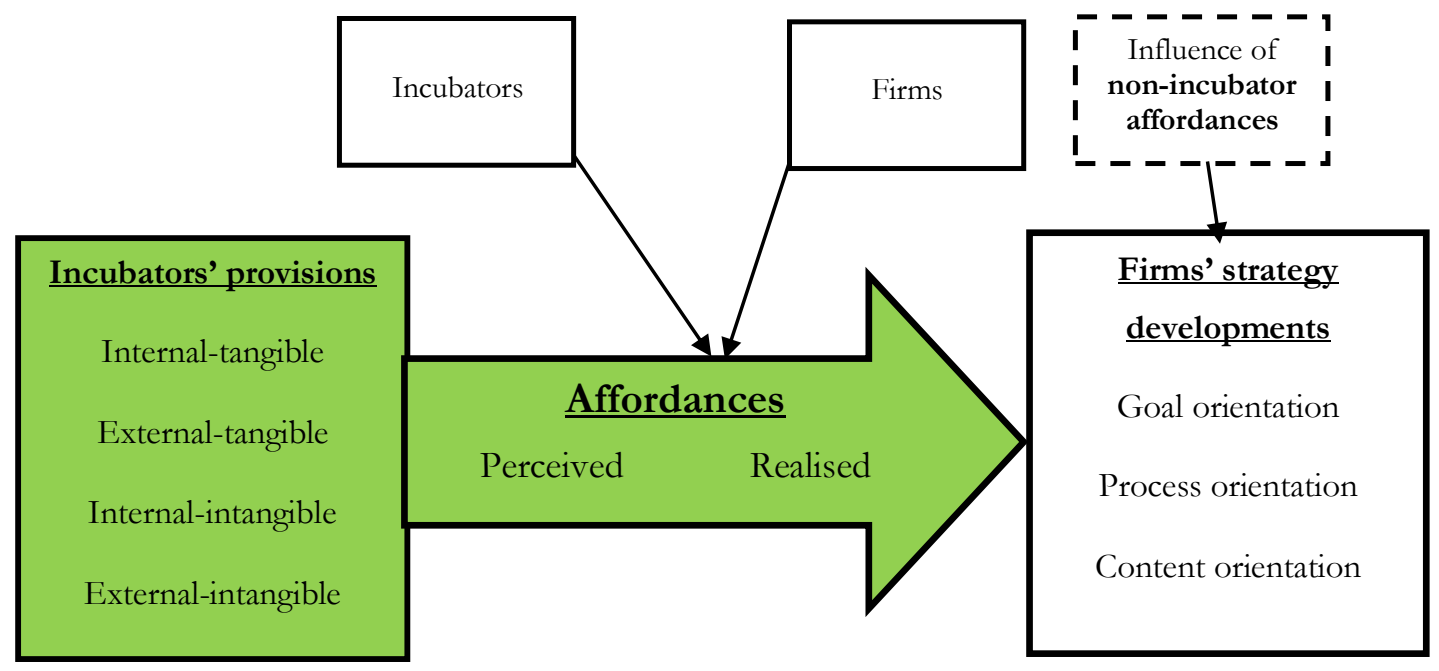

Figure 5. The conceptual model with the focus of Chapter Four highlighted. (Adapted from Figure 3).

The analysis in this chapter comprises two interwoven parts. The first part provides an overview which puts the value judgements and usage of the incubators' provisions into context to establish what differences may exist. This analysis starts with the value judgements of the provisions and how this may differ depending on whether or not the firms had used them. The purpose was to establish if there were any provisions that were valued substantially differently depending on use and what this might imply for the ensuing affordances. Following this is a comparison of the value judgements, in terms of the frequency with which the provisions were used, to establish whether or not there is any relationship between these two factors. The analysis at the end of this first section provides an overview of provision availability and usage, which gives context to the subsequent discussion, later in the chapter.

The second part of this chapter explores the nature of the affordances that arise from the provisions. The purpose here is to expand on why the differences identified earlier may exist 
by exploring the affordances of the provisions from the perspective of both the firms and the incubators.

\subsection{Comparison of value judgements between users and non-users}

The first task is to explore whether there are any provisions that were valued substantially differently depending on whether they had been used or not and what this may imply in terms of perceived and realised affordances.

Table 10 presents a summary of data that was obtained from Strand Two, the survey. Note that this set of firms is not exactly the same set of firms that participated in Strand Three of data collection (the interviews with firms) although there is a substantial overlap. The first column shows the number (and percentage) of firms that had actually used the provisions. The number of firms varies slightly for each provision as not all respondents answered all the questions. Missing values were excluded from the value judgement columns. The second column (mean if used) and the third column (mean if not used) show the mean value judgement rating based on a 100 -point sliding scale from $0=$ least valuable to $100=$ most valuable. The fourth column (mean difference) shows the differences between the means of the two value judgements. In the fifth column a t-test is used to test whether the means of the value judgements for provisions that were used and not used were significantly different, with the significance level in the last column. A typically acceptable probability error is $<0.05$ (Boslaugh \& Watters, 2008) and, accordingly, these associated provisions are highlighted in red in Table 10.

The category of provisions with the highest level of usage was the internal-intangible category, and the individual provisions with the highest use were market validation and development $(\mathrm{H})$ at $97 \%$ of firms, and strategy methodologies (E) at $89 \%$ of firms. The most valued provision by firms that had used it was connections to potential major customers (S) at 95 points, followed by funding for firms by incubator (C) at 92 points and the firms' head office being sited at the incubator (A) at 89 points. This suggests that the affordances from these provisions may have been important to the firms. The provisions that were valued the lowest by firms that had used them were connections to interns from tertiary institutions (V) at 53 points and professional services $(\mathrm{P})$ at 54 points. The affordances from these provisions may have been less important to the firms. 
Table 10

Comparison of Availability and V alue Judgements of Provisions

\begin{tabular}{|c|c|c|c|c|c|c|}
\hline Provision & $\begin{array}{l}\text { Number } \\
\text { that used } \\
\text { provision } \\
\text { ( } \% \text { of firms) }\end{array}$ & $\begin{array}{l}\text { Mean if } \\
\text { used } \\
\text { (standard } \\
\text { deviation) }\end{array}$ & $\begin{array}{l}\text { Mean if not } \\
\text { used } \\
\text { (standard } \\
\text { deviation) }\end{array}$ & $\begin{array}{l}\text { Mean } \\
\text { difference }\end{array}$ & $\begin{array}{l}\text { t-test } \\
\text { statistic }\end{array}$ & $\begin{array}{l}\text { Sig. (2- } \\
\text { tailed) }\end{array}$ \\
\hline $\begin{array}{l}\text { Firms' head office located in } \\
\text { incubator (A) }\end{array}$ & $12(50 \%)$ & $\begin{array}{l}89.17 \\
(13.36)\end{array}$ & $\begin{array}{l}39.75 \mathrm{n}=14 \\
(38.94)\end{array}$ & 49.42 & 4.15 & .001 \\
\hline $\begin{array}{l}\text { Use meeting rooms in } \\
\text { incubator }(B)\end{array}$ & $22(85 \%)$ & $\begin{array}{l}78.90 \\
(26.28)\end{array}$ & $\begin{array}{l}41.00 n=4 \\
(42.20)\end{array}$ & 37.91 & 2.43 & .023 \\
\hline $\begin{array}{l}\text { Funding for firms by } \\
\text { incubator }(C)\end{array}$ & $7(32 \%)$ & $\begin{array}{l}92.29 \\
(11.40)\end{array}$ & $\begin{array}{l}66.33 n=19 \\
(36.44)\end{array}$ & 25.95 & 1.82 & .083 \\
\hline Internal-tangible mean & & 86.79 & 49.03 & 37.76 & & \\
\hline $\begin{array}{l}\text { General business } \\
\text { administration tasks (D) }\end{array}$ & $11(32 \%)$ & $\begin{array}{l}63.09 \\
(29.73)\end{array}$ & $\begin{array}{l}52.26 \mathrm{n}=25 \\
(23.85)\end{array}$ & 10.83 & 1.06 & .306 \\
\hline Strategy methodologies (E) & $32(89 \%)$ & $\begin{array}{l}82.50 \\
(12.84)\end{array}$ & $\begin{array}{l}83.75 n=4 \\
(11.09)\end{array}$ & -1.25 & -0.19 & .854 \\
\hline $\begin{array}{l}\text { Product validation and } \\
\text { development }(\mathrm{F})\end{array}$ & $25(69 \%)$ & $\begin{array}{l}77.52 \\
(25.47)\end{array}$ & $\begin{array}{l}60.27 \mathrm{n}= \\
11(32.89)\end{array}$ & 17.24 & 1.71 & .096 \\
\hline $\begin{array}{l}\text { Pitching development and } \\
\text { practice }(G)\end{array}$ & $26(72 \%)$ & $\begin{array}{l}66.23 \\
(28.59)\end{array}$ & $\begin{array}{l}66.50 n=10 \\
(24.03)\end{array}$ & -0.3 & -0.03 & .979 \\
\hline $\begin{array}{l}\text { Market validation and } \\
\text { development }(\mathrm{H})\end{array}$ & $35(97 \%)$ & $\begin{array}{l}82.11 \\
(21.54)\end{array}$ & $50.00 \mathrm{n}=1$ & 32.11 & 1.47 & .151 \\
\hline $\begin{array}{l}\text { Financial planning and } \\
\text { management }(\mathrm{I})\end{array}$ & $18(51 \%)$ & $\begin{array}{l}70.89 \\
(19.52)\end{array}$ & $\begin{array}{l}67.06 n=18 \\
(31.04)\end{array}$ & 3.83 & 0.44 & .663 \\
\hline Growth management $(\mathrm{J})$ & $15(43 \%)$ & $\begin{array}{l}76.27 \\
(23.22)\end{array}$ & $\begin{array}{l}63.20 n=21 \\
(28.71)\end{array}$ & 13.07 & 1.44 & .159 \\
\hline $\begin{array}{l}\text { Developing a board of } \\
\text { directors or advisors }(\mathrm{K})\end{array}$ & $18(50 \%)$ & $\begin{array}{l}76.72 \\
(23.17)\end{array}$ & $\begin{array}{l}63.56 n=18 \\
(31.67)\end{array}$ & 13.17 & 1.42 & .164 \\
\hline $\begin{array}{l}\text { Developing a team of people } \\
\text { (L) }\end{array}$ & $15(43 \%)$ & $\begin{array}{l}70.13 \\
(23.31)\end{array}$ & $\begin{array}{l}68.80 n=21 \\
(24.44)\end{array}$ & 1.33 & 0.16 & .872 \\
\hline Educational workshops (M) & $25(71 \%)$ & $\begin{array}{l}64.20 \\
(29.34)\end{array}$ & $\begin{array}{l}50.70 \mathrm{n}=11 \\
(23.00)\end{array}$ & 13.50 & 1.30 & .203 \\
\hline Internal-intangible mean & & 72.96 & 62.61 & 10.35 & & \\
\hline Government grants $(\mathrm{N})$ & $21(58 \%)$ & $\begin{array}{l}69.57 \\
(24.05)\end{array}$ & $\begin{array}{l}77.20 n=15 \\
(21.69)\end{array}$ & -7.62 & -0.98 & .336 \\
\hline $\begin{array}{l}\text { Angel investors or venture } \\
\text { capitalists }(\mathrm{O})\end{array}$ & $17(49 \%)$ & $\begin{array}{l}79.35 \\
(18.67) \\
\end{array}$ & $\begin{array}{l}85.33 n=19 \\
(17.10)\end{array}$ & -5.98 & -0.99 & .330 \\
\hline External-tangible mean & & 74.46 & 81.27 & -6.80 & & \\
\hline Professional services $(\mathrm{P})$ & $21(58 \%)$ & $\begin{array}{l}54.38 \\
(21.44)\end{array}$ & $\begin{array}{l}65.40 \mathrm{n}=15 \\
(19.79)\end{array}$ & -11.01 & -1.57 & .126 \\
\hline Subject matter experts (Q) & $21(60 \%)$ & $\begin{array}{l}74.14 \\
(17.01)\end{array}$ & $\begin{array}{l}64.93 n=15 \\
(30.70)\end{array}$ & 9.21 & 1.02 & .320 \\
\hline Potential board members (R) & $17(49 \%)$ & $\begin{array}{l}73.76 \\
(20.12)\end{array}$ & $\begin{array}{l}51.50 \mathrm{n}=19 \\
(25.49)\end{array}$ & 22.26 & 2.86 & .007 \\
\hline Potential major customers (S) & $13(36 \%)$ & $\begin{array}{l}95.08 \\
(6.10)\end{array}$ & $\begin{array}{l}87.74 n=23 \\
(24.51)\end{array}$ & 7.34 & 1.36 & .184 \\
\hline $\begin{array}{l}\text { Universities and other tertiary } \\
\text { institutions }(\mathrm{T})\end{array}$ & $16(46 \%)$ & $\begin{array}{l}58.88 \\
(21.73)\end{array}$ & $\begin{array}{l}46.58 \mathrm{n}=20 \\
(25.17)\end{array}$ & 12.30 & 1.53 & .135 \\
\hline $\begin{array}{l}\text { Business mentors from } \\
\text { outside of incubator }(\mathrm{U})\end{array}$ & $19(54 \%)$ & $\begin{array}{l}78.37 \\
(20.42)\end{array}$ & $\begin{array}{l}57.00 \mathrm{n}=17 \\
(28.34)\end{array}$ & 21.37 & 2.59 & .014 \\
\hline $\begin{array}{l}\text { Interns from tertiary } \\
\text { institutions }(\mathrm{V})\end{array}$ & $11(31 \%)$ & $\begin{array}{l}52.73 \\
(30.82) \\
\end{array}$ & $\begin{array}{l}49.25 n=25 \\
(21.66)\end{array}$ & 3.47 & 0.39 & .703 \\
\hline External-intangible mean & & 69.62 & 60.34 & 7.21 & & \\
\hline
\end{tabular}


Note that the data in Table 10 is drawn from Strand Two $(n=37)$ and not from the incubator interviews from Strand Three. Hence some totals for the provision usage and awareness, while similar, do not equate with the subsequent discussion.

While it is interesting to know what provisions were used, what is potentially more interesting is the value that firms placed on the provisions, and if this value differed according to whether or not the provisions had been used. Provisions that had high differences in value judgements may indicate, for example, that firms are realising affordances that they had not perceived or that the non-users did not want or need the provisions; however, this cannot be ascertained from the data. While differences can be seen in the mean difference column, few of the differences were actually statistically different. Differences in the internal-tangible category of provisions, namely the firms' head office being located in incubator (A) and the use of meeting rooms in incubator (B) had differences in value judgement means that were statistically greater at, respectively, 49 and 37 points by firms that had used these provisions. Similarly the value judgment mean was over 21 points greater for users than non-users of the provisions of connections to potential board members (R) and 21 points greater for connections to business mentors outside the incubator $(\mathrm{U})$. Other provisions also had high, but not statistically significant differences in means including assistance with product validation and development $(\mathrm{F})$, help with developing a board of directors $(\mathrm{K})$, educational workshops $(\mathrm{M})$ and assistance with growth management $(J)$.

These high differences indicate that firms that had used these provisions valued them more highly than firms that had not used them, therefore it could tentatively be concluded that the perceived affordances of the provisions were lower than the realised affordances. It is important to note however, that the value perception data was gathered from two sets of firms, users and non-users and not from the same firms before and after they used the provisions. Therefore the difference could occur because the non-users did not need the provision and accordingly judged its value lower.

Note that the total number of firms that provided data for provisions $A, B$ and $C$ was just 26 (as opposed to 36 firms) as this data was collected subsequent to the original survey, Strand Two.

In some cases the value judgement ratings of provisions were lower by firms that had used them, but this occurred to a lesser extent and the differences are not statistically significant. 
Notably, connections to professional services (P) was 11 points lower for firms that had used this provision compared to those that had not, and connections to government grants $(\mathrm{N})$ was nearly eight points lower, although neither of these are statistically significant. This difference may indicate that firms that had not used these provisions believed them to be of greater value than the firms that had used these provisions, potentially indicating that the perceived affordances from these provisions were higher than the realised affordances. However the data did not specifically generate information to address this and further research is needed before making these claims.

Overall, there appeared to be the greatest difference in the value judgements of the internaltangible provisions between the firms that had used these provisions and those that had not, followed by the internal-intangible and the external-intangible provisions. Overall, firms that had not used these provisions valued them lower than firms that had used them.

\subsection{Comparison of value judgements and usage frequency}

The above analysis looks only at whether the provisions had been used or not in comparison to the value judgements, and not the frequency of usage. Frequency of usage is an important consideration because if a provision is used repeatedly, this may imply that ongoing affordances could be realised from subsequent use. Conversely, a low frequency of use could imply that ongoing affordances cannot be realised from subsequent use. In Figure 6 the value judgements of the provisions are compared to their usage rates using a scatter chart. The purpose is to establish if and how the value judgements of provisions and the frequency of use are related, and what inferences, if any, can be drawn from this.

Figure 6 shows the average value judgements of the provisions ( $\mathrm{Y}$ axis) and the average usage frequencies of the provisions ( $\mathrm{X}$ axis) for cases where only provisions were used. The provisions were colour-coded according to their category (refer to key). The data about usage rates were again generated from the survey used in Strand Two of the data collection. The survey respondents were asked to indicate their frequency of usage from just once (value $=$ 1) to almost daily (value $=7$ ).

Note that there is some difference in the sets of firms that comprised the initial analysis in this chapter (which was obtained from the data from Strand Two) and the set of firms that comprised the analysis below and for the remainder of the Findings and Analysis chapters (which was obtained from the data from Strand Three). This difference is because not all 
firms that participated in the survey in Strand Two also participated in the interviews in Strand Three, and vice versa.

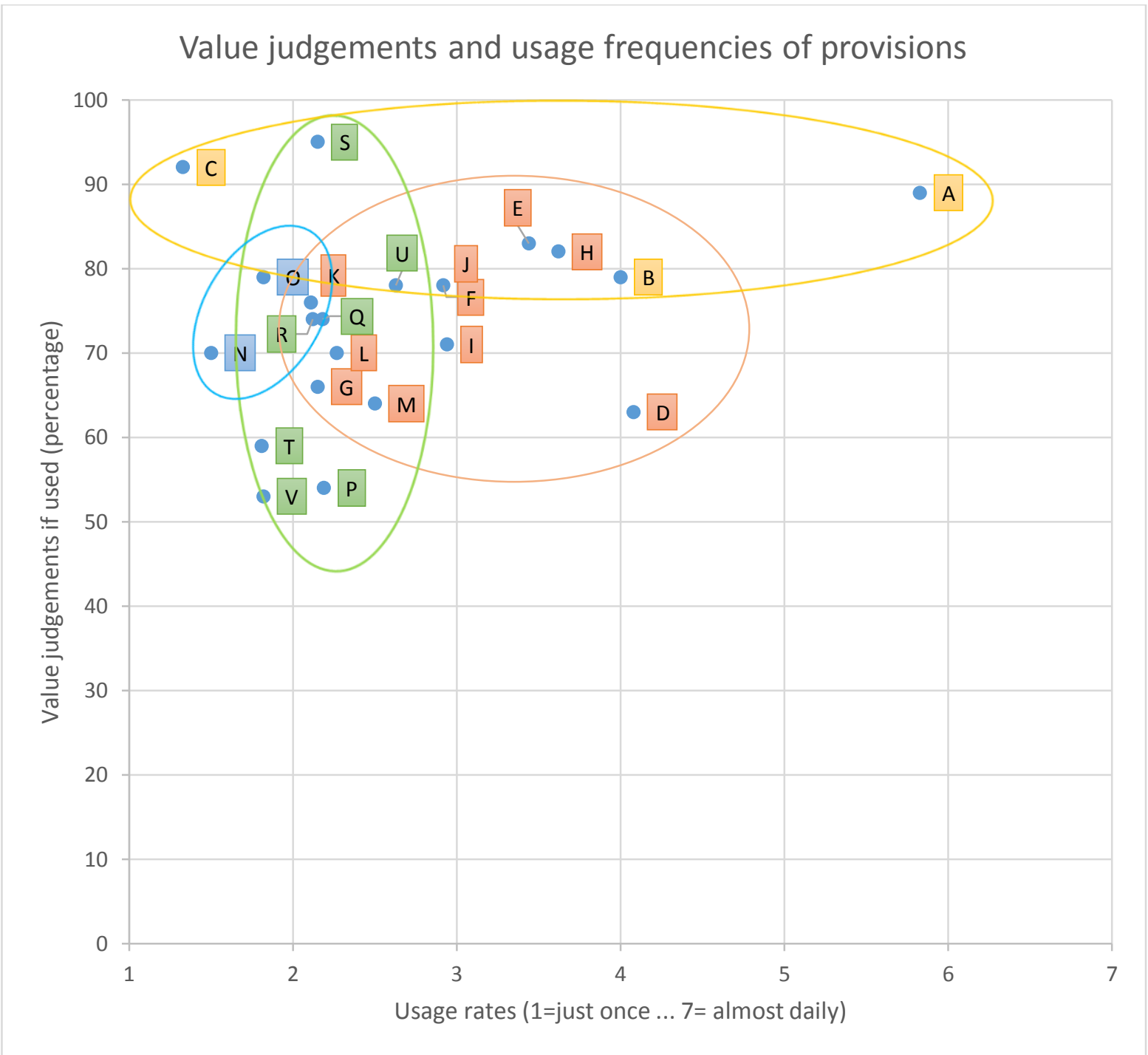

Figure 6. Value judgements and usage frequency of provisions if used (averages)

Key to the colour coding of provisions in Figure 6

\begin{tabular}{|l|l|}
\hline Internal-tangible & \\
\hline Internal-intangible & \\
\hline External-tangible & \\
\hline External-intangible & \\
\hline
\end{tabular}

Overall, there appears to be little relationship between the value judgements and the average usage frequency of the provisions; however, there does appear to be some relationship between the categories of provisions, as circled. 
The internal-tangible (yellow) and internal-intangible (orange) provisions generally had higher usage frequency and higher than other provisions (average of 3.72 and 2.91 respectively). The high usage frequency could be explained by the fact that the provisions are internal and are, by definition, provided to the firm from inside the incubator, and so may be more readily accessible due to the close physical proximity of the firm to the incubator staff, and correspondingly the relative ease of providing the provision by the incubator. Notable are the provisions locating the firms' head office in incubator $(\mathrm{A})$, use of meeting rooms in incubator (B), assistance with strategy methodologies (E) and with market validation and development $(\mathrm{H})$, where both the value judgements and the usage frequencies were high. The high usage frequency may indicate that these provisions have a greater number of affordances associated with them or that affordances can be realised multiple times with ongoing benefit. However, the provision of assistance with general business administration tasks (D) had similarly high usage rates but a relatively lower value judgement. This indicates that, while this provision can be used frequently, the affordances may be limited in value or availability, or not perceived.

The external-tangible provisions had a relatively low average frequency of use (1.5 for connections to government grants, $\mathrm{N}$, and 1.8 for connections to angel investors or venture capitalists, O) and high value judgement. The external-intangible provisions had an average frequency of use (average of 2.13) and the largest difference in average value judgements, ranging from a low of 53\% for connections to interns (V) to a high $95 \%$ for connections to potential major customers (S).

Further, usage frequency may not be related to value judgements because some provisions may have specific affordances and only need to be used once in order for the maximum affordances to be extracted. For example, connections to government grants $(\mathrm{N})$ or angel investors or venture capitalists $(\mathrm{O})$ may only need to be used once, that is, if the initial connection resulted in capital being raised. However this notion of maximum value being potentially extracted from a single use of a provision may not always explain usage frequency differences. It may be that the realised affordances of provisions were of less value than what was originally perceived, meaning that firms did not continue to use these affordances due to poor experiences of prior use. For example, the usage frequency appeared relatively low for the provision of connections to professional services $(\mathrm{P})$ and the value judgement appeared 
lower for firms that had used this provision than for those that had not. This concept is explored further in Chapter 8.

\subsection{Differences in awareness of provision availability and usage}

The analysis thus far has explored the value judgements of the provisions in relation to how they may vary with use, and how the value judgements compare to frequency of use. Figure 7 provides a visual overview of the extent to which the provisions are known about and used. The analysis also provides context to the more detailed analysis that follows in the latter part of this chapter.

Figure 7 shows that, overall, the awareness of availability and the usage of the internalintangible and the external-tangible provisions appears high, the overall usage of the externalintangible provisions is low, as were provisions $\mathrm{C}$ and $\mathrm{L}$. The possible reasons for why the provisions were used, known about and viewed as available are detailed next in the analysis of the data from both the incubators and the firms. Note that provisions $\mathrm{A}$ and $\mathrm{C}$ were not provided in all incubators. 


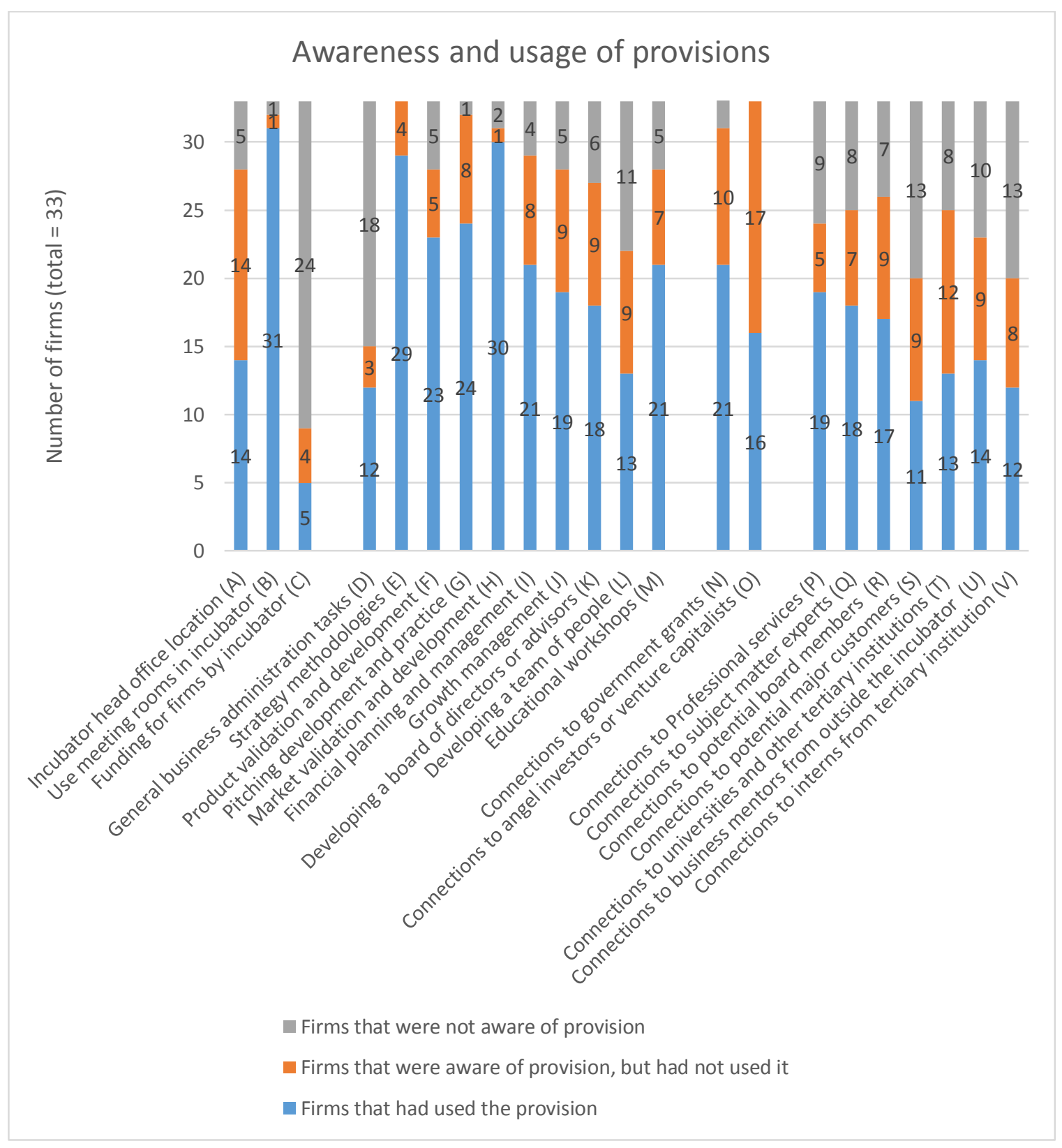

Figure 7. Summary of awareness of availability and the usage of the intemal-tangible provisions

\subsection{The nature of the affordances from the provisions}

The above analysis revealed what differences exist between the value judgements and usage of the provisions. It showed the extent to which the provisions were valued relative to their categories of provisions and how this may differ depending on whether or not the provisions were used. It also showed that the value judgements did not appear to be related to the frequency with which the provisions were used, and that usage and awareness rates vary. Next these findings are expanded upon by exploring the nature of the affordances that arose from the individual provisions from the perspective of both the firms and the incubators. 
The purpose of this analysis is to understand why the provisions may be used, that is, what affordances ensue. This analysis leads into Chapter Five, which explores the incubators' influence on strategy development. A summary count of the provisions that the influential affordances arose from is presented in Table 12, Chapter Five. The following analysis of each provision is primarily based on the data from the open-ended questions to the incubators and the firms (from Strand Three). It is important to note that during the interviews the incubators and the firms were not prompted about specific provisions. This explains, for example, the number of firms that discussed the use of each provision and does not generally reflect the number that actually used the provision. The number of firms that comprise the following analysis is 33 , which were from all six incubators in the study.

\subsubsection{Affordances of the internal-tangible provisions}

\subsubsection{Head office location and general office facilities (A and B)}

The head offices of 14 firms were located within five incubators, although one incubator did not offer this. However 30 of the 33 firms said they used the incubators' facilities, such as meeting rooms, from time to time. Interestingly, the average value judgement of these provisions was high (89 and 79 points respectively) for firms that had used them and much lower (40 and 41 points respectively) for those that had not. This may indicate that the nonusers do not want or need these provisions. The affordances derived by firms from the provisions received little mention even though they included cost savings (4B and 14D), infrastructure support (32A) and tended to relate to specific functions. Some firms in incubator $\mathrm{C}$ also felt a sense of connection to other entrepreneurs (10C, 21C and 30C) the affordances from which did not appear to relate to specific functions. The affordances from provisions $\mathrm{A}$ and $\mathrm{B}$ are considered unlikely to be substituted by the affordances of provisions within the incubator, but could be substituted with external affordances.

\subsubsection{Funding for firms by incubator (C)}

Just two incubators (A and E) emphasised the provision of funding for firms from their own sources and a correspondingly low number of firms (9) either used or were aware of the availability of this provision. The differences between the incubators are analysed further in Chapter Seven. The value judgement of this provision was moderately high by users at 92 points and the usage frequency was, on average, low. For incubator E providing funding to firms was a major part of their purpose: 
We're a provider of seed funds ...We raise the money from high net-worths, institutional investors, local councils and a range of sources ... So having several hundred thousand dollars to invest in an opportunity does change the dynamic and that obviously becomes much more meaningful than saying 'we can provide some advice and support'.

By contrast, incubator B considered that their investment in the firms was by way of time and not money, saying,

We're not the people who are investing our money into them, we are doing that just by the nature of working with them.

The affordances from the provision of funding for the firms by the incubator included increasing the firms' financial capability, which was done infrequently. These provisions also appeared to be able to be substituted for the provision of connections to angel investors or venture capitalists $(\mathrm{O})$.

\subsubsection{Affordances of the internal-intangible provisions}

The provisions in the internal-intangible category had relatively high rates of awareness of availability and usage, which appeared to be because the provisions were more readily available to the firms. The value judgements were moderate compared to the other categories of provisions, but were commonly greater for firms that had used these provisions than for those that had not, which may imply that the perceived affordances were lower than the realised affordances. The relatively high usage frequency may imply that additional affordances could be extracted from subsequent use, as discussed in Chapter Eight. Next these factors are explored further for each provision in this category.

\subsubsection{Assistance with general business administration tasks (D)}

The provision of assistance with general business administration tasks was used by just 12 firms from five incubators with a very high usage frequency, but relatively low value judgement compared to the category average. Interestingly, 18 firms did not know this provision was available and these firms were frequently in the broad-focused incubators. The differences between the incubators are analysed further in Chapter Seven. Incubator E was the only incubator to highlight the provision's importance, saying that the type of support for the firms involved "company secretarial roles." Affordances were realised by firms $20 \mathrm{E}$, $25 \mathrm{E}$ and $28 \mathrm{E}$ from that incubator. Firm $28 \mathrm{E}$ explained the benefits as being "great, I don't have to worry about that." Incubator E explained the rationale for providing this support was that firms "can't do all the accounts properly ... we provide a lot of support initially." 
Similarly, firm 32A further explained the benefits of using this provision:

I have used the incubator to essentially offload those things that I don't do well, like a lot of the administrative tasks.

The provision of assistance with general business administration tasks appeared to have useful affordances for the firms that used them and, similar to provisions A and B, helped the firms with some specific functions.

\subsubsection{Assistance with strategy methodologies (E)}

The provision of assistance with strategy methodologies was used by 29 of the 33 firms interviewed and was highlighted by the managers from all six incubators as being important. This provision had a very high usage frequency by the firms, which signals that ongoing affordances may have been able to have been extracted from subsequent use of the provision.

Given that the role of incubators is to develop firms with high-growth potential, as concluded from the literature review, it is not surprising that incubators emphasise strategy methodologies and that substantial affordances arise as a result. Incubator D said, "We give them a strategic framework to work within, where they probably wouldn't have one." Incubator B said, "We provide them, first of all, with an understanding of what a business strategy is and why you need it."

Specific strategy methodologies were employed by the incubators, with the Lean Start-up and Business Model Canvas methodologies being mentioned as key tools by incubators A, B, C and E.

Firm 23E reflected on the use of these methodologies:

I didn't really know too much about the Lean Methodology before I came here. It does seem incredibly focused on getting people their results as quick as possible for as little money as possible, which makes a lot of sense.

Incubator D used workbooks that they had designed for use in their structured workshops:

There are workbooks for each of these things. There is a [planning] workbook, a market validation workbook, and there are a series of documents and programmes around incubation and the journey. So there is a framework that we want everybody to work in and around, that's very important. 
From this same incubator firm 31D viewed these workbooks as "where the most value lies" and firm 5D summed up their purpose:

[Incubator D] helped us capture it all together ... as soon as we started to get it down using templates and structures you start to see gaps.

It appeared that the use of these tools helped create structure in the minds of the firms, whereas previously there may have been confusion and a lack of focus. Firm 10C described this specifically:

What the [strategy methodologies] did, they presented to me a solution to get rid of the storm that was going on in my head, filter it down ...You then do it with a clear thought process, other than an emotional attachment.

Firm 6C from that same incubator similarly highlighted their new level of focus:

We now know where we're going to go, how we're going to go there, and what the numbers should be, and what we need to focus on.

The role of the incubators' methodologies in providing the basis from which the incubator could then challenge the firms was discussed by incubators A, B and C. For example, incubator A said:

We introduce firms to new ways of looking at things, different revenue models, talk to them about the strategic value that the company can potentially create and how that might be valued by others, how does it actually practically fit in.

Presumably the incubators' use of strategy methodologies enabled them to challenge the firms' strategy in a more structured way. The notion that the incubator challenged strategic decisions was reflected in the comments by firms 7D, 6C, 10C, 30C, 8D, 19D and 3F. Firm 30C explained:

Incubators make companies ask the key questions, like how to monetise, what the compelling problem is, identifying their market, and their sales channels.

Firm 19D explained:

They challenged us to consider different permutations of how we took the product to market. We had a lot of debate.

Similarly, firm 8D said:

By asking the right questions, they challenge you and because they've got the experience they can just give you the direction. 
Firm 3F explained:

You felt accountable. They are almost like a board. So they were kind of driving that behaviour and challenging you.

Firm 10C discussed how the incubator instilled the need to get a second opinion on everything:

Before I make a plan about anything, I now talk to somebody instead of just assuming that I know the answers ... I don't make any assumptions anymore - I simply ask people ... It's made me realise that the business is about meeting the customers' needs and not about meeting my ego.

While the emphasis appeared to be on the incubators providing strategy methodologies, which then provided a framework with which to challenge strategies, the incubators did not appear to actually make the strategic decisions for the firm, as explained by incubator $\mathrm{F}$ who said:

It's their decision about what they want to do and the discipline of being able to tell them "it's not my strategy, it's your strategy that's there."

Similarly, incubator A said that incubators bring clarity to what the key questions are and then firms gather information against that and that informs focus, which is the key output of strategy," emphasising that the information informs the decision-making, not the incubator itself. Firm 1B said that the incubator did not tell them what to think, but rather "they've been effective in telling us how to think." Interestingly, firm 8D wanted the incubator to say "this is what you need to do" so they could focus on operational matters. However, incubator D did not comply. Firm 25E was also reluctant to focus on more strategic aspects saying, "the attraction is to focus on the technical things."

The main affordances of strategy methodologies appeared to be that they provided structure to the strategy development process through a combination of tools, which gave a framework and on which the incubator could challenge the firms' strategic decisions which in turn enabled the firm to reach their own informed decisions. This approach appeared to be common across all incubators. Overall the scope of affordances from this provision appeared to be very broad after first starting off narrowly; by providing the firm with structure and frameworks this then led to a broad scope of potential affordances. This provision was often used in conjunction with provision $\mathrm{H}$, as analysed in Chapter Five. 
Substitution of affordances of this provision with affordances from other provisions was considered unlikely.

\subsubsection{Assistance with product validation and development (F)}

The provision of assistance with product validation was used by 23 firms in five incubators, with moderately high usage-frequency compared to the category average. It was highlighted as being important by just three incubators, which indicates a difference in the incubators' level of involvement in this process. This difference is analysed further in Chapter Seven. Notably, the firms that had used this provision valued it substantially higher than those that had not used it.

One incubator considered that a critical part of their role was to help the firms produce prototypes and data, which were then put in front of customers. Similarly, incubator E had a high involvement in the product validation and development process. It was a key part of their mandate and closely tied to investment in the firm. As they explained,

So the first step was to get that technology working in some shape or form. It doesn't necessarily have to be the final product, but it has to be such that it confirms the value proposition that we're anticipating. So it's quite solely focused around product-market match, quite solely focused around innovation. When they [firms] get that value hypothesis confirmed, the firm can raise more money because we can see that this number of customers have got the same problem and therefore we would be able to grow a business that will do XYZ.

The comment from a firm in incubator E, 28E, reflected this process:

The first three months I spent basically looking at the technology, saying "does it look like it is going to work, it's got some opportunity, are there market opportunities," and we decided yes, there was; and so we got another tranche of investment.

The incubators also helped some firms design the actual product validation process $(20 \mathrm{E}$, $7 \mathrm{D}, 10 \mathrm{C}$ and $26 \mathrm{~F})$. Overall, the affordances arising from the provision of assistance with product validation and development appeared to relate to help with specific functions with relatively defined outcomes. This provision was sometimes used in conjunction with provisions $\mathrm{E}$ and $\mathrm{H}$, as analysed in Chapter Five.

\subsubsection{Assistance with pitching development and practice (G)}

The provision of pitching development and practice appeared to have relatively high usage rates at 24 firms. However, their value judgements were relatively low compared to the category average. Four of the incubators highlighted the importance of this provision. The 
affordances that arose were frequently orientated around obtaining external investment. For example, this is how incubator B explained the purpose of pitching development and practice:

We like to set up investor panels where people can practice their pitches in front of a team of investors and for them to pick holes and to run them through the mill.

This provision was discussed by few firms. The affordances came in the form of helping with specific functions such as the content format of the presentations ( $2 \mathrm{~F}$ and $15 \mathrm{~A})$ and from increasing pitching confidence $(3 \mathrm{~F})$. The provision was sometimes used in conjunction with provisions $\mathrm{R}$ and $\mathrm{O}$.

\subsubsection{Assistance with market validation and development $(\mathrm{H})$}

The provision of market validation and development was valued highly and used by 30 firms and correspondingly was highlighted as being important by five incubators. The usage frequency was high compared to the category average, indicating that ongoing affordances could be extracted from subsequent use. Value judgement was also high.

The purpose of market validation was to help firms gain an in-depth understanding of their customers. Incubators A and B focussed on this need, saying respectively,

The idea of focusing on what is really required, focusing on the customer for the product, that's kind of ingrained in us now.

There's always an alternative way of doing things, so actually understanding their customers helps guide the strategy. We would encourage them to really understand their customers first before they actually have a strategy of where they are heading to.

Firms 24B and 10C explained it succinctly, saying respectively,

We are completely guilty of having our solution before we have a problem. So our interaction with [the incubator] has really been to undo that or take it back to the start and say "look, first figure out where the problem is."

When you don't have the tools to validate your business you hold on to some misconceptions ... when you get given the tools you quickly go, "oh that was crap, let's stop that.".

It appeared that undergoing the process of market validation is generally only initially done because it is a requirement of the incubators; left to their own devices the firms would not do it $(1 \mathrm{~B}, 21 \mathrm{C}, 11 \mathrm{D})$. Firm 1B said that the incubator mandated that they "go overseas and talk to other people in this space ... figure out what more people than just you are thinking." 
Similarly firm 11D said that they were "kind of forced into a structured format that made you talk to a whole bunch of potential customers."

Incubator F explained the priority of market validation focus saying, "I think their approach to market validation is the number one because that's what we focus on most." This incubator reflected this importance by bringing in an overseas expert on market validation, as did incubator D. Firm 3F explained what this expert said:

It doesn't matter what stage your business is at. Before you do anything, with marketing a new product or whatever, you've got to validate it. It's not market research, it's validation. You got to call 100 people.

Firms were also encouraged to undertake competitor analyses, and therefore not just to look at their own customers. Firm 24B said they were encouraged to be looking at "other websites and see what they were doing." The need to do competitor analysis was discussed by incubators $\mathrm{D}$ and $\mathrm{F}$ which emphasised the detail of what is required for market validation, with incubator $\mathrm{D}$ saying that it involves investigation of:

What is the market that you are operating in? Who are the key players in there? What are the dynamics of the market? Is it a growth market? Is it a declining market? Is it a saturated market? Why are the key players successful? What are their unique propositions?

The incubator itself can also play an active role in assisting with the detail of the specific market validation activities, with affordances relating to advice and assistance with specific tasks. This included assistance with obtaining the data needed from the market validation. For example, firm 17D's incubator was unusual in that they actually undertook some of the validation work. This work involved desk research on the firm's industry with the firm saying "they are not in my industry, but [they are] quite good; I am surprised by what they have done." Assistance was also offered with developing the process of market validation enabling more detailed and efficient information gathering (9A, 24B, 17D, 22D).

Sometimes the incubators played a valuable role in providing introductions to experts. Incubator $\mathrm{F}$ emphasised the value of their connections in this validation process:

We put them in front of experienced people who have done it before, so they often decide not to do things the way they originally wanted to do it.

The value of connections was reflected in the responses from firms 30C and 11D. Firm 11D emphasised the value of the reputation of the incubator when calling organisations in the incubator's networks in order to undertake market validation: 
I'm used to getting knocked back and all that kind of stuff, and to it taking forever and a day to get to meet with people. When I was calling up people trying to set up meetings for the market validation process you know it was like, [incubator name] was like the magic carpet. Basically everyone said, "oohh, someone from [incubator name]; this is interesting," So basically I was able to see everyone I wanted to see.

Similar to the provision of strategy methodologies (which the affordances were often realised in conjunction with) the main affordances from the provision of market validation appeared to be the incubator giving the firm a structured way to find out more about their market, thus challenging their initial assumptions and opening doors along the way. The scope of affordances also appeared to be very broad overall, having first started off being rather narrow, by providing the firm with guidance on the market validation process which then led to a wider scope of potential affordances.

\subsubsection{Assistance with financial planning and management (I)}

The provisions of assistance with financial planning and management was used by 21 firms from across all the incubators, but only incubator A acknowledged the importance of this provision during the interviews. The affordances resulting from this provision appeared to revolve mainly around helping the firms with specific functions such as general financial management and forecasting $(5 \mathrm{D}, 8 \mathrm{D}, 9 \mathrm{~A}, 26 \mathrm{~F})$ valuations $(15 \mathrm{~A}, 30 \mathrm{C})$ and advice about the investment process (12D, 23E). This provision was sometimes used in conjunction with provision $\mathrm{O}$ and substituted with provision $\mathrm{P}$. This provision had average value judgements and usage frequencies.

\subsubsection{Assistance with growth management (J)}

The provision of assistance with growth management was not mentioned by the firms despite 19 firms indicating on the survey that they had used it. The usage frequency and value judgements were moderately high compared to the category average. Four of the incubators emphasised its importance. Incubator B said, “There's no better time to sort out the structure for your business for growth than at the very beginning." Potentially the concept of growth management was unclear in the minds of the firms' managers, thus receiving no specific mention in the interviews, and therefore the affordances remain unknown. 


\subsubsection{Assistance with developing a board of directors or advisors (K)}

The provision of developing a board of directors or advisors was used by 18 firms. The usage frequency was low and value judgements were moderate compared to the category average; however, firms that had used this provision valued it at a higher rate than those which had not used it. Incubators A and B emphasised their role in assistance with developing a board of directors or advisors, and of the ensuing affordances of this governance, which related to providing strategic advice and direction. The firms that used this provision were mainly in the broad-focused incubators (the differences between the incubators are analysed in Chapter Seven). Firm 26F was the only one to mention how the incubator helped with the governance development process, the affordance of which was on a practical level of developing shareholder agreements. This provision was sometimes used in conjunction with provision $\mathrm{R}$ (as analysed in Chapter Five). Given the relative lack of data it is unknown whether other affordances may arise from this provision.

\subsubsection{Assistance with developing a team of people (L)}

The provision of assistance with developing a team of people was used by 13 firms from all incubators. The usage frequency and value judgements were average compared to the category average. Interestingly 11 firms did not know this provision was available and these firms were mainly in the narrow-focused incubators (the differences between the incubators are analysed in Chapter Seven). Four incubators specifically highlighted the importance of the incubators' role in helping firms develop their teams with incubator D saying,

That's a very important part of the job, building that team ... [we ask] "what is this team in this for, and as individuals what do you want out of this company?”

However, the only firms from this incubator to discuss this provision, firms 14D and 22D, talked about the value being on a more practical level, saying the incubator helped with things like job descriptions. The definition of the firm's team was not necessarily limited to the actual employees within the firm, but rather to the incubator staff themselves. Incubator C said, "In simple terms the incubator is your team that you are going to build," which was reflected in a comment by firm $14 \mathrm{C}$ :

By coming to [incubator C] it's helped me to understand that in order to build a proper business, instead of a successful product, you need the right people around you [the incubator team]. 
Therefore there may have been differences in the way that the firms and the incubators defined what was meant by this provision. From the limited information available the affordances appear to relate mainly to assistance with specific functions.

\subsubsection{Providing educational workshops (M)}

The provision of educational workshops was used by 21 firms and was highlighted as important by four incubators. The average value judgement and usage frequency was low compared to the category average. Interestingly 12 firms did not use this provision and this appeared to vary according to the incubator that the firms were in (the differences between the incubators are analysed in Chapter Seven).

The affordances from the provision of educational workshops consisted of providing a vehicle for the delivery of other provisions, for example the provisions of E, F, H and I. The topics covered in these workshops was stated by incubator $\mathrm{C}$ to include:

The start-up methodology, how to grow, capability and networks, introduces entrepreneurs to tools, coaches, investors and networks ... target market.

\subsubsection{Affordances of the external-tangible provisions}

Overall the external-tangible category of provisions had the highest level of awareness of availability by firms but the usage frequencies were relatively low when compared to all the provisions. This may signal that while gaining capital through investors or grants may have been important to the firm, the affordances of the provisions may not need to be used frequently. It may also signal that firms may not have been at an appropriate stage of their development to utilise these connections.

\subsubsection{Connections to government grants (N)}

The provision of connections to government grants was used by 21 firms spread across all of the incubators. The value judgement was moderate, and only two firms did not know this provision was available. The usage frequency was low indicating that many firms may not have been ready or able to, access government grants. Interestingly none of the incubators mentioned connections to government grants as an important provision.

The affordances that arose out of these connections to government grants appeared to relate to assistance with completing specific functions such as funding applications (32A and 24B) and connections to the people within the funding agencies (16C and 19D). 


\subsubsection{Connections to angel investors and venture capitalists (O)}

The provision of connections to angel investors or venture capitalists was used by 16 firms from five incubators, although many firms were not successful in capital raising will be discussed in Chapter Five. All firms were aware of this provision and their value judgement was relatively high. Interestingly 16 firms did not use this provision and these firms were mainly in particular incubators (the differences between the incubators are analysed in Chapter Seven). The usage frequency was low, potentially for similar reasons to connections to government grants as discussed above.

Incubator A summed up their focus on capital:

Our value propositions are based around the belief that companies have two issues when they first come to see us. One is management capability and capacity, and the other is money. That is what they are seeking help from us for, and so everything we do is geared around that.

This focus on capital was echoed by incubator B who said that their objective was:

Ultimately lining up the first real investment round. So we might have a number of seed rounds or a seed round during the earlier stages but during or at the end of the growth phase there should be a [more substantial investment] round.

This attaining of investment was achieved by firm $4 \mathrm{~B}$ from this same incubator:

[Incubator B] introduced us to somebody who had a similar business [overseas], and who is now a shareholder.

For incubator E, capital raising is a critical component of their purpose:

First we bring investment capital ... and this is further supported by capital from external sources. Secondly, we bring extensive national and international networks of investors, which increase the chance of commercial success.

Firms 33A, 18C, 30C and 13E echoed the value of the incubators' connections in helping raise capital. Firm 33A said,

I couldn't imagine trying to raise capital in New Zealand with something so early like what we have got without the help of an incubator ... the links that [incubator A] have are really important.

A major affordance of the provision of connections to angel investors and venture capitalists appears to be the ability to connect to individuals and organisations that the firm may not have otherwise been able to connect to for the purpose of obtaining capital. This provision 
was sometimes used in conjunction with provisions $\mathrm{G}$ and I, and substituted for C (refer Chapter Five).

\subsubsection{Affordances of the external-intangible provisions}

Overall the awareness and usage rates of the external-intangible provisions were lower than for the other categories and there was a relatively wide difference in the value judgements.

\subsubsection{Connections to professional services $(P)$}

The provision of connections to professional advisors was used by 19 firms from all the incubators, but only highlighted as important by two incubators. Similarly, the firms judged its value to be relatively low compared to the category average. Interestingly 14 firms did not use this provision, with the firms in some incubators having much higher usage rates than others (the differences between the incubators are analysed in Chapter Seven).

Specifically, the connections to professional services included marketing consultants (4B), accountants (18C and $2 \mathrm{~F}$ ) and lawyers (21C and 12D). Some of the affordances from these provisions seemed to mirror the affordances from the internal provisions. These organisations provided services to incubator firms because, according to incubator $\mathrm{B}$, they "have an interest and a passion for helping start-up companies." Similar to provisions A, B and $\mathrm{D}$ this provision helped the firms with a range of tasks and was potentially also substituted for affordances from provision $\mathrm{E}$.

\subsubsection{Connections to subject matter experts (Q)}

The provision of connections to subject matter experts was used by 18 firms across all incubators but only two incubators emphasised its importance. The usage frequencies and value judgements were at the category average. Incubator $\mathrm{C}$ said, "I can provide subject matter experts in engineering, science, technology, whatever you want to do." Incubator E had a process of specifically seeking these subject matter experts out:

So we're looking at some technology at the moment that would be useful in the forestry industry, but we don't have any contacts in the industry yet. But obviously we will have to develop them.

Firm 19D talked of the increased speed of the connections to subject matter experts that was enabled through the incubator's involvement saying:

Within 48 hours they had us hooked up with a team from [a research institution] ... if it had been myself, that would have taken me two weeks to get there to find someone who is an expert. It is having that at your fingertips which has just been fantastic. 
This ease of making connections was echoed by firm 32A who said:

What they did help us do is find local resources, say like regulatory consultants, engineering consultants, building consultants ... they really helped facilitate those sorts of interactions.

Firms realised affordances associated with this provision of obtaining industry advice and expertise that they might not have otherwise been able to obtain.

\subsubsection{Connections to potential advisory and board members (R)}

The provision of connections to potential advisory and board members was used by 17 firms in five incubators, and three incubators highlighted the importance of this provision. This provision is closely related to the provision of assistance with the development of a board of directors $(K)$ and had similar usage and value judgements with the firms that had used the provision valuing it to a greater extent than those than had not used it. The connection between these two provisions is analysed further in Chapter Five. Also, similarly, the firms that used this provision were mainly in the broad-focused incubators (Chapter Seven). Incubator D said, "Trying to get a strong advisory board around them is important." This incubator's success with this function was reflected by firm 14D: "The [incubator] helped us populate that list, and helped make introductions to certain people." Similarly incubator B said, "What I can provide [firms with] is an advisory board of directors."

The affordances to firms were relatively narrow and related to the incubator helping to identify the skills firms needed and connecting them to appropriate individuals in order to form their board. Firms 9A, 4B, 6C and 33E all acknowledged the relative ease with which the board formation process could occur with the help of the incubator. Provision $\mathrm{R}$ was sometimes used in conjunction with provisions C, G and K (refer Chapter Five).

\subsubsection{Connections to potential major customers (S)}

Despite having the highest value judgement by firms that had used it, the provision of connections to potential major customers was used by just 11 firms in four incubators. The firms in some incubators had much higher usage rates than others and these differences are analysed in Chapter Seven. Incubator E had a specific approach of being instrumental in finding a reference customer for the firms.

So we'd engage initially in phone conversations with industry players and start building conversations and then progress that towards some kind of early customer.

Firm 23E from that same incubator explained: 
We've had lots of discussions with the initial reference customers for the technology from all sorts of different industries, and it is about trying to identify the jobs that they required to be done.

No other incubator mentioned this provision, but firms 10C, 30C, 14D and 2F mentioned that the incubator could connect them to potential major customers. Firm 10C said that the incubator manager "can contact people that I can't, that's really valuable."

Therefore the affordance from connections to potential major customers appears to be the ability for the firm to connect to people and organisations that they could not otherwise have connected to on their own. Despite the relatively low usage rates, this provision appeared to have a relatively broad range of affordances.

\subsubsection{Connections to universities and other tertiary institutions (T)}

The provision of connections to universities was used by 13 firms from across five incubators, but only two incubators highlighted its importance. The usage frequency and value judgements were low relative to other provisions in this category. Incubator D discussed the value of accessing people from universities with specific skills to fill identified gaps, such as "scientists and engineers, and mathematicians ... the business school." However, the only firms that discussed actually realising these types of affordances were from incubator $\mathrm{C}$. These firms called on specific expertise within a university to help with specific functions such as competitive analysis (10C) and product development (21C and 30C). In addition to providing expertise from individuals, universities are also generators of intellectual property. Incubator $\mathrm{E}$ viewed this as a key purpose of their relationship and was due to this university being "the biggest game in town in terms of commercialisation opportunities." The affordances tended to relate to the firms' operations and strategic functions.

\subsubsection{Connections to business mentors from outside the incubator (U)}

The provision of connections to business mentors external to the incubator was used by 14 firms from five incubators. The usage frequencies and value judgements were moderately high compared to other provisions in this category, but notably the firms that had used this provision valued it more highly than those that had not. The affordances from this provision included help with specific tasks such as marketing (11F, 29B), sales and investment advice (12D), financial forecasting and product packaging (31D) and helping the firm 'build a story' 
(29B). Interestingly, the incubators varied in their view of the use of external mentors. The affordances were more general in other cases, as in the case of firm 10C:

I can think I'm on the right path and [if] someone can prove to me that it's just in my head, I can just stop that because somebody has been in that space before. They've seen it; I'm in it for the first time. There's no point reinventing the wheel. There's a reason that they're mentors. It's shaped what I do massively. I used them all the time.

Some incubators valued the use of mentors differently. For example, incubator D's mentors formed a critical part of the relationship that the incubator had with the firms, and in many cases were the firms' principal advisors. This indicates a positive view of what external mentors can provide. At the other extreme, the external mentors were seen negatively, as incubator $\mathrm{E}$ put it when asked if they use mentors:

I encourage our entrepreneurs to get out and talk to as many people (e.g. mentors) as they possibly can but I caution them that $90 \%$ of what they hear will be rubbish.

While the incubators' views on the provision of connections to business mentors varied, the affordances appeared to be related to providing the firms with specific functions and with more general advice. Therefore this provision appeared to be able to be substituted for provisions E, F and I, most notably in incubator D. These incubator differences are analysed further in Chapter Seven.

\subsubsection{Connection to interns (V)}

The provision of connections to university interns was used by 12 firms from across all incubators, but was highlighted as important by only two incubators. The usage frequency and value judgement were very low. Again the way that the incubators engaged with interns varied across the incubators. For example, in incubator D interns were used for administration-type roles:

Each start-up that comes in gets an intern. That intern will work with four or five companies at a time ... they are the [incubator] glue: they organise all the meetings, the meeting rooms, they keep meeting notes, they keep track of the actions, they keep everything on track and they provide the database [and] the client history update for me.

At the other end of the scale, interns are taken on with a view to them becoming CEOs of the companies themselves, as incubator E explained:

[The incubator] is able to provide internship resources, what we're starting to call CEO-designate roles. If a technology looks like it has got potential we will employ an intern or a business analyst- 
type role with the view that they will become the CEO of this thing when it gets funded and up and running.

The affordances enabled by the use of interns appear to relate to providing the firms with assistance with administrative functions or fulfilling specific roles within the firm.

\subsection{Summary table}

Table 11 presents a summary of the characteristics of the affordances of provisions drawn from the preceding analysis.

Table 11

Summary of the Characteristics of the Affordances of the Provisions

\begin{tabular}{|c|c|c|}
\hline & Provision & $\begin{array}{l}\text { Characteristics of affordances of provisions (analysed further in } \\
\text { Chapter Five) }\end{array}$ \\
\hline \multirow{2}{*}{ 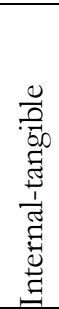 } & $\begin{array}{l}\text { Firms' head office } \\
\text { located in incubator } \\
\text { (A) and use of } \\
\text { meeting rooms (B) }\end{array}$ & $\begin{array}{l}\text { Some specific affordances, others more general. Unlikely to be } \\
\text { substituted for other provisions within the incubator. The value } \\
\text { judgements were high at } 89 \text { and } 79 \text { points respectively. Usage frequency } \\
\text { high at } 5.83 \text { and } 4 \text { respectively. }\end{array}$ \\
\hline & $\begin{array}{l}\text { Funding for firms by } \\
\text { incubator }(C)\end{array}$ & $\begin{array}{l}\text { Narrow affordances related to attaining capital. May sometimes cluster } \\
\text { with provisions I, K and R and be substituted with O. Value high at } 92 \\
\text { points. Usage low at } 1.33 \text {. }\end{array}$ \\
\hline \multirow{9}{*}{ 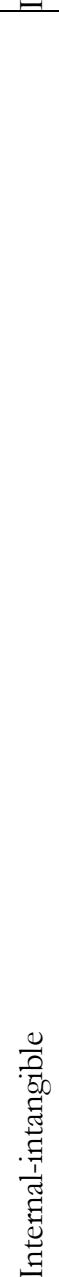 } & $\begin{array}{l}\text { General business } \\
\text { administration tasks } \\
\text { (D) }\end{array}$ & $\begin{array}{l}\text { Narrow range of affordances which involved help with specific } \\
\text { administration tasks. Clustering and substitution with other provisions } \\
\text { unlikely. Value low at } 63 \text { points. Usage high at } 4.08 \text {. }\end{array}$ \\
\hline & $\begin{array}{l}\text { Strategy } \\
\text { methodologies (E) }\end{array}$ & $\begin{array}{l}\text { Narrow range of affordances initially which then led to broader scope of } \\
\text { opportunities. Some clustering with provision } \mathrm{H} \text {. Substitution was } \\
\text { unlikely. Value high at } 83 \text { points. Usage high at } 3.44 \text {. }\end{array}$ \\
\hline & $\begin{array}{l}\text { Product validation } \\
\text { and development }(\mathrm{F})\end{array}$ & $\begin{array}{l}\text { Narrow range of affordances which involved help with the validation } \\
\text { process. Some clustering with provisions } \mathrm{E} \text { and } \mathrm{H} \text {. Substitution less likely. } \\
\text { Value high at } 78 \text { points. Usage high at } 2.92 \text {. }\end{array}$ \\
\hline & $\begin{array}{l}\text { Pitching } \\
\text { development and } \\
\text { practice }(G)\end{array}$ & $\begin{array}{l}\text { Narrow range of affordances which included exposure to potential } \\
\text { investors and increased confidence. Some clustering with provisions } \mathrm{R} \\
\text { and } \mathrm{O} \text { and had some substitution with } \mathrm{O} \text {. Value moderate at } 66 \text { points. } \\
\text { Usage moderate at } 2.15 \text {. }\end{array}$ \\
\hline & $\begin{array}{l}\text { Market validation } \\
\text { and development } \\
(\mathrm{H})\end{array}$ & $\begin{array}{l}\text { Narrow range of affordances initially which then led to broader scope of } \\
\text { opportunities. Some clustering with provision E. Substitution was } \\
\text { unlikely. Value high at } 82 \text { points. Usage high at } 3.62 \text {. }\end{array}$ \\
\hline & $\begin{array}{l}\text { Financial planning } \\
\text { and management (I) }\end{array}$ & $\begin{array}{l}\text { Narrow range of affordances that involved help specific planning and } \\
\text { management tasks. Some clustering with provision } O \text { and some } \\
\text { substitution with provision P. Value moderate at } 71 \text { points. Usage high at } \\
\text { 2.94. }\end{array}$ \\
\hline & $\begin{array}{l}\text { Growth } \\
\text { management }(J)\end{array}$ & $\begin{array}{l}\text { The affordances were unknown. The firms' own governance may act as } \\
\text { substitute. Value high at } 76 \text { points. Usage high at } 3.06 \text {. }\end{array}$ \\
\hline & $\begin{array}{l}\text { Developing a board } \\
\text { of directors or } \\
\text { advisors }(\mathrm{K})\end{array}$ & $\begin{array}{l}\text { Narrow range of affordances that involved help with establishment of } \\
\text { board. Sometimes clustered with provision R. Substitution less likely. } \\
\text { Value high at } 76 \text { points. Usage moderate at } 2.11 \text {. }\end{array}$ \\
\hline & $\begin{array}{l}\text { Developing a team } \\
\text { of people }(\mathrm{L})\end{array}$ & $\begin{array}{l}\text { Narrow range of affordances that involved help with establishment of } \\
\text { team. May have clustered with provision J. Substitution could have come } \\
\text { from firms' governance. Value moderate at } 70 \text { points. Usage moderate at } \\
2.27 \text {. }\end{array}$ \\
\hline
\end{tabular}




\begin{tabular}{|c|c|c|}
\hline & $\begin{array}{l}\text { Educational } \\
\text { workshops }(\mathrm{M})\end{array}$ & $\begin{array}{l}\text { Provision acted as a delivery vehicle for other affordances. Sometimes } \\
\text { clustered with provisions E, F, H and I. Value low at } 64 \text { points. Usage } \\
\text { moderate at } 2.5 \text {. }\end{array}$ \\
\hline \multirow[b]{2}{*}{ 震 } & $\begin{array}{l}\text { Government grants } \\
\text { (N) }\end{array}$ & $\begin{array}{l}\text { Narrow affordances which related to attaining capital. Clustering and } \\
\text { substitution unlikely. Value moderate at } 70 \text { points. Usage low at } 1.5 \text {. }\end{array}$ \\
\hline & $\begin{array}{l}\text { Angel investors or } \\
\text { venture capitalists } \\
\text { (O) }\end{array}$ & $\begin{array}{l}\text { Narrow affordances which involved the attaining of capital. Sometimes } \\
\text { clustered with provisions G and I and substituted for C. Value high at } 79 \\
\text { points. Usage low at } 1.82 \text {. }\end{array}$ \\
\hline \multirow{7}{*}{ 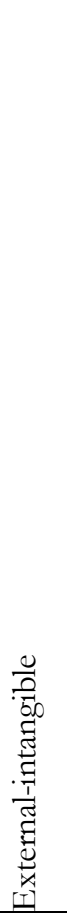 } & $\begin{array}{l}\text { Professional services } \\
\text { (P) }\end{array}$ & $\begin{array}{l}\text { Wide range of affordances which involved help with specific tasks. } \\
\text { Potentially clustered and was substituted with provision E. Value low at } \\
54 \text { points. Usage moderate at } 2.19 \text {. }\end{array}$ \\
\hline & $\begin{array}{l}\text { Subject matter } \\
\text { experts }(\mathrm{Q})\end{array}$ & $\begin{array}{l}\text { Narrow range of affordances which involved help with specific industry } \\
\text { advice. Sometimes clustered and was substituted with E. Value moderate } \\
\text { at } 74 \text { points. Usage moderate at } 2.18 \text {. }\end{array}$ \\
\hline & $\begin{array}{l}\text { Potential board } \\
\text { members }(\mathrm{R})\end{array}$ & $\begin{array}{l}\text { Narrow range of affordances which involved help with developing a } \\
\text { board. Sometimes clustered with provisions } C, G \text { and } K \text {. Value moderate } \\
\text { at } 74 \text { points. Usage moderate at } 2.12 \text {. }\end{array}$ \\
\hline & $\begin{array}{l}\text { Potential major } \\
\text { customers }(\mathrm{S})\end{array}$ & $\begin{array}{l}\text { Narrow range of affordances which involved help reaching key } \\
\text { customers. Sometimes clustered and was substituted with provision E. } \\
\text { Value high at } 95 \text { points. Usage moderate at } 2.15 \text {. }\end{array}$ \\
\hline & $\begin{array}{l}\text { Universities and } \\
\text { other tertiary } \\
\text { institutions }(\mathrm{T})\end{array}$ & $\begin{array}{l}\text { Wide range of affordances which involved help with operational and } \\
\text { strategic functions. Degree of clustering or substitution unknown. Value } \\
\text { low at } 59 \text { points. Usage low at } 1.81 \text {. }\end{array}$ \\
\hline & $\begin{array}{l}\text { Business mentors } \\
\text { from outside of } \\
\text { incubator (U) }\end{array}$ & $\begin{array}{l}\text { Wide range of affordances which involved help with mainly strategic } \\
\text { tasks. Sometimes clustered and was substituted with provisions E, F and I } \\
\text { in some incubators. Value high at } 78 \text { points. Usage moderate at } 2.63 \text {. }\end{array}$ \\
\hline & $\begin{array}{l}\text { Interns from tertiary } \\
\text { institutions }(\mathrm{V})\end{array}$ & $\begin{array}{l}\text { Wide range of affordances which involved help with specific, mainly } \\
\text { administrative, tasks. Sometimes was substituted with provision E in } \\
\text { some incubators. Value low at } 53 \text { points. Usage low at } 1.82 \text {. }\end{array}$ \\
\hline
\end{tabular}

\subsection{Chapter summary}

The question that Chapter Four addressed was: What are the affordances from incubators' provisions? It was found that the value judgements, scope, and the frequency of use of the provisions varied. Overall, the most highly used and valued affordances came from the internal-tangible, followed by the internal-intangible and external-intangible provisions. However, the value judgements of these categories of provisions were sometimes lower for firms that had not used them than for firms that had used them. This may signal that the realised affordances from these provisions were higher than the perceived affordances or that firms did not use these provisions because they did not think they needed them. The usage frequency and value judgements did not appear to be related, perhaps due to the ability or otherwise of the firm to extract ongoing value from the provision.

The range of affordances varied, ranging from provisions that had a narrow range to those with a much broader range. The provisions with a narrow range of affordances often related to assistance with functional activities, for example assistance with general business 
administration tasks (D) or connecting the firm to people and organisations that the firms could not otherwise have connected to on their own, for example connections to potential major customers $(\mathrm{S})$.

On the other hand the affordances of some provisions appeared to start off being quite specific but then broadened or became less specific and in doing so influenced strategy development in a multitude of ways, for example, market validation and development $(\mathrm{H})$ and strategy methodologies (E). These provisions appeared to provide structure to the strategy development process by initially providing tools, and then challenging strategic decisions, thus enabling firms to reach their own conclusions and make more informed decisions.

It seems that some provisions could be substituted for other provisions in that they had similar affordances. Notably, the provision of funding for firms by the incubator $(C)$ was sometimes substituted for the provision of connections to angel investors or venture capitalists $(\mathrm{O})$ in some cases in incubator $\mathrm{A}$. In addition, the advice that came from incubator staff was sometimes substituted for advice from business mentors from outside the incubator $(\mathrm{U})$, most notably in incubator $\mathrm{D}$. These differences are analysed further in Chapter Seven.

Provisions were sometimes used in conjunction with other provisions, as the affordances were related in that they clustered together; for example provisions relating to gaining investment and governance, notably financial planning and management (I), assistance with setting up a board of directors $(\mathrm{K})$, connections to angel investors and venture capitalists $(\mathrm{O})$ and to potential board members (R). This concept is analysed further in Chapter Five.

Differences were noticed between incubators with respect to this concept and will be analysed further in Chapter Seven. 


\section{Findings and analysis - Influence of affordances on strategy development}

\subsection{Chapter introduction}

Chapter Four revealed the nature of the affordances by analysing the incubators' provisions. Chapter Five addresses the sub-question: How may the provisions' affordances influence strategy development? The analysis takes a strategy development-centric view as opposed to the provision-centric view in Chapter Four, to explore if and how the strategies of firms developed along each strategy development orientation and the specific nature of the affordances that influenced these changes. The conceptual model in Figure 8 highlights the focus of this chapter.

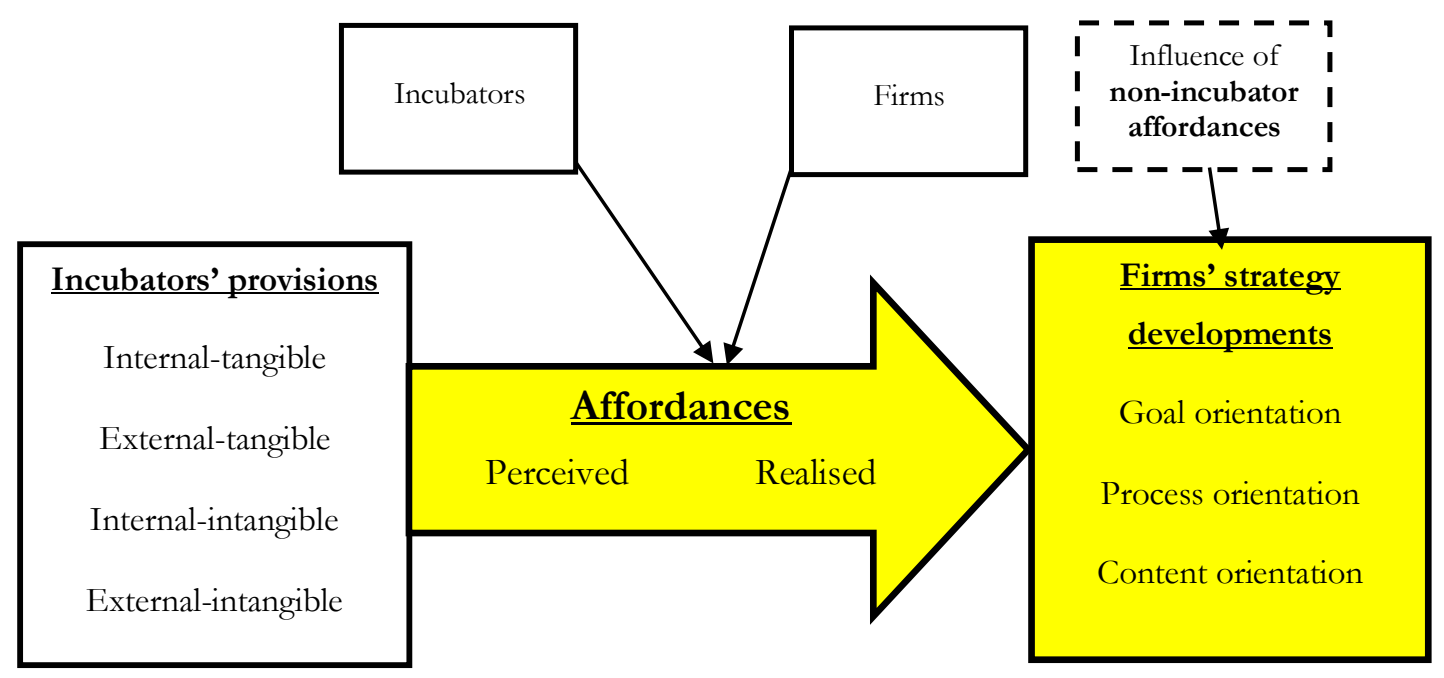

Figure 8. The conceptual model with the focus of Chapter Five highlighted. (Adapted from Figure 3).

The analysis commences with a summary of the number of instances that affordances from the provisions that influenced firms' strategy developments. The summary is followed by a more in-depth analysis using data drawn from the interviews with both the firms (Strand Three) and the incubators (Strand One).

\subsection{Summary counts of instances where affordances from provisions influence strategy development}

In the literature review it was argued that there were three major orientations along which strategy developments could be observed: goals, process and content. The goal orientation incorporated the direction in which the goals may change. The process orientation encompassed two aspects: whether strategies became more deliberate or more emergent, and 
changes in the firms' degree of planning. The content orientation encompassed change to the firms' product scope, partnership status, competitive emphasis and time allocation.

Figure 9 and Table 12 provide a summary of the in-depth analysis that occurs later in this chapter. Figure 9 summarises both the extent to which the strategy development continuums changed and the categories of provisions that were of most influence. It will be argued that changes to the firms' goal and process orientations were almost exclusively influenced by affordances from the internal-intangible provisions, whereas the affordances of influence on the firms' content orientations came from a more diverse range of provisions. Notably the two categories of tangible provisions appear to have little influence.

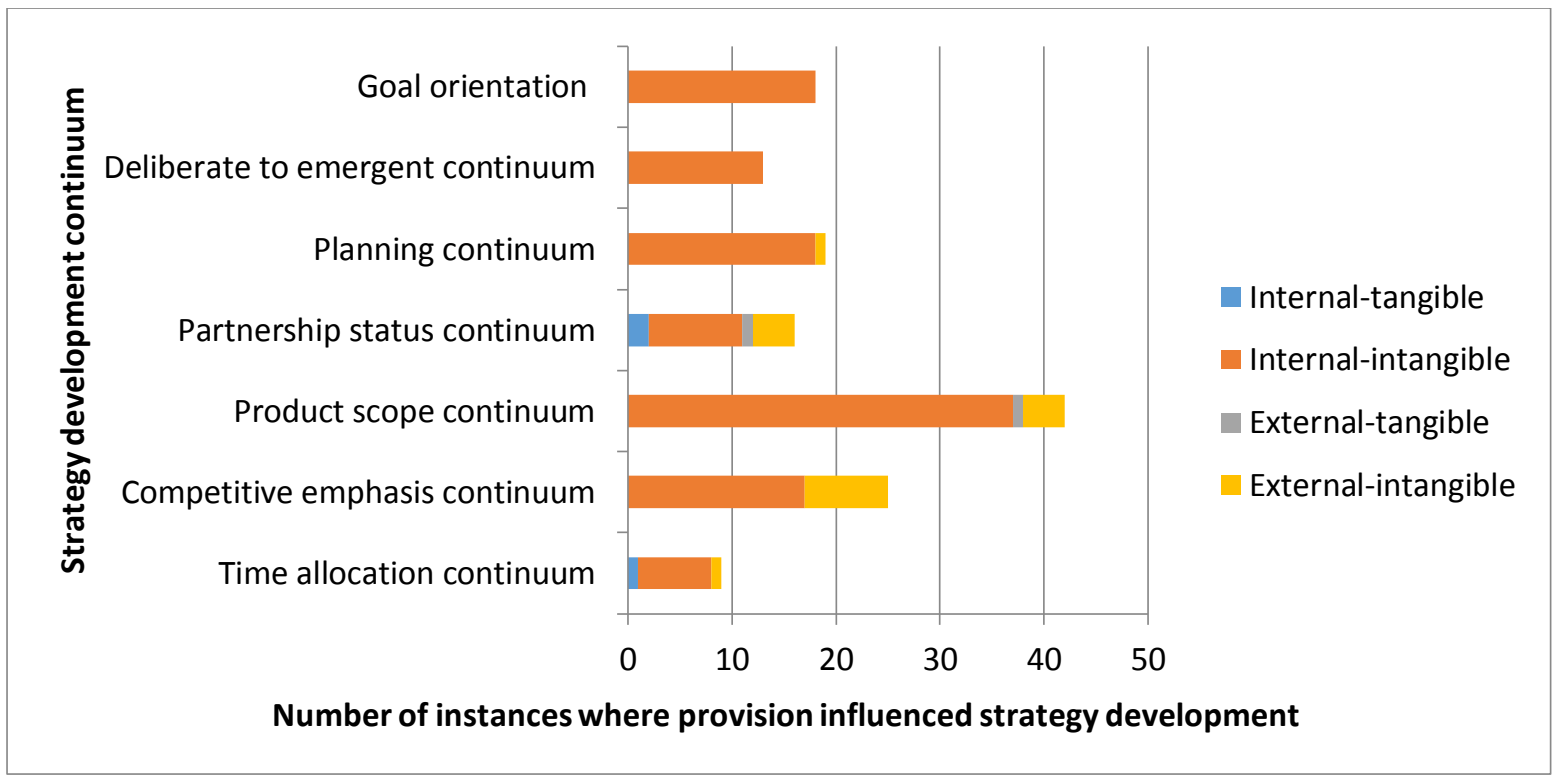

Figure 9. Summary of the categories of provisions that influenced strategy development

Table 12 summarises whether the specific provisions and their associated affordances were deemed to be of influence. The numbers in the boxes indicate the number of instances where influence occurred. The affordances of some provisions influenced multiple strategy development dimensions. This explains why, for example, the number of instances where affordances from the provision of assistance with strategy methodologies (E) was greater than the 33 participant firms. This is analysed further, later in this chapter.

It is also important to note that in some instances single strategy developments were influenced by the affordances of multiple provisions, and the totals are shown at the bottom of each provision category. This explains why, in some cases, the number of instances was, again, greater than the number of firms, indicating that some provisions may cluster together. 
For example, product scope changes were influenced by a total of 42 provisions. Again, this is analysed further in this chapter.

Table 12

The Number of Instances Where Each Provision Influenced Strategy Development

\begin{tabular}{|c|c|c|c|c|c|c|c|c|c|c|}
\hline & \multirow[b]{3}{*}{ Inc. } & \multicolumn{7}{|c|}{ Strategy developments } & \multirow{3}{*}{$\begin{array}{l}\text { Total no. } \\
\text { of } \\
\text { instances } \\
\text { where } \\
\text { provision } \\
\text { was of } \\
\text { influence }\end{array}$} & \multirow[b]{3}{*}{$\begin{array}{l}\text { Percentage } \\
\text { of firms } \\
\text { that had } \\
\text { used } \\
\text { provision }\end{array}$} \\
\hline & & \multirow[b]{2}{*}{$\begin{array}{l}\text { Goal } \\
\text { orientation }\end{array}$} & \multicolumn{2}{|c|}{ Process orientation } & \multicolumn{4}{|c|}{ Content orientation } & & \\
\hline & & & $\begin{array}{l}\text { Deliberate } \\
\text { or } \\
\text { emergent } \\
\text { process }\end{array}$ & $\begin{array}{l}\text { Planning } \\
\text { process }\end{array}$ & $\begin{array}{l}\text { Partnership } \\
\text { status } \\
\text { changes }\end{array}$ & $\begin{array}{l}\text { Product } \\
\text { scope } \\
\text { changes }\end{array}$ & $\begin{array}{l}\text { Competitive } \\
\text { emphasis } \\
\text { changes }\end{array}$ & $\begin{array}{l}\text { Time } \\
\text { allocation } \\
\text { changes }\end{array}$ & & \\
\hline \multirow{4}{*}{ 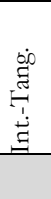 } & A & & & & & & & & 0 & 42 \\
\hline & B & & & & 1 & & & & 1 & 94 \\
\hline & $\mathrm{C}$ & & & & 1 & & & 1 & 2 & 15 \\
\hline & Tot. & 0 & 0 & 0 & 2 & 0 & 0 & 1 & 3 & \\
\hline \multirow{11}{*}{ 莣 } & $\mathrm{D}$ & & & & & & & & 0 & 30 \\
\hline & $\mathrm{E}$ & 11 & 8 & 11 & 1 & 18 & 9 & 6 & 64 & 88 \\
\hline & $\mathrm{F}$ & & & & & 6 & & & 6 & 70 \\
\hline & G & & & & & & & & 0 & 73 \\
\hline & $\mathrm{H}$ & 4 & 4 & 4 & & 12 & 6 & 1 & 31 & 91 \\
\hline & I & 2 & 1 & 3 & 2 & 1 & 2 & & 11 & 64 \\
\hline & $\mathrm{J}$ & 1 & & & 1 & & & & 2 & 58 \\
\hline & $\mathrm{K}$ & & & & 5 & & & & 5 & 55 \\
\hline & $\mathrm{L}$ & & & & & & & & 0 & 42 \\
\hline & $\mathrm{M}$ & & & & & & & & 0 & 64 \\
\hline & Tot. & 18 & 13 & 18 & 9 & 37 & 17 & 7 & 119 & \\
\hline \multirow{3}{*}{ 蓠 } & $\mathrm{N}$ & & & & . & . & & & 0 & 64 \\
\hline & $\mathrm{O}$ & & & & 1 & 1 & & & 2 & 48 \\
\hline & Tot. & 0 & 0 & 0 & 1 & 1 & 0 & 0 & 2 & \\
\hline \multirow{8}{*}{ 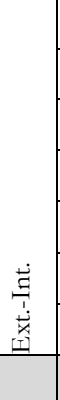 } & $\mathrm{P}$ & & & & & 1 & 2 & & 3 & 58 \\
\hline & $\mathrm{Q}$ & & & & & & 1 & & 1 & 55 \\
\hline & $\mathrm{R}$ & & & & 3 & 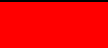 & . & & 3 & 51 \\
\hline & $S$ & & & & 1 & 3 & 2 & 1 & 7 & 33 \\
\hline & $\mathrm{T}$ & & & & & & 1 & & 1 & 39 \\
\hline & $\mathrm{U}$ & & & 1 & & & 2 & & 3 & 45 \\
\hline & $\mathrm{V}$ & & & & & & & & 0 & 36 \\
\hline & Tot. & 0 & 0 & 1 & 4 & 4 & 8 & 1 & 18 & \\
\hline
\end{tabular}

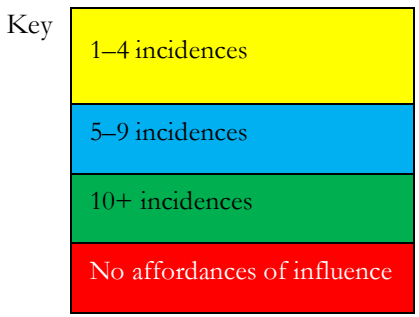


The goal orientation and process orientation appeared to be predominantly influenced by affordances of the provisions of strategy methodologies $(\mathrm{E})$, market validation and development $(\mathrm{H})$ and financial planning and management (I). All but one of the affordances that influenced these orientations were from the internal-intangible category of provisions.

The provisions of influence for the content orientation were more diverse. The partnership status continuum was most influenced by the affordances from the provisions of assistance with developing a board of directors $(\mathrm{K})$ and by connections to potential board members (R). Interestingly, affordances from the provision of connections to angel investors or venture capitalists $(\mathrm{O})$ were nominated in only one case as influencing partnership status. The affordances that were of most influence along the product scope continuum were from the provisions of strategy methodologies $(\mathrm{E})$, followed by market validation and development $(\mathrm{H})$, and product validation and development $(\mathrm{F})$. Similarly, the most influential affordances for competitive emphasis changes were from the provisions of strategy methodologies $(\mathrm{E})$, followed by market validation and development $(\mathrm{H})$. However, a range of affordances from the external-intangible provisions were also of influence. The affordances from the provision of strategy methodologies (E) were the biggest source of influence for time allocation changes.

Notably, there are a lot of red boxes, indicating that the affordances of many provisions had no direct influence on strategy development. These affordances may have however supported other provisions and helped to generate their affordances. For example, firms may have realised affordances from the provision of educational workshops (M) which included education about strategy methodologies (E).

\subsection{Exploration of strategy development orientations and the affordances of influence}

While the above analysis is interesting in that it provides an overview of the provisions that influenced the strategy developments, it does not give any insight about the direction of change or why the changes were made. The following analysis explores both the direction of change along each strategy development orientation and the type of affordances of influence, and the relationship between them.

Each strategy development orientation is analysed by first giving context to the number and direction of changes and the provisions that were of influence. This overview is followed by 
an in-depth investigation into the key themes presented, which is achieved by combining illustrative examples from individual firms and the points of view of the incubators. This presents an in-depth understanding of this largely unexplored relationship.

Note that not all firms changed on every strategy development dimension due to the incubator's' influence. The number of dimensions on which firms changed ranged from 1-7 (refer Table 24, Chapter Six).

\subsubsection{Goal orientation}

Sixteen of the 33 firms interviewed made changes along their goal orientation due to the influence of the incubators. Of the 16 firms eight increased the scope of their goals, two reduced the scope of their goals and the goals became more precise for six firms, see Table 13. The affordances of influence all came from the internal-intangible provisions, mainly from either assistance with strategy methodologies $(\mathrm{E})$ or from market validation and development $(\mathrm{H})$. There appeared to be no noticeable relationship between the nature of the affordances realised from the provisions and the direction of change. Given that affordances from both provisions $\mathrm{E}$ and $\mathrm{H}$ appeared to influence goals, and in a non-specific direction, indicates that these affordances may result in similar opportunities for action and could therefore potentially be substitutable for each other. There were only two cases $(8 \mathrm{D}, 15 \mathrm{~A})$ where multiple provisions were of influence in the goal orientation changes.

Table 13

Direction of Goal Orientation Changes and the Provisions of Influence

\begin{tabular}{|l|l|}
\hline Direction of change & Firms and provisions \\
\hline Goals increased & $\begin{array}{l}\text { 1B }(\mathrm{E}), 6 \mathrm{C}(\mathrm{E}), 7 \mathrm{D}(\mathrm{H}), 8 \mathrm{D}(\mathrm{E}, \mathrm{J}), 15 \mathrm{~A}(\mathrm{E}, \mathrm{I}), 18 \mathrm{C}(\mathrm{E}), \\
\text { 23E }(\mathrm{E}), 29 \mathrm{~B}(\mathrm{E})\end{array}$ \\
\hline Goals more precise & $5 \mathrm{D}(\mathrm{E}), 13 \mathrm{E}(\mathrm{E}), 17 \mathrm{D}(\mathrm{H}), 19 \mathrm{D}(\mathrm{H}), 26 \mathrm{~F}(\mathrm{I}), 31 \mathrm{D}(\mathrm{E})$ \\
\hline Goals reduced & $10 \mathrm{C}(\mathrm{E}), 24 \mathrm{~B}(\mathrm{H})$ \\
\hline $\begin{array}{l}\text { No change attributable to } \\
\text { incubator influence }\end{array}$ & $17(52 \%)$ \\
\hline
\end{tabular}

As concluded from the literature review, the stated purpose of incubators is to grow and nurture the development of NEFs. This notion was supported by incubator B who said that the ventures "basically have to grow at high rates or they will be exited." Incubator C emphasised that this growth should come from exports and a global product is needed to achieve that. It appeared that all firms may not have come into the incubator with these high goals in mind. Incubator A stated that their entrepreneurs tended to come out of regional 
areas and were shaped by their environment and therefore have their sights set low, and that "a lot of them are ignorant ... of the possibilities of what they could achieve."

This sentiment was echoed by firm 6C which said,

Before we were saying, "wouldn't it be good if it takes off here and we could get Australia?" Now Australia, Europe, North America ... it's all easily within our grasp.

This firm changed their goals after realising the affordances related to the provision of strategy methodologies and advice. They said:

[Incubator C] showed us the right models, and the right-thinking, and some of the things that people [were] talking about, we hadn't even thought about before.

The affordance of having strategic decisions challenged, as a result of following the incubators' strategy methodologies, played a substantial role in increasing the goals for firms 1B, 8D 15A, 18C, 23E and 29B. Firm 15A was challenged about their goals with regards to their investment strategy saying,

[Incubator advisor] said "We've got to look outside of New Zealand and Australia. What is the market in America?" And I'm thinking, far out, why don't we just concentrate on New Zealand? And [the advisor] goes "no, investors don't want that, they want to look at the global side of it." While the incubators sought firms with high growth potential, and therefore high goals, this potential may be unrealistic. Incubator F explained:

At the beginning they (firms) know that our criteria is global ambition, so they all say they have it. During pre-incubation I find that in reality they actually don't want to do it.

The goals may have been set high initially because the firms know that incubators want highgrowth firms and so they pitch their goals at a high level just to get into the incubator. The firms' goals could also have been initially set too high due to inexperience rather than deliberate intent and subsequently decreased during incubation. Firm 24B explained that their original financial forecasts were "quite unsophisticated [and high]" and came to this conclusion due to the affordance of being challenged to find out more about their customer base from the provision of market validation $(\mathrm{H})$. This was the case for firms 7D, 19D and $31 \mathrm{D}$.

However, this lowering of goals may not be the end of the journey for the firm. Incubator D regarded the tendency of firms to reduce goals as not uncommon; it was something that often occurred before a rise in goals: 
It's a rocky road that they take. They tend to start very high. Then they'll segment, analyse, validate and they'll all kind of go down, down, down. Then they curve back up again. It's almost like a confidence curve.

This idea of scaling goals back before increasing them at a more sustainable rate was reflected by firm 10C which said that the incubator made them scale back their goals and that they were now "a lot more achievable." The firm did this due to the affordance of being given strategy methodologies and then being challenged to find out more about their customers.

Incubator $\mathrm{E}$ took the position of not focusing on setting goals for the firm at an early stage due to the fact that there are so many unknowns about the potential of the product.

We have a hypothesis as to where we think the customer will get some value. The first step is to prove that they get that value, so we don't get carried away with what their growth model is going to be ... we don't know yet whether the customer is going to get any value out of it.

Firm 13E from the same incubator reflected this flexible approach and said that as a result their goals have now "changed from wishful thinking to realistic thinking." They did this after being given the tools to help develop their strategy.

Differences between the incubators are analysed further in Chapter Seven.

For some firms (4B, 19D, 22D) their end goals had not changed, but achieving their anticipated growth had been slower than expected. Firm 19D explained:

My growth ambitions in terms of where we want to end up have always been the same. I have always been thinking big markets, not New Zealand. In terms of how quickly those growth aspirations have been realised, it has been incredibly slow. I certainly didn't expect to be two years and still doing the research, to be honest.

The goals of other firms (5D, 17D, 31D and 26F) also remained the same in terms of size but just became more precise due to the use of strategy methodologies, which gave the firms structure around how they could achieve their goals. Firm 5D explained:

I guess, the overall goal hasn't changed much but there is definitely a path or a roadmap to that strategy.

It appears that in cases where the firms' goals changed they increased in scope or became more precise and that this may have happened early on in the incubation process. The key sources of influence were the affordances of giving firms tools and challenging their strategic decisions, leading to them making their own informed decisions, mainly from the provisions 
of strategy methodologies $(\mathrm{E})$ and market validation and development $(\mathrm{H})$. The views of the incubators appeared to be somewhat aligned to what actually happened with the firms (Chapter Seven).

\subsubsection{Process orientation}

The process orientation comprises two continuums: the deliberate to emergent continuum, and the planning continuum.

\subsubsection{Deliberate to emergent continuum}

Table 14 illustrates that just nine firms changed along the deliberate to emergent continuum.

Table 14

Direction of Change on the Deliberate to Emergent Continuum and the Provisions of Influence

\begin{tabular}{|l|l|}
\hline Direction of change & Firms and provisions \\
\hline Emergent to deliberate & $2 \mathrm{~F}(\mathrm{E}), 8 \mathrm{D}(\mathrm{E}, \mathrm{I}), 13 \mathrm{E}(\mathrm{E}, \mathrm{H}), 26 \mathrm{~F}(\mathrm{E})$ \\
\hline Deliberate to emergent & $4 \mathrm{~B}(\mathrm{H}), 10 \mathrm{C}(\mathrm{E}), 16 \mathrm{C}(\mathrm{E}), 22 \mathrm{D}(\mathrm{E}, \mathrm{H}), 30 \mathrm{C}(\mathrm{H}, \mathrm{I})$ \\
\hline $\begin{array}{l}\text { No change attributable to incubator } \\
\text { influence }\end{array}$ & $24(73 \%)$ \\
\hline
\end{tabular}

The affordances of influence were again solely from the internal-intangible category of provisions. Like the changes to the goal orientation, the affordances were mostly from the provisions of either assistance with strategy methodologies (E) or market validation and development $(\mathrm{H})$. However, there were differences in the actual affordances of the provisions according to the direction of the changes, as analysed next. Interestingly there were four firms $(8 \mathrm{D}, 13 \mathrm{E}, 22 \mathrm{D}$ and $30 \mathrm{C})$ in which the provisions appeared to cluster together indicating that possibly there was a wider scope of influence for changes on this continuum. In all cases the clustering of the provisions involved a combination of provision $\mathrm{E}$, and either $\mathrm{H}$ or assistance with financial planning and development (I).

\subsection{How and why firms became more deliberate or emergent}

The limited number of firms that changed along the deliberate to emergent continuum and the fact that some firms became more deliberate is surprising given that the Lean Start-up methodology appeared to be commonly employed by the incubators. The Lean Start-up methodology is considered to be an emergent approach to strategy development as it emphasises strategic experimentation (Ries, 2011). Therefore it could have been expected that the strategies of most firms would become more emergent. Incubator D explained their approach: 
In the early stage of incubation we really kind of used as lean an approach as possible ... working through "what is the customer, what is the market, how do we build this thing and get it out there as quickly and as cost effectively as possible?"

The firms that developed a more emergent approach were influenced by the affordances from the provisions of strategy methodologies (E) and market validation and development $(\mathrm{H})$. The actions of firm 22D reflected their incubator manager's statement about using a lean but systematic approach; as a result firm 22D stated, “it's been an evolving kind of strategy." This lean approach was also seen in other firms that emphasised the need to be flexible (4B, 10C and 30C). Firm 4B emphasised the value of the provision of market validation, which the incubator required firms to undertake and, as a result, their strategy became more emergent.

One of the things that I've learnt is that the market really determines what your strategy is ... it's a constant level of validation.

Incubator $\mathrm{C}$ viewed the strategy development process as often being emergent but with a deliberate goal, taking "a zigzag path" to get there. This approach of knowing where you are going but not necessarily how you will get there was reflected by firm 10C from the same incubator, who said, "In order to make that vision real, I need to be flexible." However, as incubator F noted, experimentation can also mean failure, and that can be problematic as people do not want to risk failure. This notion that firms may be afraid of experimenting with their strategies was furthered by incubator D, who said that they encourage experimentation and the less successful firms are:

... the ones that want to stay behind the desk and do plans and live in an ethereal world ... but really don't want to go out there and do it.

Incubator $\mathrm{E}$ had quite a specific approach to the strategic experimentation process. They started with one customer for early validation of the market need and product, and then based their strategy according to this customer's needs. This customer recognised that "there is a problem in their industry, they'd like to see it solved and they are willing to work with us to help do that".

In contrast to the emergent and deliberate dimension, some firms $(2 \mathrm{~F}, 8 \mathrm{D}, 13 \mathrm{E}, 26 \mathrm{~F})$ noticeably changed to a more deliberate approach to strategy development, although this was not noted as a possible outcome by the incubators. Notably, these firms emphasised the 
influence of the incubator from the affordance of providing structure to the firms' strategy. Firm 26F explained:

The beauty of going through a programme like that [incubation] is that you tend to stick to what you started out to do, and you feel like you have a responsibility... [The incubator] has taught us to just step back, and set up a process, let's set a timeline for when we do that.

From this analysis it appears that the changes firms make along the deliberate to emergent continuum are not nearly as marked as the incubators predicted, that is, only five firms became more emergent, and four became more deliberate. The key affordances of influence for the firms that become more emergent were related to the provision of market validation $(\mathrm{H})$ and strategy methodologies $(\mathrm{E})$ to help the firms find out information and to systematically develop their strategies. The key affordance for firms that developed a more deliberate approach was about enabling greater structure for strategy development. All the affordances that influenced the firm along this continuum came from the internal-intangible provisions, predominantly from strategy methodologies $(\mathrm{H})$ and market validation and development (E).

\subsubsection{Planning continuum}

Eleven firms changed their approach to planning, with the level of planning increasing for seven firms, going down for three firms, and becoming more precise for two firms (see Table 15). The affordances that influenced the changes were most closely associated with the internal-intangible category of provisions and, like the changes to the goal and deliberate to emergent continuum, were mainly from assistance with strategy methodologies $(\mathrm{E})$ and to a lesser extent, market validation and development $(\mathrm{H})$. There were six firms for which the provisions appeared to cluster together (2F, 4B, 10C, 13E, 15A, 22D), again possibly indicating that the influence came from a range of sources. Like the changes on the deliberate to emergent continuum the clustering was a combination of provision $\mathrm{E}$ and either $\mathrm{H}$ or assistance with financial planning and development (I), which are to some extent all related to planning. The provisions that had affordances that influenced the various directions of changes on this continuum were similar. However, like the changes on the deliberate to emergent continuum, there were differences in the affordances of the provisions which, in this case, seemed to vary according to the individual incubators. 
Table 15

Direction of Planning Continumm Changes and the Provisions of Influence

\begin{tabular}{|l|l|}
\hline Direction of change & Firms and provisions \\
\hline Planning went up & $\begin{array}{l}\text { 2F }(\mathrm{E}, \mathrm{I}), 5 \mathrm{D}(\mathrm{E}), 7 \mathrm{D}(\mathrm{E}), 12 \mathrm{D}(\mathrm{E}), 15 \mathrm{~A}(\mathrm{E}, \mathrm{I}), \\
\text { 22D }(\mathrm{E}, \mathrm{H}), 31 \mathrm{D}(\mathrm{E})\end{array}$ \\
\hline Planning went down & 4B (E, H), 6C (E), 16C (E), 30C (E, H) \\
\hline $\begin{array}{l}\text { Planning became more precise or } \\
\text { purposeful }\end{array}$ & 10C $(\mathrm{E}, \mathrm{H}, \mathrm{U}), 13 \mathrm{E}(\mathrm{I})$ \\
\hline $\begin{array}{l}\text { No change attributable to incubator } \\
\text { influence }\end{array}$ & $20(61 \%)$ \\
\hline
\end{tabular}

Only four firms reduced the amount of planning they did which may indicate that they had come into the incubator with a business plan. However, they had to abandon their plans due to changes in their strategy, thus moving from a highly planned mode to less planned mode. Incubator $\mathrm{C}$ explained the rationale behind this change in approach:

[Years ago] we required companies to create a business plan, so these guys would go off and produce a tome. I don't know if I ever read one. We realised that this is a waste of space. The ideas change quickly and getting people to build a business plan [like this] was not going to work.

Firm 6C, from the same incubator, acknowledged the value of this change in approach and that the practice appears to have changed in recent years, perhaps largely due to the affordances of strategy tools such as the Lean Start-up methodology:

We came in here and the first thing that they said is “you don't need a business plan, here's a canvas." I'd never seen a canvas before. So instantly that changed our thinking from having to wade through every year and do this business plan that sits in a drawer and nobody looks at anyway to, suddenly, a one-page working canvas that goes on the wall with post-it notes. For creative people that is perfect. What a breakthrough. I should have done it years ago.

Firm 30C explained:

I came in and I had a business plan, and I had a financial plan, and they have all gone. They were just totally unrealistic. So the market that we are targeting has changed ... I learnt all about pivoting, and we've been testing the market since.

Similarly firm 16C said that:

When I came here the [incubator] wanted a 100-page business plan as well. Those days have changed, which is great. That is all for the better I think. There are so many things in a start-up that are a lot more important than paperwork. 
This firm came to this conclusion after realising the affordances associated with the provisions of market validation $(\mathrm{H})$ and financial planning and management (I).

While the incubators' approaches to strategy development tended to be based on the Lean Start-up methodology, this does not mean that planning was not undertaken, just that the plans tended to be more evidence-based, as incubator B explained:

I would rather see a business plan that is full of evidence, based on testing of the business model ... from there you can create a business case.

Incubator E explained that plans are only developed following a clear definition of customer requirements. So after obtaining evidence first about what customers want:

I expect people to be able to define the technical specifications that the customer is after ... So definition of customer requirements. There's definitely planning in there, if you take a product to market, if you're developing a product, you have to plan.

Incubators $\mathrm{A}, \mathrm{E}$ and $\mathrm{F}$ all emphasised the need for firms to undertake planning processes especially if they are preparing for investment processes. Firms $2 \mathrm{~F}, 13 \mathrm{E}$ and $15 \mathrm{~A}$ and from these incubators acknowledged their incubator's help with both clarifying their strategies and with financial planning in preparation for becoming investment-ready.

Incubator D seemed to particularly emphasise planning tools, and this also appeared to influence some firms in this incubator to increase their level of planning $(5 \mathrm{D}, 7 \mathrm{D}, 12 \mathrm{D}, 22 \mathrm{D}$ and 31D). Firm 7D explained:

They (incubator) bring in a template that disciplines and challenges you and that means you actually go further, deeper, harder into what you actually need to do.

Firm 5D emphasised the speed at which this process occurred, saying that their plan "all sort of developed quite quickly once we got [the incubator] involved."

By contrast to the deliberate to emergent continuum there seemed to be more alignment between the incubators' views on what changes would actually occur along the planning continuum with what actually occurred in firms. However, there was a reasonably clear distinction between the approaches of some of the incubators. This distinction ranged from incubator $\mathrm{C}$ which de-emphasises planning - after historically relying on it heavily - to incubators $\mathrm{A}$ and $\mathrm{E}$ that emphasise the financial aspects and evidence-based planning, to incubators $\mathrm{D}$ and $\mathrm{F}$ that emphasise increased planning and the use of planning tools (see Chapter Seven). 
Nearly all the affordances that influenced changes in firms' planning were in the form of being given the structure and tools to gather information to inform strategic decisions which predominantly came from the provision of strategy methodologies $(\mathrm{E})$. Other supporting affordances were from the provisions of market validation and development $(\mathrm{H})$ and financial planning and management (I).

\subsubsection{Content orientation}

Content orientation, according the discussion in the literature review, categorises partnership status changes and product scope changes as core, and the competitive emphasis and time allocation changes as peripheral (Nicholls-Nixon et al., 2000). However what seemed apparent while conducting the interviews was that some of the strategy developments relating to the firms' product scope and partnership status could be viewed as 'less core' than others and, similarly, some of the changes to the competitive emphasis could be viewed as being less peripheral than others. Table 16 presents a summary of the specific types of strategy development along the content orientation as they are deemed to impact on the core or periphery of the firm. A new category is added, 'middle', to indicate cases where the changes were considered neither core nor peripheral.

Table 16

Where the Content Orientation Strategy Developments May Fall on the Core-Periphery Continumm

\begin{tabular}{|c|c|c|c|}
\hline & Core & Middle & Periphery \\
\hline $\begin{array}{l}\text { Partnership } \\
\text { status changes }\end{array}$ & $\begin{array}{l}\text { Addition of } \\
\text { shareholders (which } \\
\text { included the addition } \\
\text { of directors). }\end{array}$ & $\begin{array}{l}\text { Addition of non- } \\
\text { shareholder directors. } \\
\text { Addition of advisory } \\
\text { group. }\end{array}$ & \\
\hline $\begin{array}{l}\text { Product scope } \\
\text { changes }\end{array}$ & $\begin{array}{l}\text { Product ceases. } \\
\text { Product scope } \\
\text { increased. } \\
\text { Products substantially } \\
\text { different. }\end{array}$ & $\begin{array}{l}\text { Product more scalable } \\
\text { General product } \\
\text { evolution. }\end{array}$ & \\
\hline $\begin{array}{l}\text { Competitive } \\
\text { emphasis } \\
\text { changes }\end{array}$ & & Changed target market. & $\begin{array}{l}\text { Competitive emphasis } \\
\text { increased. } \\
\text { Refined target market. }\end{array}$ \\
\hline $\begin{array}{l}\text { Time allocation } \\
\text { changes }\end{array}$ & & & $\begin{array}{l}\text { More efficient use of } \\
\text { time. } \\
\text { Switched focus of } \\
\text { activities. }\end{array}$ \\
\hline
\end{tabular}




\subsubsection{Partnership status continuum (core and middle)}

Partnership status changes were defined as changes made to the firms' ownership status, as per the definition established by Nicholls-Nixon et al. (2000), but with the addition of changes to their governance structure.

The partnership status changed for ten firms as a result of the incubators' influence. In eight instances the number of shareholders went up, all resulting in an increase in shareholder directors, and in two instances just the governance increased through the addition of nonshareholder directors or an advisory board. The direction of change along this continuum appears to be in line with the incubators' predictions.

Notably, the affordances of influence came from a variety of provisions, but were predominantly from the internal-intangible and the external-intangible provisions. Unusually, when compared to the influence of changes on the other strategy development continuums, the influence of the affordances from the provision of strategy methodologies (E) was apparent only in one case (33A). Thus the wide variety of provisions of influence signal that their affordances may be substitutable. For example, increases in shareholders were not just influenced by affordances from the provision of connections to assistance with developing a board of directors $(\mathrm{K})$ and connections to angel investors or venture capitalists $(\mathrm{O})$, as in the case of firm 18C; the changes were influenced instead by connections to potential major customers (S), as in the case of firm 4B.

There was also a relatively high degree of clustering of the affordances of provisions, indicating that there is some connection between the provisions. For example, the provision of assistance with developing a board of directors $(\mathrm{K})$ clustered with provisions $\mathrm{C}, \mathrm{J}, \mathrm{O}$ and $\mathrm{R}$. This clustering may also indicate that several provisions were needed to influence the change, reflecting the possible relative importance placed on these changes by the firm, perhaps due to the nature of the changes being core to the firm.

Table 17

Direction of Partnership Status Changes and the Provisions of Influence

\begin{tabular}{|l|l|}
\hline Direction of change & Firms and provisions \\
\hline Shareholders increased (core) & $\begin{array}{l}\text { 1B }(\mathrm{I}), 4 \mathrm{~B}(\mathrm{~S}), 7 \mathrm{D}(\mathrm{I}), 13 \mathrm{E}(\mathrm{C}, \mathrm{K}), 16 \mathrm{C} \\
(\mathrm{B}), 18 \mathrm{C}(\mathrm{K}, \mathrm{O}), 20 \mathrm{E}(\mathrm{J}, \mathrm{K}), 33 \mathrm{~A}(\mathrm{E}, \mathrm{R})\end{array}$ \\
\hline Governance increased (middle) & $6 \mathrm{C}(\mathrm{K}, \mathrm{R}), 32 \mathrm{~A}(\mathrm{~K}, \mathrm{R})$ \\
\hline $\begin{array}{l}\text { No change attributable to incubator } \\
\text { influence }\end{array}$ & $23(70 \%)$ \\
\hline
\end{tabular}


In most cases the incubators themselves became a shareholder in the firms. This practice occurred in five incubators and the equity stake ranged from $2.5 \%$ to $70 \%$, with most incubators taking about $6 \%$ equity. For the purposes of this analysis, increasing incubator equity in the firms is not considered to represent change in partnership status changes unless the equity stake was substantial given that in almost all firms the incubator was a minor shareholder.

Access to additional and non-incubator investors was discussed in the literature review as being a highly valued provision of incubators. While it was a desired outcome of the all the incubators, just eight firms were successful in capital raising, and correspondingly, acquiring new shareholders during incubation. For Incubator A raising capital was the "ultimate destination" for their firms. Firm 33A was successful in this mission, helped in part by the affordance of being connected to providers of capital that they may not have otherwise been able to connect to. Capital raising was a critical part of their mandate for incubator $\mathrm{E}$ and correspondingly, they had a very structured investment process.

Firms $13 \mathrm{E}$ and $20 \mathrm{E}$ from this incubator were both successful in capital raising after realising affordances from the incubator of investment advice and connections to potential investors. Gaining capital appeared to be the driving force for incubators A and E. However, for incubator $\mathrm{C}$ the driving force was acquiring expertise for the firm, which would then lead to money:

I'm looking for smarts rather than the money. Get the smarts and you'll tend to find the money. It's just getting the smarts on board.

This situation was experienced by firm $11 \mathrm{C}$ whose incubator had gained an investor who was initially introduced to the firm on the basis of providing advice, but who later ended up investing in the firm. Similarly, but in another incubator, firm $4 \mathrm{~B}$ was introduced by the incubator to someone who had a very similar business in the US on the premise of sharing expertise. The investor later became a shareholder and the investor's firm also became a strategic partner of the incubator firm.

In all cases where investment was obtained, it appeared that at least one board member was also added. This could be because investors wanted to ensure that they had a governance role, giving them more confidence in their investment. This appeared to be the case for firm 
33A that originally had an establishment board, which was superseded by a board of directors, when the investors joined. The incubator helped with:

working out what our capital needs were, helping define the budget to meet those needs, helping - obviously - with the contacts, but also developing the story and being sort of the, I suppose, the voice of the investor.

Firms $1 \mathrm{~B}$ and $7 \mathrm{D}$ also received assistance from their incubators in the successful raising of capital, mainly through affordances resulting from financial planning.

In some cases however, the governance structure changes were less formal, with just advisory boards being formed. Incubator D confirmed the need for advisory boards saying, "trying to get a strong advisory board around them is important." Firm 6C discussed the process of forming an advisory board and emphasised the affordances from the provisions of connections to potential advisory group members:

So the guys that we have got on our advisory group, they've come through [the incubator] ... again it is part of that process of knowing that if there is somebody we want we can just pick up the phone and say "we've got a gap here", or "we don't know something here, who have you got?" We know that they will find someone for us.

From the discussion above it appears that partnership status changes, while relatively infrequent, involved more than just an increase in shareholders, they also involved an increase in governance and, with that, came added expertise. The affordances that influenced these changes came from the incubators' connections to investors, business mentors and potential major customers and financial management, which sometimes came from a cluster of provisions. It seems that there is not one common pattern of affordances that led to changes along the partnership status continuum. Incubators $A$ and $E$ were heavily focused on raising capital for the firms and this is analysed further in Chapter Seven.

\subsubsection{Product scope changes (core and middle)}

Product scope changes were defined as changes to the firms' scope of products and services which may require major investment in fixed assets, as per the Nicholls-Nixon et al. (2000) definition.

The product scope changed for 28 firms due to the incubators' influence. Along this continuum it was not a simple matter of the product scope increasing, which it did in six firms; the product scope changed through becoming more scalable (six firms), through evolution (ten firms), by becoming substantially different (five firms) and, in one case, 
ceasing to be available. The changes were influenced mainly by the affordances from internal-intangible provisions, with assistance with strategy methodologies (E) and with market validation and development $(\mathrm{H})$ being prevalent. The fact that the affordances of these two provisions were most prevalent is perhaps unsurprising as they represent substantial functions of business incubators, and, arguably, have the most direct connection to strategy development.

Many of the provisions appeared to cluster together, although not in any common way. While there appeared to be no distinctive patterns that arose from the provisions and by the direction of change, differences were noticed in both the affordances of influence and the direction of change according to the firms' product type. Similar to the partnership status changes, the high degree of clustering of affordances may reflect the relative importance placed on product scope changes by the firm. This is concluded because the influence often came from many affordances and not just one.

Table 18

Product Scope Changes and the Provisions of Influence

\begin{tabular}{|l|l|}
\hline Direction of change & Firms and provisions \\
\hline Product scope went up (core) & 8D (E), 17D (E, H), 20E (E), 28E (E, F) \\
\hline $\begin{array}{l}\text { Product became more scalable } \\
\text { (middle) }\end{array}$ & $\begin{array}{l}\text { 3F (F), 4B (E), 6C (F), 10C (E, S), 21C (F, H), 29B } \\
(\mathrm{E})\end{array}$ \\
\hline Product evolved (middle) & $\begin{array}{l}\text { 1B }(\mathrm{E}, \mathrm{H}), 2 \mathrm{~F}(\mathrm{~S}), 7 \mathrm{D}(\mathrm{E}, \mathrm{H}), 11 \mathrm{D}(\mathrm{E}, \mathrm{H}), 13 \mathrm{E}(\mathrm{H}), \\
\text { 14D (E), 15A (H), 22D (E, H), 23E (E), 33A (F) }\end{array}$ \\
\hline Product was different (core) & $\begin{array}{l}\text { 9A (H), 16C (E), 18C (E, O), 30C (E, I, S), 31D (E, } \\
\mathrm{H}), 25 \mathrm{E}(\mathrm{F}, \mathrm{H})\end{array}$ \\
\hline Product scope went down (core) & $19 \mathrm{D}(\mathrm{E}), 27 \mathrm{~F}(\mathrm{E}, \mathrm{H}, \mathrm{P}$ ceased firm) \\
\hline $\begin{array}{l}\text { No change attributable to incubator } \\
\text { influence }\end{array}$ & $5(15 \%)$ \\
\hline
\end{tabular}

It appeared that the types of product scope changes depended on the type of products that the firms sold. For example, information-technology-related products tended to be developed in a drive to become more scalable, whereas physical products tended to be developed by becoming more platform-based. For example, an information technologybased firm, 29B, sought to make their product more scalable after first doing "the classic start-up thing of just hack it, then make it work." This approach was similar to that of firms 1B, 3F, 6C, 10C, 18C and 21C that all realised affordances associated with strategy methodologies and product validation to improve the scalability of their products. The drive for scalability was also evident in firm 4B that started off with a product in physical form and changed it to an information-technology product. 
The cases where the product scope became more platform-based $(8 \mathrm{D}, 17 \mathrm{D}, 19 \mathrm{D}, 20 \mathrm{E}, 23 \mathrm{E}$, $28 \mathrm{E}$ ) involved situations where firms sought to increase the range of commercialisation opportunities, and involved general expansion of the range of products available. The influence of these changes came almost exclusively from the affordances of provisions of strategy methodologies $(\mathrm{E})$ and market validation $(\mathrm{H})$. A physical product-based firm, 20E, talked of their evolution from a "one-hit wonder" to the present:

We're kind of more of a platform company [now], with the potential to create several different products that are based around the same technology and the same expertise, and how that would fit in with what the market needs, and what areas we can address and which ones we can't.

The development of the technology in this way was influenced by the affordances of providing more structure to the firms' strategy. In Chapter Six the notion of the firms' products being related to the differences in the direction of change and the affordances of influence is explored further.

The processes that firms went through to find out more about customer needs influenced product scope changes. Key affordances came from the provision of market validation $(\mathrm{H})$ and all of the incubators emphasised the importance of this provision. For incubator $\mathrm{E}$ market validation initially involved working with a single reference customer as a key part of their process:

Before we've incorporated [the firm] we've worked out who the first reference customer is going to be. We'll build a product for that reference customer, which will mean a bit of work in and out the lab, eventually doing a trial with the customer. We try to get to a trial with the customer in some shape or form within 12 months.

Firm 13E explained how they followed this process and built several prototypes of the product, before testing it with the reference customer, with affordances being realised as a result of using their incubator's established product and market validation methodologies:

We took it out to its first test run to a factory ... we thought this was fantastic ... we had enough success that on the basis of that the client said "yep, we are still keen, so go away, do what you need to do and come back again."

For other firms in this incubator the physical product was changed substantially to meet the needs of a newly identified customer segment. This was the case for firm 25E who said that the previous product was "a very difficult area to be in; it is also a very low-value area, a high-quantity, low-value area whereas [the new product is] in fact [in a] high-value area." For 
this firm's incubator, E, the decision criteria around identifying realistically achievable highvalue product areas was quite defined.

If they [a firm's CEO] come to us and go, "we'll hit to \$2-3m mark with this one; the customer is more forgiving, the performance requirements aren't so high, the cost to get it into the market is less" [then] it's an easy decision for us to make, “yeah let's do that one.” It's easy because we know what our criteria are.

The other incubators had less structured roles in the process of getting the firms to understand their customers and how they should respond accordingly. Firms 1B, 3F, 9A, $11 \mathrm{D}$ and 15A discussed how their products had evolved due to the affordances resulting from the provision of market validation. The changes were therefore influenced by the incubator indirectly, that is, the outcomes from interaction with the market influenced their decisions. On the other hand, firms 7D, 11D, 14D and 16C were influenced more directly, that is, by the incubator challenging their decisions. Firm 7D explained:

One of the interesting things that [the incubator manager] said originally, he said that "I don't get what you are doing, I don't understand it." He probably said this so many times, it really annoyed me ... as a result of that, I reworked the website probably three or four times to what [it] is now. And hopefully it is kind of clearer.

Echoing this notion of gaining clarity, incubator D discussed the need for firms to clearly define what it is they are offering customers and to reduce their product scope.

We're trying to focus them down. A really core piece that I see on the journey is focussing them down through the validation and through the incubation journey [to decide] what is the niche that they fit in? They may have aspirations to be a global player but they've got to start by dominating a niche somewhere.

The differences between the incubators and their approach to product development is analysed further in Chapter Seven.

Many firms also undertook minor product developments. This included intellectual property protection, as in the case of firm 33A.

Firm 19D narrowed their product range after being challenged by the incubator:

When we came in here we had a plethora of products and we didn't know which one we were going for.

One firm ceased operations and this included ceasing the relationship with the incubator. After going through the market validation process they said, 
We have decided to call it quits on this opportunity, knowing full well that we have actually learnt a lot from the whole exercise.

Product scope changes appeared to vary according to the type of product that the firm sold, with product-based firms changing to become more platform-based, and information technology firms becoming more scalable with associated differences in the affordances of influence.

\subsubsection{Competitive emphasis changes (periphery and middle)}

Competitive emphasis changes are defined as encompassing changes to the strategic positioning of the firms' products and services which can necessitate alternative marketing strategies, as per the Nicholls-Nixon et al. (2000) definition.

The competitive emphasis changed for 21 firms (refer Table 19). In eight firms the competitive emphasis increased, that is, they were targeting the same market but their marketing efforts increased. No firms reduced their competitive emphasis; however, ten firms refined their target market and three firms changed their target market. The types of changes made ranged from changes in the marketing strategy - which tended to be more peripheral - to changes to the target market, which tended to have greater implications for the firm. The direction of the changes appeared to be relatively in line with the incubators' views of what changes would be made.

Many of the affordances that influenced competitive emphasis changes came from the internal-intangible provisions, with assistance with strategy methodologies (E) and market validation and development $(\mathrm{H})$ again being quite prevalent. Notably substantial influence also came from a range of other internal-intangible and external-tangible provisions.

There was little clustering of provisions, perhaps signalling that competitive emphasis changes were less important, given that fewer affordances influenced the changes for each firm. The wide range of provisions also suggests that there is a degree of substitutability of provisions, similar to the partnership status continuum. For example, in some instances competitive emphasis changes were influenced by affordances from the provision of connections to professional services $(\mathrm{P})$, whereas in other cases the changes were made only due to assistance with market validation and development $(\mathrm{H})$. 
Table 19

Competitive Emphasis Changes and the Provisions of Influence

\begin{tabular}{|l|l|}
\hline Direction of change & Firms and provisions \\
\hline $\begin{array}{l}\text { Competitive emphasis went up } \\
\text { (periphery) }\end{array}$ & 4B (P), 12D (E), 13E $(\mathrm{E}), 15 \mathrm{~A}(\mathrm{E}), 16 \mathrm{C}(\mathrm{P})$, \\
\hline $\begin{array}{l}\text { Competitive emphasis refined } \\
\text { (periphery) }\end{array}$ & 78C $(\mathrm{E}), 21 \mathrm{C}(\mathrm{H}, \mathrm{Q}, \mathrm{S}), 22 \mathrm{D}), 8 \mathrm{H}(\mathrm{E}), 10 \mathrm{C}(\mathrm{E}), 11 \mathrm{D}(\mathrm{U}), 17 \mathrm{D}$ \\
& $(\mathrm{H}), 23 \mathrm{E}(\mathrm{E}), 24 \mathrm{~B}(\mathrm{H}), 29 \mathrm{~B}(\mathrm{E}), 30 \mathrm{C}(\mathrm{E}, \mathrm{I})$, \\
& $31 \mathrm{D}(\mathrm{U})$ \\
\hline Market changed (middle) & $6 \mathrm{C}(\mathrm{I}), 9 \mathrm{~A}(\mathrm{H}), 32 \mathrm{~A}(\mathrm{~T})$ \\
\hline $\begin{array}{l}\text { No change attributable to incubator } \\
\text { influence }\end{array}$ & $12(36 \%)$ \\
\hline
\end{tabular}

Changes to the firms' marketing strategy due to having strategic decisions challenged included changes to the product name to align it better to customer needs and changes to the understanding of which target market to pursue. This was the case for firm 29B:

[The advisor] got us thinking in the right way ... It's kind of hard to describe [but] it has made me think more about markets ... so the thinking is a lot more ordered and strategic.

Two firms changed their target market altogether. Firm 9A changed to an earlier stage in the value chain, but they were essentially still solving the same problem for the same customers. They previously focused on selling their products to manufacturers, where their product was just a component of another product; but switched to focus on selling their product as a stand-alone product. This change was made due to the affordance of understanding the need for market validation saying, "After dealing with [the incubator], it became important to get the market validation understood for the aftermarket product."

Firm 30C also moved their target market to an earlier stage in the value chain after realising that there was little value in selling their product directly to the end customers. The key affordances that were realised were from the provisions of help with financial planning and management (I) and having strategic decisions challenged, enabling the firm to identify and pursue more lucrative opportunities.

Firms also sought to grow by expanding their target markets. For firms 15A, 18C and 32A the target markets simply increased from a local focus to more of a global focus. However, expansions did not just come in terms of market size, they also came from increasing the number of target market groups. Firm 30C, as discussed above, also expanded their target market to include a completely unrelated market, but it was one that could utilise the same product. This was also the case for firm $21 \mathrm{C}$ that remained with the original market but saw an opportunity with a completely different market. The affordances of influence were from 
provisions that included connections to subject matter experts $(Q)$, universities $(T)$ and potential major customers (S).

The tactic of partnering with other organisations was also used as a way to increase the market potential. This was done by firm 7D who partnered in order to obtain access to their target customers:

We are now the business development partner for [industry bodies]... and they promote us through the membership network. They have got 1200 members, people who are specifically devoted to [our area of expertise].

The affordances that influenced this competitive emphasis change came from the provisions of connections to potential major customers $(\mathrm{S})$ and market validation $(\mathrm{H})$.

Sometimes in order to grow, firms sought to contract their target market, a move which may appear to be counter-intuitive. The logic for this approach was discussed by a manager from incubator B, who also emphasised that firms should try to narrow their market.

[Firms generally have] a tendency to try and do way too much and to enter new markets and try and be all things to all people. We try to narrow the focus even further and say pick something and do it really well. It's that and being really clear about what you're offering and why it's better than anything else that's out there.

Firm 29B from that same incubator experienced this type of change after being challenged by the incubator to just focus on one particular opportunity.

Ten firms refined their market, a move that appeared to be based on the premise that, in order to be the most effective, firms need to prioritise quality over quantity. For example, firm 10C, scaled their target markets down as a result of the affordance of having their strategic decisions challenged:

I was advised to scale it down, to prove it with the [end customers] first and say to [the secondary market] "these [end customers] are already using it." So we scaled it down for the [end customers], rather than have the goal for the [secondary market] companies.

Firms 8D, 17D and 23E indicated that their customer base essentially remained the same, but now they will only work with customers that fit certain criteria. Firm 8D, for example, said that they will now only do work for the larger, higher-value customers because the incubator challenged them to look at the value that they were extracting from their original target customers, and to assess the ongoing viability of this market. 
We developed a system for when I do get an enquiry. If they don't get more than seven out of ten I say "no" ... most of the time now I say "no". It just means that we can focus on what's really important.

Firms 4B, 11D, 12D, 16C and 31D did not so much change their competitive emphasis, rather they just increased the momentum. They did this by using the services of external marketing advisors that the incubator connected them to. Firm 16C explained:

My approach to marketing now is to find somebody else who knows how to do this stuff and do it well, and get them to do it ... [the external sales specialist we use] doesn't have any qualms cold calling.

Firm 22D undertook what appeared to be the most market validation of any of the firms. Notably, this firm was perhaps one that seemed to need it the most, admitting that they created the product before they even knew of the market for it. This firm did substantial market validation which involved 45 one-on-one interviews with their end customers. As a result of this validation they were able to determine the basis of their competitive emphasis:

So the standard [approach] where companies find a problem and create a solution, we created the solution and then found the problem ... so we had a product that was ready but we didn't have a market, or a market understanding ... now we have our different target markets, and a tiered pricing structure based on the different abilities, and the last bit of this puzzle now is to really understand how to get to those people.

This firm admitted that they probably would not have undertaken the market validation work if it had not been for the incubator making them do it. Similarly, firm 24B came into the incubator with a product already developed. They explained:

[The incubator] provided a voice of reason. Whenever you talk to someone and we say "we're doing [product] for [market]" and they go "oh cool." That sounds great. The typical, inexperienced entrepreneur will say, "That's my validation done, people think this is a good idea," whereas [the incubator] provides the ... "well, that's well and good, but did they say they would pay for it? Don't believe the hype; don't get sucked into people getting excited because there's probably a 'but"'.

Again, the incubator strongly influenced the firm by encouraging them to understand their market through affordances associated with market validation.

Based on the literature review it could be expected that the affordances associated with market validation would feature highly in influencing the competitive emphasis changes, given that the purpose of market validation is to gain a better understanding of the market. 
However, while market validation was a substantial influencing factor in many cases, other affordances, notably from connections to external professional advisors (P), played an equally major role.

From the above discussion it appears that the competitive emphasis changes were influenced by both the internal-intangible provisions - predominantly by having their strategic decisions challenged and by being made to do market validation - and by the external-intangible provisions predominantly by various professional advisors.

\subsubsection{Time allocation continuum (peripheral)}

Time allocation changes refer to changes to the time that the firm allocates to various activities (Nicholls-Nixon et al., 2000).

\subsection{Overview of observations}

The time allocation changed for just eight firms as a result of the incubators' influence (refer Table 20). Correspondingly, just one incubator predicted that firms would make changes along this dimension. Three firms became more efficient in how they operated and five switched their focus to other activities. Like the goal and process orientation changes, the affordances from the internal-intangible provisions influenced the time allocation changes the most. The main influence came from the provision of strategy methodologies $(\mathrm{E})$ and there was only one instance of clustering. Unexpectedly affordances from the provision of assistance with market validation and development $(\mathrm{H})$ did not influence any changes along this continuum.

Table 20

Direction of Time Allocation Changes and Provisions of Influence

\begin{tabular}{|l|l|}
\hline Direction of change & Firms and provisions \\
\hline Switched focus (periphery) & $\begin{array}{l}8 \mathrm{D}(\mathrm{E}), 13 \mathrm{E}(\mathrm{C}), 14 \mathrm{D}(\mathrm{E}), 17 \mathrm{D}(\mathrm{H}), 26 \mathrm{~F} \\
(\mathrm{E}, \mathrm{S})\end{array}$ \\
\hline More efficient (periphery) & $2 \mathrm{~F}(\mathrm{E}), 4 \mathrm{~B}(\mathrm{E}), 10 \mathrm{C}(\mathrm{E})$ \\
\hline $\begin{array}{l}\text { No change attributable to incubator } \\
\text { influence }\end{array}$ & $25(76 \%)$ \\
\hline
\end{tabular}

Only incubator $\mathrm{D}$ discussed how firms might change the way they spend their time while in the incubator. They emphasised that firms spent too much time trying to guild the lily, whereas they actually needed to get over to the market, understand it and understand what the competition is, and that is what the incubator encouraged. 
Firms 2F, 4B and 10C operated with greater efficiency due to increasing their focus on certain activities. For firm $2 \mathrm{~F}$ this was due to affordances arising from being part of the incubators' strategy development programme and using associated strategy development tools:

Every single step of the journey I have been given homework, and every single step of the journey I have had to turn that homework in before the next session, and either [primary adviser] or [secondary advisor] had gone over it, and told me where I had gone wrong.

Firm 14D also realised the affordances relating to strategy methodologies (E), but these methodologies had the effect of forcing them to switch their focus.

The main value initially was the fact that we were forced to spend a lot of time on aspects of the business that we would have just gone past. So it was more the time, rather than the wise words.

However not all firms were so open to being told what to spend their time on by the incubator. Firm 6C did not make any changes to their time allocation, saying:

We don't want to be beholden to somebody else; we don't want someone saying "what are you doing today, what about these hours, where are the results?" That's not why you go into business for yourself.

Firm $4 \mathrm{~B}$ changed their time allocation due to the incubator creating a sense of urgency, but with undesirable results:

I think [the incubator has] certainly had a bearing on levels of urgency and that has [had] good and bad parts. It's good because if you didn't have that kind of getting pushed along you probably wouldn't necessarily do it ... [but] it put undue pressure on us and the CTO quit because of the too ridiculous levels of goals that we're trying to hit. It was not realistic.

How the firms spent their time also appeared to shift as the firms matured. For firm $3 \mathrm{~F}$ the CEO spent more time working on the firms' strategy as opposed to operational matters and, similarly, firm 8D focused more on sales as opposed to operational matters. The affordances associated with the provision of assistance with market validation $(\mathrm{H})$ were the main influence behind the time allocation changes. This was evident for firm 17D who said that their focus had moved away from product development to validating the product with potential customers as a direct result of the affordance of being helped to undertake market validation. Firm 26F previously spent their time selling to customers but it switched to a different business model and focused on engaging potential partners, due to the affordance 
of having their strategic thinking challenged and to connections to potential strategic partners.

In the early stages what firms did with their time appeared to be more likely to be influenced by the incubator. As the firms matured the incubator had less influence and this is explored further in Chapter Six. Overall, few changes were made along the time allocation orientation, and what changes were made were mostly influenced by affordances from a narrow range of provisions. 


\subsection{Summary table}

Table 21 presents a summary of the nature of affordances of the provisions that influenced strategy development drawn from the preceding analysis.

Table 21

Summary of the Nature of the Affordances of the Provisions That Influenced Strategy Development

\begin{tabular}{|c|c|}
\hline $\begin{array}{l}\text { Strategy } \\
\text { development }\end{array}$ & How affordances of provisions influenced strategy development \\
\hline Goal orientation & $\begin{array}{l}\text { There was minimal clustering of the affordances of provisions, with single } \\
\text { affordances being sufficient to influence the firms' goals in most cases. } \\
\text { The affordances came from a narrow range of provisions (mainly E and H) } \\
\text { indicating that the affordances may be less able to be substituted with affordances } \\
\text { from other provisions. } \\
\text { The types of affordances realised did not seem to be related to the direction of the } \\
\text { goal orientation changes. }\end{array}$ \\
\hline $\begin{array}{l}\text { Deliberate to } \\
\text { emergent } \\
\text { continuum }\end{array}$ & $\begin{array}{l}\text { There was some clustering of the affordances of provisions, and this occurred with } \\
\text { provisions } \mathrm{E}, \mathrm{H} \text { and } \mathrm{I} \text {. } \\
\text { All the affordances came from a narrow range of provisions (just } \mathrm{E}, \mathrm{H} \text { and } \mathrm{I} \text { ) } \\
\text { indicating that, like the goal orientation changes, the affordances may be less able to } \\
\text { be substituted with affordances from other provisions. } \\
\text { The affordances influenced changes in both directions on this continuum. }\end{array}$ \\
\hline Planning continuum & $\begin{array}{l}\text { There was some clustering of the affordances of provisions, and this occurred with } \\
\text { provisions E, H, I and U. } \\
\text { Most of the affordances came from a narrow range of provisions, but the range was } \\
\text { slightly broader than for the goal orientation and the deliberate to emergent } \\
\text { continuum. This may indicate that the affordances of some provisions could be } \\
\text { substituted for others. } \\
\text { Like the deliberate to emergent continuum the affordances influenced changes in } \\
\text { both directions. }\end{array}$ \\
\hline $\begin{array}{l}\text { Partnership status } \\
\text { changes continuum }\end{array}$ & $\begin{array}{l}\text { There was a large degree of clustering of affordances of provisions (frequently K } \\
\text { with either J, O or R), this influence from mutiple sources potentially reflected the } \\
\text { core nature of the changes. } \\
\text { The affordances of influence came from a wide range of provisions, which } \\
\text { potentially means that the affordances from some provisions can more easily be } \\
\text { substituted with affordances from other provisions. }\end{array}$ \\
\hline $\begin{array}{l}\text { Product scope } \\
\text { changes continuum }\end{array}$ & $\begin{array}{l}\text { Like the partnership status changes there was a large degree of clustering of } \\
\text { affordances of provisions (frequently E with F, H, I, O or S), and again, this } \\
\text { influence from mutiple sources potentially reflected the core nature of the changes. } \\
\text { The affordances of influence came from a moderately wide range of provisions, } \\
\text { indicating that the affordances from some provisions may be able to be substituted } \\
\text { with affordances from other provisions. }\end{array}$ \\
\hline $\begin{array}{l}\text { Competitive } \\
\text { emphasis changes } \\
\text { continuum }\end{array}$ & $\begin{array}{l}\text { Like the goal orientation changes there was little clustering of affordances of } \\
\text { provisions, with single affordances being sufficient to influence the firms' goals in } \\
\text { most cases. This influence from mainly single sources potentially reflected the } \\
\text { peripheral nature of the changes. } \\
\text { Like the partnership status changes, there was a wide range of provisions of } \\
\text { influence on this continuum, indicating that the affordances from some provisions } \\
\text { may be able to be substituted with affordances from other provisions. }\end{array}$ \\
\hline $\begin{array}{l}\text { Time allocation } \\
\text { changes continuum }\end{array}$ & $\begin{array}{l}\text { Similar to the competitive emphasis changes there was little clustering of } \\
\text { affordances of provisions, potentially reflected the peripheral nature of the changes. } \\
\text { The affordances came from a range of provisions (C, E, H and S) which had wide } \\
\text { scope of influence, potentially reflecting a greater degree of substitutability. }\end{array}$ \\
\hline
\end{tabular}




\subsection{Chapter summary}

The question that Chapter Five addressed was: How and why do the incubators' affordances influence strategy development? The affordances of the incubators' provisions influenced the firms' strategy developments in various ways. The affordances that were of greatest influence came from the internal-intangible category of provisions and these provisions generally had a wide scope of affordances.

Interestingly, the goal and process orientations were almost exclusively influenced by the internal-intangible provisions. With respect to the process orientation how firms changed on the deliberate to emergent continuum differed depending on the firms' product type and how the firms changed along the planning continuum differed depending on the incubator that the firms were in. These differences between the types of firms and incubators will be analysed further in Chapters Six and Seven respectively.

The provisions of strategy methodologies (E) and assistance with market validation and development $(\mathrm{H})$ were the dominant source of influence, perhaps reflecting the wider scope of influence of the affordances and their reduced potential to be substituted with affordances from other provisions. The influence of these provisions was often in the form of giving the firms the structure and tools to uncover and test new opportunities, thus obtaining the information required to inform their strategic decisions. By contrast, other provisions appeared to be able to be more readily substituted. On the partnership status and the competitive emphasis continuums a range of different provisions appeared to have similar affordances and simialr strategy developments that were influenced as a result.

On the content orientation continuums the degree of clustering of affordances of provisions appeared to reflect the degree to which the changes impacted the core or periphery of the firms. For example, affordances from multiple provisions tended to influence changes that were considered to be core, perhaps indicating the relative importance of these changes, and subsequently the need for a wider scope of influence. The affordances that influenced the content orientation were frequently in the form of assisting the firms with specific tasks and with connections to people or organisations that the firms otherwise might not have been able to connect to. The product scope continuum had the highest level of change of all the strategy development dimensions. The direction in which the product scope changed appeared to depend on the type of product the firm produced and these differences between firms will be analysed further in Chapter Six. 


\section{Findings and analysis - Firm-specific factors}

\subsection{Chapter introduction}

In Chapter Five it was found that some firm-specific factors appeared to be related to how they developed their strategies on the content orientation. These factors included a firm's product type (whether physical or information-technology) and governance structure. It was apparent that how the firms' strategies developed and the affordances of influence was important.

This chapter addresses the sub-question: 'How may the firm-specific factors be related to the provisions' influence on strategy development?' In Chapter Six a variety of firm-specific factors are explored to establish if there are any other factors that could be related to how the affordances of the incubators' provisions influenced strategy development. The focus of Chapter Six is highlighted in Figure 10.

The first part of the analysis is an overview of the firm-specific factors using tables to show how the factors compare to the firms' overall usage rate of provisions and to the number of strategy developments that the firms' made due to the incubators' influence. The purpose is to identify any patterns worthy of further exploration. The second part of the analysis in this chapter is a more in-depth exploration of these patterns, paying attention to the rates of awareness and usage of provisions, and to the type of strategy developments made. The purpose is to gain an in-depth understanding of the nature of the affordances that were influential and how these related to the firm-specific factors.

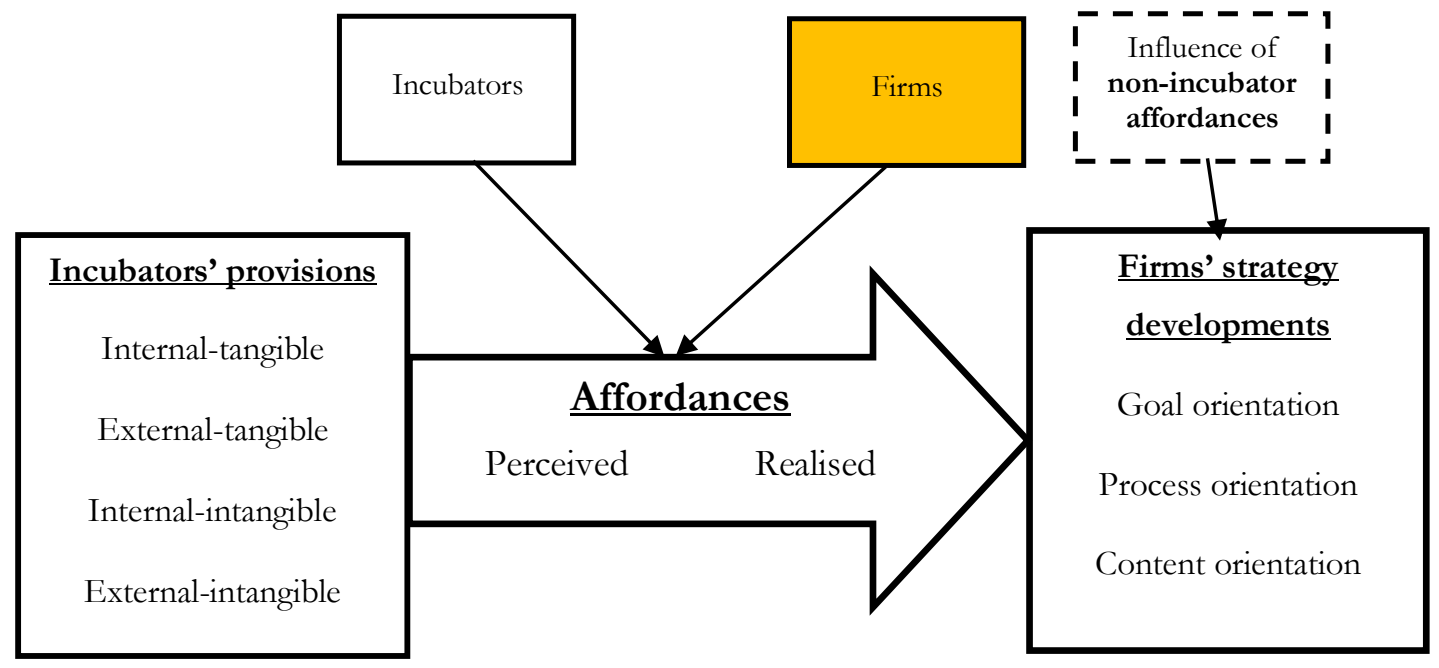

Figure 10. The conceptual model with the focus of Chapter Six highlighted. (Adapted from Figure 3). 


\subsection{Analysis of patterns in the firm-specific factors}

During the data collection process a number of distinguishing characteristics of the firms were observed. These factors were the firms' stage of development and age and on entry into the incubator; the type of product they produced; the location of their head office; the governance and investment structure; the background of the interview participant; the firms' duration in the incubator; and the number of employees. Also included were factors affecting the firms' relationship with the incubators, namely their level of interaction with the incubator advisor, and with other firms in the incubator.

The data is presented in two tables: Tables 23 and 24. In Table 23 the firms are ordered according to the number of provisions that they had used; in Table 24 the firms are ordered according to the number of strategy developments they made due to the incubators' influence. Provision awareness and use, and strategy developments are analysed separately as firms that use more provisions may not correspondingly make more strategy developments. The purpose of these two tables is to identify if there are any patterns in the data.

Table 22

Key to Characteristics of Firms

\begin{tabular}{|c|c|c|c|c|c|c|c|c|c|c|}
\hline 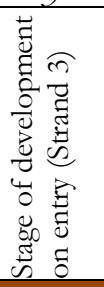 & 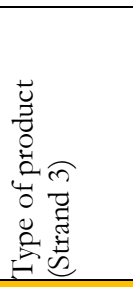 & 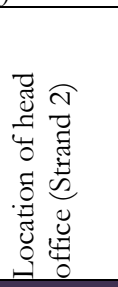 & 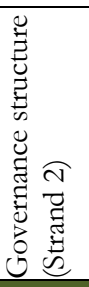 & 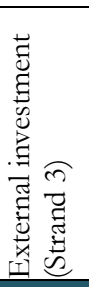 & 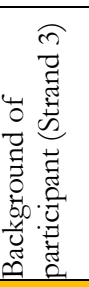 & 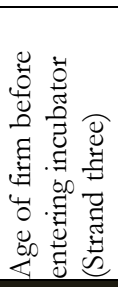 & 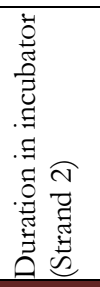 & 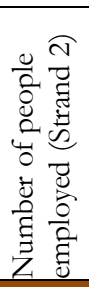 & 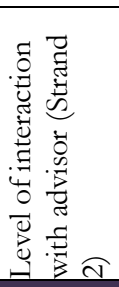 & 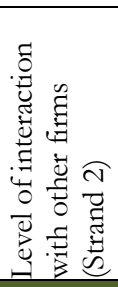 \\
\hline 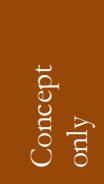 & 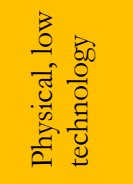 & 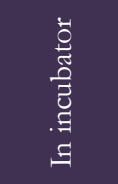 & 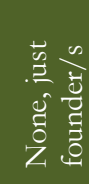 & $\begin{array}{l}\tilde{g} \\
\overline{0} \\
z\end{array}$ & 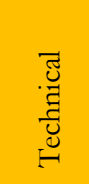 & 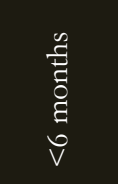 & 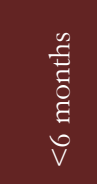 & - & 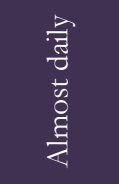 & 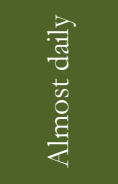 \\
\hline 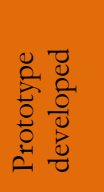 & 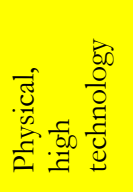 & 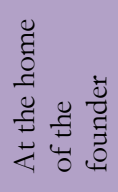 & 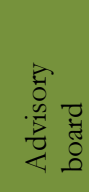 & 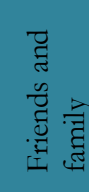 & 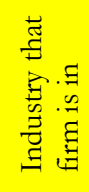 & 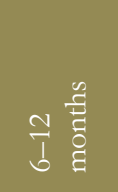 & 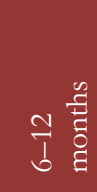 & $\underset{d}{J}$ & 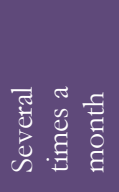 & 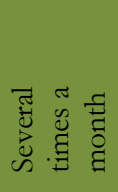 \\
\hline 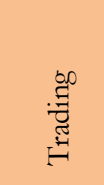 & 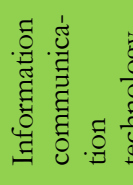 & 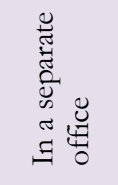 & 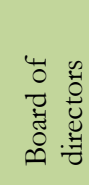 & 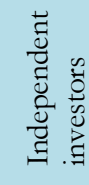 & 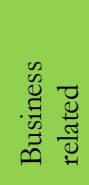 & 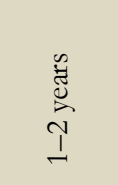 & 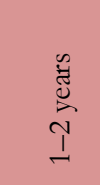 & $\stackrel{+}{i n}$ & 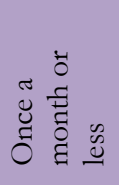 & 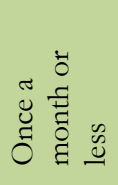 \\
\hline 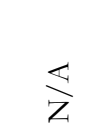 & $\frac{\overleftrightarrow{Z}}{\mathrm{Z}}$ & 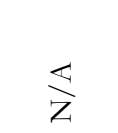 & $\frac{\varangle}{z}$ & $\frac{\varangle}{Z}$ & $\begin{array}{l}\ddot{\breve{J}} \\
\stackrel{\tilde{0}}{0}\end{array}$ & 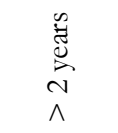 & 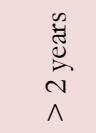 & 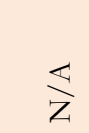 & $\begin{array}{l}\vec{\Delta} \\
\bar{\Delta} \\
\bar{Z}\end{array}$ & 峞 \\
\hline
\end{tabular}


Table 22 shows how the data for each factor were grouped. Some of the data were categorical, for example, the location of the firms' head office was either in the incubator, at the home of the founder, or in a separate office. Other factors which were analysed consisted of interval data, for example, duration in the incubator. Table 22 is the key and it shows how these types of groupings are represented as either distinct colours or gradations of colours to illustrate the measures within each category. This approach enabled easy visual identification of the extent to which the factor occurred. 


\subsubsection{Firms ordered by provision-usage rates}

Table 23

Characteristics of Firms' Ordered by Number of Provisions Used (Note. The firms that used provisions the most are at the top of the table.)

\begin{tabular}{|c|c|c|c|c|c|c|c|c|c|c|c|c|}
\hline 䛼 & $\begin{array}{l}\text { Number of } \\
\text { provisions } \\
\text { used by firm }\end{array}$ & $\begin{array}{l}\text { Stage of } \\
\text { development } \\
\text { on entry }\end{array}$ & $\begin{array}{l}\text { Type of } \\
\text { product }\end{array}$ & $\begin{array}{l}\text { Location of } \\
\text { head office }\end{array}$ & $\begin{array}{l}\text { Governance } \\
\text { structure }\end{array}$ & $\begin{array}{l}\text { External } \\
\text { investment }\end{array}$ & $\begin{array}{l}\text { Background } \\
\text { of } \\
\text { participant }\end{array}$ & $\begin{array}{l}\text { Age of firm } \\
\text { before } \\
\text { entering } \\
\text { incubator }\end{array}$ & $\begin{array}{l}\text { Duration in } \\
\text { incubator }\end{array}$ & $\begin{array}{l}\text { Number of } \\
\text { people } \\
\text { employed }\end{array}$ & $\begin{array}{l}\text { Level of } \\
\text { interaction } \\
\text { with advisor }\end{array}$ & $\begin{array}{l}\text { Level of } \\
\text { interaction } \\
\text { with other } \\
\text { firms }\end{array}$ \\
\hline $26 \mathrm{~F}$ & 20 & & & & & & & & & & & \\
\hline $28 \mathrm{E}$ & 19 & & & & & & & & & & & \\
\hline $16 \mathrm{C}$ & 18 & & & & & & & & & & & \\
\hline $6 \mathrm{C}$ & 17 & & & & & & & & & & & \\
\hline 19D & 17 & & & & & & & & & & & \\
\hline $30 \mathrm{C}$ & 17 & & & & & & & & & & & \\
\hline $25 \mathrm{E}$ & 16 & & & & & & & & & & & \\
\hline $33 \mathrm{~A}$ & 16 & & & & & & & & & & & \\
\hline $23 \mathrm{E}$ & 16 & & & & & & & & & & & \\
\hline $22 \mathrm{D}$ & 16 & & & & & & & & & & & \\
\hline $18 \mathrm{C}$ & 16 & & & & & & & & & & & \\
\hline $4 \mathrm{~B}$ & 16 & & & & & & & & & & & \\
\hline $21 \mathrm{C}$ & 15 & & & & & & & & & & & \\
\hline $14 \mathrm{D}$ & 14 & & & & & & & & & & & \\
\hline $10 \mathrm{C}$ & 13 & & & & & & & & & & & \\
\hline $13 \mathrm{E}$ & 13 & & & & & & & & & & & \\
\hline 1B & 12 & & & & & & & & & & & \\
\hline $20 \mathrm{E}$ & 12 & & & & & & & & & & & \\
\hline $7 \mathrm{D}$ & 10 & & & & & & & & & & & \\
\hline $2 \mathrm{~F}$ & 10 & & & & & & & & & & & \\
\hline $8 \mathrm{D}$ & 10 & & & & & & & & & & & \\
\hline $12 \mathrm{D}$ & 9 & & & & & & & & & & & \\
\hline $3 \mathrm{~F}$ & 9 & & & & & & & & & & & \\
\hline 11D & 9 & & & & & & & & & & & \\
\hline $32 \mathrm{~A}$ & 9 & & & & & & & & & & & \\
\hline $5 \mathrm{D}$ & 9 & & & & & & & & & & & \\
\hline $27 \mathrm{~F}$ & 8 & & & & & & & & & & & \\
\hline $29 \mathrm{~B}$ & 8 & & & & & & & & & & & \\
\hline $9 \mathrm{~A}$ & 8 & & & & & & & & & & & \\
\hline $15 \mathrm{~A}$ & 7 & & & & & & & & & & & \\
\hline $24 \mathrm{~B}$ & 7 & & & & & & & & & & & \\
\hline 31D & 4 & & & & & & & & & & & \\
\hline $17 \mathrm{D}$ & 2 & & & & & & & & & & & \\
\hline
\end{tabular}


The purpose of Table 23 is to establish whether the firm-specific factors are related to the firms' usage levels of provisions.

Some minor patterns were noticed based on the colour gradations and these served as triggers for the need to do further analysis on certain firm-specific factors. Firms that had external governance and external investment used slightly more provisions as evident in the lighter colour being more apparent at the top. No relationships were observed between the number of people employed in the firms, the stage of development on entry into the incubator, or the background of the interview participants, and the number of provisions used. It could have been expected that interview participants that were from a business, as opposed to a technical or industry background, would have used fewer incubator provisions because of their prior knowledge and experience, but this did not appear to be the case.

Firms that were older on entry into the incubator, that had spent longer in the incubator, and that had greater levels of interaction with their advisors and with other firms, used slightly more provisions. However some of these relationships could be expected, as they relate to proximity and duration, that is, the more time you spend, and the physically closer you are to something, the more likely you may be to interact with it. No patterns were apparent when comparing the type of product with the provision usage rates, but firms with low-technology products (LTFs) appeared to have lower usage rates of provisions. This may be because the four firms in question had all been in their respective incubators for only about four months. There appeared to be no notable relationship between a firm's development stage on entry and the number of provisions used.

In summary, several patterns were apparent when comparing the firm-specific factors and the usage rates of provisions. Notably the governance and investment structure of the firm, and the duration-related factors (firms' age before entry and duration in incubator) appeared to be somewhat related to higher usage rates of provisions.

\subsubsection{Firms ordered by number of strategy developments}

In Table 24 the firms are ordered according to the levels of strategy development that were influenced by the incubator, with the firms with the highest number of instances at the top. Like the analysis of the usage of provisions in Table 23, some interesting patterns were apparent when analysing the firm-specific factors. 
Firms with information-technology related products (ITFs) underwent noticeably more strategy developments that were influenced by incubators than firms with high-technology products (HTFs). However, as explained earlier, there were no notable differences in provision usage for these two groups, apart from the ITFs having a higher number provisions that they only knew about and had not used.

Firms that were older on entry into the incubator and that had been in it for a longer time underwent slightly more strategy developments, a similar result to the usage of provisions, as discussed earlier. However the firms' stage of development on entry did not appear to be related to their level of strategy development. Firms that had both an external governance structure and external investment appeared slightly less likely to undergo strategy developments as a consequence of incubator influence.

Minor patterns were observed regarding the number of strategy developments and the number of people employed and the background of the interview participant. The participants whose backgrounds were from specific industries, that is, not from a technical or business background, appeared to undergo marginally higher levels of strategy developments. The location of the head office did not seem to have any bearing on the number of strategy developments occurring as a result of the incubators' influence. However firms which had their head offices in the incubator used a greater number of provisions. A possible reason for this anomaly is that firms which have head offices outside of the incubator may use provisions in a more considered manner, and avoid using provisions just because they are more readily accessible due to their closer proximity. Firms that interacted with their incubator advisor once a month or less had marginally fewer strategy developments.

Similar to the provision usage rates, patterns were apparent when analysing the firm-specific factors and the number of strategy developments that were made due to the incubators' influence. These were most apparent in the type of product and, to a lesser extent, the duration that the firm had been in the incubator and their governance structure. 
Table 24

Characteristics of Firms Ordered by the Number of Strategy Developments Made (Note. The firms that made the most strategy developments are at the top of the table.)

\begin{tabular}{|c|c|c|c|c|c|c|c|c|c|c|c|c|}
\hline Firm & $\begin{array}{l}\text { Number of } \\
\text { provisions } \\
\text { used by firm }\end{array}$ & $\begin{array}{l}\text { Stage of } \\
\text { development } \\
\text { on entry }\end{array}$ & $\begin{array}{l}\text { Type of } \\
\text { product }\end{array}$ & $\begin{array}{l}\text { Location of } \\
\text { head office }\end{array}$ & $\begin{array}{l}\text { Governance } \\
\text { structure }\end{array}$ & $\begin{array}{l}\text { External } \\
\text { investment }\end{array}$ & $\begin{array}{l}\text { Background } \\
\text { of participant }\end{array}$ & $\begin{array}{l}\text { Age of firm } \\
\text { before } \\
\text { entering inc. }\end{array}$ & $\begin{array}{l}\text { Duration in } \\
\text { incubator }\end{array}$ & $\begin{array}{l}\text { Number of } \\
\text { people } \\
\text { employed }\end{array}$ & $\begin{array}{l}\text { Level of } \\
\text { interaction } \\
\text { with advisor }\end{array}$ & $\begin{array}{l}\text { Firms' level of } \\
\text { interaction } \\
\text { with others }\end{array}$ \\
\hline $13 \mathrm{E}$ & 7 & & & & & & & & & & & \\
\hline $10 \mathrm{C}$ & 6 & & & & & & & & & & & \\
\hline $4 \mathrm{~B}$ & 6 & & & & & & & & & & & \\
\hline $6 \mathrm{C}$ & 5 & & & & & & & & & & & \\
\hline $16 \mathrm{C}$ & 5 & & & & & & & & & & & \\
\hline $8 \mathrm{D}$ & 5 & & & & & & & & & & & \\
\hline $7 \mathrm{D}$ & 5 & & & & & & & & & & & \\
\hline $15 \mathrm{~A}$ & 4 & & & & & & & & & & & \\
\hline $17 \mathrm{D}$ & 4 & & & & & & & & & & & \\
\hline $18 \mathrm{C}$ & 4 & & & & & & & & & & & \\
\hline $30 \mathrm{C}$ & 4 & & & & & & & & & & & \\
\hline $31 \mathrm{D}$ & 4 & & & & & & & & & & & \\
\hline $22 \mathrm{D}$ & 4 & & & & & & & & & & & \\
\hline $2 \mathrm{~F}$ & 4 & & & & & & & & & & & \\
\hline 11D & 4 & & & & & & & & & & & \\
\hline 1B & 3 & & & & & & & & & & & \\
\hline 29B & 3 & & & & & & & & & & & \\
\hline $23 \mathrm{E}$ & 3 & & & & & & & & & & & \\
\hline $26 \mathrm{~F}$ & 3 & & & & & & & & & & & \\
\hline $9 \mathrm{~A}$ & 2 & & & & & & & & & & & \\
\hline $33 \mathrm{~A}$ & 2 & & & & & & & & & & & \\
\hline $20 \mathrm{E}$ & 2 & & & & & & & & & & & \\
\hline $32 \mathrm{~A}$ & 2 & & & & & & & & & & & \\
\hline $24 \mathrm{~B}$ & 2 & & & & & & & & & & & \\
\hline $21 \mathrm{C}$ & 2 & & & & & & & & & & & \\
\hline 14D & 2 & & & & & & & & & & & \\
\hline 19D & 2 & & & & & & & & & & & \\
\hline $28 \mathrm{E}$ & 2 & & & & & & & & & & & \\
\hline $12 \mathrm{D}$ & 2 & & & & & & & & & & & \\
\hline $5 \mathrm{D}$ & 2 & & & & & & & & & & & \\
\hline $25 \mathrm{E}$ & 1 & & & & & & & & & & & \\
\hline $27 \mathrm{~F}$ & 1 & & & & & & & . & & & & \\
\hline $3 \mathrm{~F}$ & 1 & & & & & & & & & & & \\
\hline
\end{tabular}

141: Findings and analysis - Firm-specific factors 


\subsection{Relationships to explore further}

From the discussion above, it appears evident that some factors stand out as worthy of further exploration. The most notable patterns relate to the firms' product type, governance and investment structure, and duration-related factors. Interestingly, it appeared that ITFs and firms with no external governance (NGFs) or investment underwent the greatest number of strategy developments without corresponding increases in the number of provisions used. These two factors are analysed first, followed by the duration-related factors. Other firm-specific factors are also examined more closely to see if they are related to the incubators' influence on strategy development. A decision was made to analyse just the firms' external governance structure as opposed to external investment as well, because almost all the firms with external governance structure also had external investment and, as discussed later, the investor board members appeared to have the same degree of influence as the non-investor board members.

Table 25

Key to the Provision Codes

\begin{tabular}{|l|}
\hline Provision codes \\
\hline Internal-tangible provisions \\
\hline Firm's head office located in incubator $(\mathrm{A})$ \\
\hline Use meeting rooms in incubator $(\mathrm{B})$ \\
\hline Funding for firms by incubator $(\mathrm{C})$ \\
\hline Internal-intangible provisions \\
\hline General business administration tasks $(\mathrm{D})$ \\
\hline Strategy methodologies $(\mathrm{E})$ \\
\hline Product validation and development $(\mathrm{F})$ \\
\hline Pitching development and practice $(\mathrm{G})$ \\
\hline Market validation and development $(\mathrm{H})$ \\
\hline Financial planning and management $(\mathrm{I})$ \\
\hline Growth management $(\mathrm{J})$ \\
\hline Developing a board of directors or advisors $(\mathrm{K})$ \\
\hline Developing a team of people $(\mathrm{L})$ \\
\hline Educational workshops $(\mathrm{M})$ \\
\hline External-tangible provisions \\
\hline Government grants $(\mathrm{N})$ \\
\hline Angel investors or venture capitalists $(\mathrm{O})$ \\
\hline External-intangible provisions \\
\hline Professional services (P) \\
\hline Subject matter experts $(\mathrm{Q})$ \\
\hline Potential board members $(\mathrm{R})$ \\
\hline Potential major customers (S) \\
\hline Universities and other tertiary institutions (T) \\
\hline Business mentors from outside of incubator (U) \\
\hline Interns from tertiary institutions (V) \\
\hline
\end{tabular}


The analysis for the main firm-specific factors identified above starts with heat maps showing the provision usage and awareness for each firm, categorised into groups within these factors. The purpose is to identify any notable differences in the way that the different groups of firms used, or were aware of, the provisions. This is followed by an exploration of if and how the strategy developments varied between these groups. An analysis of each strategic development dimension was conducted; however, in the interests of conciseness and relevance, only those instances where differences were most apparent are displayed. A complete set of comparison tables are in Appendix G.

\subsubsection{Type of product}

There are differences in the awareness and usage of the provisions between the product types, as shown in the heat maps in Tables 27 to 29. The firms in the tables are grouped according to the incubators that they are in. Few of the ITFs knew about funding from within the incubator $(\mathrm{C})$ and, similarly, very few knew about the provision of assistance with general business administration tasks (D). There appears to be a difference in the extent to which the affordances of the provisions are only ever perceived and not realised according to the firms' product type. The ITFs and the LTFs had a higher rate of awareness of provisions without any usage, whereas the HTFs had lower awareness rates overall, but higher usage. The usage rates for the LTFs appeared to be lower than for the HTFs and the ITFs. Again, this could be explained by the relative newness of the LTFs.

Table 26

Key for the Provision Awareness and Usage Tables

\begin{tabular}{|l|l|}
\hline Provision used & \\
\hline Provision known about, but not used & \\
\hline Provision not known about & \\
\hline
\end{tabular}

Note: Key applies to Tables 27-29 
Table 27

Provision Awareness and Usage by ITFs (17 firms)

\begin{tabular}{|c|c|c|c|c|c|c|c|c|c|c|c|c|c|c|c|c|c|c|c|c|c|c|}
\hline$\overbrace{\text { Firm }}^{\text {Provision }}$ & $\mathrm{A}$ & B & C & $\mathrm{D}$ & $\mathrm{E}$ & $\mathrm{F}$ & $\mathrm{G}$ & $\overline{\mathrm{H}}$ & $\mathrm{I}$ & $\mathrm{J}$ & $\mathrm{K}$ & $\mathrm{L}$ & $\mathrm{M}$ & $\mathrm{N}$ & $\mathrm{O}$ & $\mathrm{P}$ & Q & $\mathrm{R}$ & S & T & $\mathrm{U}$ & $\bar{V}$ \\
\hline $15 \mathrm{~A}$ & & & & & & & & & & & & & & & & & & & & & & \\
\hline & & & & & & & & & & & & & & & & & & & & & & \\
\hline 1B & & & & & & & & & & & & & & & & & & & & & & \\
\hline $4 \mathrm{~B}$ & & & & & & & & & & & & & & & & & & & & & & \\
\hline $29 \mathrm{~B}$ & & & & & & & & & & & & & & & & & & & & & & \\
\hline & & & & & & & & & & & & & & & & & & & & & & \\
\hline $6 \mathrm{C}$ & & & & & & & & & & & & & & & & & & & & & & \\
\hline $10 \mathrm{C}$ & & & & & & & & & & & & & & & & & & & & & & \\
\hline $16 \mathrm{C}$ & & & & & & & & & & & & & & & & & & & & & & \\
\hline $18 \mathrm{C}$ & & & & & & & & & & & & & & & & & & & & & & \\
\hline $21 \mathrm{C}$ & & & & & & & & & & & & & & & & & & & & & & \\
\hline $30 \mathrm{C}$ & & & & & & & & & & & & & & & & & & & & & & \\
\hline & & & & & & & & & & & & & & & & & & & & & & \\
\hline 7D & & & & & & & & & & & & & & & & & & & & & & \\
\hline 11D & & & & & & & & & & & & & & & & & & & & & & \\
\hline $12 \mathrm{D}$ & & & & & & & & & & & & & & & & & & & & & & \\
\hline 14D & & & & & & & & & & & & & & & & & & & & & & \\
\hline 17D & & & & & & & & & & & & & & & & & & & & & & \\
\hline $22 \mathrm{D}$ & & & & & & & & & & & & & & & & & & & & & & \\
\hline & & & & & & & & & & & & & & & & & & & & & & \\
\hline $3 \mathrm{~F}$ & & & & & & & & & & & & & & & & & & & & & & \\
\hline$\%$ usage & f & 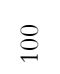 & 0 & $\stackrel{\infty}{\sim}$ & a & 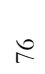 & $\infty$ & \pm & กิ & in & f & in & $\stackrel{2}{2}$ & in & in & f & in & f & f & $\stackrel{\text { a }}{\mathrm{N}}$ & f & in \\
\hline
\end{tabular}

Table 28

Provision Awareness and Usage by HTFs (12 firms)

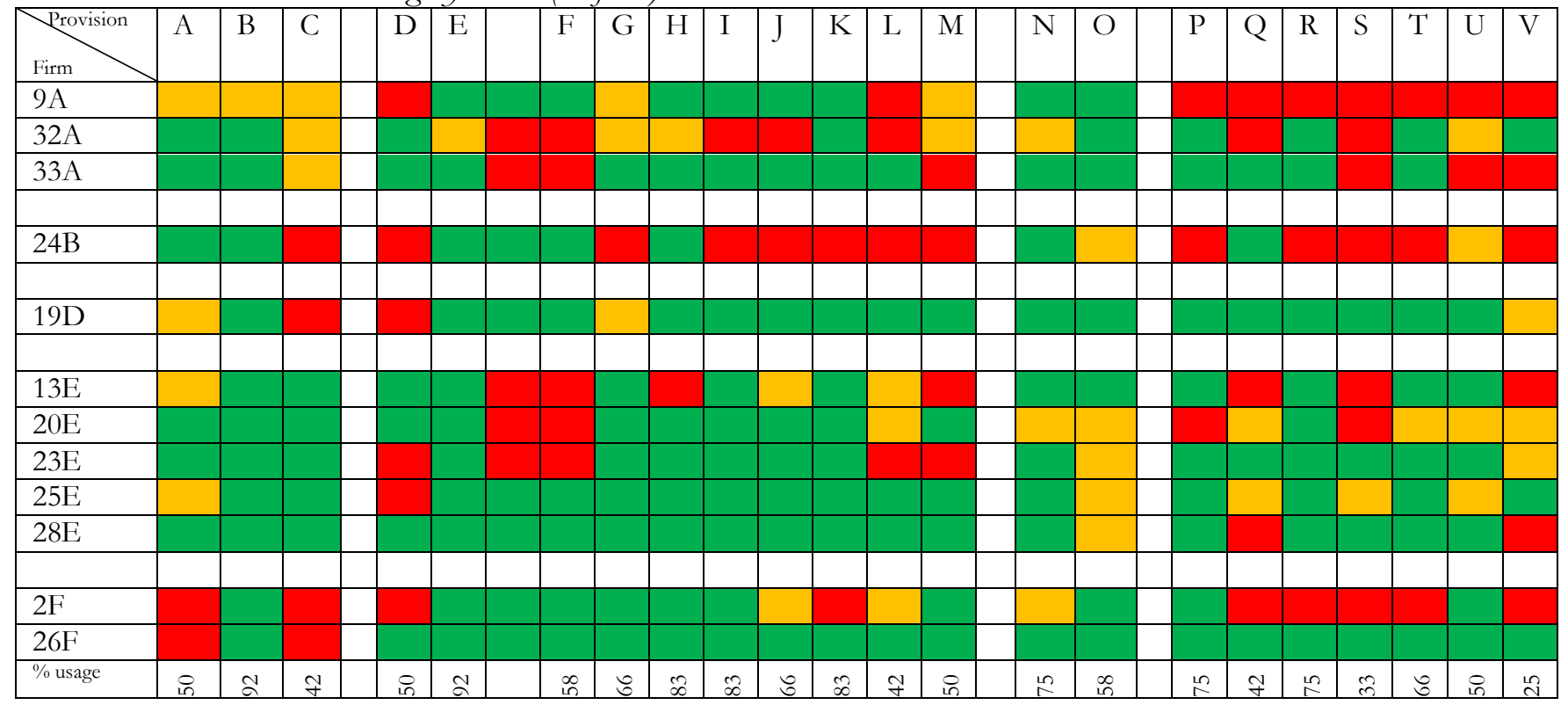


Table 29

Provision Awareness and Usage by LTFs

\begin{tabular}{|c|c|c|c|c|c|c|c|c|c|c|c|c|c|c|c|c|c|c|c|c|c|c|}
\hline$\overbrace{\text { Firm }}^{\text {Provision }}$ & A & B & C & $\mathrm{D}$ & $\mathrm{E}$ & $\bar{F}$ & G & $\mathrm{H}$ & I & $\mathrm{J}$ & $\bar{K}$ & $\mathrm{~L}$ & $\mathrm{M}$ & $\mathrm{N}$ & $\mathrm{O}$ & $\mathrm{P}$ & Q & $\mathrm{R}$ & $\mathrm{S}$ & $\overline{\mathrm{T}}$ & $\overline{\mathrm{U}}$ & V \\
\hline $5 \mathrm{D}$ & & & & & & & & & & & & & & & & & & & & & & \\
\hline $8 \mathrm{D}$ & & & & & & & & & & & & & & & & & & & & & & \\
\hline $31 \mathrm{D}$ & & & & & & & & & & & & & & & & & & & & & & \\
\hline & & & & & & & & & & & & & & & & & & & & & & \\
\hline $27 \mathrm{~F}$ & & & & & & & & & & & & & & & & & & & & & & \\
\hline \% usage & & in & & ng & 8 & n & in & 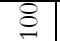 & $\therefore$ & 0 & & 0 & in & in & 0 & in & $n$ & & $\stackrel{2}{1}$ & 18 & $\stackrel{n}{2}$ & \\
\hline
\end{tabular}

\subsubsection{The firms' product type and the goal orientation}

The firms' product type appeared to be related to the strategy developments made due to the incubators' influence on the goal and process orientations, and on the product scope and competitive emphasis continuums in the content orientation. The goals of ITFs tended to increase (as circled), whereas for the physical product-based firms, which are the HTFs and LTFs, the goals tended to get more precise or to decrease (as circled in Table 30).

Table 30

Goal Orientation Changes According to Firms' Product Type

\begin{tabular}{|c|c|c|c|}
\hline Type of change along continuum & ITF (17 firms) & HTF (12 firms) & LTF (4 firms) \\
\hline Goals increased & $\begin{array}{l}1 \mathrm{~B}(\mathrm{E}), 6 \mathrm{C}(\mathrm{E}), 7 \mathrm{D}(\mathrm{H}), 15 \mathrm{~A} \\
(\mathrm{E}, \mathrm{I}), 18 \mathrm{C}(\mathrm{E}), 29 \mathrm{~B}(\mathrm{E})\end{array}$ & $23 \mathrm{E}(\mathrm{E})$ & $8 \mathrm{D}(\mathrm{E}, \mathrm{J})$ \\
\hline Goals more precise & $17 \mathrm{D}(\mathrm{H})$ & $\begin{array}{l}\text { 19D (H), 13E } \\
(\mathrm{E}), 26 \mathrm{~F}(\mathrm{I})\end{array}$ & $5 \mathrm{D}(\mathrm{E}), 31 \mathrm{D}(\mathrm{E})$ \\
\hline Goals decreased & $10 \mathrm{C}(\mathrm{E})$ & $24 \mathrm{~B}(\mathrm{H})$ & \\
\hline $\begin{array}{l}\text { Number of firms with no change attributable } \\
\text { due to incubator influence (percentage of } \\
\text { firms in group) }\end{array}$ & $9(53 \%)$ & $7(58 \%)$ & $1(25 \%)$ \\
\hline
\end{tabular}

The affordances from the provisions that influenced the goal orientation changes for the HTFs tended to relate to specific strategy development tools as opposed to more general advice. For example, firm $13 \mathrm{E}$ had a technologically advanced product and the goals became more precise due to the planning process enforced by the incubator. The affordances realised by the ITFs were frequently quite broad and mainly related to having the firms' strategic decisions challenged. This was indeed the case for firm 18C which, as a consequence of being challenged, switched their goals from local to global.

Overall, the HTFs tended to make less drastic goal orientation changes than the ITFs. These changes tended to be influenced by affordances from similar provisions that were related to help with specific functions and were well defined, as opposed to being influenced by, broader and more general advice.

\subsubsection{The firms' product type and the deliberate to emergent continuum}

The firms' product type also appeared to be related to the changes on the deliberate to emergent continuum. Notably, all the physical product-based firms (HTFs and LTFs) that 
changed went from emergent to deliberate, and the all the ITFs that changed went from deliberate to emergent (as circled in Table 31). This may imply that product-based firms start off in the more emergent phase and then confirm their strategies during incubation. This is explored further in Chapter Eight. The types of affordances realised by the product-based firms typically related to providing structure and clarity. Firm 8D reflected this in that they initially sold a range of products with little regard to which ones were actually profitable and then narrowed their focus after realising the affordances from the incubator's provisions of financial planning and clarification of their strategy.

Table 31

Deliberate to Emergent Continuum Changes According to Firms' Product Type

\begin{tabular}{|l|l|l|l|}
\hline Type of change along continuum & HTF (12 firms) & LTF (4 firms) & ITF (17 firms) \\
\hline & $\begin{array}{l}2 \mathrm{~F}(\mathrm{E}), 13 \mathrm{E}(\mathrm{E}, \mathrm{H}), \\
26 \mathrm{~F}(\mathrm{E})\end{array}$ & $8 \mathrm{D}(\mathrm{E}, \mathrm{I})$ & \\
\hline Emergent to deliberate & & & $\begin{array}{c}4 \mathrm{~B}(\mathrm{H}), 10 \mathrm{C}(\mathrm{E}), 16 \mathrm{C} \\
(\mathrm{E}), 22 \mathrm{D}(\mathrm{E}, \mathrm{H}), 30 \mathrm{C} \\
(\mathrm{H}, \mathrm{I})\end{array}$ \\
\hline $\begin{array}{l}\text { Number of firms with no change } \\
\text { attributable due to incubator influence } \\
\text { (percentage of firms in group) }\end{array}$ & $9(75 \%)$ & $3(75 \%)$ & \begin{tabular}{l}
$12(71 \%)$ \\
\hline
\end{tabular} \\
\hline
\end{tabular}

\subsubsection{The firms' product type and the planning continuum}

The firms' product type appeared to have a marked relationship with the types of changes firms made on the planning continuum. Only two HTFs changed their approach to planning due to the incubators' influence. The level of change for the ITFs was much higher. The affordances of influence were similar for all firms that changed, and tended to be more focussed on the tools for strategy development and on the provision of help with financial planning and management (I). It is notable in Table 32 that many firms in Incubator D increased their planning, whereas firms in Incubator $C$ reduced their planning. These differences will be analysed further in Chapter Seven.

Table 32

Planning Continumm Changes According to Firms'Product Type

\begin{tabular}{|c|c|c|c|}
\hline $\begin{array}{l}\text { Type of change along } \\
\text { continuum }\end{array}$ & HTF (12 firms) & LTF (4 firms) & ITF (17 firms) \\
\hline Planning increased & $2 \mathrm{~F}(\mathrm{E} \mathrm{I})$ & $5 \mathrm{D}(\mathrm{E}), 31 \mathrm{D}(\mathrm{E})$ & $\begin{array}{l}\text { (E, I), 22D (E, H) } \\
(\mathrm{E}), 15 \mathrm{X}\end{array}$ \\
\hline $\begin{array}{l}\text { Planning became more precise or } \\
\text { purposeful }\end{array}$ & $13 \mathrm{E}(\mathrm{I})$ & & $10 \mathrm{C}(\mathrm{E}, \mathrm{H}, \mathrm{U})$ \\
\hline Planning decreased & & & $\begin{array}{l}\text { 4B (E, H), 6C (E), } \\
16 \mathrm{C}(\mathrm{E}), 30 \mathrm{C}(\mathrm{E}, \mathrm{H})\end{array}$ \\
\hline $\begin{array}{l}\text { Number of firms with no change } \\
\text { attributable due to incubator } \\
\text { influence (percentage of firms in } \\
\text { group) }\end{array}$ & $(10(83 \%)$ & $2(50 \%)$ & $8(47 \%)$ \\
\hline
\end{tabular}




\subsubsection{The firms' product type and the product scope continuum}

The level of product scope changes was very high across all firms; however, once more there appeared to be interesting differences in the direction of change in the HTFs and ITFs (as circled in Table 33). The HTFs' products mainly just evolved, which frequently followed the realisation of affordances that related to practical functions such as connections to reference customers, strategy development tools, and assistance with the product validation process as opposed to having their strategic decisions challenged, which was a common affordance from the provision of strategy methodologies (E) for ITFs. Firm 33A was fairly typical of many of the HTFs in that they were at the early stages of trialling their products with customers. They had to revise the product following the initial prototypes proving to be too large and cumbersome for the customers. In this instance the incubator assisted with this trial process by working through the product development process with the firm. None of the HTFs radically changed their product scope.

Most of the HTFs that changed were in incubator $\mathrm{E}$ and most of the ITFs were in incubator C and D. These differences will be explored further in Chapter Seven.

Table 33

Product Scope Changes According to Firms' Product Type

\begin{tabular}{|c|c|c|c|}
\hline $\begin{array}{l}\text { Type of change along } \\
\text { continuum }\end{array}$ & HTF (12 firms) & $\begin{array}{l}\text { LTF (4 } \\
\text { firms) }\end{array}$ & ITF (17 firms) \\
\hline Product scope increased (core) & $\begin{array}{l}20 \mathrm{E}(\mathrm{E}), 23 \mathrm{E}(\mathrm{E}), 28 \mathrm{E}(\mathrm{E}, \\
\mathrm{F})\end{array}$ & $8 \mathrm{D}(\mathrm{E})$ & $17 \mathrm{D}(\mathrm{E}, \mathrm{H})$ \\
\hline Product more scalable (middle) & & & $\begin{array}{l}\text { 4B (E), 3F (F), 6C (F), 10C (E, } \\
\text { S), 21C (F, H), 29B (E) }\end{array}$ \\
\hline Product evolved (middle) & $\begin{array}{l}\text { 2F (S), 9A (H), 13E }(\mathrm{H}), \\
33 \mathrm{~A}(\mathrm{~F}), 25 \mathrm{E}(\mathrm{F}, \mathrm{H})\end{array}$ & & $\begin{array}{l}\text { 1B (E, H), 7D (H), 11D (E, H), } \\
14 \mathrm{D}(\mathrm{E}), 15 \mathrm{~A}(\mathrm{H}), 22 \mathrm{D}(\mathrm{E}, \mathrm{H})\end{array}$ \\
\hline Product was different (core) & & $31 \mathrm{D}(\mathrm{E}$, & $\begin{array}{l}16 \mathrm{C}(\mathrm{E}), 18 \mathrm{C}(\mathrm{E}, \mathrm{O}), 30 \mathrm{C}(\mathrm{E}, \mathrm{I}, \\
\mathrm{S})\end{array}$ \\
\hline Product scope decreased (core) & $\begin{array}{l}19 \mathrm{D}(\mathrm{E}), 27 \mathrm{~F}(\mathrm{E}, \mathrm{H}, \mathrm{P} \\
\text { ceased firm) }\end{array}$ & & \\
\hline $\begin{array}{l}\text { Number of firms with no change } \\
\text { attributable due to incubator } \\
\text { influence (percentage of firms in } \\
\text { group) }\end{array}$ & $2(17 \%)$ & $2(50 \%)$ & $1(6 \%)$ \\
\hline
\end{tabular}

\subsubsection{The firms' product type and the competitive emphasis continuum}

The firms' product type also appeared to be related to changes on the competitive emphasis continuum. Notably, more ITFs underwent competitive emphasis changes than the HTFs (as circled in Table 34). The affordances that influenced the changes were generally related to the provisions of strategy methodologies $(\mathrm{E})$ and market validation $(\mathrm{H})$ for the HTFs, and were from a broader scope of provisions for the ITFs. 
Table 34

Competitive Emphasis Changes According to Firms' Product Type

\begin{tabular}{|c|c|c|c|}
\hline Type of change along continuum & HTF (12 firms) & LTF (4 firms) & ITE (17 firms) \\
\hline $\begin{array}{l}\text { Competitive emphasis increased } \\
\text { (periphery) }\end{array}$ & $13 \mathrm{E}(\mathrm{E})$ & & $\begin{array}{l}4 \mathrm{~B}(\mathrm{P}), 12 \mathrm{D}(\mathrm{E}), \\
15 \mathrm{~A}(\mathrm{E}), 16 \mathrm{C}(\mathrm{P}), \\
18 \mathrm{C}(\mathrm{E}), 21 \mathrm{C}(\mathrm{H}, \mathrm{Q}, \\
\mathrm{S}), 22 \mathrm{D}(\mathrm{H})\end{array}$ \\
\hline $\begin{array}{l}\text { Competitive emphasis refined } \\
\text { (periphery) }\end{array}$ & 23E (E), 24B (H) & $8 \mathrm{D}(\mathrm{E}), 31 \mathrm{D}(\mathrm{U})$ & $\begin{array}{l}7 \mathrm{D}(\mathrm{H}), 10 \mathrm{C}(\mathrm{E}) \\
\text { 11D (U), 17D (H), } \\
\text { 29B (E), 30C (E, I), } \\
\text { S) }\end{array}$ \\
\hline Market changed (middle) & 9A $(\mathrm{H}), 32 \mathrm{~A}(\mathrm{~T})$ & & $66(\mathrm{I})$ \\
\hline $\begin{array}{l}\text { Number of firms with no change } \\
\text { attributable due to incubator influence } \\
\text { (percentage of firms in group) }\end{array}$ & $7(58 \%)$ & $2(50 \%)$ & $3(18 \%)$ \\
\hline
\end{tabular}

In summary, the firms' product type appeared to be related to the extent to which affordances were perceived and realised, to the capacity that the firms had to be influenced by the incubator, and to the range of affordances from the same provisions resulting in different types of strategy developments, or opportunities for action.

\subsubsection{Governance structure}

The firms' governance structure also appeared to be related to the extent to which the firms were aware of and used the provisions as illustrated in Tables 35 and 36 . The firms are ordered according to the incubators that they are in.

This section may appear somewhat tautological due to its alignment with the analysis of changes on the firms' partnership status continuum in Section 5.3.3.1, which is, firms that had a governance structure almost always underwent partnership status changes. The degree of this alignment is demonstrated in Table 39. However, this section is deemed necessary as it analyses the data further - exploring how the firms' governance structure relates to the other strategy development continuums, beyond partnership status and with interesting findings.

Key for the Provision Awareness and Usage Tables (35.36)

\begin{tabular}{|l|l|}
\hline Provision used & \\
\hline Provision known about, but not used & \\
\hline Provision not known about & \\
\hline
\end{tabular}


Table 35

Provision Awareness and Usage by WGFs (14 firms)

\begin{tabular}{|c|c|c|c|c|c|c|c|c|c|c|c|c|c|c|c|c|c|c|c|c|c|c|}
\hline${ }_{\text {Firm }}^{\text {Provision }}$ & A & B & C & D & $\mathrm{E}$ & $\mathrm{F}$ & G & $\mathrm{H}$ & I & $\mathrm{J}$ & K & $\mathrm{L}$ & M & $\mathrm{N}$ & $\mathrm{O}$ & $\mathrm{P}$ & Q & $\mathrm{R}$ & S & $\mathrm{T}$ & $\mathrm{U}$ & $\mathrm{V}$ \\
\hline $32 \mathrm{~A}$ & & & & & & & & & & & & & & & & & & & & & & \\
\hline $33 \mathrm{~A}$ & & & & & & & & & & & & & & & & & & & & & & \\
\hline & & & & & & & & & & & & & & & & & & & & & & \\
\hline 1B & & & & & & & & & & & & & & & & & & & & & & \\
\hline $24 \mathrm{~B}$ & & & & & & & & & & & & & & & & & & & & & & \\
\hline $29 \mathrm{~B}$ & & & & & & & & & & & & & & & & & & & . & & & \\
\hline & & & & & & & & & & & & & & & & & & & & & & \\
\hline $18 \mathrm{C}$ & & & & & & & & & & & & & & & & & & & & & & \\
\hline & & & & & & & & & & & & & & & & & & & & & & \\
\hline $5 \mathrm{D}$ & & & & & & & & & & & & & & & & & & & & & & \\
\hline $7 \mathrm{D}$ & & & & & & & & & & & & & & & & & & & & & & \\
\hline 14D & & & & & & & & & & & & & & & & & & & & & & \\
\hline 19D & & & & & & & & & & & & & & & & & & & & & & \\
\hline & & & & & & & & & & & & & & & & & & & & & & \\
\hline $13 \mathrm{E}$ & & & & & & & & & & & & & & & & & & & & & & \\
\hline $20 \mathrm{E}$ & & & & & & & & & & & & & & & & & & & & & & \\
\hline $23 \mathrm{E}$ & & & & & & & & & & & & & & & & & & & & & & \\
\hline $28 \mathrm{E}$ & & & & & & & & & & & & & & & & & & & & & & \\
\hline \% usage & in & 8 & নे & q & 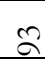 & in & t & $\infty$ & to & in & 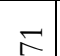 & ㄴ. & in & t & in & $\Gamma$ & in & tै & ते & 요 & 요 & बे \\
\hline
\end{tabular}

Table 36

Provision Awareness and Usage by NGFs (19 firms)

\begin{tabular}{|c|c|c|c|c|c|c|c|c|c|c|c|c|c|c|c|c|c|c|c|c|c|c|}
\hline$\overbrace{\text { Firm }}^{\text {Provision }}$ & A & B & C & $\mathrm{D}$ & $\mathrm{E}$ & $\mathrm{F}$ & G & $\mathrm{H}$ & I & $\mathrm{J}$ & $\mathrm{K}$ & $\mathrm{L}$ & $\mathrm{M}$ & $\mathrm{N}$ & $\mathrm{O}$ & $\mathrm{P}$ & Q & $\mathrm{R}$ & S & $\mathrm{T}$ & $\mathrm{U}$ & V \\
\hline $9 \mathrm{~A}$ & & & & & & & & & & & & & & & & & & & & & & \\
\hline $15 \mathrm{~A}$ & & & & & & & & & & & & & & & & & & & & & & \\
\hline & & & & & & & & & & & & & & & & & & & & & & \\
\hline $4 \mathrm{~B}$ & & & & & & & & & & & & & & & & & & & & & & \\
\hline & & & & & & & & & & & & & & & & & & & & & & \\
\hline $6 \mathrm{C}$ & & & & & & & & & & & & & & & & & & & & & & \\
\hline $10 \mathrm{C}$ & & & & & & & & & & & & & & & & & & & & & & \\
\hline $16 \mathrm{C}$ & & & & & & & & & & & & & & & & & & & & & & \\
\hline $21 \mathrm{C}$ & & & & & & & & & & & & & & & & & & & & & & \\
\hline $30 \mathrm{C}$ & & & & & & & & & & & & & & & & & & & & & & \\
\hline & & & & & & & & & & & & & & & & & & & & & & \\
\hline $8 \mathrm{D}$ & & & & & & & & & & & & & & & & & & & & & & \\
\hline 11D & & & & & & & & & & & & & & & & & & & & & & \\
\hline $12 \mathrm{D}$ & & & & & & & & & & & & & & & & & & & & & & \\
\hline 17D & & & & & & & & & & & & & & & & & & & & & & \\
\hline $22 \mathrm{D}$ & & & & & & & & & & & & & & & & & & & & & & \\
\hline $31 \mathrm{D}$ & & & & & & & & & & & & & & & & & & & & & & \\
\hline & & & & & & & & & & & & & & & & & & & & & & \\
\hline $25 \mathrm{E}$ & & & & & & & & & & & & & & & & & & & & & & \\
\hline $2 \mathrm{~F}$ & & & & & & & & & & & & & & & & & & & & & & \\
\hline $3 \mathrm{~F}$ & & & & & & & & & & & & & & & & & & & & & & \\
\hline $26 \mathrm{~F}$ & & & & & & & & & & & & & & & & & & & & & & \\
\hline $27 \mathrm{~F}$ & & & & & & & & & & & & & & & & & & & & & & \\
\hline$\%$ usage & $\approx$ & 2 & 0 & $\vec{\sim}$ & 吕 & $\curvearrowright$ & 2 & $\stackrel{n}{\Omega}$ & $\hat{6}$ & $\infty$ & ๆ & f & 运 & $\hat{3}$ & f & 天 & $\hat{n}$ & I & $\hat{n}$ & 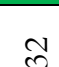 & ₹ & $\hat{y}$ \\
\hline
\end{tabular}


The WGFs had higher usage rates of the internal-tangible provisions, specifically having their head office in the incubator $(\mathrm{A})$ and having received funding from the incubator $(\mathrm{C})$. The WGFs seemed to be aware of fewer numbers of provisions, but the ratio of awareness to use was higher.

There also appeared to be a relationship between the firms' governance and the strategy developments made due to the influence of the incubator on the goal orientation, and to the deliberate to emergent and time allocation, continuums.

\subsubsection{The firms' governance structure and the deliberate to emergent continuum}

The firms' governance structure appeared to be related to changes along the deliberate to emergent continuum, with proportionally fewer WGFs undergoing changes (as circled in Table 37). The changes for all firms were mainly due to the affordances from provisions of strategy methodologies $(\mathrm{E})$ and market validation and development $(\mathrm{H})$ and were associated with providing structure and clarity, with strategy development tools and with market validation-related activities.

Table 37

Deliberate to emergent Continum Changes According to Firms' Governance Structure

\begin{tabular}{|c|c|c|}
\hline Type of change along continuum & WGF (14 firms) & NGF (19 firms) \\
\hline Emergent to deliberate & $13 \mathrm{E}(\mathrm{E}, \mathrm{H})$ & $2 \mathrm{~F}(\mathrm{E}), 8 \mathrm{D}(\mathrm{E}, \mathrm{I}), 26 \mathrm{~F}(\mathrm{E})$ \\
\hline Deliberate to emergent & 4B $(\mathrm{H}), 16 \mathrm{C}(\mathrm{E})$ & $\begin{array}{l}10 \mathrm{C}(\mathrm{E}), 22 \mathrm{D}(\mathrm{E}, \mathrm{H}), 30 \mathrm{C} \\
(\mathrm{H}, \mathrm{I})\end{array}$ \\
\hline $\begin{array}{l}\text { Number of firms with no change attributable due to } \\
\text { incubator influence (percentage of firms in group) }\end{array}$ & $11(79 \%)$ & $13(68 \%)$ \\
\hline
\end{tabular}

The notion that NGFs are potentially pre-investment and are experimenting with their strategies in order to find where the value lies was reflected in the experience by firm 22D. This firm entered the incubator with a very deliberate strategy, and was initially very fixed on it because it was where the founder's passion lay. However they ended up with a strategy that was quite emergent, saying, "If you have a strategy at the start it's never going to be that six months later ... it's been an evolving kind of strategy." This firm changed to a more emergent approach due to a need to find a profitable market, which could lead to getting investment.

\subsubsection{The firms' governance structure and planning continuum}

Interestingly, fewer WGFs made changes along the planning continuum, whereas the rate of change was higher for NGFs (as circled in Table 38). Again, most of the firms that made changes along this continuum were from incubators $\mathrm{C}$ and $\mathrm{D}$, suggesting that the differences 
in the incubators may account for the differences, as opposed to the investment structure.

These differences will be analysed further in Chapter Seven.

Table 38

Planning Continum Changes According to Firms' Governance Structure

\begin{tabular}{|l|l|l|}
\hline Type of change along continuum & WGF (14 firms) & NGF (19 firms) \\
\hline Planning increased & $5 \mathrm{D}(\mathrm{E}), 7 \mathrm{D}(\mathrm{E})$ & $\begin{array}{l}\text { 2F (E, I), 12D (E), 15A (E, I), } \\
\text { 22D (E, H), 31D (E) }\end{array}$ \\
\hline Planning became more precise or purposeful & $13 \mathrm{E}(\mathrm{I})$ & $10 \mathrm{C}(\mathrm{E}, \mathrm{H}, \mathrm{U})$ \\
\hline Planning decreased & $4 \mathrm{~B}(\mathrm{E}, \mathrm{H}), 16 \mathrm{C}(\mathrm{E})$ & $6 \mathrm{C}(\mathrm{E}), 30 \mathrm{C}(\mathrm{E}, \mathrm{H})$ \\
\hline $\begin{array}{l}\text { Number of firms with no change attributable } \\
\text { due to incubator influence (percentage of firms } \\
\text { in group) }\end{array}$ & $9(64 \%)$ & $11(58 \%)$ \\
\hline
\end{tabular}

The WGFs seemed to be more stable along the process orientation, that is, they made fewer changes along this orientation that were influenced by the incubator, or indeed by any other source.

\subsubsection{The firms'governance structure and the partnership status}

Table 39

Partnership Status Changes According to Firms' Governance Structure

\begin{tabular}{|l|l|l|}
\hline Type of change along continuum & WGF (14 firms) & NGF (19 firms) \\
\hline Shareholders increased (core) & $\begin{array}{l}1 \mathrm{~B}(\mathrm{I}), 4 \mathrm{~B}(\mathrm{~S}), 7 \mathrm{D}(\mathrm{I}), 13 \mathrm{E} \\
\mathrm{C}, \mathrm{K}), 16 \mathrm{C}(\mathrm{B}), 18 \mathrm{C}(\mathrm{K}, \\
\mathrm{O}), 20 \mathrm{E}(\mathrm{J}, \mathrm{K}), 33 \mathrm{~A}(\mathrm{E}, \mathrm{R})\end{array}$ & \\
\hline Governance increased (middle) & $32 \mathrm{~A}(\mathrm{~K}, \mathrm{R})$ & $6 \mathrm{C}(\mathrm{K}, \mathrm{R})$ \\
\hline $\begin{array}{l}\text { Number of firms with no change attributable } \\
\text { due to incubator influence (percentage of firms } \\
\text { in group) }\end{array}$ & $5(36 \%)$ & $18(95 \%)$ \\
\hline
\end{tabular}

Eleven of the 17 WGFs underwent changes to their partnership status since entering the incubator, with most coming from a situation of having no external shareholders or governance. The affordances of influence appeared similar across the two groups, with the focus of the incubator on providing connections to their networks and on assistance with helping firms get investment-ready.

Note that there is an almost complete overlap between this analysis and the analysis in Section 5.3.3.1 which explored how firms changed along the partnership status continuum. Table 39 shows the extent to which the WGFs and the NGFs changed their partnership status, with only one of the 16 NGFs changing along the partnership status continuum, the change of which did not actually encompass a change to the governance of the firm. 


\subsubsection{The firms'governance structure and time allocation}

The governance structure appeared to be marginally related to the level of influence that the incubator had on time allocation changes. Six NGFs changed along this continuum, while only two WGF firms changed. The most influential affordance for the NGFs was the challenging of strategic decisions (refer Table 70 in Appendix G). Again this suggests that the WGFs may be more stable, that is, they did not need to change the way they spent their time, or that how they spend their time is influenced by the firms' board of directors and not by the incubator.

In summary, the firms' governance structure appeared to be related to the extent to which affordances were perceived and realised, and to the capacity that the firms had to be influenced by the incubator, with substantial differences noted. The affordances of influence were often common to both groups of firms, with the exception of affordances on the deliberate to emergent continuum.

\subsubsection{Duration-related factors}

Perhaps unsurprisingly, the firms that had been in the incubator longer had used and were aware of more provisions, especially provisions in the external-intangible category. Firms that were older on entry into the incubator used slightly more provisions and underwent slightly more strategy developments.

The duration-related factors also appeared to be related to the provisions that the firms were aware of and used, and also to the strategy developments made due to the incubators' influence on the planning and the partnership status continuums.

\subsubsection{Provision awareness and usage and the firms' duration in the incubator}

What is interesting regarding the duration-related factors is that the level of usage for provisions was substantially greater for firms that had been in the incubator longer (see Tables 40 and 41). This may signal that different affordances are realised by firms at different stages. The external-intangible provisions all had noticeably more use by the firms that had been in the incubator longer, as well as the specific provisions of assistance with developing a board of directors or advisors $(\mathrm{K})$ and assistance with developing a team of people (L). The firms are grouped in the tables according to the incubator that they were in.

Key for the Provision Awareness and Usage Tables (40\&41)

\begin{tabular}{|l|l|}
\hline Provision used & \\
\hline Provision known about, but not used & \\
\hline Provision not known about & \\
\hline
\end{tabular}


Table 40

Provision Awareness and Usage by Firms Which Had Been in the Incubator Less Than One Year (16 firms)

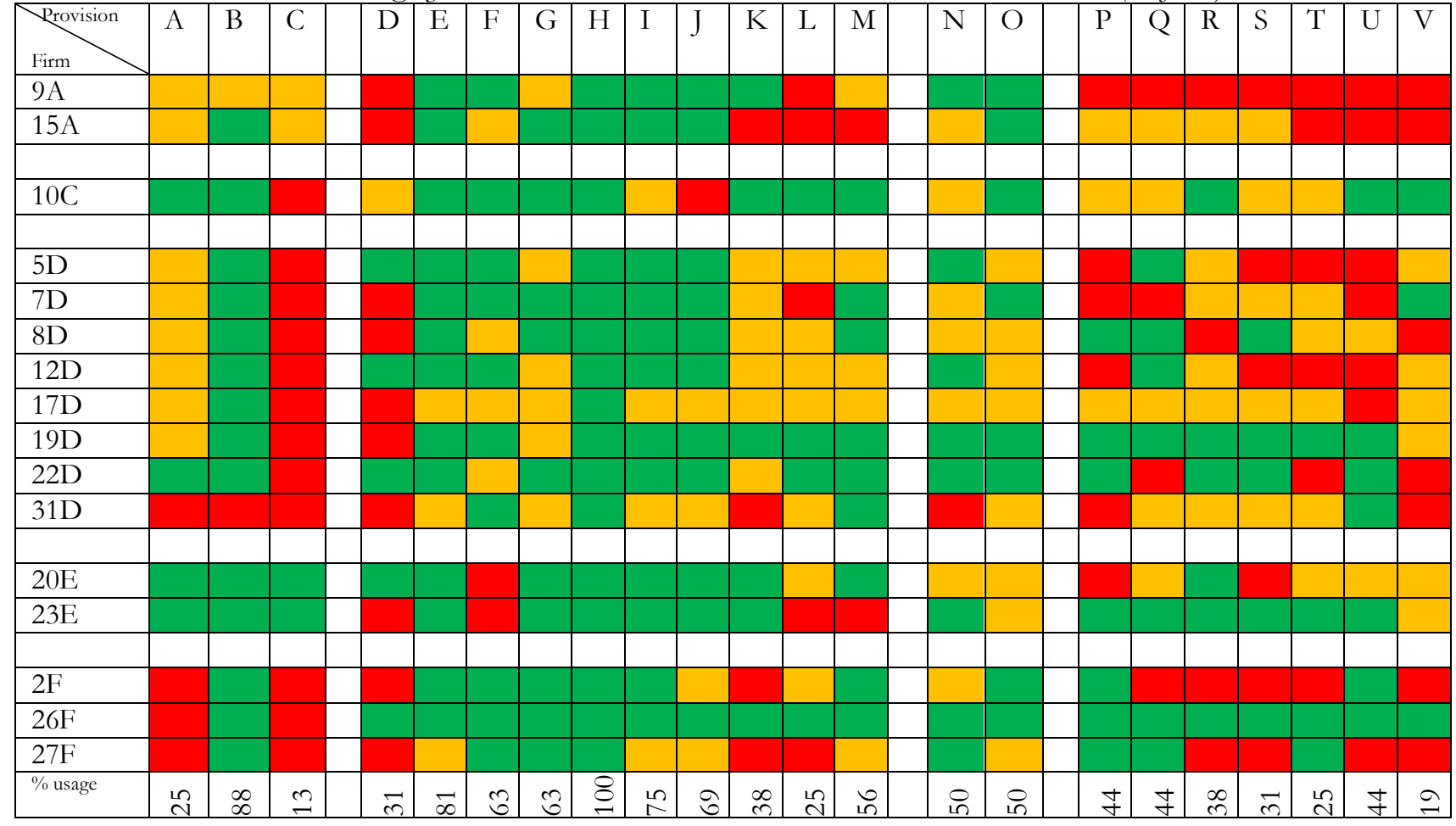

Table 41

Provision Awareness and Usage by Firms Which Had Been in the Incubator More Than One Year (17 firms)

\begin{tabular}{|c|c|c|c|c|c|c|c|c|c|c|c|c|c|c|c|c|c|c|c|c|c|c|}
\hline$\overbrace{\text { Firm }}^{\text {Provision }}$ & A & B & C & D & $\mathrm{E}$ & $\mathrm{F}$ & G & $\mathrm{H}$ & I & J & K & $\mathrm{L}$ & $\mathrm{M}$ & $\mathrm{N}$ & $\mathrm{O}$ & $\mathrm{P}$ & Q & $\mathrm{R}$ & S & $\mathrm{T}$ & $\mathrm{U}$ & V \\
\hline $32 \mathrm{~A}$ & & & & & & & & & & & & & & & & & & & & & & \\
\hline $33 \mathrm{~A}$ & & & & & & & & & & & & & & & & & & & & & & \\
\hline & & & & & & & & & & & & & & & & & & & & & & \\
\hline 1B & & & & & & & & & & & & & & & & & & & & & & \\
\hline $4 \mathrm{~B}$ & & & & & & & & & & & & & & & & & & & 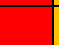 & 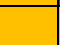 & 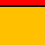 & \\
\hline $24 \mathrm{~B}$ & & & & & & & & & & & & & & & & & & & & 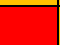 & & \\
\hline $29 \mathrm{~B}$ & & & & & & & & & & & & & & & & & & & 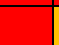 & 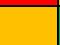 & & \\
\hline & & & & & & & & & & & & & & & & & & & & & & \\
\hline $6 \mathrm{C}$ & & & & & & & & & & & & & & & & & & & & & & \\
\hline $16 \mathrm{C}$ & & & & & & & & & & & & & & & & & & & & & & \\
\hline $18 \mathrm{C}$ & & & & & & & & & & & & & & & & & & & & & & \\
\hline $21 \mathrm{C}$ & & & & & & & & & & & & & & & & & & & 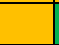 & & & \\
\hline $30 \mathrm{C}$ & & & & & & & & & & & & & & & & & & & . & 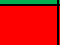 & & \\
\hline & & & & & & & & & & & & & & & & & & & & & & \\
\hline 11D & & & & & & & & & & & & & & & & & & & & & & \\
\hline 14D & & & & & & & & & & & & & & & 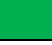 & 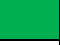 & & & & 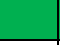 & 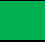 & \\
\hline & & & & & & & & & & & & & & & 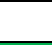 & & & 1 & & 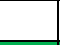 & & \\
\hline $13 \mathrm{E}$ & & & & & & & & & & & & & & & & & & & & 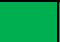 & & \\
\hline $25 \mathrm{E}$ & & & & & & & & & & & & & & & & & & & & & & \\
\hline $28 \mathrm{E}$ & & & & & & & & & & & & & & & & & & & & & & \\
\hline & & & & & & & & & & & & & & & & & & & 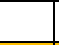 & & & \\
\hline $3 \mathrm{~F}$ & & & & & & & & & & & & & & & & & & & & & & \\
\hline$\%$ usage & in & 8 & $\infty$ & 2 & g & $\stackrel{0}{2}$ & 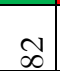 & $\infty$ & nn & 金 & $\Xi$ & in & $\Sigma$ & $\stackrel{0}{2}$ & F & $F$ & 요 & in & $m$ & n & f & in \\
\hline
\end{tabular}




\subsubsection{Provision awareness and usage and the firms' age on entry into the incubator}

The provision usage for the external-intangible provisions was greater for the firms that were older on entry into the incubator. However, the difference wasn't as pronounced as the firms' duration in the incubator, as analysed above. (Refer to Tables $42 \& 43$ ). Again, the firms are grouped according to the incubators that they were in.

Key for the Provision Awareness and Usage Tables (42\&43)

\begin{tabular}{|l|l|}
\hline Provision used \\
\hline Provision known about, but not used \\
\hline Provision not known about \\
\hline
\end{tabular}

Table 42

Provision Awareness and Usage by Firms Which Were Less Than One Year Old on Entry into the Incubator (19 firms)

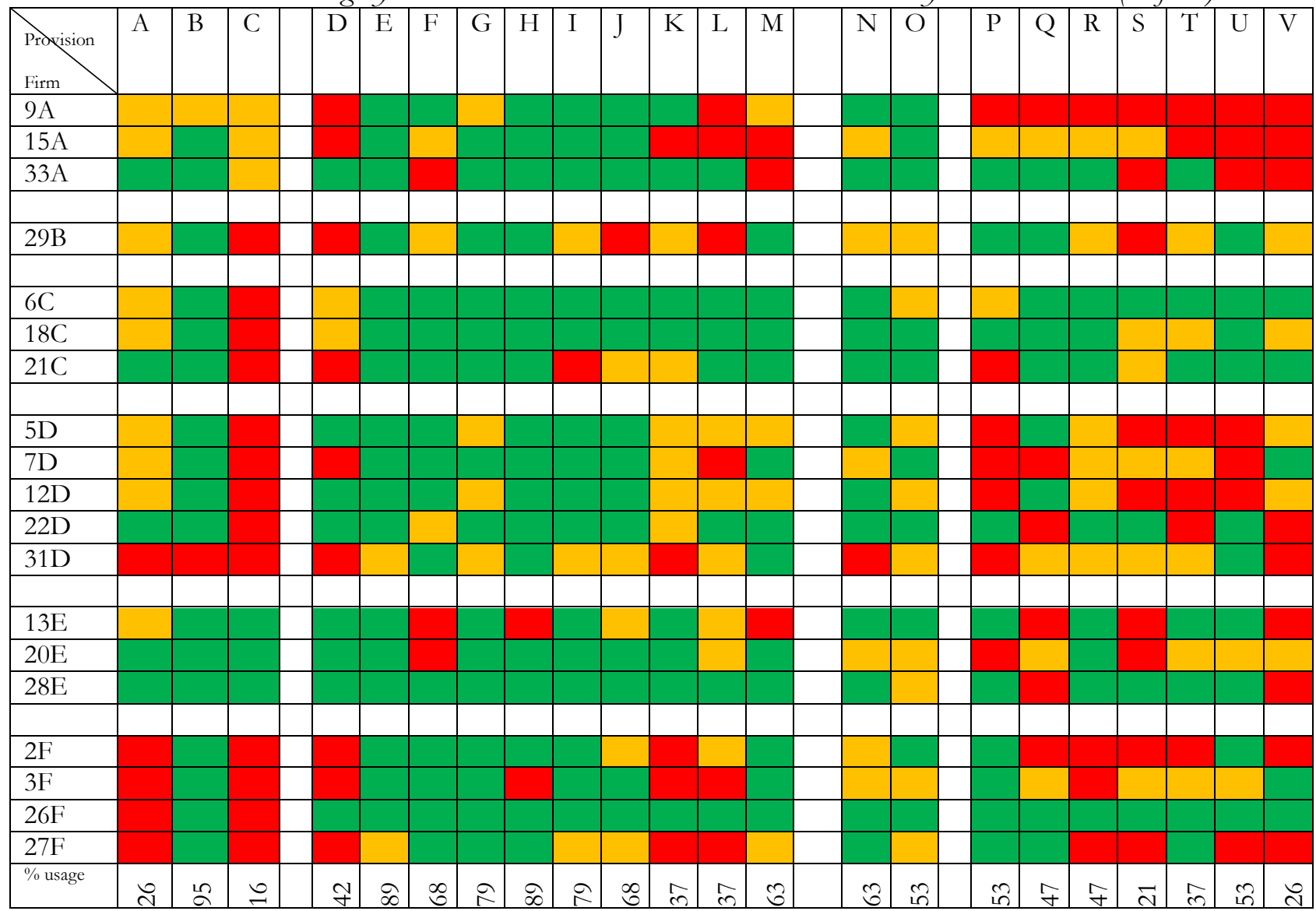


Table 43

Provision Awareness and Usage by Firms Which Were More Than One Year Old on Entry into the Incubator (14 firms)

\begin{tabular}{|c|c|c|c|c|c|c|c|c|c|c|c|c|c|c|c|c|c|c|c|c|c|c|}
\hline $\begin{array}{l}\text { Provision } \\
\text { Firm }\end{array}$ & A & B & $\mathrm{C}$ & $\mathrm{D}$ & $\mathrm{E}$ & $\mathrm{F}$ & $\mathrm{G}$ & $\mathrm{H}$ & I & $\mathrm{J}$ & $\mathrm{K}$ & $\mathrm{L}$ & $\mathrm{M}$ & $\mathrm{N}$ & $\mathrm{O}$ & $\mathrm{P}$ & Q & $\mathrm{R}$ & S & $\mathrm{T}$ & $\mathrm{U}$ & $\mathrm{V}$ \\
\hline $32 \mathrm{~A}$ & & & & & & & & & & & & & & & & & & & & & & \\
\hline & & & & & & & & & & & & & & & & & & & & & & \\
\hline $1 \mathrm{~B}$ & & & & & & & & & & & & & & & & & & & & & & \\
\hline $4 \mathrm{~B}$ & & & & & & & & & & & & & & & & & & & & & & \\
\hline $24 \mathrm{~B}$ & & & & & & & & & & & & & & & & & & & & & & \\
\hline & & & & & & & & & & & & & & & & & & & & & & \\
\hline $10 \mathrm{C}$ & & & & & & & & & & & & & & & & & & & & & & \\
\hline $16 \mathrm{C}$ & & & & & & & & & & & & & & & & & & & & & & \\
\hline $30 \mathrm{C}$ & & & & & & & & & & & & & & & & & & & & & & \\
\hline & & & & & & & & & & & & & & & & & & & & & & \\
\hline $8 \mathrm{D}$ & & & & & & & & & & & & & & & & & & & & & & \\
\hline 11D & & & & & & & & & & & & & & & & & & & & & & \\
\hline 14D & & & & & & & & & & & & & & & & & & & & & & \\
\hline 17D & & & & & & & & & & & & & & & & & & & & & & \\
\hline 19D & & & & & & & & & & & & & & & & & & & & & & \\
\hline & & & & & & & & & & & & & & & & & & & & & & \\
\hline $23 \mathrm{E}$ & & & & & & & & & & & & & & & & & & & & & & \\
\hline $25 \mathrm{E}$ & & & & & & & & & & & & & & & & & & & & & & \\
\hline \% usage & t & 8 & $\Xi$ & \pm & $\triangleright$ & 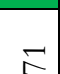 & t & $\approx$ & $\stackrel{q}{q}$ & $\dddot{q}$ & $\curvearrowright$ & in & tु & t & $\stackrel{f}{q}$ & t & t & ㅇ & in & $\dddot{q}$ & 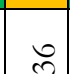 & \\
\hline
\end{tabular}

\subsubsection{Duration-related factors and the planning continuum}

The duration-related factors seemed to be related to both the number and direction of changes on the planning continuum (as circled in Table 44). Firms that had been in the incubator less than one year were the only firms to increase their level of planning and were commonly from incubator D. Firms that had been in more than one year were the only firms for which planning decreased and were commonly from incubator C. Similarly, firms which were younger on entry into the incubator were more likely to increase their planning (as circled in Table 45). This variance among the incubators is explored further in Chapter Seven. The affordances of influence were generally common across the two groups.

Table 44

Planning Continumm Changes According to Firms' Duration in Incubator

\begin{tabular}{|l|l|l|}
\hline Type of change along continuum & Less than one year (16-firms) & More than one year (17 firms) \\
\hline Planning increased & $\begin{array}{l}2 \mathrm{~F}(\mathrm{E}, \mathrm{I}), 5 \mathrm{D}(\mathrm{E}), 7 \mathrm{D}(\mathrm{E}), 12 \mathrm{D} \\
(\mathrm{E}), 15 \mathrm{~A}(\mathrm{E}, \mathrm{I}), 22 \mathrm{D}(\mathrm{E}, \mathrm{H}), \\
31 \mathrm{D}(\mathrm{E})\end{array}$ & \\
\hline $\begin{array}{l}\text { Planning became more precise or } \\
\text { purposeful }\end{array}$ & $10 \mathrm{C}(\mathrm{E}, \mathrm{H}, \mathrm{U})$ & $13 \mathrm{E}(\mathrm{I})$ \\
\hline Planning decreased & & $\begin{array}{l}4 \mathrm{~B}(\mathrm{E}, \mathrm{H}), 6 \mathrm{C}(\mathrm{E}), 16 \mathrm{C}(\mathrm{E}), 30 \mathrm{C} \\
(\mathrm{E}, \mathrm{H})\end{array}$ \\
\hline $\begin{array}{l}\text { Number of firms with no change } \\
\text { attributable due to incubator influence } \\
\text { (percentage of firms in group) }\end{array}$ & $8(50 \%)$ & $11(65 \%)$ \\
\hline
\end{tabular}


Table 45

Planning Continum Changes According to Firms' Duration of Existence before Entry into the Incubator

\begin{tabular}{|c|c|c|c|c|}
\hline Type of change along continuum & $\begin{array}{l}<6 \text { months } \\
\text { (10 firms) }\end{array}$ & $\begin{array}{l}\text { 6-12 months } \\
\text { (9 firms) }\end{array}$ & $\begin{array}{l}1-2 \text { years }(6 \\
\text { firms) }\end{array}$ & $\begin{array}{l}>2 \text { years }(8 \\
\text { firms) }\end{array}$ \\
\hline Planning increased & $\begin{array}{l}5 \mathrm{D}(\mathrm{E}), 31 \mathrm{D} \\
(\mathrm{E})\end{array}$ & $\begin{array}{l}2 \mathrm{~F}(\mathrm{E}, \mathrm{I}), 7 \mathrm{D} \\
(\mathrm{E}), 12 \mathrm{D}(\mathrm{E}) \\
15 \mathrm{~A}(\mathrm{E}, \mathrm{I}) \\
22 \mathrm{D}(\mathrm{E}, \mathrm{H})\end{array}$ & & \\
\hline $\begin{array}{l}\text { Planning became more precise or } \\
\text { purposeful }\end{array}$ & & $13 \mathrm{E}(\mathrm{I})$ & $10 \mathrm{C}(\mathrm{E}, \mathrm{H}, \mathrm{U})$ & \\
\hline Planning decreased & & $6 \mathrm{C}(\mathrm{E})$ & $30 \mathrm{C}(\mathrm{E}, \mathrm{H})$ & $\begin{array}{l}\text { 4B (E, H) } \\
16 \mathrm{C}(\mathrm{E})\end{array}$ \\
\hline $\begin{array}{l}\text { Number of firms with no change } \\
\text { attributable due to incubator influence } \\
\text { (percentage of firms in group) }\end{array}$ & $8(80 \%)$ & $2(22 \%)$ & $4(67 \%)$ & $6(75 \%)$ \\
\hline
\end{tabular}

\subsubsection{Duration-related factors and the partnership status continuum}

The changes to the partnership status were related to the duration that the firms had been in the incubator but not to the firms' age on entry into the incubator. This may suggest that the changes occur more frequently as firms mature.

Table 46

Partnership Status Changes According to Firms' Duration in Incubator

\begin{tabular}{|l|l|l|}
\hline Type of change along continuum & Less than one year (16 firms) & More than one year (17 firms) \\
\hline Shareholders increased (core) & $7 \mathrm{D}(\mathrm{I}), 20 \mathrm{E}(\mathrm{J}, \mathrm{K})$ & $\begin{array}{l}1 \mathrm{~B}(\mathrm{I}), 4 \mathrm{~B}(\mathrm{~S}), 13 \mathrm{E}(\mathrm{C}, \mathrm{K}), 16 \mathrm{C}(\mathrm{B}), \\
18 \mathrm{C}(\mathrm{K}, \mathrm{O}), 33 \mathrm{~A}(\mathrm{E}, \mathrm{R})\end{array}$ \\
\hline Governance increased (middle) & & $6 \mathrm{C}(\mathrm{K}, \mathrm{R}), 32 \mathrm{~A}(\mathrm{~K}, \mathrm{R})$ \\
\hline $\begin{array}{l}\text { Number of firms with no change } \\
\text { attributable due to incubator influence } \\
\text { (percentage of firms in group) }\end{array}$ & $14(88 \%)$ & $9(53 \%)$ \\
\hline
\end{tabular}

Interestingly, the affordances of the provisions that influenced changes for the newer firms all came from the internal provisions, whereas for the older firms the provisions were just as likely to come from the external provisions, although there were only two newer firms that changed on this continuum (refer Table 46).

\subsubsection{Duration-related factors and product type}

The firms' age at entry into the incubator appeared to be slightly related to the type of product that they produced. Table 47 compares these factors. It appears that the ITFs are slightly more likely to be older on entry, and the physical-product-based firms slightly younger. However there appeared to be no relationship between the firms' age on entry into the incubator and the types of product changes made. 
Table 47

Comparison of Age of Firm on Entry with Type of Product

\begin{tabular}{|l|l|l|l|l|}
\hline Type of product & $<\mathbf{6}$ months & $\mathbf{6 - 1 2}$ months & $\mathbf{1 - 2}$ years & $>\mathbf{2}$ years \\
\hline ITF & $9 \mathrm{~A}, 18 \mathrm{C}$ & $\begin{array}{l}3 \mathrm{~F}, 7 \mathrm{D}, 12 \mathrm{D}, \\
15 \mathrm{~A}, 22 \mathrm{D}, 29 \mathrm{~B}\end{array}$ & $\begin{array}{l}6 \mathrm{C}, 10 \mathrm{C}, 14 \mathrm{D}, \\
30 \mathrm{C}\end{array}$ & $\begin{array}{l}1 \mathrm{~B}, 4 \mathrm{~B}, 11 \mathrm{D}, \\
16 \mathrm{C}, 17 \mathrm{D}, 24 \mathrm{~B}\end{array}$ \\
\hline HTF & $\begin{array}{l}20 \mathrm{E}, 21 \mathrm{C}, 26 \mathrm{~F}, \\
28 \mathrm{E}, 33 \mathrm{~A}\end{array}$ & $2 \mathrm{~F}, 13 \mathrm{E}, 19 \mathrm{D}$ & $32 \mathrm{~A}$ & $25 \mathrm{E}$ \\
\hline LTF & $5 \mathrm{D}, 27 \mathrm{~F}, 31 \mathrm{D}$ & & $8 \mathrm{D}$ & \\
\hline
\end{tabular}

\subsubsection{Other firm-specific factors that were related to strategy developments}

There did not appear to be any relationship between the remaining firm-specific factors and the awareness of availability and usage of the provisions. Therefore, unlike the previous analysis, the provision summary tables are not included in the following analyses.

\subsubsection{Stage of development on entry into incubator}

The analysis in Section 6.3.3.2 explored the age of firms when they entered the incubator. It is considered also worthwhile to explore the extent to which it is related to the stage of development on entry. Table 48 presents a comparison between these two factors and shows that there is a slight trend towards firms that were at the concept-only stage being younger ( $<6$ months) on entry into the incubator. However it also shows that the firms that were older on entry ( $>1$ year) had little relationship to the stage of development. Therefore it is concluded that the stage of development on entry should be analysed separately to the firms' age on entry into the incubator.

Table 48

Comparison of Age of Firm on Entry into the Incubator with Stage of Development

\begin{tabular}{|l|l|l|l|}
\hline & \multicolumn{4}{|l|}{ Stage of development on entry } \\
\hline $\begin{array}{l}\text { Age of firm on entry into } \\
\text { incubator }\end{array}$ & Concept only & Prototype developed & Trading \\
\hline$<6$ months black & $5 \mathrm{D}, 18 \mathrm{C}, 20 \mathrm{E}, 26 \mathrm{~F}, 28 \mathrm{E}$ & $9 \mathrm{~A}, 21 \mathrm{C}, 27 \mathrm{~F}, 33 \mathrm{~A}$ & $31 \mathrm{D}$ \\
\hline $6-12$ months & 2F, 7D, 23E & $13 \mathrm{E}, 15 \mathrm{~A}, 22 \mathrm{D}$ & $3 \mathrm{~F}, 6 \mathrm{C}, 12 \mathrm{D}, 29 \mathrm{~B}$ \\
\hline $1-2$ years & $10 \mathrm{C}, 14 \mathrm{D}, 30 \mathrm{C}, 32 \mathrm{~A}$ & & $8 \mathrm{D}, 19 \mathrm{D}$ \\
\hline$>2$ years white & & $1 \mathrm{~B}, 11 \mathrm{D}, 24 \mathrm{~B}, 25 \mathrm{E}$ & $4 \mathrm{~B}, 16 \mathrm{C}$ \\
\hline
\end{tabular}

Whether firms took a more deliberate or emergent approach to strategy development due to the incubators' influence did not appear to be related to the firms' stage of development on entry into the incubator. It could have been expected that firms that were already trading, for example, would become more deliberate or not change at all, but this did not appear to be the case. Only a slight relationship was noted regarding the firms' stage of development on entry and the number of firms that changed their product scope, with slightly more of the less advanced firms increasing their product scope, and with slightly more firms that were 
already trading making their products more scalable or just evolving them. The firms' stage of development on entry did not appear to be related to changes in their partnership status, which is somewhat surprising, as it could be expected that firms that were at a more advanced stage would be more likely to be successful in gaining investment.

In summary, the duration that the firms had been in the incubator appeared to be related to the extent to which provisions were known about and used. The capacity to influence differed, resulting in different strategy developments. However, the scope of affordances of provisions that influenced the strategy developments were similar for changes to the planning continuum, but were more diverse for changes on the partnership status continuum.

\subsubsection{Background of the interview participant}

The background of the interview participants appeared to have little bearing on how the firms were aware of and used the provisions or on the firms' strategy development, with the exception of minor differences on the goal orientation and the product scope dimension.

The interview participants of the firms whose product scope increased were from technical backgrounds and the affordances of influence were mainly from the provisions of strategy methodologies (E) and market validation and development $(\mathrm{H})$ in the form of providing the firm with tools and helping them with specific functions. The firms with interview participants from business backgrounds did not increase their goals.

\subsubsection{Location of head office, number of people employed and interaction with advisor and other firms}

Interestingly few relationships were identified regarding the location of the firms' head office, the number of people employed in the firms, and the firms' level of interaction with their advisor and other firms. Firms with two or more employees were the only ones to change on the partnership status continuum. The firms that interacted more with their advisors and with other firms were more likely to change on the deliberate to emergent continuum. 


\subsection{Summary table}

Table 49

Summary of the Nature of the Affordances of the Provisions That Influenced Strategy Development

\begin{tabular}{|l|l|}
\hline Firm characteristics & Nature of affordances from provisions \\
\hline Type of product & $\begin{array}{l}\text { There were differences in the realisation rates of affordances with the ITFs } \\
\text { realising fewer affordances from the external provisions than the HTFs. } \\
\text { Similar affordances were realised from the same provisions and resulted in } \\
\text { different strategy developments on the deliberate to emergent, planning, } \\
\text { product scope and competitive emphasis continuums. }\end{array}$ \\
\hline Governance structure & $\begin{array}{l}\text { There were differences in the realisation rates of affordances with the WGFs } \\
\text { realising more affordances of provisions than the NGFs. } \\
\text { Similar affordances were realised from the same provisions resulting in } \\
\text { different strategy developments on the goal orientation and process } \\
\text { orientation, and on the partnership status continuum and time allocation } \\
\text { continuums. } \\
\text { The affordances from the same provisions varied in how they influenced } \\
\text { firms on the deliberate to emergent continuum. }\end{array}$ \\
\hline $\begin{array}{l}\text { Duration-related } \\
\text { factors }\end{array}$ & $\begin{array}{l}\text { There were differences in the realisation rates of affordances with the firms } \\
\text { that had been in the incubator longer realising affordances from the external } \\
\text { provisions more. } \\
\text { Similar affordances came from the same provisions resulting in different } \\
\text { strategy developments on the planning continuum. } \\
\text { The affordances from different provisions resulted in similar opportunities } \\
\text { for action on the partnership status continum. }\end{array}$ \\
\hline $\begin{array}{l}\text { Stage of development } \\
\text { on entry into incubator }\end{array}$ & $\begin{array}{l}\text { Similar affordances came from the same provisions resulting in different } \\
\text { strategy developments on the planning continuum. }\end{array}$ \\
\hline $\begin{array}{l}\text { Background of } \\
\text { interview participant }\end{array}$ & $\begin{array}{l}\text { Similar affordances came from the same provisions resulting in different } \\
\text { strategy developments on the product scope continuum. }\end{array}$ \\
\hline Location of head office & No substantial differences noted. \\
\hline $\begin{array}{l}\text { Number of people } \\
\text { employed }\end{array}$ & No substantial differences noted. \\
\hline $\begin{array}{l}\text { Level of interaction } \\
\text { with advisor }\end{array}$ & No substantial differences noted. \\
\hline
\end{tabular}

\subsection{Chapter summary}

The sub-question that Chapter Six addressed was: How may the firm-specific factors be related to the incubators' influence on strategic development?

It was found that the firm-specific factors were related to the extent to which the firms perceived and realised the affordances of provisions and to the scope of the influence that the affordances had on strategy development. Notable factors were the firms' product type, governance structure and the duration-related factors.

For the firms' product type it appeared that there were differences in perceptions and realisations of affordances, based on differences in provision awareness and usage. The WGFs and the HTFs appeared to have lower awareness of the provisions but the number of 
provisions used was higher. In addition, it appeared that the incubators' capacity to influence the firms differed, depending on the firms' product type. This was apparent in that the ITFs increased their goals to a much greater degree. In addition, the physical-product firms that changed became more deliberate, whereas the ITFs tended to become more emergent due to the influence of the incubator. The products of the ITFs became more scalable in a drive for efficiency, whereas the products for the HTFs tended to become more platform-based in a drive to increase their product scope. The ITFs were more likely to change their competitive emphasis. Overall, it appeared that the strategies of the ITFs are more likely to change than the HTFs.

For the firms' goverance structure differences were again seen in the provision awareness and usage. It also appeared that the incubators' ability to influence strategy development varied, and this was seen in that the types of affordances that influenced changes on the deliberate to emergent continuum were different for the WGFs and the NGFs. Similar affordances appeared to result in different directions of change along the goal orientation, process orientation, partnership status continuum and time allocation continuum. Overall, the NGFs made more changes than the WGFs along the planning, the deliberate to emergent continuum, the planning continuum, and along the time allocation continuum as a consequence of the influence of the incubator.

The age of the firm on entry into the incubator and the duration that the firms had been in the incubator also seemed to be related to the provision awareness and usage. Again, similar affordances resulted in different strategy developments and this was apparent on the planning continuum. Newer firms did more planning that was influenced by the incubator, and older firms less planning. The older firms used external provisions to a greater extent. The firms that were younger on entry into the incubator were less likely to increase their competitive emphasis. Interestingly, there appeared to be no relationship between the age of the firms on entry and the firms' product type.

Differences were also noticed with respect to the incubators that the firms were in and this will be analysed further in Chapter Seven. 


\section{Findings and analysis - Incubator-specific factors}

\subsection{Chapter introduction}

The analysis in Chapters Four, Five and Six found that there were differences in the provisions and their influence on the firms' strategy development, as well as differences in the characteristics of the firms in the incubators.

This chapter address the sub-question: 'How may the incubator-specific factors be related to the provisions' influence on strategy development?' It does this by investigating whether the differences in the firms' provision usage, and in the affordances that influence strategy development, may be explained, in part, by differences between the incubators. That is, do the firms behave the way they do because of the incubator that they are in? The analysis incorporates data from all three stands.

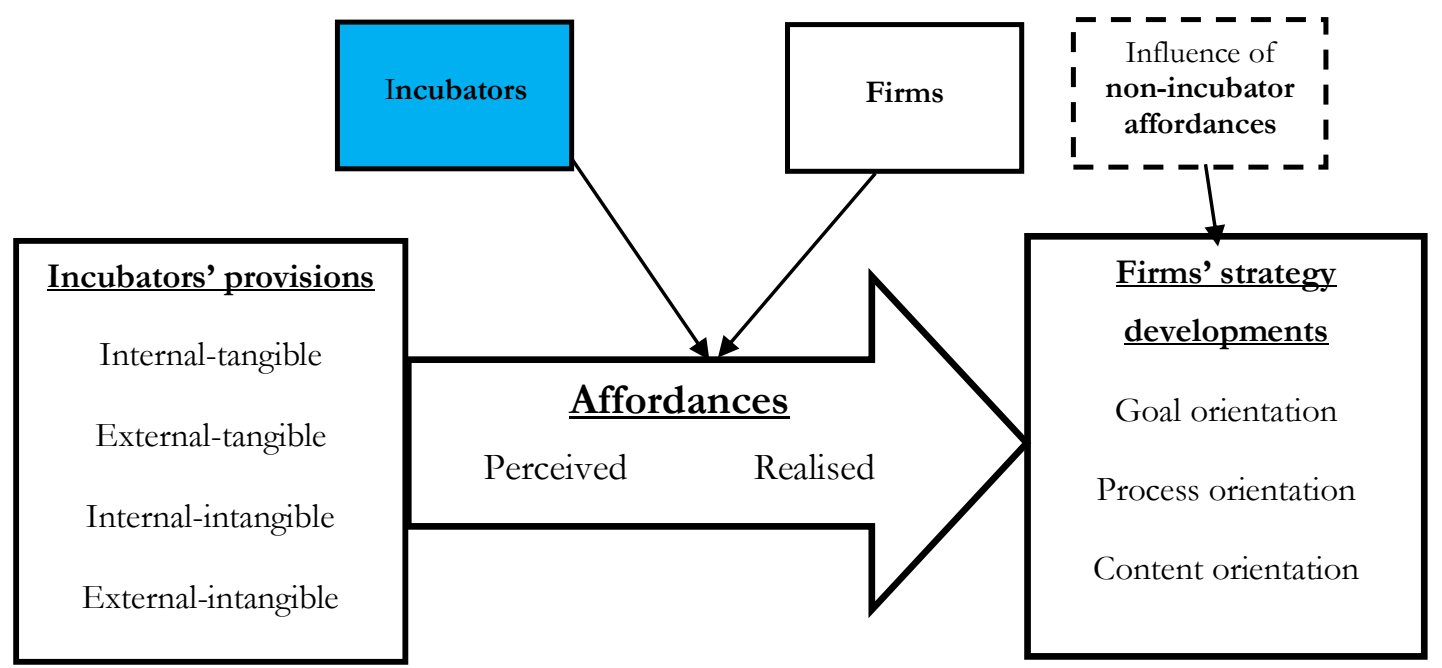

Figure 11. The conceptual model with the focus of Chapter Seven highlighted. (Adapted from Figure 3).

First an overview is presented of the distinguishing characteristics of the incubators based on data from the interviews with the incubator managers (Strand One). This data encompasses the incubators' selection criteria for new firms and the scope of the programmes that they offer. The incubators are consequently placed on a continuum according to the degree of their focus on just incubation or on a wider range of services to the business community. A summary is presented of the provisions that the incubators considered important and of the strategy developments that they emphasised; again, this is using data from Strand One. The purpose of this overview is to give context to the characteristics and behaviours of the individual incubators. Finally, the individual incubator's characteristics and the strategy 
developments they anticipated are triangulated with the firms' awareness of availability and usage of provisions, and with the strategy developments that occurred as a result. The purpose is to determine if there is an alignment between the firms and their respective incubators, and to disentangle any anomalies that are present, for example, why some incubators may expect that certain strategy developments would occur, whereas their firms do not develop their strategies in that way.

\subsection{Incubator-specific factors on a continuum}

The first step in exploring the differences in the incubators is to establish if and how the incubators differ. The distinguishing characteristics of the incubators were the size of the firms on entry into the incubator in terms of number of people; the stage of development of the product on entry into the incubator; whether the incubator sought substantial equity in the firm; and the focus of activities beyond just incubation, that is, if they provided only incubation-related services or if they offered other services to the business community. There appeared to be some commonalities between all these factors, for example, incubators that had a more defined focus also selected firms with sole proprietors, and that were at the prototype development stage. Incubators $\mathrm{A}$ and $\mathrm{E}$ were deemed to be narrow-focused incubators (NFIs). Incubators B, D and F were are deemed to be broad-focused incubators (BFIs), and incubator $\mathrm{C}$ was in the middle of the continuum. Table 50 provides a summary of these factors for each incubator.

Table 50

Summary of Incubator-specific Factors Ordered According to its Focus of Activities and Equity in Firms

\begin{tabular}{|c|c|c|c|c|}
\hline 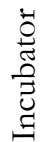 & Size of firms & $\begin{array}{l}\text { Stage of product } \\
\text { development }\end{array}$ & Equity in firms & $\begin{array}{l}\text { Focus of activities beyond } \\
\text { incubation }\end{array}$ \\
\hline $\mathrm{E}$ & Mainly individuals & $\begin{array}{l}\text { Prototype } \\
\text { developed }\end{array}$ & 50-70\% (very high) & Just incubation \\
\hline A & Mainly individuals & $\begin{array}{l}\text { Prototype } \\
\text { developed }\end{array}$ & $1-10 \%$ (medium) & $\begin{array}{l}\text { Incubation }+ \text { pre-incubation } \\
\text { programmes only }\end{array}$ \\
\hline $\mathrm{C}$ & Mainly individuals & Mixed & $1-10 \%$ (medium) & $\begin{array}{l}\text { Incubation }+ \text { pre-incubation } \\
\text { programmes only }\end{array}$ \\
\hline B & Mainly teams & Mixed & $1-10 \%$ (medium) & Wide variety of programmes \\
\hline $\mathrm{D}$ & $\begin{array}{l}\text { Mix of individuals } \\
\text { and teams }\end{array}$ & Mixed & 1-10\% (medium) & Wide variety of programmes \\
\hline $\mathrm{F}$ & $\begin{array}{l}\text { Mix of individuals } \\
\text { and teams }\end{array}$ & Mixed & None & Wide variety of programmes \\
\hline
\end{tabular}


Note. The Table 50 is ordered with the NFIs at top and the BFIs at the bottom.

\subsubsection{Overview of incubators' perceptions of provisions that are most important}

In Strand One of data collection the incubators were asked about the provisions that they regarded as being the most important for the development of the firms. Table 51 presents a summary of these views, which were analysed more fully in Chapter Five.

What is apparent is that all the incubators emphasised the importance of the provision of strategy methodologies (E), which is to be expected given that, according to the literature review, the role of incubators is to support and develop firms and this implies that strategy methodologies would potentially be used. No incubators specifically mentioned the provisions of connections to government grants $(\mathrm{N})$ or to potential major customers $(\mathrm{S})$.

Table 51

Summary of the Provisions Viewed as Important as Anticipated by the Incubators

\begin{tabular}{|c|c|c|c|c|c|c|c|c|c|c|c|c|c|c|c|c|c|c|c|c|c|c|}
\hline \multirow{2}{*}{ 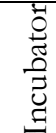 } & \multicolumn{3}{|c|}{$\begin{array}{l}\text { Internal } \\
\text { tangible }\end{array}$} & \multicolumn{10}{|c|}{ Internal intangible } & \multicolumn{2}{|c|}{$\begin{array}{l}\text { External } \\
\text { tangible }\end{array}$} & \multicolumn{7}{|c|}{ External intangible } \\
\hline & A & B & $\mathrm{C}$ & $\mathrm{D}$ & $\mathrm{E}$ & $\mathrm{F}$ & G & $\mathrm{H}$ & I & $\mathrm{J}$ & $\mathrm{K}$ & $\mathrm{L}$ & $\mathrm{M}$ & $\mathrm{N}$ & $\mathrm{O}$ & $\mathrm{P}$ & Q & $\mathrm{R}$ & $\mathrm{S}$ & $\mathrm{T}$ & $\mathrm{U}$ & V \\
\hline $\mathrm{E}$ & & & & & & & & & & & & & & & & & & & & & & \\
\hline A & & & & & & & & & & & & & & & & & & & & & & \\
\hline $\mathrm{C}$ & & & & & & & & & & & & & & & & & & & & . & & \\
\hline B & & & & & & & & & & & & & & & & & & & & & & \\
\hline $\mathrm{D}$ & & & & & & & & & & & & & & & & & & & & & & \\
\hline $\mathrm{F}$ & & & & & & & & & & & & & & & & & & & & & & \\
\hline
\end{tabular}

\begin{tabular}{|l|l|l|l|l|}
\hline Key & $\begin{array}{l}\text { Highly } \\
\text { important }\end{array}$ & $\begin{array}{l}\text { Moderately } \\
\text { important }\end{array}$ & Not important & Importance not mentioned by interviewee \\
\hline
\end{tabular}

Incubator A emphasised just the internal-intangible and the external-tangible provisions. Incubator B emphasised just internal-intangible provisions as being highly important. Incubator C, D and F appeared similar in that they emphasised just internal-intangible and external-intangible provisions as being highly important. Incubator E emphasised provisions across the whole four categories as being highly important. Notably, some incubators had a very structured approach at the start of the incubation process which involved putting firms through multi-firm based workshops. This was the case for all incubators except A and E, that had a more individualised approach to the development of the firm. The differences in the two approaches may have impacted the paths that the firms took in their strategy development process, in that the firms in the incubators with the structured workshops may have undergone a similar strategy development process to other firms in the same incubator. 


\subsubsection{Incubators' expectations of strategy developments that occur}

Again, during Strand One the incubators were asked to talk about the strategy developments that they believed the firms commonly underwent. Table 52 presents a summary of this data, which was also analysed in Chapter Five. Notably, the incubators were again not prompted about specific types of strategy developments because the purpose of the questions was to establish the incubators' views without interviewer bias.

Table 52

Summary of the Strategy Developments Emphasised by the Incubators

\begin{tabular}{|c|c|c|c|c|c|c|c|}
\hline & Goal & Process or & tation & Content ori & tation & & \\
\hline Inc. & $\begin{array}{l}\text { Growth } \\
\text { ambitions }\end{array}$ & $\begin{array}{l}\text { Deliberate } \\
\text { or } \\
\text { emergent } \\
\text { process }\end{array}$ & $\begin{array}{l}\text { Planning } \\
\text { process }\end{array}$ & $\begin{array}{l}\text { Partnership } \\
\text { status } \\
\text { changes }\end{array}$ & $\begin{array}{l}\text { Product } \\
\text { scope } \\
\text { changes }\end{array}$ & $\begin{array}{l}\text { Competiti } \\
\text { ve } \\
\text { emphasis } \\
\text { changes }\end{array}$ & $\begin{array}{l}\text { Time } \\
\text { allocation } \\
\text { changes }\end{array}$ \\
\hline $\mathrm{E}$ & $\begin{array}{l}\text { Direction } \\
\text { initially } \\
\text { unknown }\end{array}$ & $\begin{array}{l}\text { Deliberate } \\
\text { to } \\
\text { emergent }\end{array}$ & $\begin{array}{l}\text { Planning } \\
\text { goes up } \\
\text { and more } \\
\text { purposeful }\end{array}$ & $\begin{array}{l}\text { Investment } \\
\& \\
\text { governance } \\
\text { increase }\end{array}$ & $\begin{array}{l}\text { Product } \\
\text { scope gets } \\
\text { refined }\end{array}$ & $\begin{array}{l}\text { Market } \\
\text { gets } \\
\text { refined }\end{array}$ & \\
\hline A & $\begin{array}{l}\text { Emphasis } \\
\text { increased }\end{array}$ & $\begin{array}{l}\text { Deliberate } \\
\text { to } \\
\text { emergent }\end{array}$ & $\begin{array}{l}\text { Planning } \\
\text { more } \\
\text { purposeful }\end{array}$ & $\begin{array}{l}\text { Investment } \\
\& \\
\text { governance } \\
\text { increase }\end{array}$ & & & \\
\hline $\mathrm{C}$ & $\begin{array}{l}\text { Emphasis } \\
\text { increased }\end{array}$ & $\begin{array}{l}\text { Deliberate } \\
\text { to } \\
\text { emergent }\end{array}$ & $\begin{array}{l}\text { Planning } \\
\text { goes down }\end{array}$ & $\begin{array}{l}\text { Investment } \\
\& \\
\text { governance } \\
\text { increase }\end{array}$ & $\begin{array}{l}\text { Product } \\
\text { scope gets } \\
\text { refined }\end{array}$ & $\begin{array}{l}\text { Competiti } \\
\text { ve } \\
\text { emphasis } \\
\text { gets } \\
\text { refined }\end{array}$ & \\
\hline B & $\begin{array}{l}\text { Mismatch/ } \\
\text { realign }\end{array}$ & & $\begin{array}{l}\text { Planning } \\
\text { more } \\
\text { purposeful }\end{array}$ & $\begin{array}{l}\text { Investment } \\
\& \\
\text { governance } \\
\text { increase } \\
\end{array}$ & $\begin{array}{l}\text { Helped } \\
\text { pivot idea }\end{array}$ & $\begin{array}{l}\text { Encourage } \\
\text { d to } \\
\text { narrow } \\
\text { market }\end{array}$ & \\
\hline D & $\begin{array}{l}\text { Emphasis } \\
\text { increased }\end{array}$ & $\begin{array}{l}\text { Deliberate } \\
\text { to } \\
\text { emergent }\end{array}$ & $\begin{array}{l}\text { Planning } \\
\text { goes down }\end{array}$ & $\begin{array}{l}\text { Get an } \\
\text { advisory } \\
\text { board }\end{array}$ & $\begin{array}{l}\text { Product } \\
\text { scope does } \\
\text { down }\end{array}$ & & $\begin{array}{l}\text { Focus on } \\
\text { market } \\
\text { validation } \\
\text { activities }\end{array}$ \\
\hline $\mathrm{F}$ & $\begin{array}{l}\text { Emphasis } \\
\text { reduced }\end{array}$ & $\begin{array}{l}\text { Deliberate } \\
\text { to } \\
\text { emergent }\end{array}$ & $\begin{array}{l}\text { Planning } \\
\text { goes up } \\
\text { and more } \\
\text { purposeful }\end{array}$ & $\begin{array}{l}\text { Investment } \\
\& \\
\text { governance } \\
\text { increase }\end{array}$ & & & \\
\hline
\end{tabular}

\begin{tabular}{|l|l|l|l|}
\hline Key & Major emphasis & Moderate emphasis & No mention by interviewees \\
\hline
\end{tabular}

Table 52 seems to show there are no discernible patterns or differences between the incubators, apart from some incubators anticipating more strategy developments than others, and the greater emphasis of incubators $\mathrm{A}$ and $\mathrm{E}$ on investment. However, what is interesting is how these anticipated strategy developments compare to the actual strategy developments that occur in the firms, as discussed next. 


\subsubsection{Summary count of actual strategy developments}

Table 53 shows the percentage of firms that changed along each continuum for the NFIs and the BFIs. Incubator $\mathrm{C}$ is situated in the middle of the continuum.

Table 53

Comparison of Percentage of Changes along Each Continuum According to Incubator Type

\begin{tabular}{|l|l|l|l|l|l|l|l|}
\hline & Goal & $\begin{array}{l}\text { Deliberate } \\
\text { and } \\
\text { emergent }\end{array}$ & Planning & $\begin{array}{l}\text { Partnership } \\
\text { status }\end{array}$ & $\begin{array}{l}\text { Product } \\
\text { scope }\end{array}$ & $\begin{array}{l}\text { Competitive } \\
\text { emphasis }\end{array}$ & $\begin{array}{l}\text { Time } \\
\text { allocation }\end{array}$ \\
\hline $\begin{array}{l}\text { NFIs (E \& } \\
\text { A) }\end{array}$ & $\begin{array}{l}33 \%(40 \& \\
25 \%)\end{array}$ & $\begin{array}{l}11 \%(20 \& \\
0 \%)\end{array}$ & $\begin{array}{l}22 \%(20 \& \\
25 \%)\end{array}$ & $\begin{array}{l}44 \%(40 \& \\
50 \%)\end{array}$ & $\begin{array}{l}89 \%(100 \\
\& 75 \%)\end{array}$ & $\begin{array}{l}56 \%(40 \&) \\
75 \%)\end{array}$ & $\begin{array}{l}11 \% \\
0 \%)\end{array}$ \\
\hline $\begin{array}{l}\text { Incubator } \\
\text { C }\end{array}$ & $50 \%$ & $50 \%$ & $66 \%$ & $50 \%$ & $100 \%$ & $100 \%$ & $16 \%$ \\
\hline $\begin{array}{l}\text { BFIs (B,D } \\
\text { \& F) }\end{array}$ & $\begin{array}{l}56 \%(\text { range } \\
25-100 \%)\end{array}$ & $\begin{array}{l}28 \%(\text { range } \\
20-50 \%)\end{array}$ & $\begin{array}{l}39 \%(\text { range } \\
25-50 \%)\end{array}$ & $\begin{array}{l}17 \%(\text { range } \\
0-50 \%)\end{array}$ & $\begin{array}{l}78 \%(\text { range } \\
75-80 \%)\end{array}$ & $\begin{array}{l}56 \%(\text { range } \\
0-75 \%)\end{array}$ & $\begin{array}{l}33 \%(\text { range } \\
25-50 \%)\end{array}$ \\
\hline
\end{tabular}

\subsection{The influence of individual incubators: A triangulated perspective}

In this next analysis the incubators' views are compared to what happened in the firms. Specifically the incubators' perceptions of what provisions were important, what strategy developments may occur, and what may influence them, are compared to the actual provisions that the firms used and the provisions that the firms knew about and did not use, what strategy developments occurred, and the affordances that influenced them. To do this each incubator and their corresponding firms are analysed individually in the order of their location on the continuum according to their breadth of focus, commencing with the NFIs. For the analysis of provisions only the data from Strand One and Two are used. In the analysis of the incubators' influence on strategy development only the data from Strand One and Strand Three were used.

\subsubsection{Incubator E}

\subsubsection{Provision awareness and usage in Incubator $E$}

The usage rates of the provisions were higher than average at $100 \%$ for financial planning and assistance (I) for assistance with developing a board of directors or advisors $(\mathrm{K})$ and with connections to potential board members (R), refer Table 54. As explained in Chapter Five the affordances of these provisions can cluster together for the purpose of obtaining capital and external governance, which reflects the emphasis of this incubator on raising capital for firms, similar to incubator A. 
Table 54

Comparison of the Provisions Viewed as Important by Incubator E and Used by its Firms

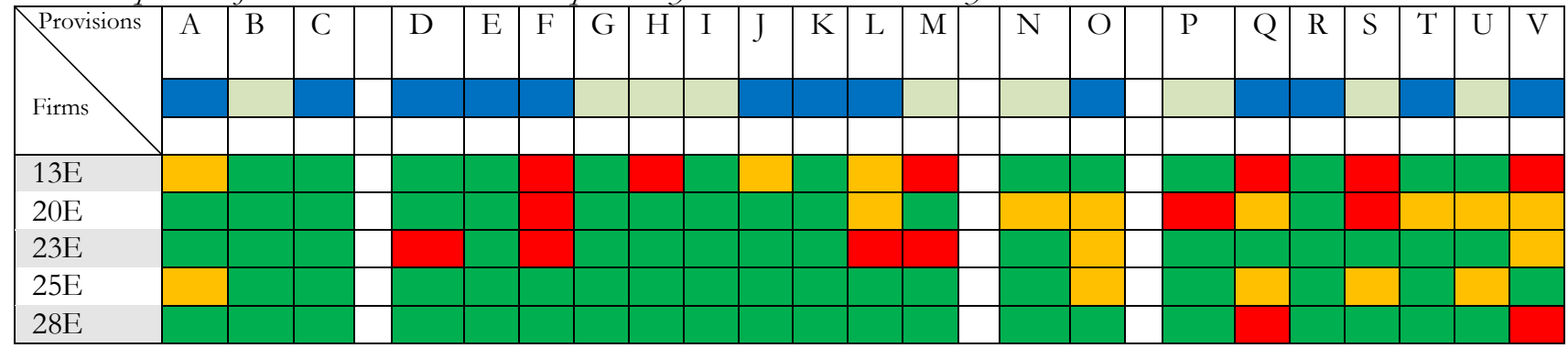

Note. Key below.

\begin{tabular}{|l|l|l|}
\hline $\begin{array}{l}\text { Provision emphasised as highly } \\
\text { important by incubator }\end{array}$ & $\begin{array}{l}\text { Provision viewed as moderately } \\
\text { important by incubator }\end{array}$ & $\begin{array}{l}\text { Importance not mentioned by } \\
\text { interviewee }\end{array}$ \\
\hline Provision used by firm & N/A for incubator E & $\begin{array}{l}\text { Provision not known about or used } \\
\text { by firm }\end{array}$ \\
\hline & $\begin{array}{l}\text { Provision known about but not } \\
\text { used by firm }\end{array}$ & \\
\hline
\end{tabular}

All of the firms in incubator E had physical, high-technology products and the interview participants were all from technical backgrounds. This specialisation by the incubator may mean that they were able to tailor their provisions to these types of products and offer a relatively specialised service to firms. This degree of focus may have meant that the affordances of provisions were more specific. The incubator emphasised its process of working with a reference customer to simultaneously validate the product and the market opportunity. However, just two of five firms used the provisions of product validation and development $(\mathrm{F})$, and of connections to subject matter experts $(\mathrm{Q})$ potential major customers $(\mathrm{S})$ and interns $(\mathrm{V})$, which are provisions that might be expected to be connected to the product validation process. Perhaps some firms viewed this process as purely a market validation exercise and not a product development exercise, and answered accordingly in the survey, or they had not been in the incubator long enough to use these provisions.

The usage rates of the provisions of growth management $(J)$ and connections to professional services $(\mathrm{P})$ were higher than for the other incubators, at four out of five firms.

Overall there was moderate alignment between the perceptions of the incubator and the provisions used by the firms. 


\subsubsection{Strategy development in incubator $E$}

Surprisingly when compared to the other incubators, only one firm changed on the process orientation, appearing to become more deliberate than emergent, and by making its planning more purposeful.

The firms had a moderate level of partnership status changes, with two of the five firms increasing along this continuum, which is considered low due to the incubators' emphasis on investment (refer Table 55).

Table 55

Comparison of Strategy Developments Anticipated by Incubator E and Undertaken by its Firms

\begin{tabular}{|c|c|c|c|c|c|c|c|}
\hline & Goal & \multicolumn{2}{|c|}{ Process orientation } & \multicolumn{4}{|c|}{ Content orientation } \\
\hline & $\begin{array}{l}\text { Growth } \\
\text { ambitions }\end{array}$ & $\begin{array}{l}\text { Deliberate or } \\
\text { emergent } \\
\text { process }\end{array}$ & $\begin{array}{l}\text { Planning } \\
\text { process }\end{array}$ & $\begin{array}{l}\text { Partnership } \\
\text { status changes }\end{array}$ & $\begin{array}{l}\text { Product scope } \\
\text { changes }\end{array}$ & $\begin{array}{l}\text { Competitive } \\
\text { emphasis } \\
\text { changes }\end{array}$ & $\begin{array}{l}\text { Time } \\
\text { allocation } \\
\text { changes }\end{array}$ \\
\hline Inc. E & $\begin{array}{l}\text { Direction } \\
\text { initially } \\
\text { unknown }\end{array}$ & $\begin{array}{l}\text { Deliberate to } \\
\text { emergent }\end{array}$ & $\begin{array}{l}\text { Planning goes } \\
\text { up and more } \\
\text { purposeful }\end{array}$ & $\begin{array}{l}\text { Capital } \\
\text { investment } \\
\text { goes up }\end{array}$ & $\begin{array}{l}\text { Product scope } \\
\text { gets refined }\end{array}$ & $\begin{array}{l}\text { Market gets } \\
\text { refined }\end{array}$ & \\
\hline \multicolumn{8}{|l|}{ Firms } \\
\hline $13 \mathrm{E}$ & $\begin{array}{l}\text { More precise } \\
\text { (E) }\end{array}$ & $\begin{array}{l}\text { Emergent to } \\
\text { deliberate (E, } \\
\mathrm{H})\end{array}$ & $\begin{array}{l}\text { More purpose } \\
\text { (I) }\end{array}$ & $\begin{array}{l}\text { Shareholders } \\
\text { up (core) C, } \\
\text { K) }\end{array}$ & $\begin{array}{l}\text { Evolution } \\
\text { (middle) (H) }\end{array}$ & $\begin{array}{l}\text { Emphasis up } \\
\text { (periphery) (E) }\end{array}$ & $\begin{array}{l}\text { Switched } \\
\text { focus } \\
\text { (periphery) } \\
\text { (C) }\end{array}$ \\
\hline $20 \mathrm{E}$ & & & & $\begin{array}{l}\text { Shareholders } \\
\text { up (core) (J, } \\
\mathrm{K} \text { ) }\end{array}$ & $\begin{array}{l}\text { Scope up } \\
(\text { core) }(\mathrm{E})\end{array}$ & & \\
\hline $23 \mathrm{E}$ & Increased $(\mathrm{E})$ & & & & $\begin{array}{l}\text { Evolution } \\
\text { (middle) (E) }\end{array}$ & $\begin{array}{l}\text { Market refined } \\
\text { (periphery) (E) }\end{array}$ & \\
\hline $25 \mathrm{E}$ & & & & & $\begin{array}{l}\begin{array}{l}\text { Different } \\
(\text { core })(\mathrm{F}, \mathrm{H})\end{array} \\
\end{array}$ & & \\
\hline $28 \mathrm{E}$ & & & & & $\begin{array}{l}\text { Scope up } \\
\text { (core) }(\mathrm{E}, \mathrm{F})\end{array}$ & & \\
\hline
\end{tabular}

Note. Key below.

\begin{tabular}{|l|l|l|}
\hline $\begin{array}{l}\text { Strategy development emphasised as highly } \\
\text { likely by incubator }\end{array}$ & $\begin{array}{l}\text { Strategy development viewed as } \\
\text { moderately likely by incubator }\end{array}$ & $\begin{array}{l}\text { Importance not mentioned by } \\
\text { interviewee }\end{array}$ \\
\hline & & $\begin{array}{l}\text { Strategy development continuum did } \\
\text { due to incubator influence }\end{array}$ \\
\hline & $\begin{array}{l}\text { not change due to incubator influence } \\
\text { influence }\end{array}$ \\
\hline
\end{tabular}

All the firms made product scope changes, mainly impacting the core of the firm. The level of changes was higher than the other incubators.

For the competitive emphasis continuum the incubator emphasised that the target markets would potentially get more refined. However this incubator had the lowest level of competitive emphasis changes with just two firms making relatively minor changes.

Overall, the main influence on strategy development was on the product scope continuum, with lower than average changes along all other continuums. 


\section{Incubator $\mathrm{E}$}

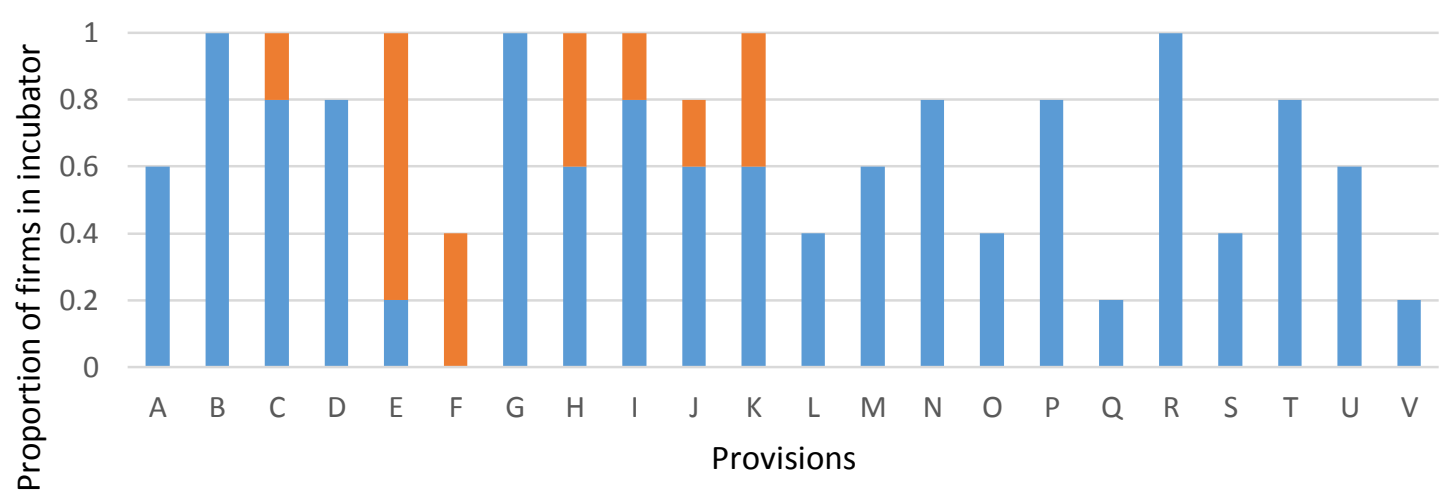

Affordances of provisions influenced strategy development

Affordances of provisions realised only, no direct influence on strategy development

Figure 12. Proportion of firms that used provisions in incubator $\mathrm{E}$ and the influence on strategy development.

\subsubsection{Summary of incubator E's influence}

The firms in incubator $\mathrm{E}$ appeared to have reasonably high usage rates of the externalintangible provisions; however, none of these provisions were cited as influencing strategy developments. The influence instead came from the internal-intangible provisions (refer Figure 12). The external-intangible provisions therefore appeared to be necessary in that, based on the analysis in Chapter Five, the incubators and firms valued them, but they were not sufficient in influencing strategy development.

This incubator focused on just incubation; it emphasised funding, governance and product validation, and its entry criteria were quite specific, that is, it sought out technologies at prototype stage and firms which had started off with just one person. This narrow and welldefined approach is reflected in the narrow range of provisions that influenced the firms' strategy development. Like incubator A, analysed next, most of the strategy developments were made to the firm's content orientations as opposed to the process orientations.

\subsubsection{Incubator A}

\subsubsection{Provision awareness and usage in incubator $A$}

In notable contrast to the other incubators, all of the firms in incubator A used the provision of connections to angel investors or venture capitalists $(\mathrm{O})$ and correspondingly the incubator highlighted the importance of this provision (refer Table 56)., like incubator E. Also at a higher level compared to other incubators was the usage of the provisions of assistance with developing a board of directors $(K)$ and financial planning and management 
(I). Incubator A emphasised the value of these provisions which, similar to incubator $\mathrm{E}$, appeared to cluster together to assist firms to raise capital. As a result of the usage of these provisions half the firms received external investment in some form and had external investors, which was a higher rate than for the firms in the other incubators.

Unusually, two of the firms did not use any external-intangible provisions and the incubator did not emphasise the importance of provisions in this category. No firms made connections to business mentors outside of the incubator $(\mathrm{U})$. Overall there was a relatively low rate usage of usage of provisions.

Table 56

Comparison of the Provisions Viewed as Important by Incubator $A$ and Used by its Firms

\begin{tabular}{|l|l|l|l|l|l|l|l|l|l|l|l|l|l|l|l|l|l|l|l|l|l|l|l|l|l|}
\hline $\begin{array}{l}\text { Provisi } \\
\text { on }\end{array}$ & A & B & C & & D & E & F & G & H & I & J & K & L & M & & N & O & & P & Q & R & S & T & U & V \\
\hline $\begin{array}{l}\text { Inc. A } \\
\text { views }\end{array}$ & & & & & & & & & & & & & & & & & & & & & & & & & \\
\hline & & & & & & & & & & & & & & & & & & & & & & & & & \\
\hline $\begin{array}{l}9 \mathrm{~A} \\
15 \mathrm{~A}\end{array}$ & & & & & & & & & & & & & & & & & & & & & & & & & \\
$32 \mathrm{~A}$ & & & & & & & & & & & & & & & & & & & & & & & & & \\
$33 \mathrm{~A}$ & & & & & & & & & & & & & & & & & & & & & & & & & \\
\hline
\end{tabular}

Note. Key below.
\begin{tabular}{|l|l|l|}
\hline $\begin{array}{l}\text { Provision viewed as emphasised } \\
\text { important by incubator }\end{array}$ & $\begin{array}{l}\text { Provision viewed as moderately } \\
\text { important by incubator }\end{array}$ & $\begin{array}{l}\text { Importance not mentioned by } \\
\text { interviewee }\end{array}$ \\
\hline Provision used by firm & $\begin{array}{l}\text { Provision known about but not used by } \\
\text { firm }\end{array}$ & $\begin{array}{l}\text { Provision not known about or used by } \\
\text { firm }\end{array}$ \\
\hline & & \\
\hline
\end{tabular}

The firms in incubator A had mainly physical products with a high-technology component as explained in Chapter Five. In addition the incubator did not appear to offer educational workshops or formal strategy development programmes; instead it appeared to work with the firms on an individual, not group, basis. Similar to incubator E, this individualised service may have meant that the affordances of the provisions were more specific.

Overall, the usage rates of provisions by the firms seemed to align with the provisions that the incubator emphasised as important.

\subsubsection{Strategy developments in incubator $A$}

For the goal orientation incubator A anticipated that the goals of firms would increase, as did half of the incubators. However the incubator influenced change to only one firm's goal orientation. 
For the process orientation incubator A anticipated that firms would embrace a more deliberate than emergent strategy, as did most of the other incubators but, unlike all the other incubators, no firms appeared to change along this continuum (refer Table 57). Incubator A anticipated that the planning done by firms would become more purposeful, like incubator $\mathrm{B}$, but the planning continuum changed in only one firm, in which case the level of planning increased. Overall the process orientation changes were minimal.

On the partnership status continuum, incubator A anticipated that the level of investment and governance would go up, like all incubators except D. This was reflected in two firms increasing along this continuum and another firm was on the path to do so. The value of incubator $\mathrm{A}$ in helping the firm gain investment was explained by firm 32A, whose founder was not from New Zealand:

I didn't really understand the start-up and the venture environment here in New Zealand, and I met one of the business development managers here at [the incubator] and I started writing a business plan and they, for lack of a better term, they Kiwi-fied it for me.

For the product scope and competitive emphasis continuums, unusually incubator A did not predict any changes. However, three firms made changes along this continuum, which was at a high level compared to the other incubators.

\section{Table 57}

Comparison of Strategy Developments Anticipated by Incubator A and Undertaken by its Firms

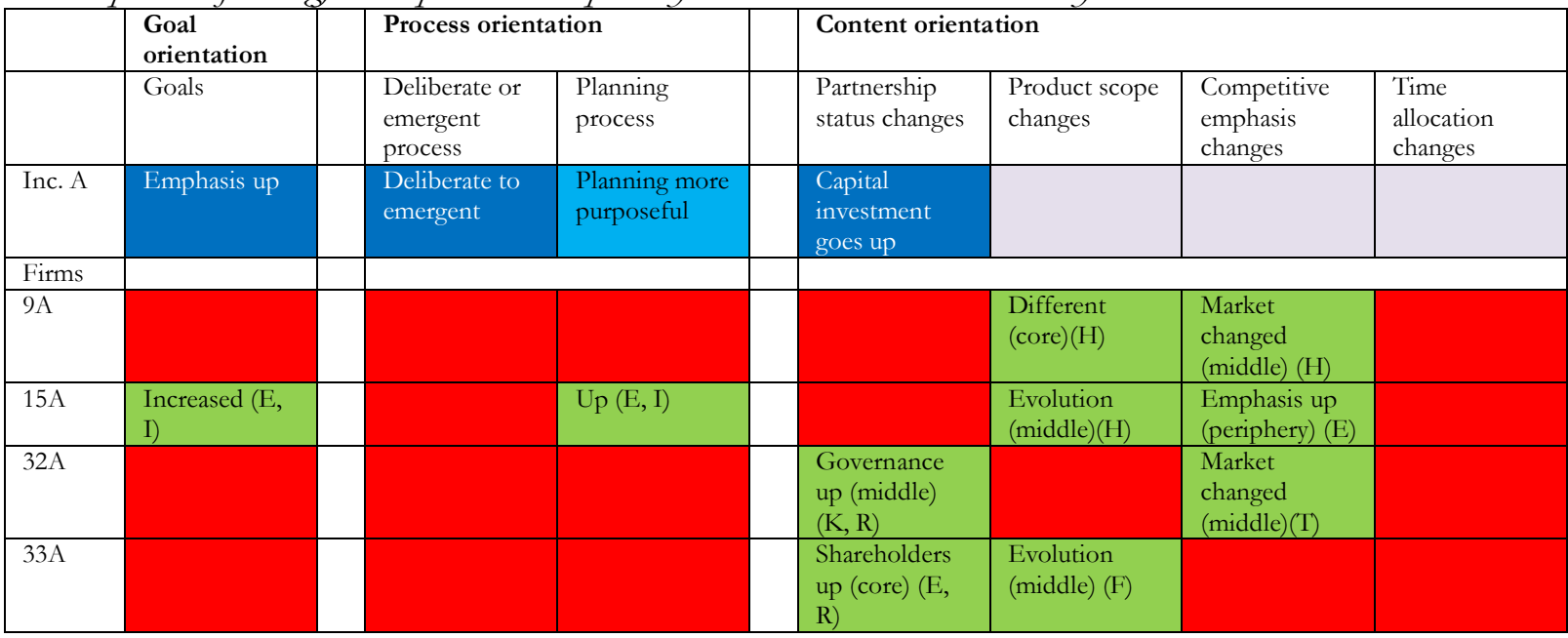

Note. Key below.

\begin{tabular}{|l|l|l|}
\hline $\begin{array}{l}\text { Strategy development emphasised as } \\
\text { highly likely by incubator }\end{array}$ & $\begin{array}{l}\text { Strategy development viewed as } \\
\text { moderately likely by incubator }\end{array}$ & $\begin{array}{l}\text { Strategy development viewed as not } \\
\text { likely by incubator }\end{array}$ \\
\hline $\begin{array}{l}\text { Strategy development continuum } \\
\text { changed due to incubator influence }\end{array}$ & $\begin{array}{l}\text { Strategy development continuum } \\
\text { changed due to non-incubator } \\
\text { influence }\end{array}$ & $\begin{array}{l}\text { Strategy development continuum did not } \\
\text { change due to incubator influence }\end{array}$ \\
\hline & & \\
\hline
\end{tabular}


Overall, there was some misalignment between the changes that this incubator anticipated and the changes that actually occurred in its firms along the planning and competitive emphasis continuums. This signalled that the affordances perceived by incubators may have not been realised by firms in the way intended by the incubator.

Most of the strategy developments were as a result of the internal-intangible provisions, with the exception of connections to potential board members $(R)$ in two instances, and connections to universities $(\mathrm{T})$ in one instance (refer Figure 13). None of the connections to investors $(\mathrm{O})$ resulted in strategy developments despite all firms using this provision.

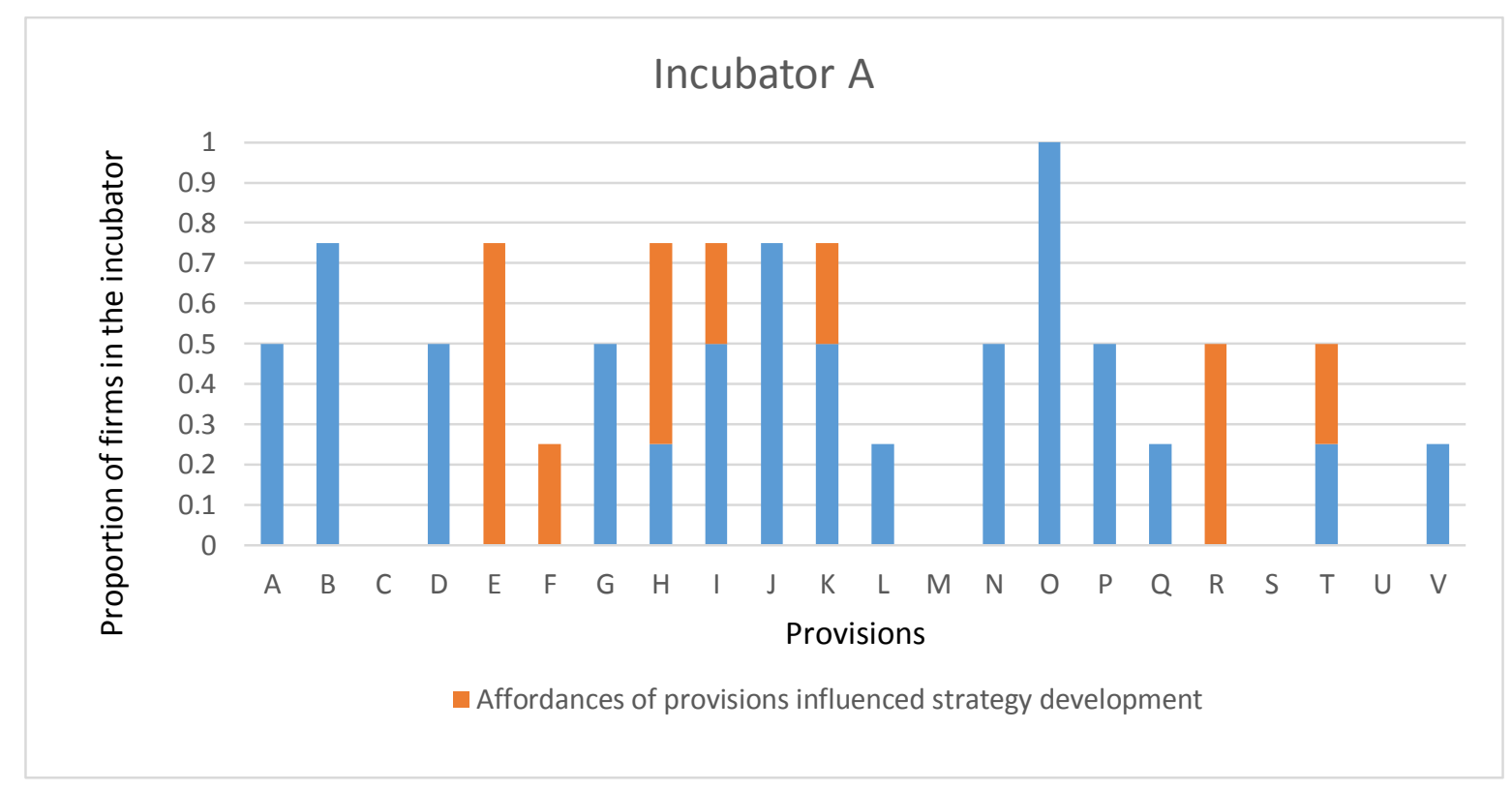

Figure 13. Proportion of firms that used provisions in incubator $A$ and the influence on strategy development

\subsubsection{Summary of incubator A's influence}

The overall approach of incubator A could be summed up as providing the firms with money, governance, and assistance with getting their market and products validated, which resulted mainly in changes to the content orientation of the firms' strategies. As with incubator $\mathrm{E}$, this presents a narrow and defined approach with some clustering of provisions for a specific purpose and a strong alignment between the provisions used and the affordances of influence. This incubator also appears to focus less on external-intangible provisions, with the exception of those that are related to governance or product development. The emphasis appears to be on developing strategy content rather than process or goals. 


\subsubsection{Incubator $\mathrm{C}$}

\subsubsection{Provision awareness and usage in incubator C}

Incubator $\mathrm{C}$ had the highest relative usage rates of the provisions. Strategy methodologies

$(\mathrm{E})$, product validation and development $(\mathrm{F})$, pitching development and practice $(\mathrm{G})$, market validation and development $(\mathrm{H})$, educational workshops $(\mathrm{M})$ and connections to potential board members (R) were used by all firms (refer Table 58). The provisions of helping develop a board of directors $(\mathrm{K})$, connections to government grants $(\mathrm{N})$, potential investors $(\mathrm{O})$, subject matter experts $(\mathrm{Q})$ and interns $(\mathrm{V})$ were all used by five out of six firms. The emphasis on certain provisions by the incubator appeared in line with the provisions used, indicating that the affordances perceived by the incubators generally matched those realised by firms.

Table 58

Comparison of the Provisions Vienved as Important by Incubator $C$ and Used by its Firms

\begin{tabular}{|l|l|l|l|l|l|l|l|l|l|l|l|l|l|l|l|l|l|l|l|l|l|l|l|l|l|}
\hline & $\mathrm{A}$ & $\mathrm{B}$ & $\mathrm{C}$ & & $\mathrm{D}$ & $\mathrm{E}$ & $\mathrm{F}$ & $\mathrm{G}$ & $\mathrm{H}$ & $\mathrm{I}$ & $\mathrm{J}$ & $\mathrm{K}$ & $\mathrm{L}$ & $\mathrm{M}$ & & $\mathrm{N}$ & $\mathrm{O}$ & & $\mathrm{P}$ & $\mathrm{Q}$ & $\mathrm{R}$ & $\mathrm{S}$ & $\mathrm{T}$ & $\mathrm{U}$ & $\mathrm{V}$ \\
\hline Inc. C & & & & & & & & & & & & & & & & & & & & & & & & & \\
\hline & & & & & & & & & & & & & & & & & & & & & & & & & \\
\hline $6 \mathrm{C} \mathrm{C}$ & & & & & & & & & & & & & & & & & & & & & & & & & \\
$10 \mathrm{C}$ & & & & & & & & & & & & & & & & & & & & & & & & & \\
$16 \mathrm{C}$ & & & & & & & & & & & & & & & & & & & & & & & & & \\
$18 \mathrm{C}$ & & & & & & & & & & & & & & & & & & & & & & & & & \\
\hline \\
\cline { 2 - 3 }
\end{tabular}

Note. Key below.

\begin{tabular}{|l|l|l|}
\hline $\begin{array}{l}\text { Provision emphasised as highly } \\
\text { important by incubator }\end{array}$ & $\begin{array}{l}\text { Provision viewed as moderately } \\
\text { important by incubator }\end{array}$ & $\begin{array}{l}\text { Importance not mentioned by } \\
\text { interviewee }\end{array}$ \\
\hline Provision used by firm & $\begin{array}{l}\text { Provision known about but not used by } \\
\text { firm }\end{array}$ & $\begin{array}{l}\text { Provision not known about or used by } \\
\text { firm }\end{array}$ \\
\hline & & \\
\hline
\end{tabular}

The high level of usage rates of the provisions could have been due to the average duration that firms had been in the incubator, being the longest of any of the incubators. Five of the six firms had been in the incubator longer than two years.

Incubator $\mathrm{C}$ offered a relatively narrowly-focused range of services to the business community, that is, just pre-incubation and incubation programmes. The firms were all focused on information-technology products (ITFs), that is, they did not have physical products. Similar to incubators $\mathrm{E}$ and A, this individualised service may have meant that the affordances could be designed to better meet the needs of firms. The concept of effectively meeting the needs of individual firms was reflected in the comment by firm 6C: 
The support they offered was dependent on what everyone's different needs were. Everyone comes in with different skill sets, different backgrounds, different stages of the idea, and so they wanted to adapt the support they offered to meet the individual's needs rather than have a oneoffer-fits-all kind of approach, which I thought was a good idea.

Another notable characteristic of the firms in incubator $\mathrm{C}$ is that two thirds had their head offices located in the incubator, they had fewer employees, and only one firm had either external investors or a formal governance structure. This close physical proximity and fewer stakeholders could have increased the firms' dependence on the incubator.

\subsubsection{Strategy development in incubator $C$}

Proportionally greater changes were made by firms in incubator $\mathrm{C}$ along the process orientation. The incubator anticipated that firms would embrace a more deliberate than emergent strategy, like most of the other incubators, and the firms that changed along this continuum did just that. The incubator anticipated that the level of planning done by firms would go down and three firms reduced the amount of planning, and for one the planning became more precise (refer Table 59).

For the partnership status continuum incubator $\mathrm{C}$ anticipated that the level of investment and governance would go up. This direction of change occurred in most firms, which was at a level that was higher than that of the other incubators.

While all of the firms made changes along the product scope continuum, some changed their products entirely, and others sought to make their products more scalable.

All the firms changed along the competitive emphasis continuum, which was unusual compared to the other incubators. This incubator's views were, overall, well aligned with those of its firms. 
Table 59

Comparison of Strategy Developments Anticipated by Incubator C and Undertaken by its Firms

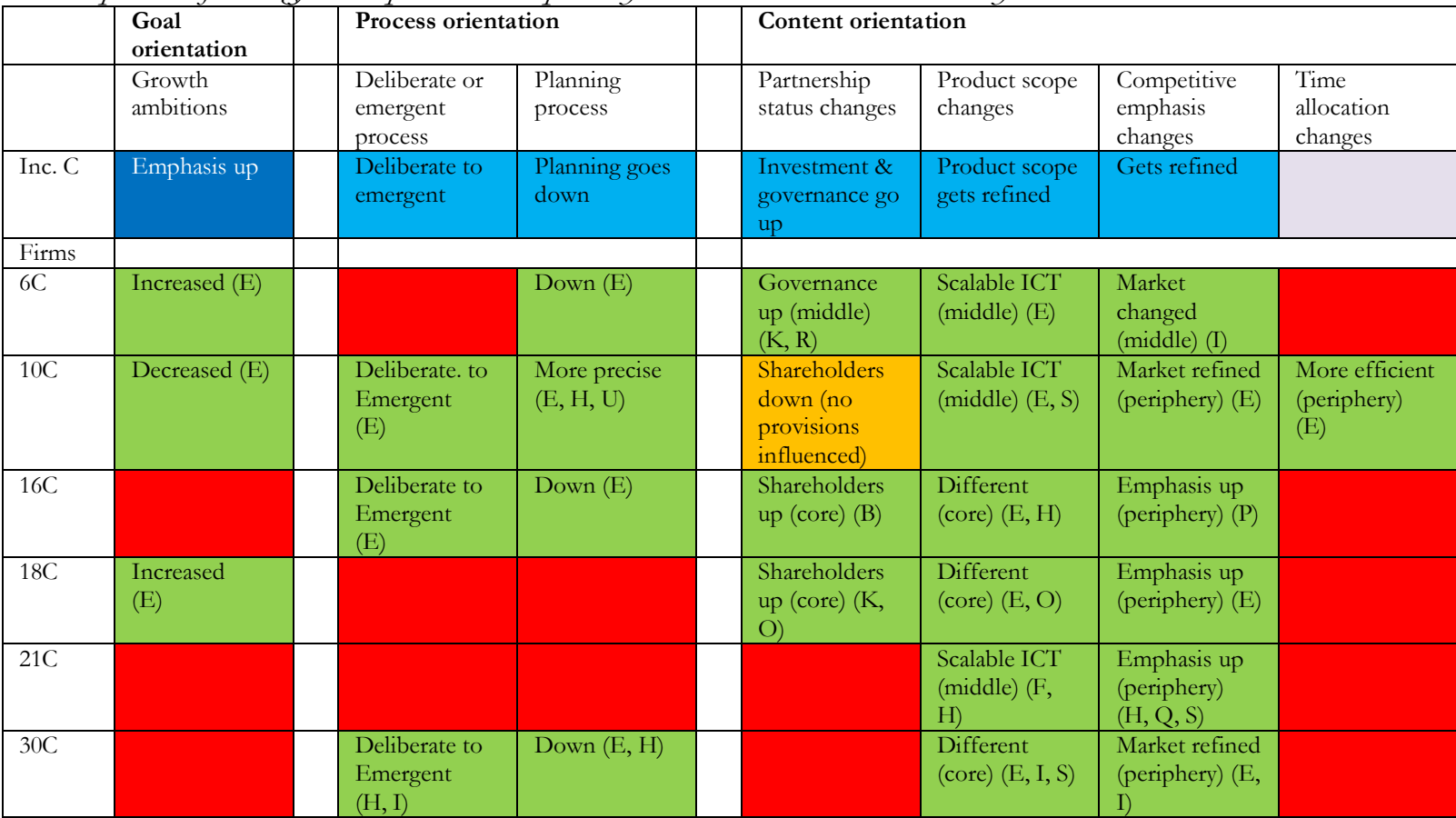

Note. Key below.

\begin{tabular}{|l|l|l|}
\hline $\begin{array}{l}\text { Strategy development emphasised as highly } \\
\text { likely by incubator }\end{array}$ & $\begin{array}{l}\text { Strategy development viewed as } \\
\text { moderately likely by incubator }\end{array}$ & $\begin{array}{l}\text { Strategy development viewed as not } \\
\text { likely by incubator }\end{array}$ \\
\hline $\begin{array}{l}\text { Strategy development continuum changed } \\
\text { due to incubator influence }\end{array}$ & $\begin{array}{l}\text { Strategy development continuum } \\
\text { changed due to non-incubator influence }\end{array}$ & $\begin{array}{l}\text { Strategy development continuum } \\
\text { did not change due to incubator } \\
\text { influence }\end{array}$ \\
\hline & & \\
\hline
\end{tabular}

The provisions that influenced the strategy developments were relatively proportionally spread across all categories of provisions (refer Figure 14).

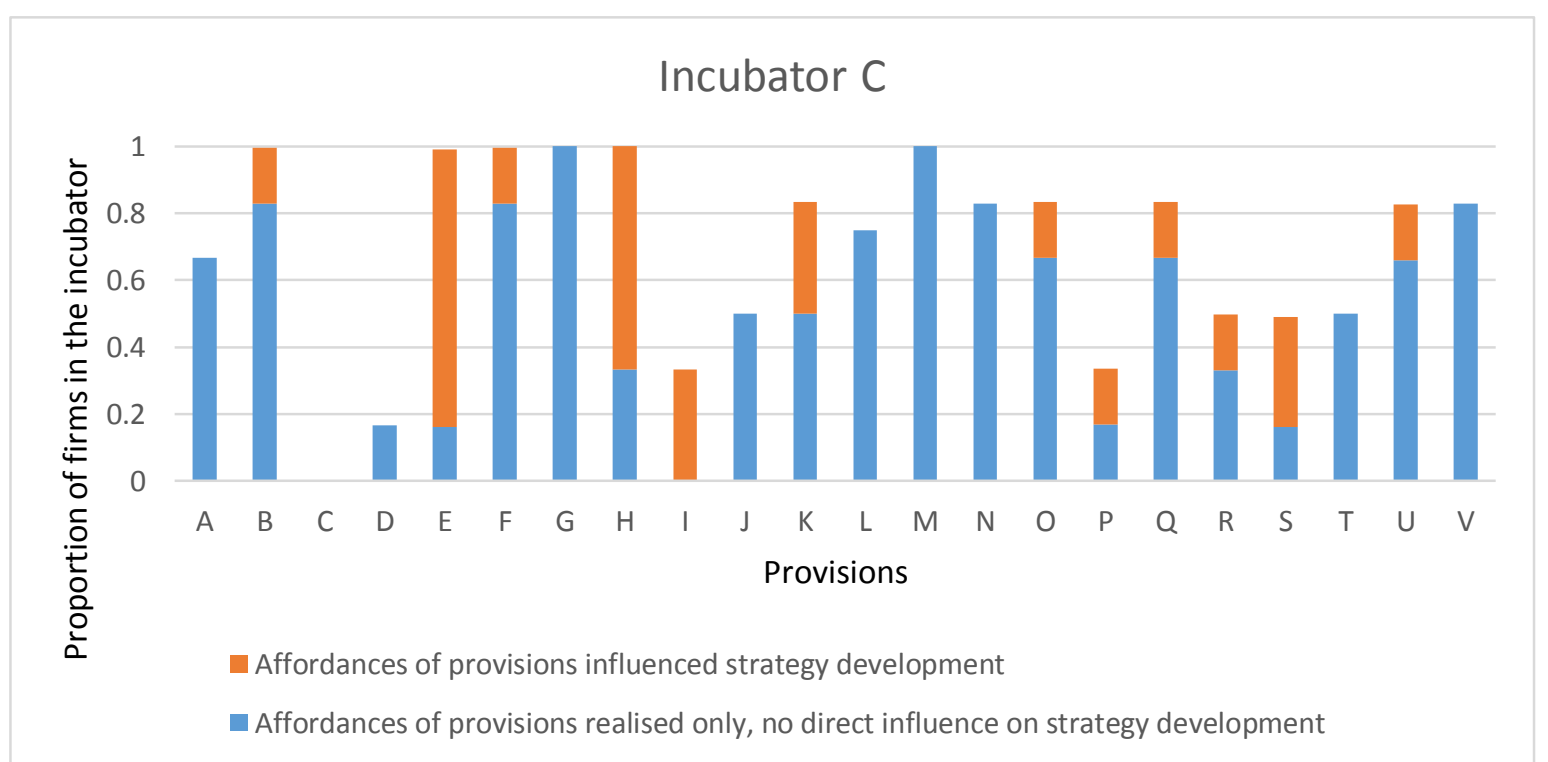

Figure 14. Proportion of firms that used provisions in incubator $\mathrm{C}$ and the influence on strategy development 


\subsubsection{Summary of incubator C's influence}

For incubator $\mathrm{C}$ the provision usage rates and the rates of strategy developments that were influenced by the incubators' provisions were higher than for any other incubator, and were generally in line with those anticipated by the incubator.

Incubator $\mathrm{C}$ had firms that were primarily made up of individuals and it offered mainly just incubation-related services, plus a limited range of services to the business community, reflecting its status of being in the middle of the NFI to BFI continuum. Overall incubator C had a high level of influence on its firms' strategy developments through a comprehensive range of provisions. Therefore the provisions appeared to have a high degree of affordances that were sufficient to influence strategy development.

\subsubsection{Incubator B}

\subsubsection{Provision awareness and usage in incubator $B$}

Firms in incubator B had higher than average usage of the provisions of product validation and development $(\mathrm{F})$, connections to subject matter experts $(\mathrm{Q})$ and professional services $(\mathrm{P})$, which were all used by three out of four firms, perhaps signalling a heavier reliance on advice from external, rather than internal, sources (refer Table 60).

Table 60

Comparison of the Provisions Viewed as Important by Incubator B and Used by its Firms

\begin{tabular}{|l|l|l|l|l|l|l|l|l|l|l|l|l|l|l|l|l|l|l|l|l|l|l|l|l|l|}
\hline & $\mathrm{A}$ & $\mathrm{B}$ & $\mathrm{C}$ & & $\mathrm{D}$ & $\mathrm{E}$ & $\mathrm{F}$ & $\mathrm{G}$ & $\mathrm{H}$ & $\mathrm{I}$ & $\mathrm{J}$ & $\mathrm{K}$ & $\mathrm{L}$ & $\mathrm{M}$ & & $\mathrm{N}$ & $\mathrm{O}$ & & $\mathrm{P}$ & $\mathrm{Q}$ & $\mathrm{R}$ & $\mathrm{S}$ & $\mathrm{T}$ & $\mathrm{U}$ & $\mathrm{V}$ \\
\hline Inc. B & & & & & & & & & & & & & & & & & & & & & & & & & \\
\hline & & & & & & & & & & & & & & & & & & & & & & & & & \\
\hline \\
1B \\
4B \\
24B
\end{tabular}

Note. Key below.

\begin{tabular}{|l|l|l|}
\hline $\begin{array}{l}\text { Provision emphasised as highly } \\
\text { important by incubator }\end{array}$ & $\begin{array}{l}\text { Provision viewed as moderately } \\
\text { important by incubator }\end{array}$ & $\begin{array}{l}\text { Importance not mentioned by } \\
\text { interviewee }\end{array}$ \\
\hline Provision used by firm & $\begin{array}{l}\text { Provision known about but not used by } \\
\text { firm }\end{array}$ & $\begin{array}{l}\text { Provision not known about or used by } \\
\text { firm }\end{array}$ \\
\hline & & \\
\hline
\end{tabular}

Overall the awareness of availability and the usage rates of the provisions were low. This is despite three out of four firms having their head offices located in the incubator, a factor which was generally related to greater usage of provisions for the firms in other incubators. 


\subsubsection{Notable aspects of incubator B's influence on strategy development}

The notable strategy developments for incubator B related to the goal and content orientations; however, few strategy developments were considered to impact at the core of the firms.

Interestingly, the affordances that influenced the strategy developments came from only three provisions, all of which were emphasised as important by the incubator (refer Table 61). Almost all strategy developments were influenced by the provisions of strategy methodologies $(\mathrm{E})$ and market validation $(\mathrm{H})$, refer Figure 15. Just one firm, 4B, was influenced by another provision, connections to professional services $(\mathrm{P})$. This limited influence of the provisions may not necessarily mean that the affordances the provisions were not useful to the firms.

\section{Table 61}

Comparison of Strategy Developments Anticipated by Incubator B and Undertaken by its Firms

\begin{tabular}{|c|c|c|c|c|c|c|c|}
\hline & \multirow{2}{*}{$\begin{array}{l}\text { Goal } \\
\text { orientation }\end{array}$} & \multicolumn{2}{|c|}{ Process orientation } & \multicolumn{4}{|c|}{ Content orientation } \\
\hline & & $\begin{array}{l}\text { Deliberate or } \\
\text { emergent } \\
\text { process }\end{array}$ & $\begin{array}{l}\text { Planning } \\
\text { process }\end{array}$ & $\begin{array}{l}\text { Partnership } \\
\text { status changes }\end{array}$ & $\begin{array}{l}\text { Product scope } \\
\text { changes }\end{array}$ & $\begin{array}{l}\text { Competitive } \\
\text { emphasis } \\
\text { changes }\end{array}$ & $\begin{array}{l}\text { Time } \\
\text { allocation } \\
\text { changes }\end{array}$ \\
\hline Inc. B & $\begin{array}{l}\text { Mismatch/ } \\
\text { realign }\end{array}$ & & $\begin{array}{l}\text { Planning more } \\
\text { purposeful }\end{array}$ & $\begin{array}{l}\text { Investment \& } \\
\text { governance go } \\
\text { up }\end{array}$ & $\begin{array}{l}\text { Recycle } \\
\text { entrepreneurs }\end{array}$ & $\begin{array}{l}\text { Encouraged to } \\
\text { narrow market }\end{array}$ & \\
\hline \multicolumn{8}{|l|}{ Firms } \\
\hline $1 \mathrm{~B}$ & Increased (E) & & & $\begin{array}{l}\text { Shareholders } \\
\text { up (core) (E) }\end{array}$ & $\begin{array}{l}\text { Evolution } \\
\text { (middle) (E, } \\
\mathrm{H})\end{array}$ & & $\begin{array}{l}\text { Switched } \\
\text { focus } \\
\text { (periphery) } \\
\text { No provisions }\end{array}$ \\
\hline $4 \mathrm{~B}$ & $\begin{array}{l}\text { Slower } \\
\text { Unknown } \\
\text { influence }\end{array}$ & $\begin{array}{l}\text { Deliberate to } \\
\text { emergent }(\mathrm{H})\end{array}$ & Down $(\mathrm{E}, \mathrm{H})$ & $\begin{array}{l}\text { Shareholders } \\
\text { up (core) (S) }\end{array}$ & $\begin{array}{l}\text { Scalable ICT } \\
\text { (middle) (E) }\end{array}$ & $\begin{array}{l}\text { Emphasis up } \\
\text { (periphery) (P) }\end{array}$ & $\begin{array}{l}\text { More efficient } \\
\text { (periphery) } \\
\text { (E) }\end{array}$ \\
\hline $24 \mathrm{~B}$ & Decreased $(\mathrm{H})$ & & & & & $\begin{array}{l}\text { Market refined } \\
\text { (periphery) } \\
(\mathrm{H})\end{array}$ & \\
\hline $29 \mathrm{~B}$ & Increased (E) & & & & $\begin{array}{l}\text { Scalable ICT } \\
\text { (middle) (E) }\end{array}$ & $\begin{array}{l}\text { Market refined } \\
\text { (periphery) (E) }\end{array}$ & \\
\hline
\end{tabular}

Note. Key below.

\begin{tabular}{|l|l|l|}
\hline $\begin{array}{l}\text { Strategy development emphasised as } \\
\text { highly likely by incubator }\end{array}$ & $\begin{array}{l}\text { Strategy development viewed as } \\
\text { moderately likely by incubator }\end{array}$ & $\begin{array}{l}\text { Strategy development viewed as not } \\
\text { likely by incubator }\end{array}$ \\
\hline $\begin{array}{l}\text { Strategy development continuum } \\
\text { changed due to incubator influence }\end{array}$ & $\begin{array}{l}\text { Strategy development continuum } \\
\text { changed due to non-incubator influence }\end{array}$ & $\begin{array}{l}\text { Strategy development continuum did not } \\
\text { change due to incubator influence }\end{array}$ \\
\hline & & \\
\hline
\end{tabular}

Incubator B appeared to be quite generalist, that is, it offered a variety of programmes to the wider business community and the firms had a mix of product types. This lack of focus may have resulted in the affordances of some provisions being less specific and having a negative influence on some firms. For example, firms 2B, 4B and 29B thought that the incubator was focusing its attention on its accelerator programme, rather than the incubator programme and that this was detrimental for the culture. Firm 29B explained: 
There's been the addition of the accelerator which has taken a lot more of the focus, and so all of those things have meant to me that the service that has been provided went through a substantial lapse.

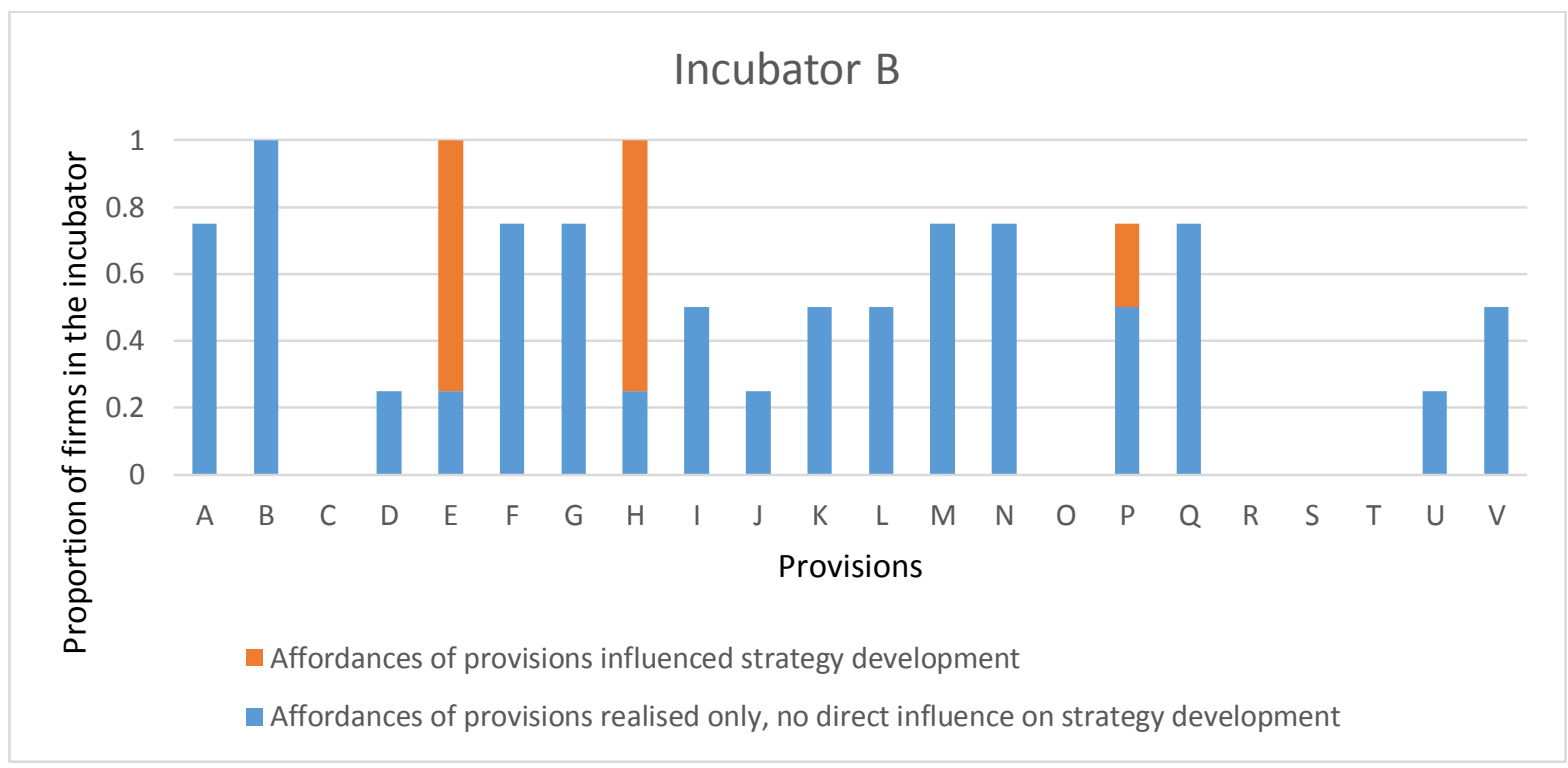

Figure 15. Proportion of firms that used provisions in incubator B and the influence on strategy development

\subsubsection{Summary of incubator B's influence}

Incubator B had a broad focus and most provisions were not sufficient to influence strategy development. Overall the number of goal orientation changes that firms made was high, the number of process orientation changes was low, and the content orientation changes appeared to impact the firms more at their periphery, rather than at their core. It is important to note that this incubator was undergoing substantial changes at the time of the interviews. This may have resulted in a lapse in support for the firms, and is possibly reflected in the lower number of provisions that were used and that influenced the firms' strategy developments. Potentially the incubator staff was instrumental in ensuring the quality of the provisions and without the incubator's support, the provisions reduced ability to influence strategy development potentially due to the lack of specificity of the affordances for each firm.

\subsubsection{Incubator D}

\subsubsection{Provision awareness and usage in incubator D}

Unusually, all firms used the provision of market validation and development $(\mathrm{H})$ and seven out of ten firms used product validation and development $(\mathrm{F})$, refer Table 62. This result 
seems to reflect this incubator's focus on the validation process, which was emphasised in their structured workshops (refer Section 4.5.1.5).

This incubator relied heavily on part-time external business mentors $(\mathrm{U})$ whom the incubator viewed as being "either entrepreneurs or corporate guys, or retirees who want to give back to the entrepreneur eco-system," rather than relying solely on internal advisors. The fact that these people were external to the incubator appeared not to be known in some instances, as was the case for firm 14D, "I'm not sure whether [the advisor] deems themself to be [incubator] staff or not." This lack of clarity on whether the advisors were internal or external may have biased the survey results (Strand Two) regarding provision usage, meaning that some firms may have indicated that they did not use external business mentors, whereas in fact they did.

Table 62

Comparison of the Provisions Vienved as Important by Incubator D and Used by its Firms

\begin{tabular}{|l|l|l|l|l|l|l|l|l|l|l|l|l|l|l|l|l|l|l|l|l|l|l|l|l|l|}
\hline & $\mathrm{A}$ & $\mathrm{B}$ & $\mathrm{C}$ & & $\mathrm{D}$ & $\mathrm{E}$ & $\mathrm{F}$ & $\mathrm{G}$ & $\mathrm{H}$ & $\mathrm{I}$ & $\mathrm{J}$ & $\mathrm{K}$ & $\mathrm{L}$ & $\mathrm{M}$ & & $\mathrm{N}$ & $\mathrm{O}$ & & $\mathrm{P}$ & $\mathrm{Q}$ & $\mathrm{R}$ & $\mathrm{S}$ & $\mathrm{T}$ & $\mathrm{U}$ & $\mathrm{V}$ \\
\hline Inc. D & & & & & & & & & & & & & & & & & & & & & & & & \\
\hline \\
\hline $\begin{array}{l}\text { 5D } \\
7 \mathrm{D} \\
\text { 8D } \\
11 \mathrm{D}\end{array}$ \\
\hline
\end{tabular}

Note. Key below.

\begin{tabular}{|l|l|l|}
\hline $\begin{array}{l}\text { Provision emphasised as highly } \\
\text { important by incubator }\end{array}$ & $\begin{array}{l}\text { Provision viewed as moderately } \\
\text { important by incubator }\end{array}$ & $\begin{array}{l}\text { Importance not mentioned by } \\
\text { interviewee }\end{array}$ \\
\hline Provision used by firm & $\begin{array}{l}\text { Provision known about but not used by } \\
\text { firm }\end{array}$ & $\begin{array}{l}\text { Provision not known about or used by } \\
\text { firm }\end{array}$ \\
\hline & & \\
\hline
\end{tabular}

None of the firms in incubator D had received any external investment during their time in the incubator, and that is despite all firms being aware of the provision of connections to angel investors or venture capitalists.

Overall this incubator appeared to have a substantial amount of provisions that were only ever known about but not used. 


\subsubsection{Strategy developments in incubator D}

For the goal orientation incubator $\mathrm{D}$ anticipated that the goals of firms would increase.

Correspondingly, its firms had reasonably high levels of goal orientation change, all either increased or became more precise, as opposed to changing in a variety of directions as many of the firms did in the other incubators (refer Table 63).

Table 63

Comparison of Strategy Developments Anticipated by Incubator D and Undertaken by its Firms

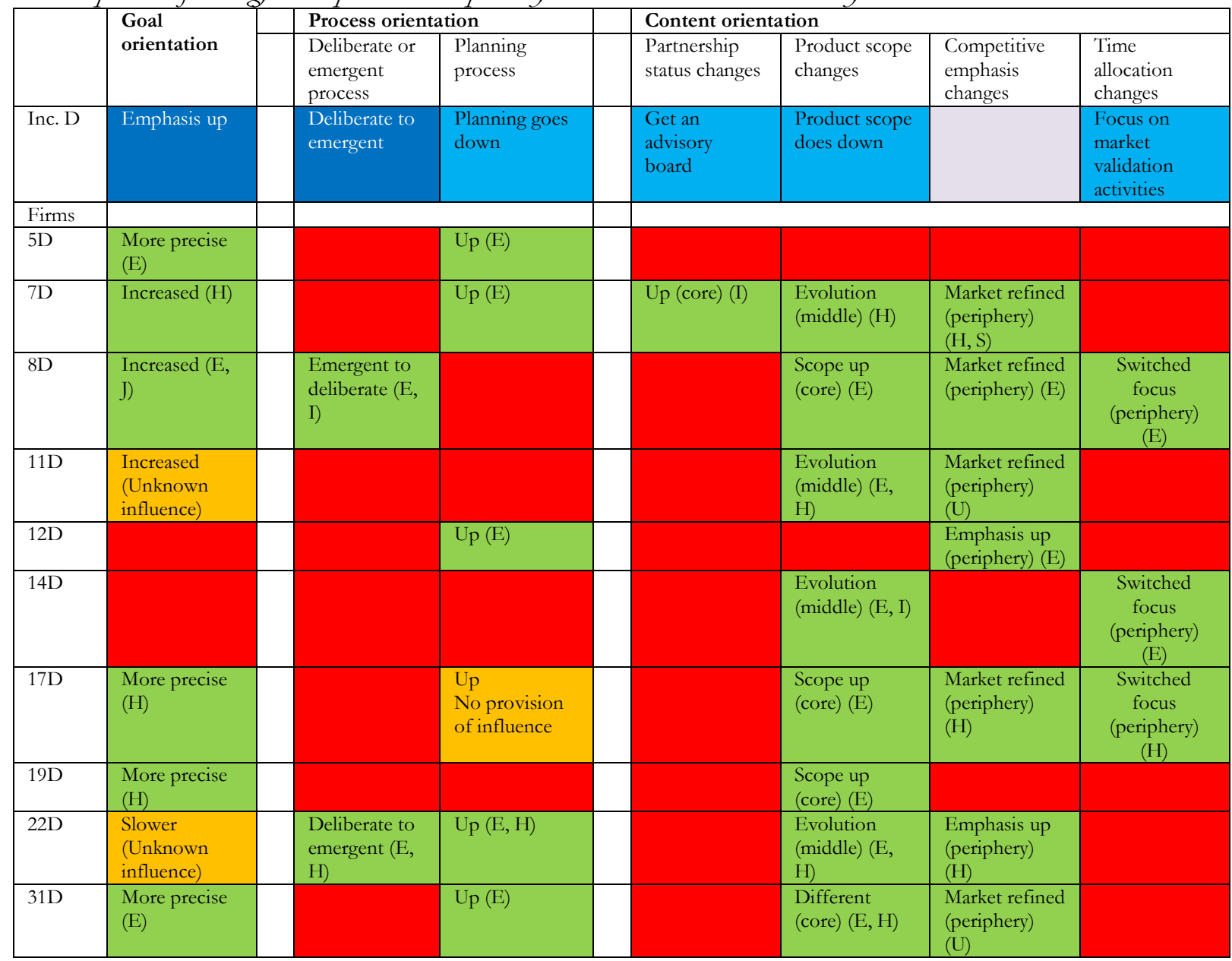

Note. Key below.

\begin{tabular}{|l|l|l|}
\hline $\begin{array}{l}\text { Strategy development emphasised as highly } \\
\text { likely by incubator }\end{array}$ & $\begin{array}{l}\text { Strategy development viewed as } \\
\text { moderately likely by incubator }\end{array}$ & $\begin{array}{l}\text { Strategy development viewed as not } \\
\text { likely by incubator }\end{array}$ \\
\hline $\begin{array}{l}\text { Strategy development continuum changed } \\
\text { due to incubator influence }\end{array}$ & $\begin{array}{l}\text { Strategy development continuum } \\
\text { changed due to non-incubator influence }\end{array}$ & $\begin{array}{l}\text { Strategy development continuum did } \\
\text { not change due to incubator influence }\end{array}$ \\
\hline & & \\
\hline
\end{tabular}

Incubator $\mathrm{D}$ anticipated that the level of planning done by firms would decrease; however, in all cases where the firms' level of planning changed, it actually increased. 
Unusually, only one firm (7D) changed along the partnership status continuum, which reflects the relatively low emphasis by the incubator.

For the product scope continuum the incubator predicted that the product scope would go down. Most of the ten firms made changes to their product scope, but none decreased, and only four impacted the core and four impacted the middle. The firms in this incubator tended to be ITFs or LTFs. Only one was a HTF. The stages of the firms' development on entry were mixed. The propensity for firms in this incubator to use the provision of product validation and development may have been related their products being less technical and easier to adapt than high-technology physical products, and therefore more likely to undergo product development, which most indeed did. The competitive emphasis changes were all considered peripheral, rather than middle.

Overall, the strategy developments of the firms were somewhat different to what incubator D predicted, notably along the planning and product scope continuums.

No strategy developments resulted from the external-tangible or external-intangible provisions except for connections to potential major customers $(\mathrm{S})$ and connections to universities and other tertiary institutions (U) (refer Figure 16). This incubator had, overall, low usage rates of provisions and low strategy developments.

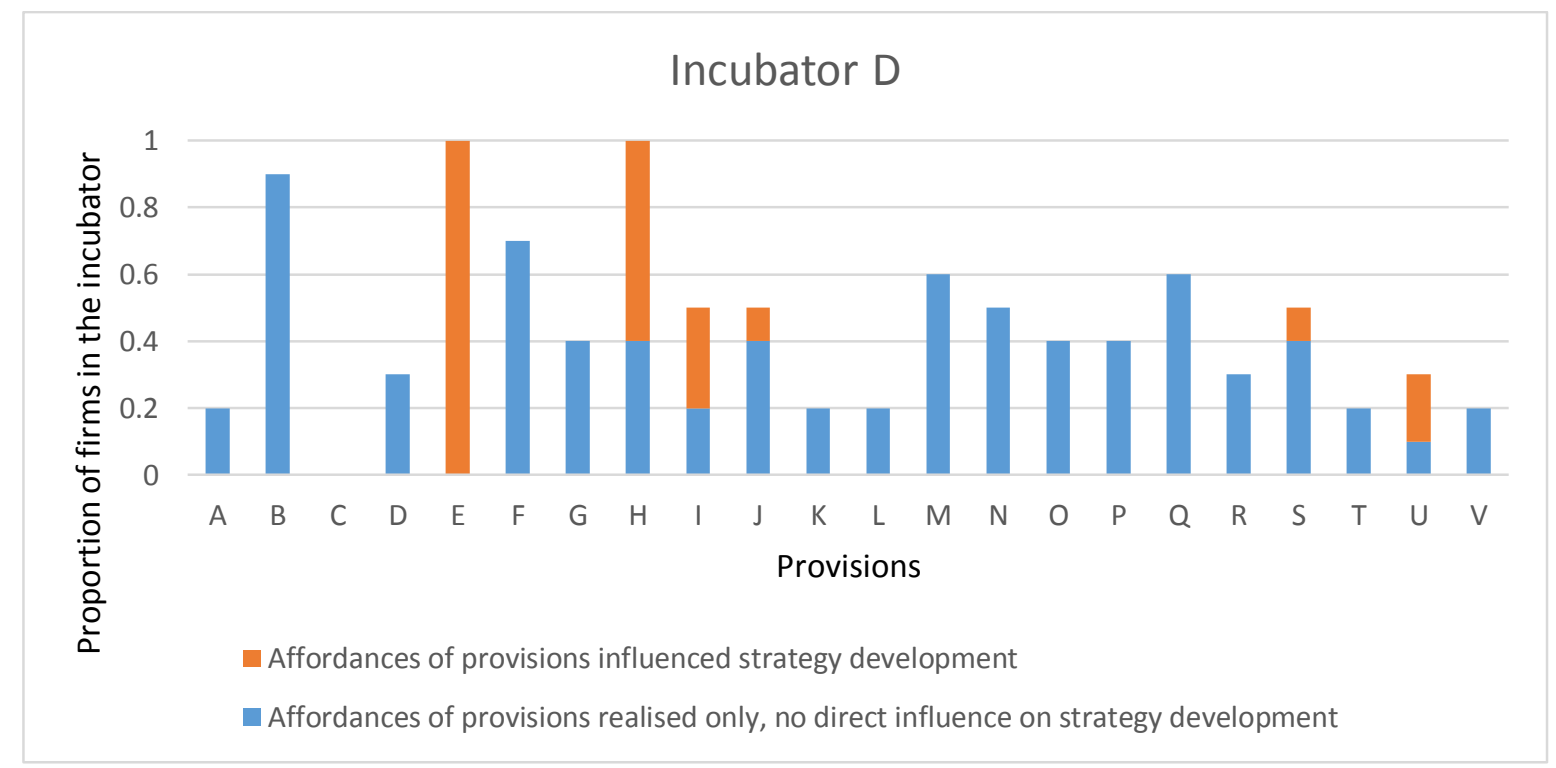

Figure 16. Proportion of firms that used provisions in incubator D and the influence on strategy development 


\subsubsection{Summary of incubator D's influence}

Incubator $\mathrm{D}$ was at the BFI-end of the continuum, that is, it had broad entry criteria for firms, offered a range of services to the business community, and some of the provisions were outsourced, indicating a degree of substitution, with potentially reduced control by the incubator over the quality of the ensuing affordances. Most of the strategy developments that were influenced by the incubator related to the firms' goal orientation and planning continuum and came from a narrow range of quite specific affordances. The content orientation changes were generally more periphery than core. There was also a degree of misalignment between what the incubator provisions and what it thought would happen, and what actually happened in the firms.

\subsubsection{Incubator F}

\subsubsection{Provision awareness and usage}

The usage rate for the provisions of product validation and development $(\mathrm{F})$ and of connections to professional services (P) was 100\% (refer Table 64). Incubator $\mathrm{F}$ also had higher than average for financial planning and management (I) and educational workshops (M) at three out of four firms. These high levels of usage appeared to mirror the provisions perceived as being most important by the incubator. The incubator appeared to have a similar focus to incubator $\mathrm{D}$, in that it emphasised providing planning tools and workshops.

Table 64

Comparison of the Provisions Vienved as Important by Incubator F and Used by its Firms

\begin{tabular}{|l|l|l|l|l|l|l|l|l|l|l|l|l|l|l|l|l|l|l|l|l|l|l|l|l|l|}
\hline & A & B & C & & D & E & F & G & H & I & J & K & L & M & & N & O & & P & Q & R & S & T & U & V \\
\hline $\mathrm{F}$ & & & & & & & & & & & & & & & & & & & & & & & & & \\
\hline & & & & & & & & & & & & & & & & & & & & & & & & & \\
\hline $2 \mathrm{~F}$ & & & & & & & & & & & & & & & & & & & & & & & & & \\
\hline $3 \mathrm{~F}$ & & & & & & & & & & & & & & & & & & & & & & & & \\
\hline $26 \mathrm{~F}$ & & & & & & & & & & & & & & & & & & & & & & & & & \\
\hline $27 \mathrm{~F}$ & & & & & & & & & & & & & & & & & & \\
\hline
\end{tabular}

Note. Key below.

\begin{tabular}{|l|l|l|}
\hline $\begin{array}{l}\text { Provision emphasised as highly } \\
\text { important by incubator }\end{array}$ & $\begin{array}{l}\text { Provision viewed as moderately } \\
\text { important by incubator }\end{array}$ & $\begin{array}{l}\text { Importance not mentioned by } \\
\text { interviewee }\end{array}$ \\
\hline Provision used by firm & $\begin{array}{l}\text { Provision known about but not used by } \\
\text { firm }\end{array}$ & $\begin{array}{l}\text { Provision not known about or used by } \\
\text { firm }\end{array}$ \\
\hline & & \\
\hline
\end{tabular}

None of the firms had external governance or received external investment while in the incubator. This is reflected in the low usage of the related provisions of helping with 
developing a board of directors or advisors $(\mathrm{K})$ and connections to potential board members (R).

The usage of the provisions of connections to potential major customers $(\mathrm{S})$ and subject matter experts (Q) was also relatively low. This could be as a consequence of the interview participants of the firms all being from industry-specific backgrounds, as opposed to a technical or business background. This may mean that the firms already had these industryspecific connections and therefore relied on the incubator for non-industry-specific provisions, such as connections to professional services, as discussed above.

One firm in this incubator used all of the provisions with the exception of the internal-tangible provisions. The rest of the firms used only a limited range of available provisions. This is a similar observation to incubator B, discussed above, an incubator which offered a wide range of services to the business community, and whose firms had relatively low usage rates of provisions, and with one outlier.

\subsubsection{Strategy developments in incubator $F$}

Table 65

Comparison of Strategy Developments Anticipated by Incubator F and Undertaken by its Firms

\begin{tabular}{|c|c|c|c|c|c|c|c|}
\hline & \multirow{2}{*}{$\begin{array}{l}\text { Goal } \\
\text { orientation }\end{array}$} & \multicolumn{2}{|c|}{ Process orientation } & \multicolumn{4}{|c|}{ Content orientation } \\
\hline & & $\begin{array}{l}\text { Deliberate or } \\
\text { emergent } \\
\text { process }\end{array}$ & $\begin{array}{l}\text { Planning } \\
\text { process }\end{array}$ & $\begin{array}{l}\text { Partnership } \\
\text { status changes }\end{array}$ & $\begin{array}{l}\text { Product scope } \\
\text { changes }\end{array}$ & $\begin{array}{l}\text { Competitive } \\
\text { emphasis } \\
\text { changes }\end{array}$ & $\begin{array}{l}\text { Time } \\
\text { allocation } \\
\text { changes }\end{array}$ \\
\hline Inc. $F$ & $\begin{array}{l}\text { Emphasis } \\
\text { down }\end{array}$ & $\begin{array}{l}\text { Deliberate to } \\
\text { emergent }\end{array}$ & $\begin{array}{l}\text { Planning goes } \\
\text { up and more } \\
\text { purposeful }\end{array}$ & $\begin{array}{l}\text { Investment } \\
\text { goes up }\end{array}$ & & & \\
\hline \multicolumn{8}{|l|}{ Firms } \\
\hline $2 \mathrm{~F}$ & & $\begin{array}{l}\text { Emergent to } \\
\text { deliberate (E) }\end{array}$ & $\mathrm{Up} \quad(\mathrm{E}, \mathrm{I})$ & & $\begin{array}{l}\text { Evolution } \\
\text { (middle) (S) }\end{array}$ & & $\begin{array}{l}\text { More efficient } \\
\text { (periphery) (E) }\end{array}$ \\
\hline $3 \mathrm{~F}$ & & & & & $\begin{array}{l}\text { Scalable ICT } \\
\text { (middle) (F) }\end{array}$ & & $\begin{array}{l}\text { More efficient } \\
\text { (periphery) } \\
\text { Natural } \\
\text { evolution }\end{array}$ \\
\hline $26 \mathrm{~F}$ & $\begin{array}{l}\text { More precise } \\
\text { (I) }\end{array}$ & $\begin{array}{l}\text { Emergent to } \\
\text { deliberate (E) }\end{array}$ & & & $\begin{array}{l}\text { Evolution } \\
\text { (middle) } \\
\text { Other } \\
\text { influence }\end{array}$ & & $\begin{array}{l}\text { Switched focus } \\
\text { (periphery) (E, } \\
\text { S) }\end{array}$ \\
\hline $27 \mathrm{~F}$ & & & & & $\begin{array}{l}\text { Ceased (core) } \\
(\mathrm{E}, \mathrm{H}, \mathrm{P})\end{array}$ & & \\
\hline
\end{tabular}

Note. Key below.

\begin{tabular}{|l|l|l|}
\hline $\begin{array}{l}\text { Strategy development emphasised as } \\
\text { highly likely by incubator }\end{array}$ & $\begin{array}{l}\text { Strategy development viewed as } \\
\text { moderately likely by incubator }\end{array}$ & $\begin{array}{l}\text { Strategy development viewed as not } \\
\text { likely by incubator }\end{array}$ \\
\hline $\begin{array}{l}\text { Strategy development continuum } \\
\text { changed due to incubator influence }\end{array}$ & $\begin{array}{l}\text { Strategy development continuum } \\
\text { changed due to non-incubator influence }\end{array}$ & $\begin{array}{l}\text { Strategy development continuum did not } \\
\text { change due to incubator influence }\end{array}$ \\
\hline & & \\
\hline
\end{tabular}

For the partnership status continuum incubator $\mathrm{F}$ anticipated that the level of investment and governance would go up, however there were no changes along this continuum (refer 
Table 65). On the product scope continuum three of the firms changed due to the incubator's influence, but only one of these was classified as impacting the core of the firm. On the competitive emphasis continuum incubator $\mathrm{F}$ did not predict any changes, and correspondingly no firms made any changes along this continuum, which was unusual compared to the other incubators.

Incubator $\mathrm{F}$ had the lowest rate of strategy developments that were influenced by the incubators' provisions. There were two provisions for which the level of the strategy developments that their affordances influenced was higher than for the other incubators: financial planning and management (I) and connections to potential major customers (S), refer Figure 17. There was some misalignment between the incubator's views and what happened with the firms along the deliberate to emergent continuum; the firms that changed, changed in the opposite way to what was predicted. There was also some misalignment in the product scope continuum with incubator F not predicting any changes, whereas all firms changed along this continuum.

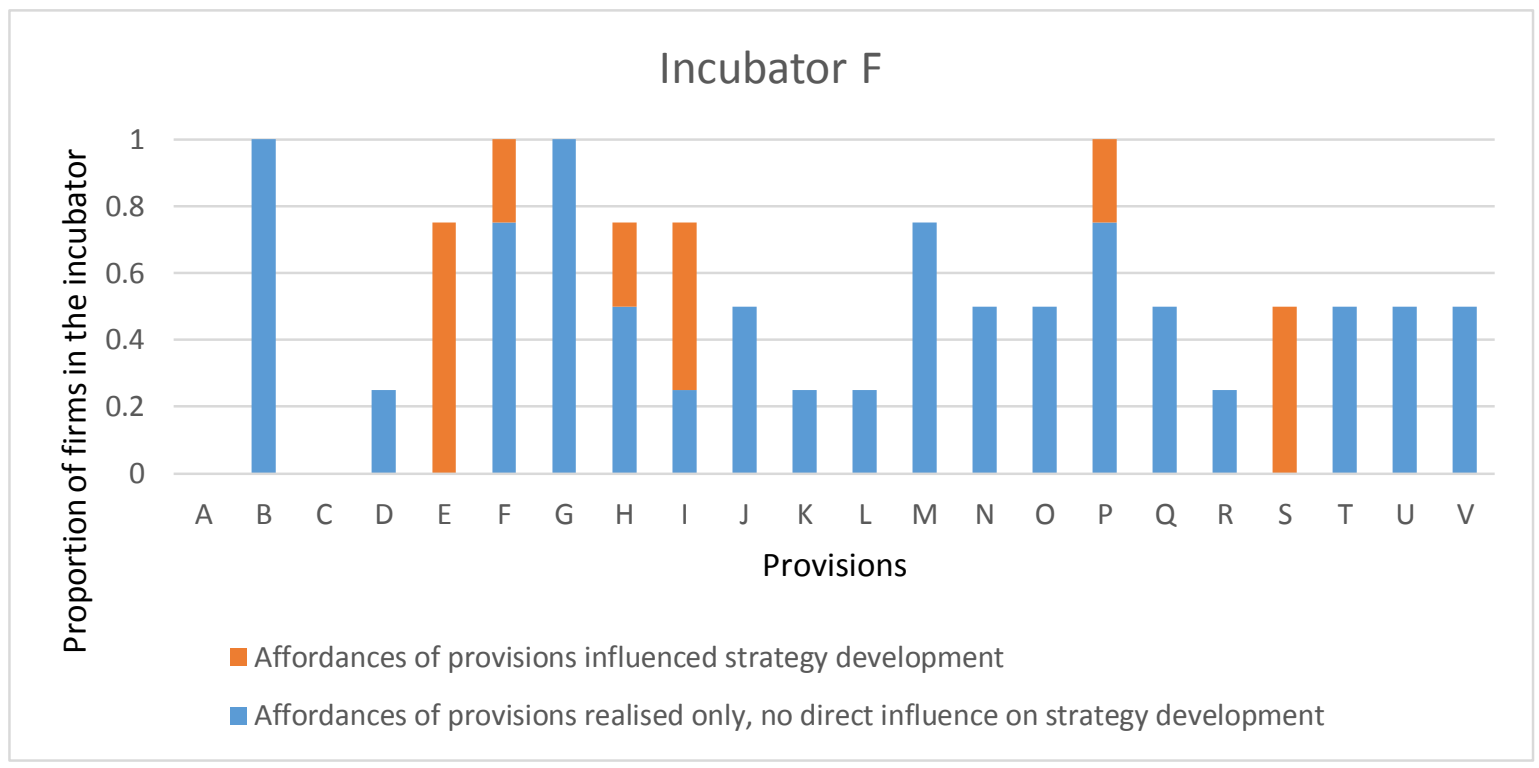

Figure 17. Proportion of firms that used provisions in incubator $\mathrm{F}$ and the influence on strategy development

\subsubsection{Summary of incubator F's influence}

Incubator F was very similar to incubators B and D - which were also at the BFI end of the continuum - in that it offered a wide range of services to the business community, and to a wide range of firms. Like incubator $\mathrm{D}$ it also emphasised offering external-intangible provisions in place of internal-intangible provisions delivered by the incubator staff, particularly connections to professional advisors $(\mathrm{P})$, indicating a degree of substitution. 
Overall incubator $\mathrm{F}$ appeared to be focused on getting firms through workshops and programmes. Few strategy developments were made overall, and those that were made along the content orientation mainly impacted the firms at their periphery, as opposed to their core, and there was a degree of mismatch between what the incubator predicted and what happened in firms. 


\subsection{Summary table}

Table 66 presents a summary of the nature of affordances that influenced strategy development within each incubator.

Table 66

Summary of the Nature of the Affordances of the Provisions That Influenced Strategy Development

\begin{tabular}{|c|c|}
\hline Incubator & Nature of affordances from provisions: Summary drawn from this chapter \\
\hline $\mathrm{E}$ & $\begin{array}{l}\text { Some clustering occured of affordances of provisions that related to product } \\
\text { development and financing. } \\
\text { A range of specific affordances was enabled due to the firms all being HTFs. } \\
\text { Many provisions appeared necessary but not sufficient to influence strategy development } \\
\text { on their own, for example provisions A and D. } \\
\text { The influence affected the core of the content orientation of the firms' strategies, namely } \\
\text { on the product scope dimension. }\end{array}$ \\
\hline A & $\begin{array}{l}\text { Some clustering occurred of affordances of provisions that related to product validation } \\
\text { and financing. } \\
\text { A range of specific affordances was enabled due to the firms all being HTFs. } \\
\text { The affordances of a range of provisions influenced strategy development. } \\
\text { There was a mismatch between the strategy developments that were predicted by } \\
\text { incubator and the strategy developments that occurred in firms. } \\
\text { The influence was mainly on the content orientation of the firms' strategies, namely } \\
\text { product scope and competitive emphasis changes. }\end{array}$ \\
\hline C & $\begin{array}{l}\text { A range of specific affordances were enabled due to the firms all being ITFs. } \\
\text { The affordances that were perceived by incubator seemed to match affordances realised } \\
\text { by firms and came from a wide range of provisions. } \\
\text { The influence on the firms' strategies was deep and broad and was across all } \\
\text { continuums. }\end{array}$ \\
\hline B & $\begin{array}{l}\text { There was some mismatch between the strategy developments that were predicted by } \\
\text { incubator and that which occurred in firms. } \\
\text { The affordances came from a relatively narrow range of provisions, mainly E and H, } \\
\text { indicating that many of the incubator's affordances, while realised, were not sufficient to } \\
\text { influence strategy development. } \\
\text { The influence on the firms' strategies was mainly focused on the goal orientation and at } \\
\text { the periphery of the content orientation. }\end{array}$ \\
\hline $\mathrm{D}$ & $\begin{array}{l}\text { The affordances came from a narrow range of provisions, mainly E, } \mathrm{H} \text { and I, indicating } \\
\text { that many other provisions were not sufficient to influence strategy development. } \\
\text { Affordances from the internal provisions were sometimes substituted with affordances } \\
\text { from external provisions, such as advice from the incubator's advisors with advice from } \\
\text { external business mentors. } \\
\text { Many affordances of provisions were not realised by firms, despite being perceived. } \\
\text { The influence on firms' strategies was mainly on the goal and process orientations and } \\
\text { on the product scope and the competitive emphasis of the content orientation. }\end{array}$ \\
\hline $\mathrm{F}$ & $\begin{array}{l}\text { Some affordances from often internally-provided provisions were substituted with } \\
\text { affordances from external provisions, such as advice from P. } \\
\text { There was some mismatch between the strategy developments that were predicted by } \\
\text { incubators and that which occurred in firms. } \\
\text { The affordances came from a narrow range of provisions, mainly E, I and S, indicating } \\
\text { that many affordances were not sufficient to influence strategy development. } \\
\text { The influence on firms' strategies seemed minimal and was mainly along the product } \\
\text { scope and time allocation dimensions. }\end{array}$ \\
\hline
\end{tabular}




\subsection{Chapter summary}

The sub-question that Chapter Seven addressed was: How may the incubator-specific factors be related to the incubators' influence on strategy development?

The analysis highlighted that there are differences in the incubators. Accordingly the incubators were put on a continuum according to whether they focused on just incubation or on a range of services to the business community. At the narrow end of the continuum are Incubators $\mathrm{E}$ and $\mathrm{A}$, and these incubators were termed narrow-focused incubators (NFIs). The NFIs focussed on just incubation-specific services and focussed on HTFs with just individuals as opposed to teams. Similarly, incubator C, which was placed nearer the middle of the continuum, focused on ICT firms, again with just individuals. This propensity to focus on specific types of firms appeared to enable a greater degree of tailoring to the needs of each firm, enabling greater specificity of affordances. The specificity was achieved through the provision and use of a relatively narrow range of internal provisions, especially in incubators $\mathrm{E}$ and A. For example, these incubators had developed their own methodologies for the validation of products and markets. The NFIs also emphasised raising capital for the firms. Consequently the affordances of some related provisions appeared to cluster together. There was a relatively high degree of the affordances of provisions appearing to be sufficient to influence strategy development. The strategy developments that were influenced by the NFIs tended to be those related to content orientation, with the process orientation changes being relatively few.

At the other end of the continuum were the broad-focused incubators (BFIs) B, D and F. These incubators offered a broader range of services to the business community beyond just incubation services. They did not specialise in specific types of firms and selected firms that consisted mainly of teams. These incubators all had structured multi-firm-based programmes, potentially meaning that the paths that the firms took, and consequently their strategy development process, were somewhat similar to the other firms in the same incubator.

This lack of focus on just incubation, individual firms or on certain types of firms seemed to suggest that the affordances of provisions were not tailored to the needs of each firm and so were less specific. While the provisions used by firms covered a broader range in the BFIs, a narrower range of provisions appeared to influence strategy development. This may indicate that many of the affordances from the provisions were not sufficient to be of influence. 
Incubators $\mathrm{D}$ and $\mathrm{E}$ tended to have a higher usage rate of provisions in the externalintangible category, with some of the functions being outsourced to the incubators' networks. This outsourcing of functions indicated that there may be a degree of substitution. The strategy developments that were influenced by the BFIs tended to be along the goal and process orientation and have peripheral influence along the content orientation. In incubators $\mathrm{B}$ and $\mathrm{F}$ there was a mismatch between the strategy developments that were predicted by incubators and what occurred in firms.

Given that there appears to be substantial differences in the incubators it is likely that if a firm was in incubator E, for example, then the incubator's influence would be different than if they went into incubator $\mathrm{F}$. This concept presents the notion that the affordances from one incubator could be substituted with the affordances from another incubator, but that doing so would potentially result in different strategy developments. However, the exact effect on individual firms could not be known from the data as no two firms in the study were identical. The differences between the incubators are explored further in the discussion in Chapter Eight. 


\section{Discussion}

\subsection{Introduction}

The research question 'How may incubators influence firms' strategy development?' was addressed through four sub-questions:

1. What are the affordances of the incubators' provisions?

2. How may the provisions' affordances influence strategy development?

3. How may the firm-specific factors be related to the provisions' influence on strategy development?

4. How may the incubator-specific factors be related to the provisions' influence on strategy development?

These questions were analysed in Chapters Four to Seven. Here, in Chapter Eight, each subquestion is addressed along with a number of key findings which are;

- the firms' value judgements of provisions sometimes differed according to use;

- the firm's product type may be important;

- the firms' governance structure may be important;

- the influence of affordances changes with time; and

- the incubators' breadth of focus appears to matter.

These key findings are discussed in relation to the research sub-questions with discussion on why they might occur and how they relate to existing knowledge. In these discussions attention is paid to how the theory of affordances (TOA) can enable nuanced insights into the incubators' influence on firms' strategy developments. Three key themes emerged about the application of the TOA in an organisational context: the specificity of affordances, the substitutability of provisions and path dependency. These themes are then discussed in relation to existing TOA knowledge.

\subsection{The conceptual model}

The original conceptual model depicted two main constructs: the incubators' provisions and the firms' strategy developments. The relationship between these constructs was shown by the arrow, which indicated that affordances come from the incubators' provisions, which can then be perceived or realised. It was noted that two main contextual factors, incubators and firms, could impact on the relationship between the two main constructs. 


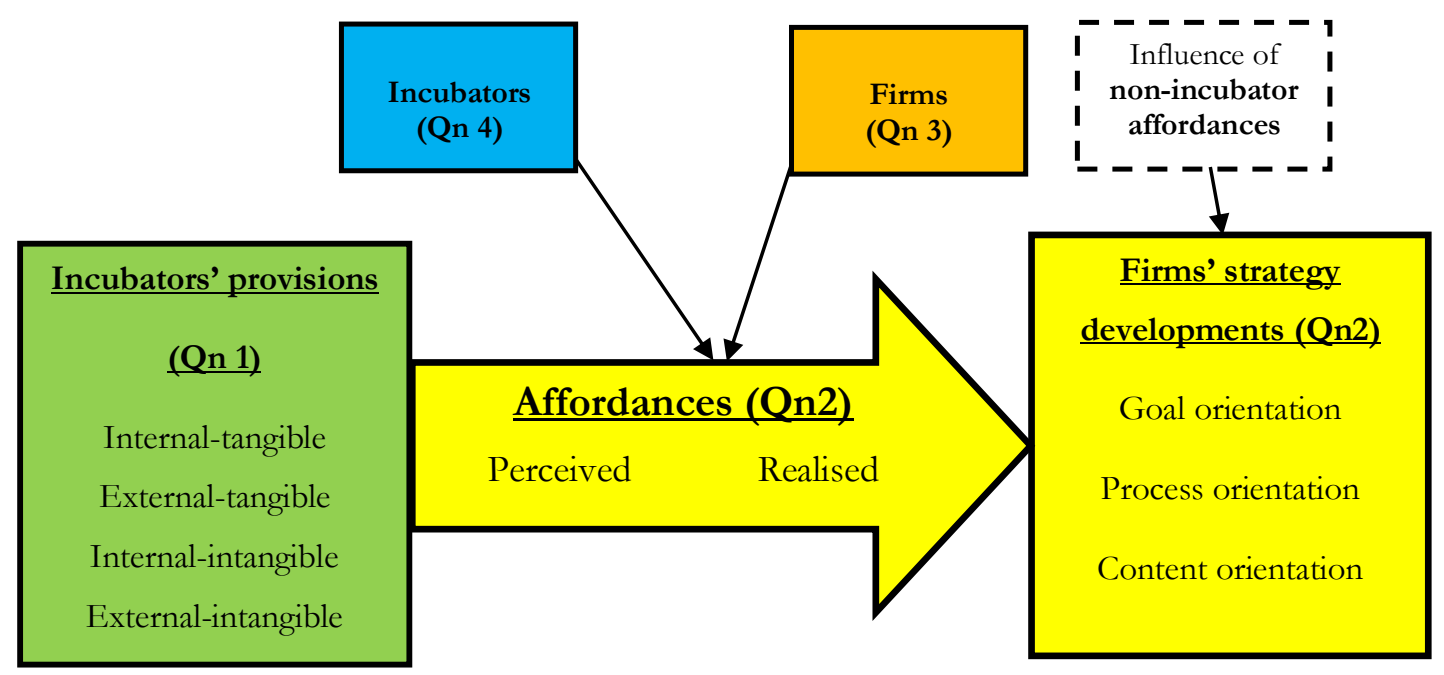

Figure 18. Conceptual model showing the relationships between the key constructs and contextual factors

Figure 18 shows how each part of the model is addressed by the study's sub-questions.

\subsection{Addressing the research questions}

Due to the linkages that became apparent in the analysis between Question One (What are the affordances of the incubators' provisions?) and Question Two (How may the provisions' affordances influence strategy development?), the findings of these two sub-questions are combined for the purpose of this discussion.

\subsubsection{Question One: What are the affordances of incubator provisions? And Question Two: How may the provisions' affordances influence strategy development?}

Chapter Four analysed the firms' value judgements, provision usage rates and the nature of the affordances of the provisions. Not surprisingly, it was found that the firms' value judgements of provisions were different depending on whether the firms had used them or not, although few variations were statistically significant. It was also found that the range of affordances and frequency of use for each provision appeared to differ between the firms. Chapter Five analysed the strategy developments that occurred in the firms and what influenced them. It was found that patterns of influence occurred across all strategy developments and that almost all patterns appeared to be related to either the differences in the firms or to differences in the incubators. In the interest of avoiding repetition in this discussion, this section simply addresses how incubators influenced strategy development overall, with reference to topics that will be expanded on in the discussion on Questions Three and Four. 


\subsubsection{The firms' value judgements of provisions differed according to use}

The value judgements of the internal-intangible provisions were measured on a scale of 0 to 100 and were generally much higher for firms that had used them, than those that had not. The cases where provisions were valued more highly by firms that had used them may indicate that firms realised affordances that they had not perceived or that the non-users did not want or need the provisions. Notable cases that were statistically different were the firms' head office being in the incubator (A), with users valuing the provision at 49 points higher than non-users; the use of meeting rooms in the incubator (B) at 37 points higher for users; connections to potential board members $(\mathrm{R})$ at 22 points higher for users' and connections to business mentors from outside the incubator $(\mathrm{U})$ at 21 points higher for users.

Overall, the internal-intangible provisions and the external-intangible provisions appeared to be judged to be more valuable by firms that had used them than by those that had not, although the data was not statistically different. Conversely, the external-tangible provisions appeared to be judged to be of less value by firms that had used them, by just under seven points, but again the data was not statistically different.

\subsection{Possible reasons for the differences}

In the literature review it was concluded that there could be wide differences in the quality and availability of incubators' provisions, and in the way that the provisions were perceived by firms. Meru and Struwig (2011), Xu (2010), and Abduh et al. (2007) found that while the internal-intangible provisions were highly valued by firms, they actually performed below the firms' expectations. In addition, Rice (2002) studied the value derived from the incubators' networks and found that the value from these external-intangible provisions was less than expected. This was because of a lack of awareness by the firm of their knowledge gaps, competencies and resources; a lack of awareness of how the incubator could help the firm; and a lack of willingness on both sides to engage with each other (Rice, 2002). Interestingly, the findings of this particular study actually suggested differently, that is, the internalintangible and the external-intangible provisions appeared to be valued at a higher level by those firms that had used them, than by those that had not, although it was not statistically different. This finding indicates that the firms that had not used these intangible provisions may have perceived fewer affordances which were realised by the firms that had used these provisions. For example, the low value judgement of the provision of product validation and development $(\mathrm{F})$ by firms that had not used it is perhaps not surprising as the incubators did 
not appear to place much importance on this provision (refer Section 4.4.2.3), and therefore the incubators may not have promoted the potential affordances. Therefore the perceived affordances were potentially lower than the realised affordances. Alternatively, of course, the firms that did not use the provisions may have simply valued them less because they did not need or want them.

In contrast, firms that had not used the provision of connections to professional services $(\mathrm{P})$ judged the value more highly than firms that had used it. Potentially the firms that had not used this provision perceived the affordances of subsidised specialist advice, as noted by Hackett and Dilts (2004b), whereas the firms that had used this provision may have found that the provision was not as low-cost or as useful as they had expected. This may suggest that the perceived affordances can be greater than the realised affordances.

\subsubsection{The affordances of provisions vary in scope and in frequency of use}

The affordances of the internal-intangible provisions had the most influence on firms' strategy development, especially along the goal and process orientations. Generally these provisions also had a high frequency of use and, as discussed above, had a higher value judgement by firms that had used them. Within this category the affordances of strategy methodologies (E) and market validation and development $(\mathrm{H})$ were deemed to be of influence in $45 \%$ and $22 \%$ of all strategy developments respectively. These two provisions appeared to cluster together, for example, firms were commonly influenced by affordances from both assistance with strategy development and assistance with market validation and development.

In Chapter Four the incubators' provisions were found to have a varying range of affordances and varying frequencies of use required in order to extract maximum value. However, most provisions were considered to have relatively singular affordances, such as help with specific functions (A, B, C, D, F, G, I, J, K, L, N, O, P, Q, R, S, T, U, V) whereas for others multiple affordances were enabled (E, H, M). Further, some provisions influenced a range of different strategy developments $(\mathrm{E}, \mathrm{H}, \mathrm{I}, \mathrm{S})$ and others did not directly influence any (A, D, G, L, M, N, V). 


\subsection{Possible reasons for the differences}

The affordances of the provisions that influenced a range of strategy developments generally did so by giving the firms the structure and tools on which to form their strategies, gather information from their environment and then challenge their assumptions, enabling the firms to reach their own informed conclusions about their strategies. The affordances therefore appeared to start off being narrow and specific before broadening in scope, which resulted in a widening of the ensuing opportunities for action. This need for firms to gather information about their environment in order to make effective decisions is reflected in the literature (Nicholls-Nixon et al., 2000; van Gelderen, 2012; Woo et al., 1994).

In contrast, other provisions had little or no direct influence on strategy development, such as office space (A) and assistance with general business administration tasks (D). However, these provisions appeared to offer specific and functional affordances, and therefore, were still considered important to the firm because they could be considered 'hygiene' factors (discussed further in Section 8.4.2.1.2) in the sense that without these provisions the firm would have less capacity to focus on its strategy development. These provisions are consequently deemed to be necessary but not entirely sufficient to influence strategy development.

Also, some provisions may need to be used only once in order for the maximum affordances to be extracted, whereas others may need to be used on an ongoing basis. For example, the provision of assistance with market validation $(\mathrm{H})$ which had an average usage frequency of 3.62 (equates to usage levels between once a month and 2-3 times a month), could be used by the firm soon after entry into the incubator in order to test their strategy, and then again at later intervals whenever the firm considered entering a new market or changing or adding a new product. Therefore, ongoing affordances could be realised from frequent use of this provision. Other provisions, such as connections to angel investors and venture capitalists $(\mathrm{O})$, could not generally be used immediately on entry into the incubator.

The frequency of use of some provisions would potentially also depend on the prior affordances realised from the provisions. This prior realisation could exert either a positive or negative influence. For example, a firm may have used the provision of connections to external business mentors $(\mathrm{U})$ with good result and therefore be inclined to use it again, and so the usage frequency increases as further affordances are realised. The incubators' influence 
on strategy development could therefore be path dependent. Figure 19 illustrates this using firm $10 \mathrm{C}$ as an example.

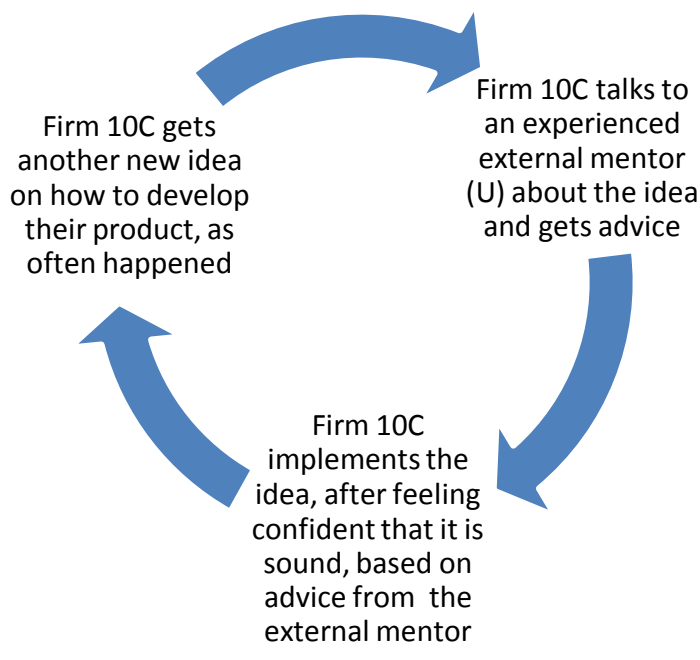

Figure 19. Example of 10C's repeated use of a provision due to the ability to extract ongoing value

On the other hand, a firm may successfully use the provision of assistance with developing a board of directors $(\mathrm{K})$ - which had a relatively low usage frequency of 2.11 (equates to usage levels once a month and just once), - but this time the provision needs to be used less often as the affordances diminish with subsequent use.

The characteristics of the firms also appear to impact on the scope of affordances that firms realise from provisions, and this is addressed in the discussion on Question Three, in Section 8.3.2.

Based on the above discussion, both the scope of the affordances of provisions and the frequency of use of the provisions could be on a continuum as presented in Figure 20. However, while it is tempting to create this continuum, it appears that the firms' prior realisation of affordances from some provisions may have a substantial impact on both the realisation frequencies and the range of affordances for other provisions.

Some provisions appeared to function as substitutes for other provisions in that their affordances had a similar type of influence. This appeared to be the case on the partnership status continuum where the provision of funding from the incubator itself $(C)$ was sometimes substituted for connections to angel investors or venture capitalists $(\mathrm{O})$. In addition, the advice that came from the incubator staff was, in some incubators, substituted 
for advice that came from business mentors $(\mathrm{U})$. These substitutions are explored further in the discussion on Question Four in Section 8.3.3.

\begin{tabular}{|c|c|c|c|c|c|}
\hline $\begin{array}{l}\text { High usage } \\
\text { frequency }\end{array}$ & $\begin{array}{l}\text { Meeting rooms } \\
\text { (B) and firms' } \\
\text { head office in } \\
\text { incubator (A) }\end{array}$ & & & & $\begin{array}{c}\text { Market } \\
\text { validation and } \\
\text { development } \\
(\mathrm{H})\end{array}$ \\
\hline & $\begin{array}{c}\text { General } \\
\text { business } \\
\text { administration } \\
\text { tasks (D) }\end{array}$ & & $\begin{array}{l}\text { Connections to } \\
\text { business } \\
\text { mentors from } \\
\text { outside the } \\
\text { incubator }(\mathrm{U})\end{array}$ & & $\begin{array}{c}\text { Strategy } \\
\text { methodologies } \\
\text { (E) }\end{array}$ \\
\hline & & $\begin{array}{l}\text { Financial } \\
\text { planning and } \\
\text { management } \\
\text { (I) }\end{array}$ & & $\begin{array}{c}\text { Growth } \\
\text { management } \\
\text { (J) }\end{array}$ & \\
\hline & $\begin{array}{c}\text { Developing a } \\
\text { team of people } \\
\text { (L) } \\
\text { Connections to } \\
\text { interns from } \\
\text { tertiary } \\
\text { institutions }(\mathrm{V})\end{array}$ & $\begin{array}{c}\text { Connections } \\
\text { to } \\
\text { professional } \\
\text { services }(\mathrm{P})\end{array}$ & $\begin{array}{l}\text { Connections to } \\
\text { subject matter } \\
\text { experts (Q) } \\
\text { Connections to } \\
\text { universities and } \\
\text { other tertiary } \\
\text { institutions (T) }\end{array}$ & $\begin{array}{l}\text { Connections } \\
\text { to potential } \\
\text { major } \\
\text { customers } \\
\text { (S) }\end{array}$ & $\begin{array}{c}\text { Product } \\
\text { validation and } \\
\text { development } \\
\text { (F) }\end{array}$ \\
\hline \multirow[t]{2}{*}{$\begin{array}{l}\text { Low usage } \\
\text { frequency }\end{array}$} & $\begin{array}{c}\text { Connections to } \\
\text { potential board } \\
\text { members }(\mathrm{R})\end{array}$ & $\begin{array}{c}\text { Pitching } \\
\text { development } \\
\text { and practice } \\
(\mathrm{G}) \\
\text { Developing } \\
\text { a board of } \\
\text { directors or } \\
\text { advisors }(\mathrm{K})\end{array}$ & $\begin{array}{l}\text { Connections to } \\
\text { angel investors } \\
\text { or venture } \\
\text { capitalists }(\mathrm{O}) \\
\text { Connections to } \\
\text { government } \\
\text { grants }(\mathrm{N})\end{array}$ & $\begin{array}{l}\text { Funding for } \\
\text { firm by } \\
\text { incubator } \\
\text { (C) }\end{array}$ & $\begin{array}{c}\text { Educational } \\
\text { workshops }(\mathrm{M})\end{array}$ \\
\hline & $\begin{array}{l}\text { Narrow range } \\
\text { of affordances }\end{array}$ & & & & $\begin{array}{l}\text { Wide range of } \\
\text { affordances }\end{array}$ \\
\hline
\end{tabular}

Figure 20. Proposed continuum of provisions according to their frequency of use and scope of affordances

\subsubsection{Question Three: How may the firm-specific factors be related to the provisions' influence on strategy development?}

In Chapter Six the different characteristics of the firms were analysed. It was found that the firms' product type may have an impact. Firms with information-technology products (ITFs) developed their strategies more, and in different ways, compared to the physical-productbased firms. It was found that the firms' governance structure may also have an impact as WGFs used the incubator provisions more, but underwent fewer strategy developments due to the incubators' influence, mainly along the goal and process orientations. It was also 
found that duration-related factors were important, with older firms doing less planning and being influenced by external provisions to a greater extent. Few differences were apparent in the firms' stage of development on entry into the incubator, the background of the interview participants, the location of the firms' head office, the number of people employed and the level of interaction the firm had with their advisor.

\subsubsection{Firms' product type}

How the affordances influenced the firms varied depending on the firms' product type. Overall, information-technology firms (ITFs) underwent greater levels of strategy developments than the high-technology-firms (HTFs). With respect to the goal orientation the ITFs changed to a greater degree: six of the eight firms increased their goals. The goals of the physical-product-based firms, however, generally became more precise or decreased, which was the case for six out of eight of these firms that changed. Of the nine firms that changed along the deliberate to emergent continuum all the ITFs that changed (five firms) adopted more emergent strategies and all the physical-product-based firms that changed (four firms) adopted more deliberate strategies.

All but five firms changed along the product scope continuum. The ITFs tended to change their product scope in a drive to become more scalable, whereas the physical-product-based firms changed in a drive to become more platform-based. The ITFs made more changes to their competitive emphasis, with 14 of the 17 ITFs changing, compared to just five of the 13 HTFs changing on this continuum. The ITFs were more aware of the availability of a large number of provisions, but did not use them to the same extent as the HTFs did.

Overall, the affordances that influenced the strategy developments in the ITFs were from provisions that were wider in scope than those that influenced the HTFs, which tended to be influenced by affordances that were narrower in scope.

\subsection{Possible reasons for these differences}

Based on the literature review and the incubators' predictions in the discussion on Question Two, it was concluded that firms would be most likely to adopt strategies that were more emergent as opposed to more deliberate (Kiss, 2010; Mintzberg \& Waters, 1985; NichollsNixon et al., 2000). The methodologies the incubators employed to facilitate this emergent approach included the widely adopted Lean Start-up and the Business Model Canvas. However, the only firms whose strategies became more emergent were the ITFs (4B, 10C, $16 \mathrm{C}, 22 \mathrm{D}, 30 \mathrm{C})$. These firms may have come into the incubator with quite a fixed idea of 
their strategy, only to have that idea change substantially during their time in the incubator. This notion of flexibility of ITFs is also reflected in the goal orientation where ITFs were more likely to increase their goals, which is in line with the conclusions of Mintzberg and Waters (1985) that NEFs have greater scope to change their strategies. On the other hand, the four physical-product-based firms that changed went from emergent to deliberate and made fewer changes to their goal orientation, potentially implying less flexibility. They also made fewer changes to their product scope. The reason that the HTFs were less flexible could have been because high-technology physical products appeared to require considerable time and investment to develop them, thus making substantial changes less feasible than changes to information-technology based products. Strategic experimentation (NichollsNixon et al., 2000) is potentially also less viable for HTFs, and it could have been further hindered by the frequent requirement for HTFs to undergo some sort of regular certification before trialling the products, which can be a long and resource-intensive process. The path that a firm had taken in terms of their choice of product type appears to have impacted the scope of affordances that influenced strategy development.

In addition, the trend towards a more deliberate strategy by the HTFs and the lack of change on this continuum by most firms, might mean that while the incubators appear to want the firms to become more emergent with their strategies, their widespread use of structured tools and programmes (refer Section 4.4.2.2) may have meant that in many cases the incubator actually had the opposite effect on the firms. Therefore, on the one hand the incubators' predicted that their provisions will make the firm adopt a more emergent strategy, but the very nature of the incubator in giving structure to the strategy development process makes the firms' strategies neither more deliberate nor emergent than they were before entry into the incubator.

Another reason why the physical-product-based firms were less likely to adopt an emergent strategy and to make fewer changes to their product scope may have been because they had already done much of their 'emergent' product validation work prior to entering the incubator. Mintzberg and Waters (1985) found that new firms' strategies may become more emergent as time goes on, and then somewhat deliberate as the firms reach maturity, although, incubator firms could hardly be considered mature. Instead, it may be that the incubators only accepted HTFs with products that were already at least partially validated. However, much of this validation may have been done prior to the firms actually forming as, 
on the whole, the HTFs had not been in operation longer than the ITFs prior to entering the incubator. In fact, it almost appeared to be the opposite (refer Table 47, Chapter Six). Over half the HTFs (13E, 19D, 20E, 23E, 25E, 28E, 33A) were actually formed out of the process of transferring technology from universities, and these technologies had often been in development for many years prior to the firm actually forming. Therefore by the time the firm was formed there was less scope to develop the product. Consequently some incubators may have been reluctant to focus on this early stage of product development for the HTFs, as they wanted firms that could achieve success in a timelier manner, and so had less influence on the product scope changes of these firms.

The ITFs, on the other hand, were potentially much more suited to emergent strategy methodologies, such as the Lean Start-up approach, which most of the incubators adopted. These firms were potentially able to develop their products more quickly and flexibly and therefore the incubators were able to provide assistance at a much earlier stage of product development. The path that the firms had taken previously in terms of product market validation and development therefore appeared to impact the degree to which incubators could influence the firms' strategy developments. Using firm 7D as an example, Figure 21 illustrates the flexibility of an ITF.

Product version A

was created and

the concept was

challenged by the incubator
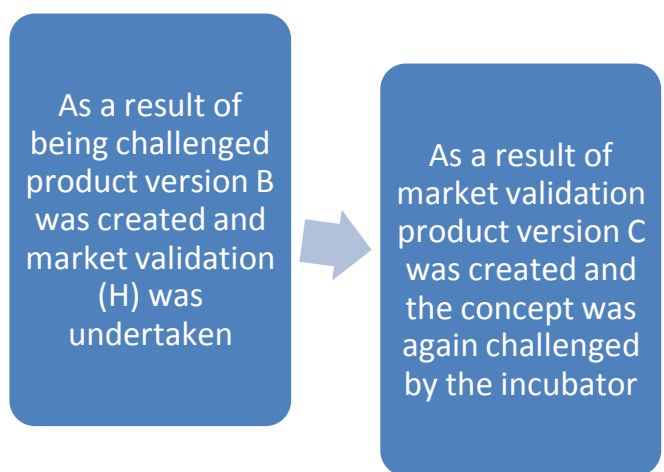

As a result of

being challenged

through the use

of strategy

methodologies

(E), product

version D was

created and

accepted by the

market

Figure 21. Example of ITF firm 7D showing how their product was flexible and why it changed substantially

It was interesting that the firms' stage of development on entry into the incubator did not appear to be related to the firms' product type. Given the discussion above, it could have been expected that HTFs would have been more likely to be at the prototype or trading stage on entry into the incubator, and that ITFs would be at the concept stage. However, given the lack of clear differentials, the likely scenario is that, while the stages of development may 
have been descriptively similar, it was the inherent constraints on the product development of the HTFs that may have been a reason why these firms did not adopt an emergent strategy. For example, HTF 24B had spent a substantial amount of money on product development and consequently was reluctant to accept the findings from the market validation process and change their product accordingly, as illustrated in Figure 22.

\section{Product cost substantial \\ $\$$ to develop viable \\ concepts}

Market validation $(\mathrm{H})$

revealed that the

applications for the

product were limited
No changes were made

to the product due to

high prior investment

Figure 22. Example of HTF firm 24B showing how prior investment in product development constrained development

The actual direction of product scope changes also appeared to vary between the ITFs and the physical product-based firms (HTFs and low-technology firms). Many of the ITFs appeared to be driven to become more scalable and the physical-product-based firms more platform-based, with none of the physical-product-based firms radically changing their product scope. This is not surprising given the physical-product-based firms' inherent product development challenges, as discussed above. The reason that the ITFs sought to become more scalable seems to have been in a drive to become more efficient enabling them to reach a larger market, more cost effectively and with less ongoing resource usage. The reason for the physical-product-based firms seeking to become more platform-based appears to be a drive to extract more value from their existing capabilities by enabling differences of their product to be sold into different markets.

There were no notable differences in the rates of provision usage between the two main product-type groups. This may signal that the extra strategy developments that the ITFs underwent were not necessarily due to greater provision use, but that the scope of influence of each provision was greater. However it is noteworthy that the HTFs had lower rates of provisions that they knew about and had not used. This may have been because the incubators that specialised in HTFs (E and A) offered the firms only what they needed and no more. Therefore there appears to be an interaction effect between the product type, the affordances realised and the ensuing strategy development. Broadly speaking, the HTFs 
underwent more core strategy developments from more specific affordances, signalling path dependency as explained further in the discussion on Question Four in Section 8.3.3.

\subsubsection{Firm's governance structure}

The firms with external governance (WGFs, 14 firms) used more provisions but made fewer strategy developments overall than the firms with no external governance (NGFs, 19 firms). Interestingly, the NGFs were more aware of the availability of the incubators' provisions, but, despite this, used them at a lower rate. The firms' external governance also appeared to be related to the types of strategy developments made and not just the number of strategy developments.

The WGFs made more changes along the goal orientation due to the incubators' influence (65\% of the WGFs changed compared to $31 \%$ of the NGFs) and made fewer changes on the process orientation ( $24 \%$ of the WGFs changed compared to $44 \%$ of the NGFs). Additionally the WGFs, unsurprisingly, had higher rates of change on the partnership status continuum at $65 \%$ compared to $18 \%$ for the NGFs. There were no notable differences in the extent of changes along the product scope and competitive emphasis continuums and the NGFs made marginally more changes along the time allocation continuum.

Overall, apart from the extent of the strategy developments, there were no obvious differences in the actual provisions used and affordances realised that influenced the changes or the direction of the changes across each strategy development orientation.

\subsection{Possible reasons for the differences}

It is possible that the WGFs' external governance structure substituted the affordances of the incubator. The notion that boards add value to NEFs is not contested (Cowling, 2003; Minichilli \& Hansen, 2007). However Machold et al., (2011) and Minichilli and Hansen (2007) concluded that, overall, little research had been done on external governance in new entrepreneurial firms (NEFs). The potential value derived from boards may suggest the firms' external governance might act as a substitute for the incubators' provisions, that is, instead of seeking advice and connections from within the incubator, the firm sometimes relied on these external sources for the associated affordances.

In fact, the type of governance structure did not seem to affect the degree to which the firms' governance influenced the firm. While most of the firms that had external governance also had external investment, there were some (5D, 14D, 19D, 24D, 29B) that had a board 
of directors or an advisory board, but did not have external investment. These five firms also tended to undergo a similarly lower level of strategy development due to the incubators' influence when compared to the firms with external investment. This lack of difference suggests that the influence of non-investor board members is comparable to the influence of investor board members.

However, the influence of the firms' external governance seemed to be distinct from the influence of other individuals associated with the firm. For example, no relationship was identified between the number of strategy developments firms made and the number of people employed in the firms. This suggests that the extra people in the firm do not substitute the incubators' or the firms' governances' influence. Influence could also have come from the firms' wider networks outside the incubator, as acknowledged in the literature discussion about the typology of entrepreneurial networks (Shahidi, 1998). However, the influence of external networks on strategy development received almost no mention by any of the firms (with the exception of influence coming from boards of directors) indicating that these external networks may not substitute the incubators' provisions.

It is interesting that the WGFs had a higher level of interaction with their incubator advisors than the NGFs did but, again, this did not correspond to an increase in strategy development. This lack of difference could mean that, while the interaction was greater, the WGFs were actually less dependent on the incubator because the advice instead came from the firms' governance. That is, the quality of the advice from the incubator potentially declined despite the quantity of the interactions remaining high. In the literature review there was discussion about the conclusion made by Rice (2002) that firms need to be responsive to the incubators' advice and to develop what Rice called an “interdependent co-production relationship." The addition of external governance may have meant that the WGFs became more dependent on the external governance and therefore this interdependence was weakened, hence the level of influence of the incubators was less. However, this study also found that the WGFs used greater numbers of provisions than the NGFs, which could suggest that the firms' governance mandated greater usage of the provisions in order to extract value. The ensuing affordances of the provisions may have been necessary but not sufficient in themselves to influence strategy development as much of the influence came instead from the firms' governance. Alternatively it could simply suggest that more provisions were used in the process of obtaining the board and investment. 
Figure 23 illustrates how the influence of the incubator changed for WGF 18C.

Strategy advice was initially just from the firm's advisor in the incubator with which regular meetings were held
The firm's first external director was appointed and they had some input into strategy. The incubator advisor meetings continued
Further directors joined,

bringing investment the firm, and consequently had

greater influence on strategy than the incubator had

Figure 23. Example of WGF firm 18C showing how and why the advice from the incubator decreased

The reason why WGFs underwent fewer changes along their process orientations may have also been due to the developmental stages of the firms. The WGFs may have been less inclined to undergo strategy developments because they had already done so prior to getting investment. Potential investors may have also been drawn to firms that were no longer in the early strategy development process. The WGFs may have been in what Mintzberg (1973) termed the adaptive mode, whereas the NEFs may have been in the planning or entrepreneurial mode. A WGF firm may have arrived in the incubator with a well-developed plan, and have subsequently obtained investment (which eight of the 14 WGFs did), therefore these firms did not necessarily change their approach to planning rather they just slightly modified their strategies. In contrast, a NGF may have arrived in the incubator with no plan at all, and subsequently substantially changed their approach to planning in the hope of getting investment. This was the case for NGF $2 \mathrm{~F}$ which changed its approach to planning dramatically and was pre-investment. They started off with almost no plan saying, "I just wanted to get the product built." Firm 2F increased their level of planning so much that they ended up entering a business plan competition. Therefore the capacity that the incubator had to influence the firm was potentially somewhat related to the firm's investment path.

\subsubsection{The influence of affordances may be related to duration factors}

Overall it was found that the firms that were older on entry into the incubator and that had been in the incubator longer used a wider range of provisions as time progressed. Notably though, the usage rate for most of the internal provisions was relatively high for firms that 
had been in the incubator for less than one year. There were some exceptions: the internal provisions that could be associated with increasing stakeholders, for example, assistance with developing a board of directors $(K)$ and assistance with developing a team of people $(L)$ had relatively low use by the newer firms, compared to the older firms. This is not surprising given that older firms were more likely to increase their partnership status. Similarly, the usage rates of the external provisions appeared to be low for the newer firms and to be higher for the firms that had been in the incubator longer. This indicates that firms may concentrate on using the internal provisions early on, and then, as they mature, use the external provisions more.

Concerning the strategy developments, differences were most notable in the changes along the planning continuum. Firms that had been in the incubator for less than one year were the only ones to increase their planning (seven out of the eight newer firms that changed). To a lesser extent, firms that were younger on entry into the incubator were more likely to increase their planning. By contrast, firms that had been in the incubator longer, and that were already trading when they entered the incubator, were the only ones to reduce their planning (four out of the five older firms that changed). This may indicate that newer firms undertake a lot of planning whereas, as they mature, the level of planning decreases as they become more focussed on doing rather than planning. The affordances of influence appeared similar and came from the provisions of assistance with strategy methodologies (E) and assistance with market validation and development $(\mathrm{H})$, which appeared to cluster together in cases where planning increased, perhaps implying that the affordances' specificity increased, as discussed later in Section 8.4.1. For decreases in planning the affordances did not cluster, perhaps implying a lower degree of specificity, as discussed in Section 8.4.1.1.2.

\subsection{Possible reasons for the differences}

Given that NEFs are inclined to undertake lots of strategic experimentation (Nicholls-Nixon et al., 2000) this higher level of planning by newer firms was somewhat unexpected, that is, it could be expected that planning would reduce in NEFs as strategic experimentation increases because the firms are in a mode of exploration and discovery. However, the incubator appears to do something that causes the opposite, and so incubator firms appear to behave differently to other NEFs. This could be because incubators have provisions that give structure to the strategies of their firms during the early phase and, as the firm matures, they become less reliant on the incubator for their strategy development, specifically for their 
planning. If this is the case it reflects the belief that firms go through different developmental stages, and the gaps that the incubator needs to fill in the firms' knowledge, competencies and resources change accordingly (Rice, 2002). This need for incubators to target resources for the stages of NEFs was alluded to by Yang (2012) and Erlewine and Gerl (2004), and in New Zealand, by Incubators New Zealand (2011b) although without explanation of how this would be achieved.

This effect of creating structure in firms early on, and the ensuing initial high level of planning by firms, might occur because the incubators tended to put firms through structured programmes (especially the broad-focused incubators D, F and B that offered multi-firm-based workshops) either prior to or soon after entry into the incubator. This may mean that the reduced level of planning by firms that had been in the incubator longer could be due to their no longer attending these structured educational workshops, as opposed to a 'natural' propensity to reduce their planning.

All the incubators also had a requirement for firms to undertake market validation upon entry into the incubator, and this may have subsequently resulted in a higher rate of planning. As discussed in the literature review Cohn (1981) and Weihrich (1982) found that the analysis of the firms' immediate and wider environment is an important component of planning. It appeared that during incubation the firms substantially increased the amount of external and internal environmental analysis, and that little analysis was undertaken prior to entry into the incubator. This environmental analysis, or market validation, then informed their planning, as opposed to firms undertaking changes to strategy without this information. Figure 24 illustrates how resources were targeted at different times for firm 22D, a process which appeared typical for many firms.

Firm attended structured workshops (M), and planning increased during this process.
Market validation $(\mathrm{H})$ was

conducted during the

workshops. Planning for new strategy resulted.
As the firm implemented their

strategy the planning reduced and the usage of external provisions increased.

Figure 24. Example of firm 22D showing how and why their level of planning decreased 
The level of planning may also have been higher just after entry into the incubator because of the nature of the provisions that firms used early on. For example, firms may have used connections to the incubators' external networks early on - such as to professional services $(\mathrm{P})$, specifically financial advice - because it was seen as being desirable and because it was subsidised, as explained by Hackett and Dilts (2004b). Therefore it may have been previously unaffordable for the firms. This type of advice early on could have led to an increase in changes along the planning continuum, that is, new firms used provision $\mathrm{P}$ early on and this resulted in changes on the planning continuum. However, it is not specifically known from the data how the realisation of specific affordances evolved or changed over time. On the other hand, the incubator may have held off connecting the firms to these external networks due to the risk of the firm damaging the incubators' relationship with the network. Firm 22D explained:

You go through stages initially to prove yourself I guess, to show that you're not going to embarrass them (the incubator). But once you show some progress and some value, it's like so these guys (the firms) are actually pretty good, they are not just all talk, and so he's (incubator advisor) been opening up doors, left, right and centre.

The differences in the way that firms changed along the planning continuum also appeared to be related to the firm-specific factors, which are detailed next in the discussion on Question Three in Section 8.3.3.

\subsubsection{Other firm-specific factors}

It might also have been expected that the firms that entered the incubator at an early stage of development, for example concept-only, would have undergone more changes along the product scope continuum than firms that were already trading on entry. However, only a minor relationship was noted regarding the firms' stage of development on entry and changes in their product scope, with slightly more concept-only firms making changes along the product scope continuum. The minimal change along the deliberate to emergent continuum, and along the product scope continuum, may indicate that the firms' stage of development upon entry into the incubator bore little relation to how the incubator sought to develop each firm, as discussed in Section 8.3.2.3.

Other firm-specific factors may influence how much firms are inclined to develop their strategies. For example, it was discussed in the literature review that a firm's limited resources may reduce strategic experimentation (Covin \& Slevin, 1989; Woo et al., 1994) and that poor 
decisions by the entrepreneurs could put the firms at considerable risk (Covin \& Slevin, 1989). The firms' limited resources and risk-aversion could also help explain the apparent reticence of firms to become more emergent in their strategy development. Incubator F specifically acknowledged the risk of failure as being a reason why firms might be reluctant to experiment with their strategies. However, risk aversion was not specifically considered in this study and presents an opportunity for further research.

The firms' readiness to engage with the incubator also appeared to impact the influence that the incubator had on the firms' strategy development. This is proposed because the number of firms' strategy developments did not proportionally decrease with time, signalling a reduction in the influence of the incubator. Some firms appeared to have outgrown the resources of the incubator. For example firms $6 \mathrm{C}$ and $4 \mathrm{~B}$ no longer wanted to be told what to do by the incubator, thus reducing the incubators' potential to influence the se firms.

\subsubsection{Question Four: How may the incubator-specific factors be related to the provisions' influence on strategy development?}

Chapter Seven analysed the incubators individually to see if their characteristics were related to the impact that they had on firms' strategic development. It was found that the incubator that the firms were in mattered and that the incubators appeared to be on a continuum as to how they influenced the firms' strategy developments.

\subsubsection{The incubator's breadth of focus mattered}

The incubators were placed on a continuum according to their breadth of focus. The relative placement of the incubators on the continuum was also related to other characteristics. For example, NFIs (A, E) were orientated around getting firms to undertake product validation and development, and capital-raising and they incubated firms with specific product types, which were mainly HTFs. These incubators placed less emphasis on the external-intangible provisions; rather, they emphasised the internal provisions. Incubators A and E took an individualised approach to the development of the firms, and they did not use multi-firmbased strategy development workshops like the other incubators did. These characteristics are summarised in Table 67. 
Table 67

Summary of the Incubator Attributes on a Continuum According to Range of Provisions

\begin{tabular}{|c|c|c|c|}
\hline \multirow{2}{*}{$\begin{array}{l}\text { Factor } \\
\text { Incubators }\end{array}$} & \multicolumn{3}{|c|}{ Narrow $\quad$ Broad } \\
\hline & E, A (NFIs) & C & B, D, F (BFIs) \\
\hline $\begin{array}{l}\text { Provisions to } \\
\text { firms }\end{array}$ & $\begin{array}{l}\text { All categories with less } \\
\text { emphasis on the } \\
\text { external-intangible } \\
\text { provisions. The } \\
\text { incubators often funded } \\
\text { firms themselves. }\end{array}$ & $\begin{array}{l}\text { All categories of } \\
\text { affordances emphasised. } \\
\text { Had highest provision } \\
\text { usage rates overall. }\end{array}$ & $\begin{array}{l}\text { All categories } \\
\text { emphasised external- } \\
\text { intangible provisions; } \\
\text { internal-tangible } \\
\text { provisions less so. }\end{array}$ \\
\hline $\begin{array}{l}\text { Product type of } \\
\text { firms }\end{array}$ & $\begin{array}{l}\text { Mainly high-technology } \\
\text { physical products. }\end{array}$ & $\begin{array}{l}\text { Mainly information } \\
\text { technology products. }\end{array}$ & Mix \\
\hline $\begin{array}{l}\text { Size of firms on } \\
\text { entry }\end{array}$ & Mainly individuals & Mainly individuals & Mainly teams \\
\hline $\begin{array}{l}\text { Focus of } \\
\text { incubation } \\
\text { outcomes }\end{array}$ & $\begin{array}{l}\text { Emphasised product } \\
\text { validation and } \\
\text { development, } \\
\text { governance and capital } \\
\text { raising. }\end{array}$ & Quite broad & $\begin{array}{l}\text { Entrepreneur and team } \\
\text { development, goal } \\
\text { setting and the process } \\
\text { of strategy development. } \\
\text { Charged a fee for pre- } \\
\text { incubation programmes. }\end{array}$ \\
\hline $\begin{array}{l}\text { Approach to } \\
\text { strategy } \\
\text { development }\end{array}$ & $\begin{array}{l}\text { Used own } \\
\text { methodologies, worked } \\
\text { with firms individually. } \\
\text { No multi-firm-based } \\
\text { workshops. Emphasised } \\
\text { the need for evidence- } \\
\text { based planning. }\end{array}$ & $\begin{array}{l}\text { Used structured } \\
\text { programmes, Business } \\
\text { Model Canvas, and Lean } \\
\text { Start-up methodology. } \\
\text { De-emphasised planning. }\end{array}$ & $\begin{array}{l}\text { Used structured multi- } \\
\text { firm-based programmes, } \\
\text { Business Model Canvas, } \\
\text { and Lean Start-up } \\
\text { methodology and } \\
\text { planning tools }\end{array}$ \\
\hline $\begin{array}{l}\text { Influence on } \\
\text { firms' strategy } \\
\text { development }\end{array}$ & $\begin{array}{l}\text { More changes at the core } \\
\text { of the content } \\
\text { orientation. Process } \\
\text { orientation changes were } \\
\text { fewer. }\end{array}$ & $\begin{array}{l}\text { Highest level of strategy } \\
\text { developments overall. }\end{array}$ & $\begin{array}{l}\text { More changes along the } \\
\text { goal and process } \\
\text { orientations, and at } \\
\text { periphery of content } \\
\text { orientation. }\end{array}$ \\
\hline $\begin{array}{l}\text { Provisions of } \\
\text { influence }\end{array}$ & $\begin{array}{l}\text { Less influence from } \\
\text { external-intangible } \\
\text { provisions. }\end{array}$ & $\begin{array}{l}\text { Even level of influence } \\
\text { from across the } \\
\text { categories of provisions. }\end{array}$ & $\begin{array}{l}\text { The influence was from } \\
\text { across a range of } \\
\text { categories. }\end{array}$ \\
\hline
\end{tabular}

The firms' strategy developments that occurred due to the influence of the NFIs tended to be along the core of the strategy content orientation, as opposed to the goal and process orientations. On the other hand, the BFIs were more orientated around providing the multifirm-based programmes, which incubators B, D and F charged for. The BFIs took in firms that were larger in size and had non-specific product types. They emphasised the externalintangible provisions. The firms' strategy developments were more orientated towards the goal and process orientations, and the periphery of their content orientation. 
The BFIs tended to have greater influence on the firms' goals than the NFIs $(56 \%$ of firms in the BFIs changed compared to $33 \%$ of firms in NFIs); on the deliberate to emergent continuum (28\% compared to $11 \%$ ); and on the planning continuum (39\% compared to $22 \%$ ). On the other hand the NFIs had a greater influence on the firms' strategy content than the BFIs, notably on the partnership status continuum $44 \%$ of firms in the NFIs changed compared to $17 \%$ of firms in BFIs and on the product scope continuum at $89 \%$ compared to $78 \%$.

\subsection{Possible reasons for the differences}

The scope of focus of incubators in New Zealand varied, as explained in Chapter One. This difference is commonly seen in incubators internationally (Al-Mubaraki \& Hamad, 2013). It was apparent that the level of investment that incubators had in firms appeared to be related to the broad versus narrow focus of the incubators. In the literature review it was discovered that gaining investment for New Zealand firms is a key emphasis of incubation (Incubators New Zealand, 2011a) and that, accordingly, incubators had strong connections to the investment community. So, while gaining investment was supposedly a key focus of $\mathrm{New}$ Zealand incubators, the incubators in the study had varying emphases on this outcome. The NFIs tended to be more orientated around gaining investment with a corresponding emphasis on the provisions of connections to potential investors $(\mathrm{O})$ and connections to board members $(\mathrm{S})$ with the affordances of which appearing to cluster together, enabling more specific affordances, whereas the BFIs tended to be orientated around developing the goals and processes of the firm, with a stronger emphasis on the provision of structured multi-firm-based programmes. The lack of individualisation of these programmes may have somewhat predetermined the paths of the firms, meaning that their strategy developments may have been similar to other firms from the same incubator. This was apparent in the planning continuum where the firms that increased their planning were most likely to be in incubator D. The firms that reduced their planning were most likely to be in incubator C. Meru and Struwig (2011) found that incubators that were more focused on generating revenue from incubator services (like the BFIs) did so at the expense of offering excellent service to the firms. In this study the BFIs charged fees for their pre-incubation programmes and workshops and consequently may have selected firms more on the basis of whether or not they could pay for these programmes, as opposed to the firms' viability and growth potential. This could help explain why the BFIs had less influence on the core of the firms' 
strategies and more on the goals and processes of the firms, as goals and processes tended to be the emphasis of the pre-incubation programmes and workshops.

Potentially, the BFIs were reducing their potential for financial risk by seeking to extract money from the firms both in the form of paid services and, to a lesser extent, in financial returns from their relatively small equity stake in the firms. However, this focus on predominantly generating revenue from paid services could have been detrimental to the development of the firms. The affordances from these paid services may have been useful to the firms, and have helped them with specific tasks, but were frequently not sufficient to influence strategy development. The NFIs, on the other hand, appeared to be driven by gaining a return on investment based on the firms' success. The NFIs relied mainly on financial returns from their larger equity stake in the firms. Given that the NFIs were generally relying solely on these uncertain financial returns, it is not unexpected that these incubators would focus their efforts where it was likely to be most beneficial for the individual firms, as opposed to providing fairly generic multi-firm-based programmes. The value of this focus by NFIs is somewhat reflected in the study by Kilcrease (2011) who found that for-profit seed capital incubators (like the NFIs) were the best-performing in terms of client satisfaction regarding the incubators' services overall. Further, the practice of specialisation according to product types by the NFIs may have meant that the incubators were able to tailor their provisions specifically to certain types of products, and accordingly, have a deeper impact. The affordances may therefore be more likely to be sufficient to influence strategy development.

Interestingly there was not much difference in the level of interaction between the firms and their advisors across the continuum of incubators. Exceptions were the incubators at the two extremes of the continuum: the firms in incubator E, a NFI, generally had very high levels of interaction with their advisor and the firms in incubator F, a BFI, generally had very low levels of interaction with their advisor. Overall, the limited difference in interaction levels between the other incubators may signal that it is not the level of interaction that is important. Instead, it may allude to what Rice (2002) has attested, that the quality of the counselling can impact on the value derived from the incubators' provisions and that this value depends on the initiator and the purpose of the interaction. It is therefore surmised that the BFIs appeared to have had what Rice would refer to as a reactive and episodic counselling approach. This type of counselling is typified by the incubators' support being 
situation-specific and more limited, with the incubator firms largely being in control of the process. The NFIs appeared to provide what Rice would refer to as continual and proactive counselling, as the incubators were more invested in the firms and therefore may have sought to have a greater degree of management of the incubation process. Further, four out of the nine firms in the NFIs (A, E) were located in the incubators, which potentially helped facilitate the continual and proactive counselling. This was in contrast to the BFIs where most of the firms were housed off-site; in incubators D and F 12 of the 14 firms were located off-site. The continual and proactive counselling approach was concluded by Rice to be the most effective approach.

The types of provisions and the ensuing affordances of influence appeared to be related to this counselling approach. For example, changes to the product scope in NFIs tended to be influenced by a narrower range of affordances (from provisions E, F, H) that assisted the firm with specific functions. The BFIs on the other hand, were influenced by affordances from the same provisions, but they were broader and less tailored and were less likely to be of influence.

In the literature review it was acknowledged that strong networks were important (Muniz et al. 2013) and that these networks can fill the firms' resource and funding gaps (Rice, 2002). Firms in the BFIs tended to use these networks to a greater extent than the NFIs. For example, incubator $\mathrm{D}$ used external business mentors $(\mathrm{U})$ extensively, and this was often substituted for the advice from the incubator's own advisors. Similarly, the firms in incubators $\mathrm{B}$ and $\mathrm{F}$ appear to have had a heavy reliance on the affordances from connections to professional advisors $(\mathrm{P})$, whose advice could arguably have been provided by the incubator internally instead. This potential substitution of internal provisions with external provisions could have put these incubators at risk of poor service outcomes for the firms. This risk could occur because, as Rice found, the experts in the network may not believe that the relationship with the firm will continue beyond incubation and so they put less effort into it, or that the incubator is not effective in managing these network relationships. The notion of substitution of affordances will be explored further in the discussion on the contributions to TOA.

An interesting question proposed here is, do incubators have any real influence on the firms at all? That is, does the incubator enable affordances that could also be available to firms from elsewhere? While this study does not specifically seek to address this question, 
inferences could be drawn based on the extent to which the incubators influenced the content orientation of the firms. In their research into how the strategies of NEFs develop, Nicholls-Nixon et al. (2000) found that changes were much more likely to occur at the periphery of a firm as opposed to the firm's core. For example, they found that competitive emphasis changes (considered periphery) were more than twice as likely to occur as partnership status, product scope and time allocation changes. The findings in this study did not reflect this. Product scope (considered to be a core change by Nicholls-Nixon et al.) changed the most, not the least, followed by competitive emphasis changes, partnership status changes, and time allocation changes. These disparities could indicate that incubators do indeed provide unique affordances, which are not otherwise substitutable, that is, they are not readily obtainable from elsewhere. This potential lack of substitution could make the firms in incubators behave differently; that is, by changing their product scope to a greater degree. Alternatively the disparity could be due to the different methodological approaches of the respective studies. For example, there may be differences between the two studies in the operationalisation of the strategy content dimensions. Nicholls-Nixon et al. (2000) contrary to the definition of product scope changes in this study - defined product scope changes as adding or dropping products as opposed to evolving or developing existing products. If the 17 firms that evolved or developed their product were discounted, leaving just the 11 firms that added or removed products, the results of the two studies would be similar. This lack of difference suggests that the incubators' provisions that influence product scope changes may be able to be substituted with objects that are available to other firms that are not in incubators. As this study did not explore a comparative sample of nonincubator firms, these propositions cannot be proven or otherwise, and this represents an opportunity for further research.

\subsection{Application of the theory of affordances}

The preceding discussion on the four sub-questions revealed interesting insights into how incubators may influence firms' strategy development and the possible reasons for any differences. TOA facilitates recognition that affordances from objects can vary in the ways that they are perceived and realised (Gaver, 1991; Norman, 1999), and that objects can have multiple affordances with respect to the same actor (Bryson et al., 2006; Maier, 2008). In this study the TOA provided a useful lens through which to address the research questions and in doing so, three underlying themes emerged regarding the application of the TOA in an 
organisational context. The themes relate to the specificity of affordances, the substitutability of objects and to path dependency.

In the following discussion please note that the terminology which is common to TOA has been used in places instead of incubator-specific terminology which has dominated the discussion until now. This means that firms are referred to as actors, incubators are referred to as the environment and provisions are referred to as objects.

Specificity refers to the scope of affordances of the individual provisions, and to the clustering of provisions resulting in combined affordances. Substitutability refers to the affordances of some objects being substitutable either with each other or with objects from outside the environment. Path dependency refers to how perceptions and realisation of affordances evolve and to how this is related to the ordering of provisions, that is, some provisions need to precede others. These themes are discussed in detail next.

Table 68 summarises the key TOA themes extracted from the findings related to the research sub-questions in the preceding discussion. 
Table 68

Summary of Key TOA Themes Extracted From the Answers to the Research Sub-Questions

\begin{tabular}{|c|c|c|c|}
\hline $\begin{array}{l}\text { Research } \\
\text { questions }\end{array}$ & Specificity & Substitutability & Path dependency \\
\hline $\begin{array}{l}\text { What are the } \\
\text { affordances of the } \\
\text { incubators' } \\
\text { provisions? }\end{array}$ & $\begin{array}{l}\text { The scope of affordances varied, ranging from } \\
\text { provisions that had specific affordances to those } \\
\text { with a broader scope. The specific affordances } \\
\text { often related to functional activities. } \\
\text { Other provisions had affordances that started off } \\
\text { specific then became broader and in doing so } \\
\text { influenced strategy development in a variety of } \\
\text { ways. }\end{array}$ & $\begin{array}{l}\text { Some provisions appeared to be able to be } \\
\text { substituted for other provisions in that they had } \\
\text { similar affordances. } \\
\text { For example, the advice that came from incubator } \\
\text { staff was sometimes substituted for external } \\
\text { advice from provisions P and U. }\end{array}$ & $\begin{array}{l}\text { The usage frequency and value judgements of } \\
\text { provisions were not necessarily related. } \\
\text { The value judgements of the intangible provisions } \\
\text { were generally lower for firms that had not used } \\
\text { them than for firms that had used them, signalling } \\
\text { that the realised affordances may be higher than } \\
\text { the perceived affordances. }\end{array}$ \\
\hline $\begin{array}{l}\text { How may the } \\
\text { provisions' } \\
\text { affordances } \\
\text { influence strategy } \\
\text { development? }\end{array}$ & $\begin{array}{l}\text { The affordances that were of greatest influence } \\
\text { overall came from the internal-intangible category } \\
\text { of provisions, ones that had a broad scope of } \\
\text { potential affordances. } \\
\text { There appeared to be a greater degree of } \\
\text { clustering of provisions in cases where the core, } \\
\text { and not the periphery, of the firms' strategy was } \\
\text { influenced. }\end{array}$ & $\begin{array}{l}\text { Provisions E and } \mathrm{H} \text { were the dominant source of } \\
\text { influence, indicating the provisions' reduced } \\
\text { ability to be substituted with others. } \\
\text { The provisions that influenced changes on the } \\
\text { partnership status and the competitive emphasis } \\
\text { continuums appeared to be more readily } \\
\text { substitutable. }\end{array}$ & $\begin{array}{l}\text { The direction of the firms' strategy developments } \\
\text { on the deliberate to emergent continuum, and on } \\
\text { the product scope continuum was related to its } \\
\text { product type. } \\
\text { The direction of the firms' changes on the } \\
\text { planning continuum appeared to be related to the } \\
\text { incubator that the firms were in. }\end{array}$ \\
\hline $\begin{array}{l}\text { How may the } \\
\text { firm-specific } \\
\text { factors be related } \\
\text { to the provisions' } \\
\text { influence on } \\
\text { strategy } \\
\text { development? }\end{array}$ & $\begin{array}{l}\text { Depending on the firms' product type and } \\
\text { governance structure similar affordances arose } \\
\text { from the same provisions but resulted in different } \\
\text { strategy developments on the planning } \\
\text { continuum. }\end{array}$ & $\begin{array}{l}\text { The attributes of the incubator to influence } \\
\text { strategy development varied depending on the } \\
\text { firms' goverance structure, even though the } \\
\text { nature and realisation of affordances of the } \\
\text { provisions were similar. This signalled that the } \\
\text { firms' boards partially substituted the incubators' } \\
\text { affordances. }\end{array}$ & $\begin{array}{l}\text { The age of the firms prior to entry into the } \\
\text { incubator and the length of time that the firms } \\
\text { had been in the incubator appeared to be related } \\
\text { to provision awareness and usage. } \\
\text { Newer firms did more planning that was } \\
\text { influenced by the incubator and older firms' less } \\
\text { planning. }\end{array}$ \\
\hline $\begin{array}{l}\text { How may the } \\
\text { incubator-specific } \\
\text { factors be related } \\
\text { to the provisions' } \\
\text { influence on } \\
\text { strategy } \\
\text { development? }\end{array}$ & $\begin{array}{l}\text { The propensity to focus on specific types of firms } \\
\text { by NFIs appeared to enable a greater degree of } \\
\text { tailoring to the needs of each firm, enabling } \\
\text { greater specificity of affordances. } \\
\text { The NFIs emphasised raising capital for the } \\
\text { firms. Consequently the affordances of some } \\
\text { related provisions appeared to cluster together, } \\
\text { which was necessary for an affordance to occur. }\end{array}$ & $\begin{array}{l}\text { Some of the BFIs' provisions were outsourced to } \\
\text { the incubators' external networks signalling that } \\
\text { there may be a degree of substitution of internal } \\
\text { with external provisions. }\end{array}$ & $\begin{array}{l}\text { The BFIs had structured multi-firm-based } \\
\text { programmes, potentially meaning that the paths } \\
\text { that the firms took, and consequently their } \\
\text { strategy development processes, were similar to } \\
\text { other firms in the same incubator. }\end{array}$ \\
\hline
\end{tabular}




\subsubsection{Contribution A: Specificity of affordances}

The specificity of affordances seemed to be related to the influence of the incubators on firms' strategy development. Maier (2008) attested that single objects may have multiple affordances with respect to the same actor, and as Zhao et al. (2013), Gram-Hanssen and Bech-Danielson (2012), van Osch and Mendelson (2011), and Fayard and Weeks (2007) recognised, affordances come from the wider environment of the actor, as opposed to just from single objects. In this study it appeared that the degree of singularity or multiplicity of affordances that arose from single or multiple provisions was important, namely that

- affordances with greater specificity can be necessary but not sufficient to influence strategy development;

- when objects cluster together (i.e. used in combination) the affordances can become more specific; and

- the characteristics of the actor (firms) and the environment (incubators) is related to the specificity of the affordances.

\subsubsection{Implications for the conceptual model}

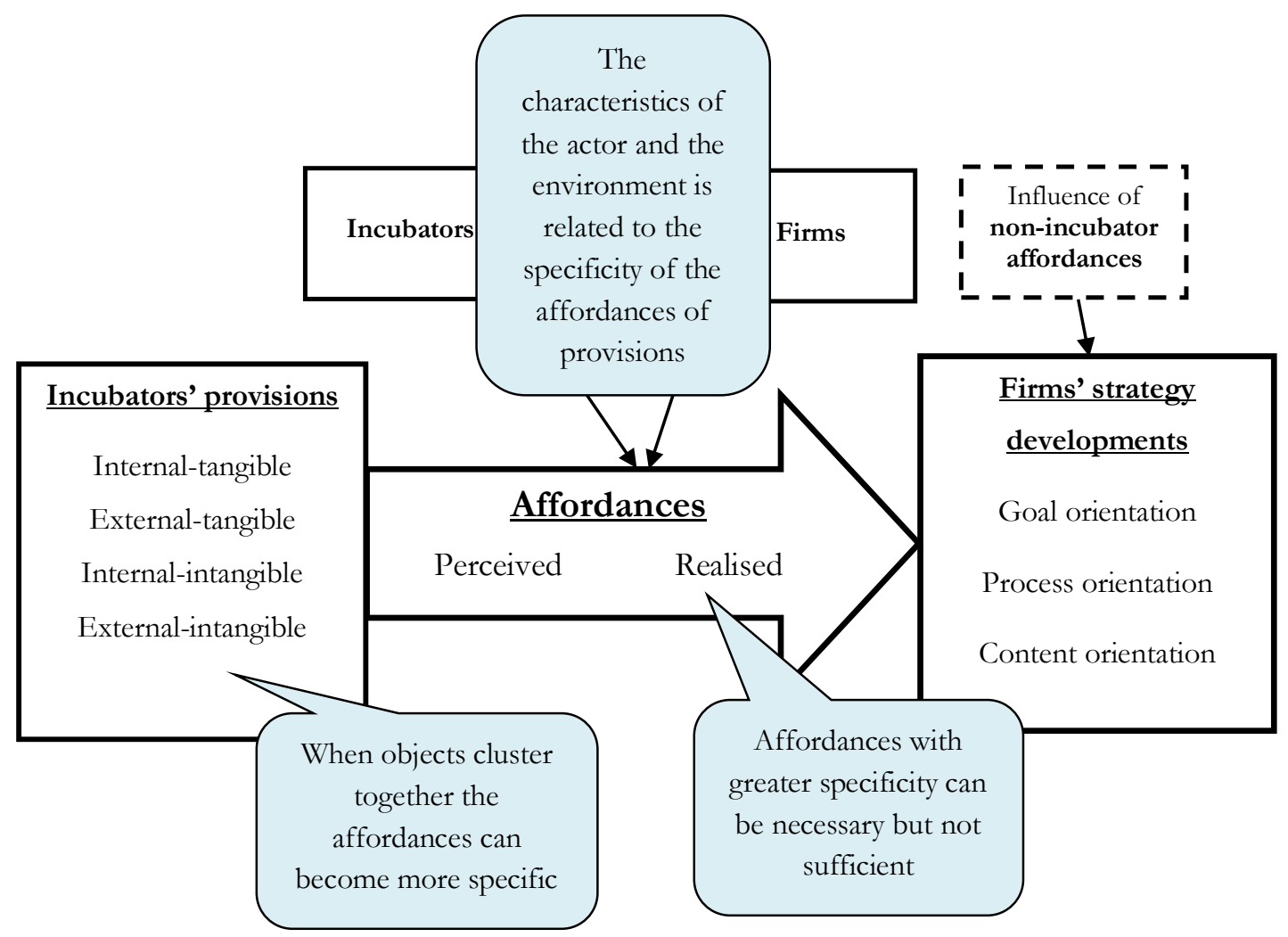

Figure 25. How the three specificity concepts are related to the conceptual model 
Figure 25 depicts the original conceptual model but with the descriptions of the three specificity concepts placed according to their relationship to the model. Each of these concepts is now discussed individually and complemented with explanatory diagrams.

\subsection{Affordances with greater specificity can be necessary but not sufficient}

It has been well acknowledged that affordances of objects are not singular, but that they can be many and varied (Bryson et al., 2006; Chemero, 2003; Fayard \& Weeks, 2007; GramHanssen \& Bech-Danielson, 2012; Maier, 2008; Norman, 1999; Sadler \& Given, 2007; van Dijk et al., 2011; Zhao et al., 2013). In this study it was found that there were differences in the degree of specificity of affordances arising from the provisions.

Most provisions helped the firm with specific functions that had a relatively fixed outcome or opportunity for action, for example providing office space (A) and assistance with general business administration tasks (D). The affordances were limited because there was often a narrowly defined set of opportunities for action, so the degree of specificity was greater. However, these affordances did not directly influence strategy development, but in some cases were considered necessary to enable it. This was because the realisation of these affordances, for example, saved the firm time and effort, giving them greater capacity to focus on other things, such as strategy development.

The affordances of other provisions were broader in scope after initially being narrower or more specific. For example, the provision of assistance with market validation and development $(\mathrm{H})$, which was about giving firms the tools to gather information and uncover opportunities, then informed their decision-making. The ensuing affordances became more complex in that the potential opportunities for action widened, there was a wider scope of potential opportunities for action.

Letiche and Lissack (2009) attested in their conceptual paper that affordances cannot be predicted and controlled and are about a range of possibilities as opposed to being about a set of rules from the past. While the findings in this study supported this notion of a wide scope of affordances, it is proposed here that this scope is somewhat predetermined by the object in that not all objects enable an equally broad range of possibilities.

Figure 26 presents a comparative example of how the specificity of affordances varies between provisions. 


\begin{tabular}{|ccc|}
\hline $\begin{array}{c}\text { Provision D } \\
\text { (professional } \\
\text { services) }\end{array}$ & $\begin{array}{c}\text { Provides specific affordances, e.g. } \\
\text { help with bookkeeping, which saves } \\
\text { the firm time, freeing them up to } \\
\text { focus on other things }\end{array}$ & $\begin{array}{c}\text { Affordances are often } \\
\text { necessary but not } \\
\text { sufficient to influence } \\
\text { strategy development }\end{array}$ \\
$\begin{array}{c}\text { Provision E } \\
\text { (strategy } \\
\text { methodologies) }\end{array}$ & $\begin{array}{c}\text { Provides initially specific then } \\
\text { broader affordances, e.g. strategy } \\
\text { mapping tools which gives the } \\
\text { framework to discover and assess a } \\
\text { range of opportunities }\end{array}$ & $\begin{array}{c}\text { Affordances are } \\
\text { necessary and sufficient } \\
\text { in that they often have a } \\
\text { direct influence on } \\
\text { strategy development }\end{array}$ \\
\hline
\end{tabular}

Figure 26. Comparative example of how specificity of affordances varies between provisions

In the preceding discussion in this chapter the range of provisions was presented on a continuum showing that potentially there is a scale of opportunity depending on the degree of specificity of the affordances. However, the scale of opportunity of each provision was not fixed, and could depend on factors such as the capacity of the firm and on their prior use of the provision, which related to the path dependency theme, discussed later in Section 8.4.3.

\subsection{When provisions cluster together the affordances can become more specific}

The use of some provisions in combination appeared to make the ensuing affordances more specific. This concept was alluded to by Sadler and Given (2007) who studied the behaviour of graduate students in relation to their university library and found that, of all the affordances, the most influential were those related to the students' personal contact with the librarians. They found that this personal contact was positively related to the realisation of other affordances, for example those associated with new technologies and services. The clustering of affordances of provisions made the affordances of other provisions more likely to be realised as the opportunities for action were more defined and were therefore more specific.

In this study it was found that the affordances of provisions can function independently of each other, like the provisions that offer specific affordances, for example, the provision of office space (A) and assistance with business administration tasks (D), mentioned previously. However, similar to the Sadler and Given study, many of the provisions appeared to need to be clustered with other provisions if their affordances were to be influential on the firms' strategy development, and the greater the degree of clustering of provisions the more specific the affordances appeared to become. 
Overall, the provisions that influenced strategy development the most were those in the internal-intangible category, and specifically assistance with strategy methodologies $(\mathrm{E})$ and assistance with market validation and development $(\mathrm{H})$. These provisions most strongly influenced the strategy developments, and they influenced almost all the goal orientation and process orientation changes. However, in many cases these two provisions were combined, and it appeared that in some cases it increased their level of influence. For example, on its own, the provision of assistance with market validation $(\mathrm{H})$ enabled the firm to gather data about their environment, which potentially opened up a vast range of opportunities. Yet the affordances are non-specific as the firm does not necessarily know which opportunity to pursue. However, when combined with the provision of assistance with strategy methodologies (E) which can encompass tools such as the Business Model Canvas, it gave the firm a framework on which to give structure to the opportunity uncovered by the market validation, and therefore the specificity of the affordances increases. The frequency of use of these combined or clustered provisions was generally high, signalling that ongoing value could be extracted. Figure 27 presents a comparative example of clustering of affordances from provisions.

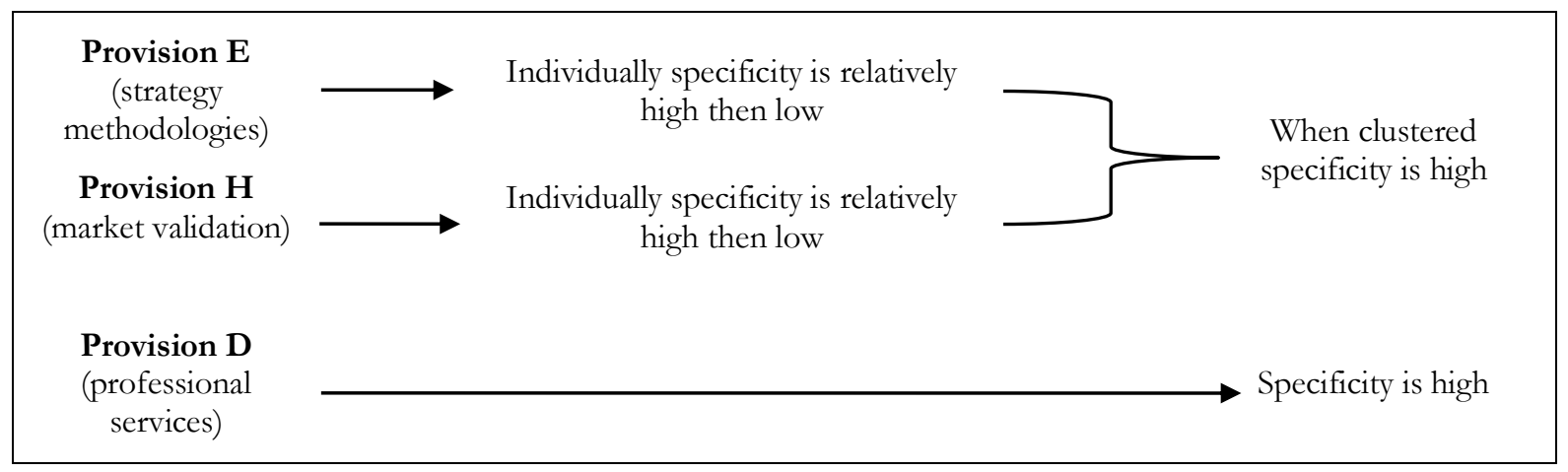

Figure 27. Comparative example of clustering of affordances from provisions

Other provisions also appeared to form clusters, which also increased their specificity. For example, when firms changed their partnership status it was frequently due to a combination of the provisions of assistance with financial planning and management (I) assistance with developing a board of directors $(K)$ and connections to potential board members $(R)$. If the provision of assistance with developing a board of directors $(\mathrm{K})$ was offered in isolation the firm may be much less likely to realise affordances from it, as the other pieces of the puzzle are also needed. Frequency of use of these provisions when used individually was low. From this example it is seen that this clustering can incorporate provisions that are from a range of provision categories - internal and external and tangible and intangible. 
Sometimes clustering is not needed to increase specificity. The provisions that influenced changes along the competitive emphasis continuum were generally singular and specific, and were commonly from the external-intangible provisions, for example, the use of a sales specialist to increase competitive emphasis. The propensity for these influential provisions to be external to the incubator may signal that the incubators' internal advisors were less equipped to assist firms with their competitive emphasis and so relied on the provision of professional services $(\mathrm{P})$ to assist firms on this dimension.

\subsection{The attributes of the actor and the environment are related to the specificity of the affordances}

It was acknowledged in the literature that the attributes of actors and the environment are related to how they perceive and realise affordances (Bryson et al., 2006; Gram-Hanssen \& Bech-Danielson, 2012; Norman, 1999; van Dijk et al., 2011).

In this study it was found that the attributes of the environment were an important influence as exemplified by affordances of the BFIs appearing less specific than the affordances of the NFIs. The NFIs tended to have a refined set of largely internal provisions that were orientated around product development and capital-raising. This tight clustering of affordances appeared to increase their specificity, making it harder for the affordances not to be perceived and realised by firms. Accordingly, NFIs tended to influence the content of the firms' strategy more deeply. On the other hand, the BFIs influenced the firms' goals and processes more, and their content less. The BFIs appeared to be trying to cater to a broader range of firms through a wider range of provisions. Therefore it seems unsurprising that overall the specificity of the affordances from the provisions of the BFIs may be dissipated and it is expected their firms would be less inclined to realise an affordance if there was uncertainty over the outcome of doing so.

Van Dijk et al. (2011) studied the process of radical technological innovation in large organisations. They found that the established institutional structures in the environment can offer affordances that can impact the innovation process. The affordances came from divisions or departments, their potentially multiple competing interests, and the ambiguity of such interests. These varying affordances enabled from the environment were found to allow the actors to pursue a variety of opportunities for action in their quest for radical innovation. Van Dijk et al. (2011) found that the actors sought out segments within the environment that were most supportive of their innovation and that were less constraining. Potentially, 
therefore, the incubator firms in this study that were seeking a radical innovation trajectory may have been more inclined to also seek environments that they deemed as having greater opportunities for action, and where the perceived specificity of affordances was less. This may explain why the firms that increased their goals were more likely to be from the BFIs.

Similarly, Bryson et al. (2006) found that affordances may be different depending on the relationship of the actor to the environment. These authors found that individuals that had a higher standing within an organisation experienced a more expansive environment, as opposed to the more restrictive environment experienced by individuals who were lower in an organisation. The findings of Bryson et al. (2006) could imply, for example, that firms in which the incubators had greater equity by the NFIs may be of a higher standing than other incubator firms, and therefore have a higher ranking in terms of their relationships to the incubators, and may have been exposed to a more expansive environment, resulting in greater opportunities for action. This may explain why firms in the NFIs underwent a greater degree of changes to the core of their strategies than the BFIs. However, this proposition cannot be confirmed as the relative relationships of the different actors to their environments were not part of this study.

Figure 28 presents a comparative example of how the environment may be related to affordances.

\begin{tabular}{|c|c|c|c|}
\hline $\begin{array}{c}\text { Incubator } \\
\text { focused (e.g. } \\
\text { incubators A\&E) }\end{array}$ & $\begin{array}{l}\text { Perceive } \\
\text { fewer } \\
\text { affordances }\end{array}$ & $\begin{array}{c}\text { Realise more affordances, } \\
\text { which may cluster and have } \\
\text { higher specificity }\end{array}$ & $\begin{array}{l}\text { More influence on } \\
\text { core of content } \\
\text { orientation, less on } \\
\text { goal and process } \\
\text { orientation }\end{array}$ \\
\hline $\begin{array}{c}\text { Incubator } \\
\text { unfocused (e.g. } \\
\text { incubators B, D } \\
\& \mathrm{~F}) \\
\end{array}$ & $\begin{array}{l}\text { Perceive } \\
\text { more } \\
\text { affordances }\end{array}$ & $\begin{array}{c}\text { Realise fewer affordances, } \\
\text { with little clustering and } \\
\text { lower specificity }\end{array}$ & $\begin{array}{c}\text { Less influence on core } \\
\text { of content orientation, } \\
\text { more on goal and } \\
\text { process orientation }\end{array}$ \\
\hline
\end{tabular}

Figure 28. Comparative example of how the environment may be related to affordances

Communication also appears to impact the specificity of affordances. A key aspect of the NFIs is their individualised approach, which further enhances the apparent specificity of the affordances. This individual approach meant that they potentially communicated information to the firms about the provisions that the firms needed only when they needed them. This represents a continual and proactive counselling approach where the incubator is in control of the communication process, as discussed earlier in Section 8.3.3.1. A substantial portion 
of the revenue for the NFIs would potentially be expected to have come from returns on their investment in the individual firms. In contrast, the BFIs appeared to rely on generating revenue from a range of sources, including their incubation programmes and workshops. This potentially meant that the BFIs would have needed to communicate their offerings more widely to the business community. This wider communication may have explained why firms in the BFIs were aware of the availability of many provisions that they had not used. The lack of specificity of the affordances of the BFIs may therefore have caused confusion among the firms potentially resulting in too much choice. However this proposition cannot be confirmed as the data collected on the firms' value judgements of provisions was anonymous (Strand Two) and so was not distinguishable by firm.

The incubators' selection criteria also appeared to impact the specificity of affordances, potentially resulting in some affordance redundancy. Affordance redundancy appeared to be the case for some firms in the BFIs that accepted a wide range of firms into their often mandatory multi-firm-based programmes. The potential lack of tailoring to the needs of the individual firms may have meant that many of the affordances were not specific or sufficient to influence strategy development. Firm $27 \mathrm{~F}$ discussed the problems they encountered with this multi-firm-based programme approach, which occurred as a consequence of the incubator not responding to the needs of individual firms:

[The incubator would just] tick the box, "we've done that now," but we hadn't really finished it, it didn't feel finished ... I never really felt we were a step closer to where we wanted to go. It was like we'd gone to a programme on how to do this and how to do that, but there was no finalisation to it.

The cause of affordance redundancy was potentially a combination of the firms being selected largely on the basis that they could pay for the programmes, as opposed to being selected based on their readiness for incubation. It could have also been due to the wide variety of firms in the programmes, which could have resulted in an inherent difficulty in providing provisions with an appropriate degree of specificity to such a diverse group. The attributes of the environment were therefore important to the relationship between affordances and strategy development.

Gibson (1979) attested that affordances were not related to the actor's knowledge, culture or to their ability to perceive them. Whereas Norman (1999) argued that affordances can be dependent on the actor's knowledge, culture and their ability to perceive them. At a general 
level Norman's view was reflected in a study by Gram-Hanssen and Bech-Danielson (2012) who found that different cultural groups of immigrants realised varying affordances from the same housing environment. This study also reflects Norman's view, that is, the actors' (firms') attributes appear to impact the specificity of affordances. This is proposed because the affordances that influenced the strategies of the HTFs tended to have a higher degree of specificity than for ITFs. The HTFs strategy development tended to be influenced by specific affordances that involved assistance with certain functions. For example the affordances that influenced the HTFs' product scope changes mainly involved connecting the firms to individuals with whom to undertake market validation, and assistance with the actual market validation process. On the other hand the ITFs tended to realise affordances in a broader way and involved the firms having their strategic decisions challenged and being made to do market validation. No determinations were made for the low-technology firms (LTFs) about affordance specificity due to the small sample size.

The reason why the HTFs strategy development were more likely to be influenced by affordances that had a higher degree of specificity was potentially due to their products having less capacity to change, as discussed earlier in Section 8.3.2.1. This reduced capacity to change may also have been the reason why none of the HTFs strategy become more emergent. The ITFs appeared to be more adaptable, and their capacity to change their strategy in a variety of directions was greater. Similarly, van Dijk et al. (2011) explored innovation trajectories for innovative companies and found that the actors' characteristics were related to the influence of affordances. Actors that had fewer constraints experienced greater opportunities for action, similar to the relative lack of constraints for the ITFs.

\subsubsection{Contribution B: Substitutability}

Substitutability refers to the affordances of some objects being substitutable both with each other and with objects from outside the environment.

The degree to which internal affordances are substitutable by the firms' external governance appeared to impact how that external governance influences firms' strategy development. TOA scholars do not suggest that affordances from some objects may be substituted by some affordances from other objects, although the complexity of affordances is acknowledged (Gaver, 1991; Gibson, 1979; Norman, 1999). For example, van Osch and Mendelson (2011) stated that affordances are the result of complex interactions between multiple actors and objects, and discussed the notion that affordances come from the wider 
environment, and that they were consequently multi-faceted in nature. While some research takes into account the wider environment (Bryson et al., 2006; Chemero, 2003; Fayard \& Weeks 2007; Gram-Hanssen \& Bech-Danielson, 2012; Zhao et al., 2013) they do not consider the specific notion of substitution from that wider environment. For example, what happens to the perception and realisation of affordances when affordances from the wider environment become available, and what happens when affordances within an environment substitute each other? It is proposed that;

- the ease of substitutability depends on the objects;

- the degree of substitutability is not usually complete; and

- the substitution of some objects can maximise affordances of other objects.

Substitution was apparent in three main ways: substitution between provisions within the incubator; substitution of provisions with objects external to the incubator-namely the firms' external governance structure.

\subsubsection{Implications for the conceptual model}

Similar to the earlier discussion on specificity in Section 8.4.1, Figure 29 depicts the original conceptual model but with the descriptions of the three substitutability concepts placed according to their relationship to the model. Each of these concepts is discussed individually and is, again, supplemented with explanatory diagrams.

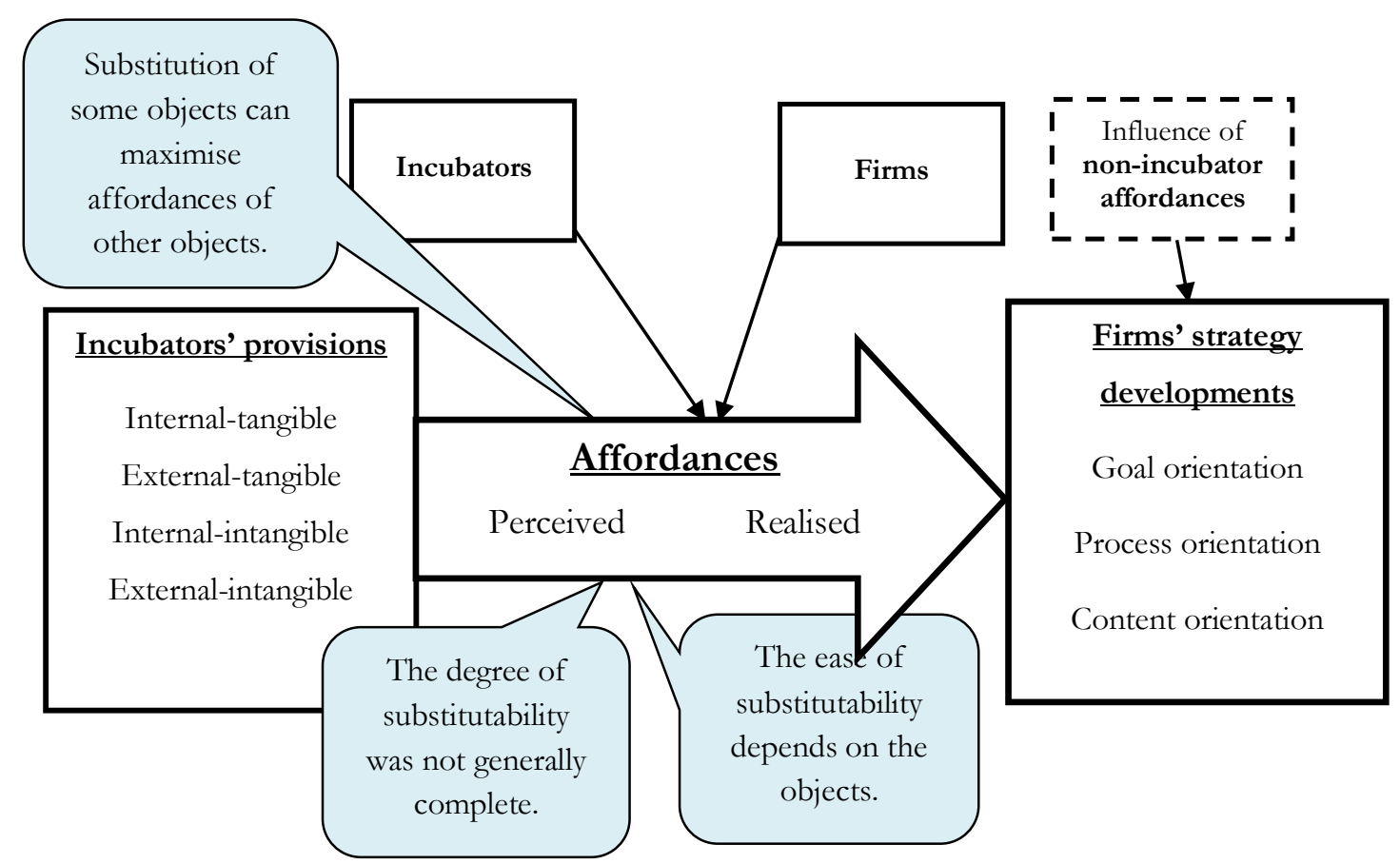

Figure 29. How the three substitutability concepts are related to the conceptual model 


\subsection{The ease of substitutability depends on the object}

Affordances were not created equal when it came to their ease of substitutability. The provisions of strategy methodologies (E) and market validation and development $(\mathrm{H})$ appeared to be the least substitutable of the provisions. These provisions influenced strategy developments in all the firms. On the goal and process orientations almost all changes were influenced by affordances from provisions $\mathrm{E}$ and $\mathrm{H}$, implying that the other provisions are less likely to act as substitutes for these two provisions for changes on these orientations. However, on the content orientation, the influence came from a variety of provisions, indicating some potential for substitution, that is, a range of different provisions may have similar affordances.

Figure 30 presents a comparative example of how the ease of substitution depends on the object (provision) and on the actor (firm).

\begin{tabular}{|c|c|c|c|c|c|c|c|}
\hline 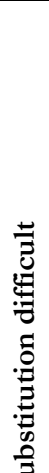 & $\begin{array}{c}\text { HTFs } \\
\text { Substitution } \\
\text { hard as } \\
\text { strategy } \\
\text { developments } \\
\text { less flexible. }\end{array}$ & $\begin{array}{l}\text { Provisions } \\
\text { E \& H } \\
\text { Harder to } \\
\text { substitute } \\
\text { with other } \\
\text { internal } \\
\text { provisions. }\end{array}$ & $\begin{array}{c}\text { Internal- } \\
\text { tangible } \\
\text { provisions } \\
\text { Harder to } \\
\text { substitute } \\
\text { with firms' } \\
\text { external } \\
\text { governance. }\end{array}$ & $\begin{array}{c}\text { Internal- } \\
\text { intangible, } \\
\text { external- } \\
\text { intangible, } \\
\text { external- } \\
\text { tangible } \\
\text { provisions } \\
\text { Easier to } \\
\text { substitute } \\
\text { with firms' } \\
\text { external } \\
\text { governance. }\end{array}$ & $\begin{array}{c}\text { Provisions } \\
\text { C (funding } \\
\text { by incubator) } \\
\& \text { O } \\
\text { (connections } \\
\text { to investors) } \\
\text { Easier to } \\
\text { substitute with } \\
\text { other internal } \\
\text { provisions. }\end{array}$ & $\begin{array}{c}\text { ITFs } \\
\text { Substitution } \\
\text { easier as } \\
\text { strategy } \\
\text { developments } \\
\text { more flexible. }\end{array}$ & 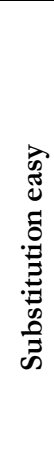 \\
\hline
\end{tabular}

Figure 30. Comparative example of how the ease of substitution depends on the object and the actor

The firms' governance structure also appeared to be able to substitute the provisions to some degree. The WGFs made fewer changes along the process orientation than the NGFs. Therefore the reason the WGFs made fewer changes along these orientations directly due to the incubators influence, could have been because the WGFs were making these changes due to influence from their own external governance instead. For example, firm 28E explained the role of their governance board in challenging their decisions, which was previously something that the incubator advisor used to do:

[The board are] really good at pulling you back, and saying "think more widely" ... they challenge you about things that you wouldn't be thinking about, because you get fixated on solving a problem, and so it's really good for making sure you are focused on things from their perspective. 
Similarly, firm 18C discussed how the decision-making process worked once they had external governance:

We tend to make decisions by sitting down with the board, just talking about them. We all have different ideas, and the right one just comes out through spending time around the table, the whiteboard, and just talking about stuff.

It is also proposed that some of the incubators' external-intangible provisions may have been substituted by the firms' external governance, as the board may have drawn upon resources from their wide networks. However none of the firms explicitly cited this type of substitution. For some firms (1B, 4B, 7D, 13E, 16C, 18C, 20E, 33A) the external-tangible provisions may also have been substituted by the external governance, namely the provision of capital being provided either directly or through connections. However, the external governance would potentially have been less likely to substitute the internal-tangible provisions such as the incubators' physical premises, unless the board members also had ready access to suitable premises.

Characteristics of the firm can sometimes mean that affordances that influence certain types of strategy development cannot be substituted. This was the case for the changes on the deliberate to emergent, planning, and competitive emphasis continuums, for which the types of changes appeared to be dictated by the types of products that the firms produced. In these instances the incubators' affordances often resulted in the ITFs becoming more emergent, doing more planning, and increasing their competitive emphasis. The HTFs, on the other hand, often became more deliberate, and had less marked changes on their planning and on their competitive emphasis continuums. In these instances substituting the incubators' affordances with other affordances would potentially have had minimal effect, as the firms' strategy development would have largely been the same due to the inherent characteristics associated with their product type. On the other hand, the changes in the partnership status and time allocation continuums did not appear to be related to the firms' product type. This lack of relationship suggests that any substitution of affordances would have the potential to have a more marked effect along these continuums as the changes were not predetermined by the characteristics of the firms. The discussion above indicates that firms' strategy developments may be a continuum from ones that are more likely to be impacted by substitution from the firms' external governance to those that are less likely to be impacted by substitution. 


\subsection{The degree of substitutability was not generally complete}

The question that remains is if such a wide range of affordances can be substituted, then what is the role of the incubator? It is proposed that while some affordances are substitutable they are not completely substitutable, otherwise there would be no reason for the firms to remain in the incubators. Potentially the point when the firm leaves the incubator is when it considers that the incubators' affordances are fully substitutable, that is the affordances are no longer needed. For example, the WGFs may transition from using the incubators' affordances, that the firms' external governance could easily replicate from elsewhere, to using affordances that the firms could less easily replicate. Affordances that the firms' external governance could replicate could be those associated with the provision of product validation $(F)$ for which the usage rates were lower for the WGFs than they were for the NGFs. Affordances that the firms' external governance were less able to replicate, and that the governance potentially made sure they were used by the WGFs, appeared to be from the provisions of connections to potential major customers $(\mathrm{S})$ and to professional advisors $(\mathrm{P})$ for which the usage rates were both greater for the WGFs than for the NGFs, and the internal-intangible provisions, as discussed earlier in Section 8.4.2.1.1. Therefore, it is proposed that the provisions could be on a continuum of substitutability based on the external governance structures' ability to replicate the affordances.

It is also proposed that it is not just the ability of the firms' governance structure to replicate the affordances that mattered, the governance structure also appeared to be related to the way that the firms engaged with the provisions. Interestingly the WGFs had a higher usage rate of the provisions despite lower strategy developments ensuing. This poses the question about why this extra usage did not translate into a greater number of strategy developments. Potentially it could have been due to the affordances of the provisions that the WGFs realised were more specific and related to hygiene factors such as those associated with the provisions of assistance with general business administration tasks (D) and that these firms realised fewer affordances that were related to strategy development such as educational workshops $(\mathrm{M})$. The hygiene-related affordances were potentially necessary to the firm but not specific enough to influence strategy development.

Further, while it is not explicitly known how the provisions that did not result in strategy developments were used by the WGFs - only that they were used - inferences can be drawn from comparing the affordances that influenced strategy development between the WGFs 
and the NGFs. For example, the affordances that influenced the changes along the competitive emphasis continuum for the WGFs were mainly from the singular provisions of assistance with strategy methodologies $(\mathrm{E})$ and market validation and development $(\mathrm{H})$, with two exceptions. However the affordances that influenced the NGFs tended to also be from the external-intangible provisions such as connections to professional services $(\mathrm{P})$, assistance with financial planning and management $(\mathrm{I})$, connections to industry experts $(\mathrm{Q})$ and connections to potential major customers (S). The limited range of provisions that influenced strategy development for the WGFs may imply that possibly their governance structure was substituting that provision's affordances, despite the WGFs using these provisions. This notion is, however, somewhat contrary to the earlier conclusion about the substitutability of provisions I and P and, therefore what provisions the external governance substitutes remains largely undetermined.

What is known though is that most of the strategy developments that the WGFs made were due to the incubators' influence, therefore, the substitution by the firms' external governance for the WGFs was not complete; that is, they only partially substituted the incubators' affordances.

As discussed earlier in this chapter, substitution can also come in the form of incubators outsourcing functions to their networks that they might have otherwise performed in-house. Incubator $\mathrm{D}$ is an example of this as the primary advisors to the firms were often external business mentors and not incubator staff. This type of substitution was sometimes detrimental, as was the case for firm 12D who had limited time with their mentor, presumably because the incubator had to pay for the mentor's services:

We didn't really realise that our time with [the incubator advisor] would be quite low. You get your one-on-one meetings, and by the time you talk about the last week, and "what shall we aim for next week?" we kind of thought that we would be able to get a whole list of points and then go away and sort of crack through it all, and then maybe have a big plan that we were working towards, but [it] hasn't really worked like that.

As ongoing affordances could generally be realised from repeated interaction with the firms' advisor, this limited interaction appeared to result in a reduction of the quality of the affordances from the advisor. Other incubators did not outsource this function and the engagement between the advisor and the firms was generally much more satisfactory. For example, at one extreme, firm 6C referred to it as a "sheer excess of support." 
Similar to incubator D, incubator $\mathrm{F}$ also appeared to make a lot of use of the provision of professional services $(\mathrm{P})$ which also appeared to substitute some of the advice from the incubator.

\subsection{Substitution of some objects can maximise the affordances of others}

Substitution does not always mean that the influence of the incubator was reduced. The NGFs tended to be aware of the availability of many provisions but did not use them. On the other hand, the WGFs had a higher rate of provision usage compared to awareness, which could be due to the high number of affordances that were realised in the process of obtaining external governance. For example, affordances from assistance with developing a board of directors or advisors $(K)$ and connections to potential board members $(R)$ had higher use by the WGFs. The affordance realisation is therefore path-dependant, and this is discussed further in Section 8.4.3.

Figure 31 presents a comparative example of how the substitution of some objects can maximise the affordances of other objects due to the varying ability of the firms to perceive affordances of provisions.

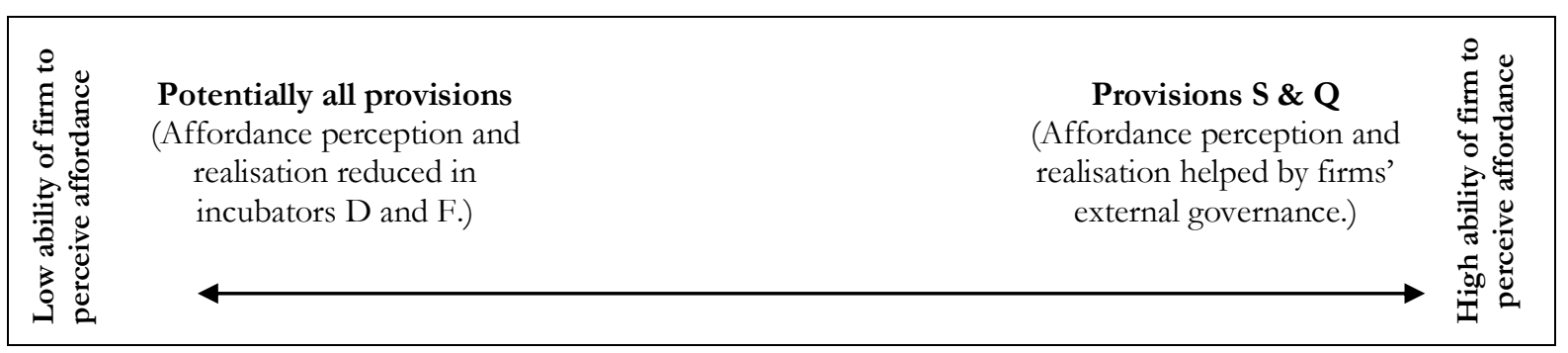

Figure 31. Comparative example of how the substitution of some objects can maximise the affordances of others

However, while some affordances were potentially realised by WGFs in the process of obtaining external governance, others may have been realised because the external governance mandated the use of the provisions. For example, the NGFs had a high rate of awareness of provisions such as connections to subject matter experts (Q) and connections to potential major customers (S) but their usage rate was relatively low. The relatively high usage rates of these provisions by the WGFs could have been due to the ability of the firms' external governance to recognise the affordances that may come from these provisions, and to their inability to replicate them. The NGFs on the other hand may have been aware of the availability of the provisions, but may not have been able to perceive any associated affordances, possibly due to their inexperience or lack of guidance from their advisor about how the provisions could be used. This finding is similar to those of Sadler and Given (2007) 
whose study was discussed in Section 2.2.1. This lack of guidance could explain why in incubators $\mathrm{D}$ and $\mathrm{F}$ there were noticeably lower levels of provision usage compared to the awareness; that is, it is possibly a consequence of substituting the internal advisors with external advisors.

\subsubsection{Contribution C: Path dependency}

Path dependency refers to how perceptions and realisation of affordances evolve over time and how this is related to the actors and the environment. This includes the path that the actors took - which in the case of incubator firms refers to their choice of product type, which incubator they would go in, the process of perception and realisation of affordances, and the strategy developments that were influenced as a result.

TOA scholars such as Gibson (1979), Norman (1999), and Gaver (1991) do not acknowledge the concept of path dependence in the process of affordance perception and realisation. However, Turvey (1992) discussed the notion of the prospective control of affordances: that is, in order to achieve the goal of the affordances the person must be able to foresee that they could complete the whole action, and the necessary sub-actions. When applied to incubator firms, Turvey's approach implies that the actions that the firms undertake impact future actions, and that the actions are only undertaken if the outcome is expected to be successful. The perception of the affordances or actions is therefore somewhat critical before the realisation of the affordances. The path-dependency concept acknowledges the role and importance of perception and specifically proposes that;

- perceptions of affordances evolve with realisation;

- affordance realisation depends on prior realisation of affordances; and

- the path of the actors, and interaction with the environment is related to the influence of the affordances.

\subsubsection{Implications for the conceptual model}

The original conceptual model showed a central arrow indicating that the affordances of the provisions would be perceived and realised in a linear way. The new model presented in Figure 32 conveys the idea that the perception and realisation of affordances evolve with realisation and can be dependent on what has happened previously. The prior path of the firms, and of the incubator environment present moderating factors. 


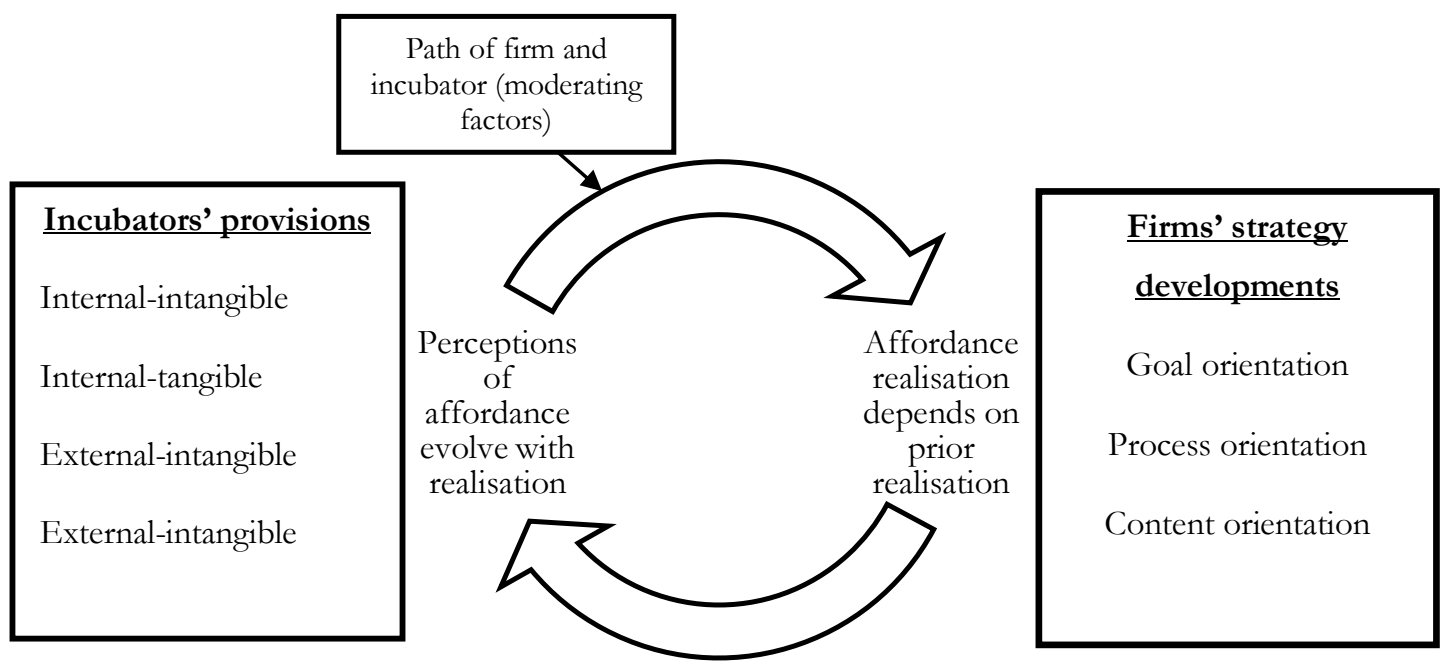

Figure 32. The conceptual model showing that affordance perception and realisation is path dependent

\subsection{Perceptions of affordances evolve with realisation}

It is widely acknowledged that the perceived and realised affordances of an object may not be the same (Chemero, 2003; Letiche \& Lissack, 2009; Norman, 1999; Sadler \& Given, 2007; Zhao et al, 2013). Perceptions of affordances can also evolve with realisation and may be different from the original intention, as van Osch and Mendelson (2011) concluded when they developed a typology of affordances as they relate to social media interaction. These authors found that affordances can be designed in that they delivered on the original intent, improvised from an intended affordance, or emergent in that the affordances were neither designed nor intended. From the preceding discussion it appears that potentially firms were able to realise not only the affordances intended by the incubator, but also the improvised and emergent affordances, and that these affordances influenced their future realisation of the affordances, thereby potentially making them path-dependent. As discussed in Section 8.4.1.1.3, Gibson (1979) attested that affordances are not drawn from actors' experience or knowledge, whereas Norman (1999) argued that affordances are related to the actors' experience or knowledge. This study found that past experience appears critical in influencing the paths related to the perception and realisation of affordances and related to both the firms and to the incubator environment. Overall, the firms seemed to have lower perceptions of value of the affordances that had not been realised. In contrast the incubators appeared to have higher perceptions of the value of the affordances that had not been realised. For example, firm $6 \mathrm{C}$ expressed their surprise about the value that could be derived from the incubators' provisions. Interestingly this firm took a lot of convincing by the 
incubator to join it, and eventually joined with the expectation of affordances coming from being surrounded by other entrepreneurs and by people that could help them with technical product issues. However, when asked what affordances they had actually experienced, they were broader in scope.

I wish we had done it 12 months earlier, I really do. And if nothing else comes out of this, I say to everybody who says that they have a business idea, "go to an incubator because the access to the people, and to the knowledge, and to the skill set, and the support and everything is just phenomenal." Having built multiple businesses on our own, to then suddenly come into this welcoming, supportive, positive environment, is phenomenal.

In their study of how Chinese college students spent their leisure time, Yang et al. (2011) found that perception of affordances can only occur when the environment meets the actor. This may explain why so many provisions were not even perceived as the actor may not have 'met' the environment (incubator). In some instances firms did not use the intangible provisions at all and so may have rarely come into contact with the incubator environment. However, as discussed earlier, the difference could also be due to firms not needing or wanting the affordances of provisions.

The firms that had not used the intangible provisions judged them as being less valuable than the firms that had used the provisions. This signals that this perception difference with use may be path-dependent, with the value judgement before use potentially being lower than the value after use. The exact reason for the lower expectations about the value of the affordances that could be derived from the intangible provisions is not clear, but it may have been that there was a general lack of awareness by firms about what incubators actually do.

Other firms may have thought that the main purpose of incubators was to provide connections to sources of capital such as investors $(\mathrm{O})$ and government grants $(\mathrm{N})$ and have subsequently not anticipated other benefits. Interestingly these provisions were judged to be of less value by firms that had used them, compared to those that had not.

The incubators' perceptions of what affordances were available to firms from their provisions potentially reduced once the provisions were used. This conclusion is based on the incubators indicating that they thought that the firms' strategies would become more emergent whereas, generally, this was not the case. This expectation of the incubators could have been based on their beliefs that the firms came in to the incubator with a very inwardlooking strategy, and would therefore become more emergent through the realisation of 
affordances such as strategy methodologies like the Lean Start-up. It is proposed that the reason that the firms' strategies did not become emergent was because of the path that the firms had already followed; that is, prior to getting into the incubator the firms had been quite emergent, whereas once in the incubator they want to settle down and put plans in place. Therefore the perceived affordances from the incubators' provisions could have been less than the incubator expected. For example, firm 22D discussed how coming into the incubator meant that they became more focussed, rather than more emergent:

We had solutions for [a variety of markets]. It was coming to [the incubator] that we had to focus.

Therefore, in some regards the affordances of the provisions became more valuable than the firms expected over time from the perspective of the firms, and less valuable over time from the perspective of the incubators.

\subsection{Affordance realisation depends on prior realisation of affordances}

As discussed above perceptions of affordances may differ based on the realisation of their affordances. Here it is proposed that while perception is important, prior realisation also plays a part in future realisation.

The discussion earlier in Section 8.3.1.2 suggested that the usage of some provisions may decrease over time, whereas for other provisions it may increase. Correspondingly, some provisions may become more important and others less important. The firms that had been in the incubator for less than one year used the internal provisions in the main, whereas the older firms used the external provisions to a greater degree. Therefore there appears to be a hierarchy of provision usage over time. It is proposed that this hierarchy depends on prior realisation. For example, all of the incubators tended to have some sort of structured programme when firms first entered the incubator, either in the form of multi-firm-based workshops or individual programmes. These programmes focused heavily on providing assistance to the firm with strategy methodologies (E) and market validation and development $(\mathrm{H})$, the affordances of which have relatively low specificity, as the ensuing outcomes following their realisation is somewhat uncertain. Once the firms' strategies were roughly formulated the firm may have realised affordances such as from assistance with financial planning and management (I) in order to formulate their plans. This path seems to be reflected in the relatively high level of planning done by the newer firms. Following the strategy formulation and planning stage, the firms appeared to engage more with the 
incubators' wider networks, the external categories of provisions. Similarly Warren et al. (2009) found that as firms grow they become more embedded in external networks. An example from the current study is illustrated in Figure 33. However, this study did not specifically take into account the order in which provisions were used, so this example is somewhat anecdotal.

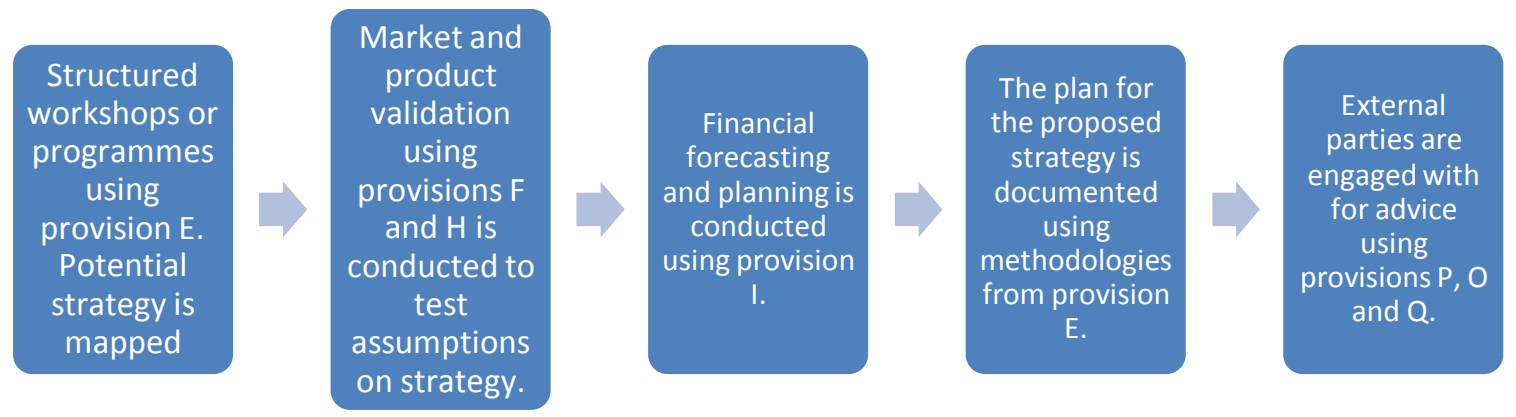

Figure 33. Example of how firms may engage with incubators' provisions over time

Some of these external provisions - such as connections to subject matter experts (Q) - were commonly used by firms that had been in the incubator for longer, presumably because these firms had already proven their worth. Other firms were seeking to get investment-ready, and establish external governance; they therefore commonly used provisions such as connections to potential board members $(\mathrm{R})$. The provisions used by these more mature firms would potentially have offered an increasingly specific level of affordances, and thus carry greater importance as time progressed. The use of the internal-intangible affordances did not appear to be substantially greater for firms that had been in the incubator for longer. Firm 4B explained about how their engagement with the incubator reduced over time, which may have been common to many firms:

When we first began two and a half years ago we had a lot of interaction with [the incubator] ...about [our firm's] strategy. So that was a weekly event with an advisor for about the first twelve months. There were also a lot of programmes and learning opportunities and workshops that we attended in addition to that in the first twelve months or so. Then it slowed down quite a lot ... [now it is] probably more like a monthly catch up, but a lot more unofficial discussions, so it is a bit more of an informal process at this point, which is fine.

From the discussion above it appears that the because incubators all seemed to make all firms go through a path-dependent process to some degree, the firms' age or stage of 
development on entry did not seem to bear much relationship to how the firms realised affordances of the provisions and their ensuing strategy developments.

The firms' learning experience from previous realisations of affordances also appeared to be related to the future realisation of the affordances. For example, if the prior experience of provision usage was poor then the firm potentially would not use it again. Van Dijk et al. (2011) found that the actors respond to the affordance in a reflexive manner, meaning that prior learning and experience was important.

Figure 34 illustrates how future affordance realisation can depend on prior realisation.

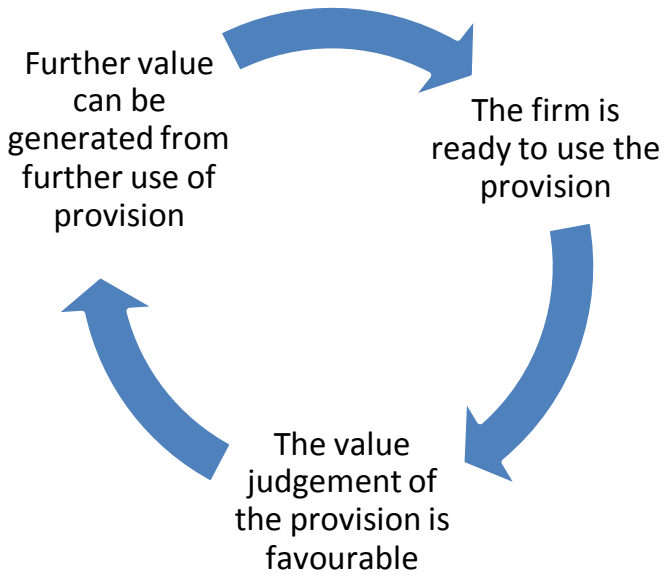

Figure 34. Factors influencing future realisation

Future realisation could be somewhat determined by whether there was the ability to extract ongoing affordances from the provisions, or if the maximum affordances could be achieved through single use, as discussed earlier in Section 8.3.1.2.

\subsection{The path of the actors and the interaction with the environment is related to the influence of the affordances of the provisions}

The concept that actors may respond differently to affordances depending on their prior choices and environment has been well established (Bryson et al., 2006; Gram-Hanssen \& Bech-Danielson, 2012; Sadler \& Given, 2007; van Dijk et al., 2011; Zhao et al., 2013). For example, Hetzner et al. (2009) studied how employees respond to changes in their workplace and found that the opportunities for action varied depending on the actors' type of work and the environment that they worked in.

Incubator firms were not all in the same situation when they entered the incubator: they had different products, were at different stages and were in different environments (incubators) 
and all this appeared to impact on the influence of affordances in strategy development. High levels of prior product development seemed to mean that fewer affordances were perceived and realised. As discussed earlier in this chapter, it is likely that firms with physical products had invested a lot more in product development prior to entering the incubator. This could be because the incubators sought firms that they could readily assist, and that this assistance was more by way of strategy processes, for example, as opposed to product development. If the HTFs had already invested a substantial amount in prototyping and testing, this could explain why they perceived and realised affordances associated with the provision of product validation and development $(\mathrm{F})$ less than the ITFs did. The lower awareness of this provision by the HTFs could have been due to the incubators providing it only to firms that specifically needed it. The provision of assistance with product validation and development $(\mathrm{F})$ therefore appeared to be what Gaver (1991) referred to as a hidden affordance in that actors only perceive the potential affordances once they are made aware of them. The incubators potentially therefore have an obligation to make firms aware of what they need, when they need it.

Further, the lower usage rate of provision F could have been because the HTFs were concerned that usage of this provision would result in their product scope changing, which they were reluctant to do given their substantial prior investment. This situation seemed to be the case for firm $24 \mathrm{~B}$ who had spent a substantial amount of money on product development, testing and patenting and, as a result, were "fixated on this one avenue". Accordingly, none of the HTFs radically changed their product scope and none adopted more emergent strategies, despite being at a similar age and stage to the ITFs and the LTFs. However, if the incubator had been involved in the HTFs' product development process earlier, before substantial amounts of money had been invested in product development, then the ensuing strategy development may have been more emergent and may have more closely resembled those of the ITFs. This emergent approach was evident in the product changes experienced for the ITF firm 30C:

The [product] has changed so radically ... my focus has shifted completely ... now it is completely different.

The ITFs had potentially made relatively minimal investment in their products prior to entry into the incubator, making them more receptive to many of the affordances arising out of the provisions, such as product validation and development $(\mathrm{F})$. 
Zhao et al. (2013) studied social media interaction design like van Osch and Mendelson (2011), and developed a similar typology of perceived affordances. Zhao et al. (2013) found that different tasks required different levels of involvement from participants, depending on the individual needs and purposes of the users, and that consequently, designers could cater to this individuality. This finding emphasises that the onus is on the design of the environment and not just the actor in order for the affordances to be of most influence.

From this discussion it could be expected that the HTFs would enter the incubator in what Mintzberg (1973) defined as the planning mode - given their prior development - and that the ITFs were more in the entrepreneurial mode given their inherent flexibility. However, as there were no discernible differences in the extent of planning undertaken by these two product-type groups, it could be that the incubator had the effect of overriding what the firm may have been naturally inclined to do. This might be the case especially in the BFIs that had multi-firm-based generic programmes meaning that the incubator may have forced unnecessary planning on the ITFs. The firms' prior development may not have been factored in by the incubator.

The stage of development that the firms were at in terms of getting investment potentially impacted affordance realisation, as discussed earlier in Section 8.3.2.2. It could be that firms that gained external investment prior to entry into the incubator would presumably be at a more advanced stage of strategy development than other firms, and therefore would be less likely to be influenced by the incubators' affordances. This was seen in the lower rates of strategy developments for these firms, particularly on the goal and process orientations. The NFIs had a well-defined process for both gaining investment and for product development.

\subsection{Chapter summary}

This discussion has highlighted how the TOA has been instrumental in addressing the research sub-questions that together form the basis of the overarching question: How may incubators influence firms' strategy development? The questions were addressed and discussed in the context of TOA, and from these, three key concepts were identified: specificity, path dependency and substitutability. Chapter Nine draws conclusions on the implications of the discussion for incubator knowledge and practice, and for the application of TOA in organisational studies. 


\section{Conclusion}

\subsection{Introduction}

This thesis set out to address the overarching research question:

How may incubators influence firms' strategy development?

It was found that firms' value judgements of provisions differed according to whether or not the provisions were used, the affordances of provisions varied in scope and in frequency of use, the firms' product type and governance structure impacted the influence of the incubator, the influence of the provisions changed over time, and the incubator's breadth of focus was important. These findings represent this study's contribution to incubator knowledge. They also have important implications for practice.

The theory of affordances (TOA) formed the basis of the conceptual model that was used to investigate the overarching question and reach the conclusions (see Figure 3, Chapter Two). A key assumption implicit in the model was that affordances result from the incubators' provisions and that these affordances may be perceived and realised by the firms, influencing changes in the firms' strategy development. It was acknowledged that factors - related to the incubator and the firm could impact this process. While the model was appropriate for mapping the research results, in the process of applying TOA three important concepts emerged that gave deeper insights into the nuances of the influence of incubators on firms' strategy development. These insights were the specificity of affordances, the substitutability of objects and path dependency of affordances of provisions.

In this chapter the contributions of this study to the application of TOA in organisational studies are discussed first, followed by the contributions to incubator knowledge, the implications for incubators and firms, the limitations of the study, and the opportunities for further research. 


\subsection{Contribution to the theory of affordances as applied in organisational studies}

While the TOA was an appropriate theoretical lens, it became apparent that the way incubators actually influenced the firms was sometimes more nuanced than the TOA indicated — as canvassed in the literature. The contributions of this study to the application of TOA in organisational studies are addressed as they relate to the specificity of the affordances, the substitutability of objects and to path dependency.

In the following discussion firms are referred to as actors, incubators are referred to as the environment, provisions are referred to as objects, and strategy developments are referred to as opportunities for action.

\subsubsection{Specificity of affordances}

Specificity refers to the scope of the affordances of the individual objects, to the clustering of objects resulting in combined affordances.

It is widely acknowledged that the affordances of objects are not singular; the affordances can be many and varied (Bryson et al., 2006; Chemero, 2003; Fayard \& Weeks, 2007; Gaver, 1991; Letiche \& Lissack, 2009; Maier, 2008, Norman, 1999; Sadler and Given, 2007; van Dijk et al., 2011; Yang et al., 2011; Zhao et al., 2013). While the findings of this study reflected this, it was also found that affordances with greater specificity (or singularity) can be necessary but not sufficient to influence actions, whereas other objects had a less specific or a broader range of affordances. Specificity also relates to the ability or otherwise to extract ongoing value from the object over time.

Also, when objects cluster together the affordances can become more specific, a concept which was alluded to by Sadler and Given (2007). Similarly, this study found that the clustering of some affordances from different objects made previously less specific affordances more specific and, in doing so, their influence on opportunities for action was more defined and sometimes deeper. Other objects appeared to function well in isolation and so clustering was not necessary.

It was also found that the attributes of the actor and the environment are related to the specificity of the affordances. While it has already been accepted that the attributes of actors and environments are connected to how they perceive and realise affordances (Bryson et al,, 2006; Gram-Hanssen \& Bech-Danielson, 2012; Norman, 1999; van Dijk et al., 2011) what 
was interesting was that the environments' attributes were related to the overall specificity and to the degree of clustering of the affordances. Environments that were narrower and focussed offered greater specificity of affordances.

\subsubsection{Substitutability of affordances}

Substitutability refers to the affordances of some objects being substitutable both with each other and with affordances from objects from outside the environment.

The literature of prominent TOA scholars (Gaver, 1991; Gibson, 1979; Norman, 1999) did not suggest that affordances from some objects may be substituted by affordances from other objects, although van Osch and Mendelson (2011) acknowledged that affordances can come from the outside the incubator.

This study found that the ease of substitutability depended on the object and ranged from objects that had affordances which appeared not able to be substituted at all to those that were frequently substituted. The substitution could occur between the objects within the immediate environment (the incubator), and between objects in the immediate and wider environments.

The degree of substitutability of objects was also not generally complete, in that while some affordances were substitutable, they were not totally substitutable. The degree of substitutability depended on the ability of other objects to replicate the affordances of the original object. It was also dependent on whether the substituted objects changed the actors' behaviours with respect to their perception and realisation of the original objects' affordances. This change could have been detrimental to the affordances of other objects within the actors' immediate environment, thus reducing their degree of specificity and ability to cluster. The substituting object could also have had a positive influence, in that it resulted in the greater perception and realisation of affordances of other objects in the immediate environment.

\subsubsection{Path dependency of affordances}

Path dependency refers to the path that the actors took, including choice of product type, choice of incubator, the process of perception and realisation of affordances, and the strategy developments that were influenced as a result.

While the concept of path dependency was not explicitly apparent in the TOA literature Norman (1999) discussed the importance of the role of prior experience and knowledge in 
affordance realisation, and Turvey (1992) discussed the notion of prospective control of affordances and how this impacts affordance realisation.

This study found that perceptions of affordances evolve with realisation, which was also attested by Norman (1999). Interestingly, in this study the actors' value judgements of objects were generally greater for users than for non-users, perhaps indicating that perceived affordances are generally fewer than realised affordances, and therefore the perception of affordances evolved in a positive way.

In addition, affordance realisation was found to depend on prior realisation of other affordances. The factors impacting future realisation related to the actors' prior experience of realising the affordances. The ability to extract ongoing value from subsequent realisation of the affordances was also important, and this was also related to the degree of affordance specificity.

It was also found that the prior path of the actors and the interaction with the environments impact the influence of affordances. It was widely acknowledged in the literature that the attributes of actors are related to how they perceive and realise affordances (Bryson et al., 2006; Gram-Hanssen \& Bech-Danielson, 2012; Norman, 1999; van Dijk et al., 2011). In this study it was found that differences in the environment impacted the process of actor selection, the perception and realisation of affordances, and the ensuing opportunities for action. Correspondingly the differences in the actor-specific factors impacted the process of environment selection, the perception and realisation of affordances, and the ensuing opportunities for action.

The TOA concepts discussed here - affordance specificity, substitutability and pathdependency - are not mutually exclusive, that is, they are somewhat connected as indicated. Importantly, the concepts build on the existing TOA, that is, they are not attempting to nullify the theories that have gone before them; instead they contribute by presenting a more nuanced theoretical lens with respect to how TOA can be applied in organisational studies. 


\subsection{Contributions to incubator knowledge}

Several contributions to incubator knowledge are apparent. These are summarised next.

\subsubsection{The firms' value judgements of provisions differed according to use}

The internal-intangible provisions were judged to be more valuable by firms that had used them than by those that had not. This is contrary to what was found by Abduh et al. (2007), Xu (2010) and Meru and Struwig (2011). The external-intangible provisions were also judged to be more valuable by firms that had used them than by those which had not, and this was contrary to the findings of Rice (2002). The reason that there are differences between this and other studies may be due to recent improvements in the incubation sector and potentially to the incubators underselling the value of their services, or simply that the firms had not used the provisions because they did not need or want them and therefore did not value them.

\subsubsection{The affordances of provisions vary in scope and in frequency of use}

Little was previously known about the incubation process (Hackett \& Dilts, 2004b) and strategy development. This study found that some provisions had a wide scope of influence, and these provisions generally exerted influence by initially giving the firms the structure and tools on which to map their strategies, uncover opportunities and then challenge the assumptions, enabling the firms to reach their own informed conclusions about their strategies. In contrast, other provisions had little or no influence on strategy development, but were considered necessary, as without these provisions the firm would not have the capacity to focus on its strategy development. The frequency of use of provisions also varied, with additional value able to be extracted from the ongoing use of some provisions but not for others.

\subsubsection{The firms' product type can affect the influence of the incubator}

When compared with the physical-product-based firms, firms with information-technology products (ITFs) developed their strategies more due to the incubators' influence, and in different ways. The ITFs were the only firms to adopt a more emergent strategy, which was at odds with the expectations of NEFs (Kiss, 2010; Mintzberg \& Waters, 1985; NichollsNixon et al., 2000). The reason for this disparity could have been due to the inherent nature of the physical-product-based firms and the structured nature of the incubators' programmes. 


\subsubsection{The firms' governance structure can affect the influence of the incubator}

Firms with external governance used more incubator provisions but underwent fewer strategy developments due to the incubators' influence than firms without an external governance structure. These differences were mainly along the goal and process orientations. The capacity for governance to influence firms strategy development has not been contested (Cowling, 2003; Minichilli \& Hansen, 2007) and it is proposed that firms' external governance acts as a substitute for the incubators' provisions, with a firm relying to some extent on the advice from their board in place of advice from the incubator.

\subsubsection{The influence of provisions changes over time}

The age of the firms on entry into the incubator and the length of time that the firms were in the incubator were two factors that mattered. The firms that were older on entry did less planning due to the incubators' influence, and were generally influenced by external provisions to a greater extent than the younger firms were. Again, given that NEFs were expected to adopt a more emergent strategy (Kiss, 2010; Mintzberg \& Waters, 1985; Nicholls-Nixon et al., 2000) this increase in planning - which implies deliberate rather than an emergent intent - was unexpected. It is proposed that the structured nature of the incubators' programmes caused this disparity.

\subsubsection{The incubator's breadth of focus can be important}

The incubators appeared to be on a continuum according to whether they focussed on just incubation or on a wider range of services to the business community. The incubators' placement on this continuum was related to their capacity to influence, and the direction of their influence on the firms' strategy development, the types of firms they incubated, their provisions, and their strategy development methodologies. While differences in the scope of focus of incubators is common (Al-Mubaraki \& Hamad, 2013) the apparent lack of focus on gaining investment was somewhat surprising, given that investment is apparently a key emphasis in New Zealand (Incubators New Zealand, 2011a). The broader-focused incubators (BFIs) focussed less on gaining investment for firms; instead their focus was on putting relatively large volumes of firms through paid multi-firm-based workshops and other revenue-generating programmes, causing dissatisfaction in some firms. This notion of dissatisfaction amongst BFIs' firms appears to be supported by Kilcrease (2011) who found that for-profit seed capital incubators - like the narrow-focused incubators (NFIs) - had the most favourable levels of client satisfaction. 


\subsection{Implications for stakeholders}

This study has implications for a variety of stakeholder groups including incubators, firms, central and local government, investors and universities. The implications along with recommendations for practice are discussed next.

\subsubsection{Incubators}

\subsubsection{Clarify purpose and structure incubator appropriately}

The incubators varied in their degree of focus on just incubation-related activities versus a wider range of services for the business community. It is recommended that incubators seek to clearly identify their purpose and investment risk tolerance, and cater to this accordingly. For example, if their purpose is to build a community of entrepreneurial people then they should focus on multi-firm-based workshops and programmes that offer affordances that are more likely to influence along the goal and process orientations of the firms' strategies. If, on the other hand, the incubator's purpose is to create profitable high-growth-oriented firms that deliver a sustainable return on investment, then they should focus on providing firms with an individualised service using a series of specialised and clustered provisions that influence the content of the firms' strategies.

\subsubsection{Review selection criteria and promote incubator accordingly}

Sometimes the incubators had limited influence on the firms' strategies due to the firms having made a substantial investment in product development prior to entering the incubator. This was the case for many of the physical-product-based firms. Some incubators' selection criteria therefore appeared to be focused on firms that are too far advanced in their product development process, meaning that these incubators had less capacity to influence the firms. These incubators should review their selection criteria and assess whether they are targeting firms that are at an appropriate stage of development.

Many firms didn't perceive the affordances of the incubator's provisions, especially those that arose from the intangible category. This low level of perception may present a problem for incubators when it comes to attracting the right kind of firms, as the firms may not perceive that incubators offer affordances of value. Consequently incubators should make extra effort to ensure that the affordances of these provisions are communicated to the types of firms that meet their entry criteria. 


\subsubsection{Consider how provisions function collectively}

The affordances of many provisions appeared to cluster together resulting in singular opportunities for action for the firms. Therefore incubators need to ensure that some provisions are not provided in isolation. For example, if the incubator provides assistance with market validation then they also need to provide appropriate methodologies so that the firms can be guided in the structure of their strategies during the market validation process. Consideration also needs to be given to the provisions that are considered to have hygienefactor-related affordances. These affordances include housing the firms within the incubators and providing assistance with general administration tasks, thus freeing up the firms to focus on their strategies.

\subsubsection{Tailor approach to strategy development to firms' needs}

The firms developed their strategies in response to the incubators' influence in diverse ways and at different times. To address this diversity the incubators should ensure that the needs of firms are addressed individually as opposed to, for example, making all firms go through the same strategy development programmes; this latter course may have had the unintended effect of reducing firms' propensity to become more emergent with their strategies. The needs of the firms also changed after raising capital and consideration should be given as to if and how the provisions should differ in the pre- and post-capital-raising phases.

\subsubsection{Firms}

\subsubsection{Select incubator based on own objectives}

Some incubators appeared to be more orientated towards the success of the firm, whereas others were more orientated towards the development of the entrepreneur. Entrepreneurs should carefully consider their needs and choose an incubator accordingly, that is, whether they are looking to gain external investment and build a high-growth firm, or whether they are looking to develop their entrepreneurial skills. Whether the incubator actively invests in firms is also an important consideration as this may impact their level of commitment to the firms.

\subsubsection{Be prepared to challenge assumptions and be open to opportunities}

The incubators generally predicted that firms would become more emergent than firms actually did. Firms may need to review their assumptions around their strategic decisions, and determine if they need to adopt a more emergent approach to their strategies and, if so, consider what the constraints may be. They should also attempt to follow through on any 
processes recommended by the incubator, particularly processes involving market validation and strategy methodologies.

However firms should be aware of any inherent constraints or opportunities that they have due to their product type and stage of development, and what scope they have for developing their strategies, and accordingly seek out the most appropriate programme.

\subsubsection{Central and local government}

Central and local government make substantial contributions to incubators by way of subsidising their operational costs, and by providing grants to firms. The contributions are made on the expectation that incubators will help improve the economic outcomes of firms that they incubate, outcomes that are over and above what the firms would achieve without the support of the incubator. Therefore, having knowledge of what incubation models and provisions are most influential on firms' strategy development, and what are not, would be highly beneficial as it would help ensure that funding is concentrated in areas where it has most impact.

\subsubsection{Switch to a performance-based model of incubation and incentivise accordingly}

Central government has shown a strong desire to move towards a performance-based model of incubation with the expansion of the technology-focused incubator concept.

Consequently the level of funding for operational expenses provided to the more traditional founder-focused incubators by central government has been steadily reducing. This reduction in funding appears to have forced many incubators to broaden the scope of services that they offer the business community in order to survive, such as offering workshops for fee-paying firms and as a form of pre-incubation, and running accelerator programmes. This means that the incubator's incentive to help firms with their strategy development, and ultimately their financial performance, may have become secondary to selling spaces on the paid workshops and other programmes. The result of which appears to be a dilution of the influence on firms in these types of incubators.

However, the founder-focused incubators would have substantial value in terms of their knowhow, networks and infrastructure, and should not be forced to diversify their services in order to survive. It is recommended that government switch their focus from trying to make the founder-focused incubators financially self-sufficient to encouraging these incubators to "stick to their knitting" by providing funding based on the economic impact of 
the incubated firms. Government could also expand the repayable grants programme criteria to allow firms from founder-focused incubators to be eligible. These initiatives would help re-align the incentives of the incubators to the firm's performance and would help ensure that incubators are much more selective in terms of firms that they incubate.

\subsubsection{Stipulate product-type specific incubators}

Given that the firm's product-type appeared to be related to the capacity of the incubator to influence the firm, government should potentially stipulate that incubators should focus on either information-technology or physical-product-based firms. This would help ensure that the incubator's provisions are tailored appropriately to the firm's needs.

\subsubsection{Apply learnings from incubation to economic development programmes}

Knowledge gained from this research regarding the application of strategy development methodologies could be applied to the wide range of business start-up programmes offered by government-funded economic development agencies.

\subsubsection{Investors}

A key proposition of incubators is their ability to help firms raise capital. They do this by helping the firms get investment-ready and by connecting them to sources of capital, such as angel and venture capital networks.

\subsubsection{Consider whether the incubator also has a vested interest in the firms}

This research suggested that incubators actively want to attract firms into their fold, especially the broad-focused incubators. A key way incubators attract firms is by emphasising their ability to raise capital. However the broad-focused incubators were not generally substantial investors in the firms, making the financial risk to these incubators of poorperforming firms low. Additionally these incubators often appeared to accept firms on the basis that they can pay for incubation-related workshops and programmes, as opposed to the incubators that select firms on their potential economic return. Investors should therefore exercise caution in investing in firms in the broad-focused incubators until such time as the incubator themselves has substantial "skin in the game". Investors should also consider investing in firms that are in incubators that specialise according to firms' product type, i.e. either physical or information-technology-based products, as opposed to a mix. 


\subsubsection{Review role of incubator once firm has external governance}

The firm's governance was found to be related to the capacity of the incubator to influence the firms, for example, firms with external governance were influenced by the incubator staff to a lesser degree. Investors should consider this reduction in influence once formal external governance is in place and re-evaluate the value of the relationship.

\subsubsection{Acknowledge the role of incubators in enforcing discipline}

Overall the research showed that incubators do influence firms' strategy development and much of this influence came from the discipline of making firms go through strategy development methodologies, and by challenging their assumptions in a structured way, that the firms might not otherwise have done. Therefore, on balance, investors may be better off investing in incubator firms as opposed other firms that have not been exposed to an incubator's influence. However, as discussed above, care should be taken by the investors to determine the legitimacy of the incubator's incentives.

\subsubsection{Universities}

Universities frequently work in collaboration with incubators. This research found that the relationship appeared to be for two main purposes; 1 . The incubator explores and develops the commercial potential of the university's research, potentially leading to the development of commercial enterprises where the university is a shareholder in the firm. 2. The university's researchers assist existing incubator firms with product development and with proof of concept research by way of being an external intangible provision.

\subsubsection{Choose alliances based on incubator's expertise}

This research showed that the incubators were on a continuum from those that specialised in high-technology physical products to those that had a broader focus on various product types. The specialist incubators appeared to be more conversant and experienced with technology and were incentivised by the success of the firms, as discussed above. Knowing which type of incubators have the most appropriate expertise and how they are incentivised, would help universities assess which alliances are the most appropriate.

\subsubsection{Have trust in the incubation process}

In general, incubators were found to have an exploratory, disciplined and evidence-based approach to strategy development. Knowing this may alleviate any reticence on the part of 
the university regarding the incubator taking control of the direction of the research, and doing so in an undisciplined fashion.

\subsubsection{Apply learnings from incubation to own programmes}

Finally, knowledge gained from this research could be applied to universities that teach entrepreneurship and commercialisation programmes, and who have technology transfer offices.

\subsection{Methodological implications}

The research methodology incorporated three strands of qualitative and quantitative data at both the data collection and the data analysis phases. This approach appeared to prove effective. Incorporating the strands during data collection allowed for the survey instrument and the interview schedules in the subsequent strands to be better informed, that is, their development was based on the literature review and on data obtained directly from the research population. Combining the strands at the data analysis phase allowed for more diverse insights to be made. For example, this process enabled the establishment of not only the usage rates of the provisions, but also specifically how they were used, and how they influenced strategy development. Further, the interview participants included both the firms and the incubators, thus enabling triangulation of the data, and therefore the possibility for the findings to be compared and contrasted.

\subsection{Limitations}

While this study was carefully designed and implemented there were some aspects that were outside the control of the researcher, and these placed restrictions on the methodology and, thereby, on the conclusions drawn.

Strand One of data collection involved interviews with the managers of the incubators. While participants were interviewed from all incubators in the population (incubators that were part of the Government-funded Incubator Support Programme), in two incubators two participants were interviewed instead of just one. This was necessary because the first interview participants did not appear to have enough depth of knowledge based on their relatively short period of employment in the incubator. This meant that for these two incubators there were two sets of interview data. However, the data from the respective interviews was compared and appeared compatible. 
Strand Two of data collection required that respondents self-report using an online survey. While this method appeared to be most appropriate for this generally technology-savvy population, there may have been limitations due to not being able to fully control who completed the questionnaire (Bryman \& Bell, 2011). The survey link was distributed anonymously and the incubator managers had to be relied upon to send the link only to those respondents that 'qualified' in terms of the criteria that were established with them prior to survey implementation.

Similarly, some of the participants in Strand Three were essentially self-selected, that is, they indicated on the earlier online survey that they would either like to be interviewed, or would consider being interviewed. There was potential for self-selection bias as this resulted in an initial imbalance in the types of firms. For example, some incubators were under-represented in terms of the number of firms that self-selected. This bias was mitigated by proactively approaching firms within the under-represented incubators to make the sample sizes more proportionally representative.

There were challenges in the process of analysing the data from Strand Three. The firms sometimes had difficulty pointing to the specific source of influence on the strategy developments. The influence sometimes came from a variety of interrelated sources, rather than one defined source. For example, the firms did not say that their goals increased because they used the provision of financial planning, and it was unusual for the firms to frame the answers in this manner. Therefore a certain degree of interpretation and judgement was required by the researcher to determine the provisions of influence, guided by the coding template.

The effects of firms' strategy developments on their performance were not explored. This would have involved a longitudinal study and detailed financial analysis. Instead the focus of this study was on the process of incubation and on understanding how incubators influence firms' strategy development, as opposed to the outcomes of incubation, about which substantial knowledge exists.

Lastly, the research was conducted only in the New Zealand context, and this localised approach could be problematic when generalising the findings due to differences in national cultures (Bryman \& Bell, 2011). New Zealand was chosen as the focus to enable comparison of a subset of incubators that operate under very similar economic and environmental conditions, and to make the data collection process easier due to the relatively close 
geographic proximity. The findings may be able to be generalised to other countries, but with awareness of the potential differences between cultural and business practices.

\subsection{Opportunities for further research}

The findings of this study could be expanded thereby giving even greater insights into the influence of incubators on firms' strategy development. In this study the application of TOA identified three key concepts which were not anticipated from the outset. For example, the concept that affordances could be substituted, and that this substitution can affect the perception and realisation of other affordances, was not expected. Therefore it is proposed that future research incorporates the three TOA concepts that were found to be most pertinent.

This study found that the affordances of some provisions appeared to be necessary but not sufficient to influence firms' strategy development. For example, the affordances from the provision of assistance with business administration tasks (D) were considered to be hygiene factors. It was also found that the NFIs appeared more likely to offer such hygiene-factorrelated provisions than the BFIs. However, it is not known what the effect would be of removing such provisions, that is, would the NFIs have the same degree of influence on the firms' strategy development if they did not offer them? The firms in the BFIs may have, for example, substituted the affordances that came from provision $\mathrm{D}$ in that they may have done their invoicing and accounts themselves. It would be interesting to know whether this form of substitution was detrimental, in that it took an excessive amount of the firms' time and energy. To address this gap in knowledge additional research could be conducted on the firms in the NFIs to explore the affordances of the hygiene-factor-related provisions in more detail, including exactly how these provisions helped the firms. Then, using this data a typology could be created of the affordances of these hygiene-factor provisions. Firms in the BFIs could then be interviewed using this typology to determine if and how these firms substitute the affordances and the impact of such substitution. Based on this further research, knowledge would be gained about how important or otherwise it is for incubators to offer provisions related to hygiene factors, and if the firm can substitute these from elsewhere with no adverse effects.

The firms' external governance was found to substitute some of the incubators' provisions, but that this type of substitution was not generally complete. Substitution by the firms' governance was also found to have the effect of maximising the affordance realisation of 
some provisions. However it was not specifically known what provisions the board could not substitute, why the firms with governance used more provisions and why they had fewer strategy developments. To address this gap it is recommended that further research is conducted that also includes firms' boards, enabling a triangulated perspective. The purpose would be to get the boards' insights on how their role complements or otherwise, the role of the incubator. It is also recommended that non-incubator firms with external governance are included in the research to understand how their boards influence the firms in the absence of the incubator environment. For example, do the boards of non-incubator firms routinely make introductions to professional advisors in their networks, whereas the incubator firms' boards instead rely on the incubator to do this? Furthermore, when comparing what is known about the incubators' influence, the influence of the boards of non-incubator firms could highlight affordances of the incubator that are not able to be substituted by boards. For example, the incubator advisor may offer the affordances of pitching development and practice $(G)$ whereas none of the firms' boards do this. Having this additional information will give insights into what it is that incubators provide that boards do not provide and vice versa, and how and why boards in incubator firms may behave differently to boards in nonincubator firms.

This study also found that the firms' prior development appeared to be related to the capacity that the incubator had to influence the firms' strategies. This finding was apparent in that the firms with different product types had different levels and types of strategy developments, and that different affordances were of influence. It was proposed that the incubators' structured programmes may have been instrumental in making the firms behave in ways that they may not have otherwise been inclined to do. However, the order in which affordances were realised was not specifically known and therefore it was not known if the affordances were appropriate to the firms' stage of development, and if the strategy methodologies of the incubators were appropriate. This gap in knowledge could be addressed by using a longitudinal approach such as by interviewing the firms at different stages, for example prior to entry into the incubator, soon after entry and prior to exiting the incubator. This information would give insights into the order in which affordances are perceived and realised, and the factors that affect this process. The purpose would be to establish the influence of different types of affordances and at different times, and if there was any affordance redundancy. 
Lastly, the research could be conducted in other geographical locations to help evaluate the generalisability of the research and to make comparisons to the New Zealand incubation sector.

\subsection{Chapter summary}

This study set out to address the research question: How may incubators influence firms' strategy development. The TOA was the theoretical lens through which this relationship was explored and, accordingly, contributions to this theory as it is applied in organisational studies were proposed. There were that affordance specificity matters, that affordances from some objects can be substituted with affordances from other objects, and that affordances can be path-dependant. Interesting insights were revealed about the perception and realisation of the affordances of incubators' provisions and about how firms develop their strategies. Factors were found to be related to the influence of the incubator, particularly the characteristics of the firms and the range of focus of the incubators. Contributions to incubator knowledge and implications for practice were proposed, for both the incubators and firms. Finally, limitations were addressed, which presented opportunities for further research into the largely unexplored field of the process of business incubation. 


\section{Appendix A: Information sheet for incubators (Phase One)}

[Name, position, organisation address]

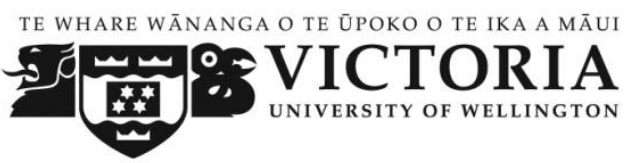

Dear [name]

Business incubation can be valuable in nurturing businesses with high growth potential, as I'm sure you can attest. The New Zealand Government recognises this too, and has just announced that it plans to fund up to four new technology incubators, at a cost of NZ\$31.3m over four years (New Zealand Government, 2014).

My name is Jenny Douché and I am passionate about business incubation and am a doctoral student in the School of Management at Victoria University of Wellington. I am inviting you, as $\mathrm{CEO}$ of one of the seven government-funded New Zealand incubators, to participate in the first phase of this study.

My research question is, "How may business incubators influence firms' strategy development?" I have long been interested in incubators and their role in helping young high-growth-orientated businesses. I first became involved in incubation in 2002 after founding one of the first businesses to graduate from Wellington's incubator, Creative HQ. Upon selling the business I had the privilege of joining Creative HQ's management team managing their pre-incubation programme, Activate. During my involvement with Creative HQ I noticed that, in many cases, the influence of the incubator on the residents' strategy development appeared substantial.

Much is known about incubators' positive economic benefits, high survival rates of resident businesses and about the incubator's provisions. However, little is known about the process of incubation, that is, how businesses within incubators develop their strategies, and the role played by incubators in this process. One of the objectives of the research will be to help incubator managers develop a more holistic understanding of the strategy developments that occur, and consequently, how they could provide the most effective services, facilities and networks. 
The research will consist of three phases. Phase One (the current phase) will involve 30minute interviews with the CEOs of each of the seven government-funded incubators. Phase Two will be an online five-minute survey questionnaire of all current resident businesses, and lastly, Phase Three will consist of in-depth interviews of selected resident businesses. Interview participants will not receive monetary compensation, but will receive a summarised report based on the final thesis.

In accordance with Phase One of the research, I would like to conduct a one-hour interview with you as CEO of [incubator name]. Note that the Phase One interviews will be undertaken before contacting the resident businesses. The purpose of the interview is to gain an understanding of the services and facilities that you provide to the residents and your overall impression of what types of strategy developments occur as a result. I will not be asking questions about specific businesses. Soon after completion of the interview you will receive a full transcript, based on which you may make factual changes.

Participation in this research is entirely voluntary. All data collected from the interviews will be treated anonymously, with neither your name nor your incubators' being reported; however, pseudonyms may be used. Other characteristics that may identify you or your organisation may also be used, but only with your consent. All data will remain confidential to me and my supervisors. Should you wish to withdraw from the project you may do so without question at any time within one month of receipt of the interview transcript. This research project has received approval from the Victoria University Human Ethics Committee.

The final thesis will be deposited in the University Library. It is also intended that one or more articles will be submitted for publication in scholarly journals.

If you have any further questions please contact me (jenny.douche@vuw.ac.nz or phone 04 479 7599) or my supervisors: Urs Daellenbach (urs.daellenbach@vuw.ac.nz or phone 04463 5732) and Sally Davenport (sally.davenport@vuw.ac.nz or phone 04463 5144).

Yours sincerely,

Jenny Douché 


\section{Appendix B: Interview consent form (Phases One and Three)}

\section{CONSENT TO PARTICIPATE IN RESEARCH}

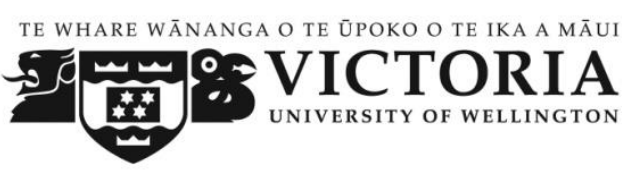

\section{Title of research: The influence of business incubators on strategy development (Note this was the original working title of the thesis)}

I have been given and have understood an explanation of this research project, and have had an opportunity to ask questions and have had them answered to my satisfaction.

I therefore agree to take part in this research based on my understanding that:

- I may withdraw myself (or any information I have provided) from this project without having to give reasons within one month of receiving the interview transcript.

- Any information I provide will be kept confidential to the researcher and the research supervisors.

- I will have an opportunity to check the transcripts of the interview and respond within a mutually agreed timeframe before publication.

- The published results will not use my name, although pseudonyms may be used.

- The published results will not use opinions or characteristics that will be attributed to me in any way that will identify me, unless I give my permission.

- The audio recording of interviews will be wiped at the end of the research unless I indicate that I would like them returned to me.

- The data I provide will not be used for any other purpose or released to others without my written consent.

- I will receive a summary of the results of the research when it is completed.

Date:

Name:

Organisation:

Signature: 


\section{Appendix C: Interview schedule (Phase One)}

\begin{tabular}{|c|c|}
\hline Data required & Question \\
\hline \multirow[t]{2}{*}{ Demographics } & $\begin{array}{l}\text { 1. Type of incubator? Number of resident firms? Types of firms? } \\
\text { Funding? Partnerships? }\end{array}$ \\
\hline & $\begin{array}{l}\text { 2. What services are offered by incubator apart from standard } \\
\text { incubation, if any? }\end{array}$ \\
\hline \multirow{3}{*}{$\begin{array}{l}\text { Incubator's } \\
\text { provisions }\end{array}$} & 3. What provisions are available for residents? \\
\hline & 4. What opportunities arise out of each of the provisions? \\
\hline & 5. Which of these opportunities are most important and why? \\
\hline \multirow{3}{*}{$\begin{array}{l}\text { Firms' } \\
\text { situation upon } \\
\text { entry into } \\
\text { incubator }\end{array}$} & $\begin{array}{l}\text { 6. What stage of development are firms generally at on arrival into } \\
\text { the incubator? }\end{array}$ \\
\hline & $\begin{array}{l}\text { 7. What do you think the residents' greatest needs from the incubator } \\
\text { are? }\end{array}$ \\
\hline & $\begin{array}{l}\text { 8. What documentation do the residents need to have completed on } \\
\text { entry into the incubator? }\end{array}$ \\
\hline \multirow{5}{*}{$\begin{array}{l}\text { Firms' strategy } \\
\text { developments }\end{array}$} & 9. Is there an overall goal for residents' strategy development? \\
\hline & $\begin{array}{l}\text { 10. Are there any standardised strategy development programme/s } \\
\text { that are embarked on for new firms? }\end{array}$ \\
\hline & $\begin{array}{l}\text { 11. Do the residents' growth ambitions tend to change during } \\
\text { incubation and how? }\end{array}$ \\
\hline & $\begin{array}{l}\text { 12. To what extent does the incubator promote planning or doing, and } \\
\text { how does this change during incubation? }\end{array}$ \\
\hline & $\begin{array}{l}\text { 13. Do any parts of the residents' strategies tend to change during } \\
\text { incubation, and to what extent? }\end{array}$ \\
\hline \multirow{4}{*}{$\begin{array}{l}\text { Perceptions on } \\
\text { influence of } \\
\text { incubation and } \\
\text { strategy } \\
\text { development }\end{array}$} & $\begin{array}{l}\text { 14. What is the most notable change that occurs in the strategies of } \\
\text { the residents? }\end{array}$ \\
\hline & $\begin{array}{l}\text { 15. What is the greatest benefit that the incubator provides to } \\
\text { residents in terms of their strategy development? }\end{array}$ \\
\hline & $\begin{array}{l}\text { 16. Do you see any consistent differences in the use of the incubator's } \\
\text { provisions between successful and unsuccessful firms? }\end{array}$ \\
\hline & $\begin{array}{l}\text { 17. Do you see any consistent differences in the strategy development } \\
\text { of successful and unsuccessful firms? }\end{array}$ \\
\hline
\end{tabular}




\section{Appendix D: Online survey (Phase Two)}

Thank you for clicking on to the link to this survey. It should take about ten minutes to complete. Before starting the survey please review the information below.

\section{About the researcher}

My name is Jenny Douché and I'm passionate about business incubation. I'm also a doctoral student in the School of Management at Victoria University of Wellington. I first became involved in incubation in 2002 after founding one of the first companies to graduate from Creative HQ and, upon selling the company I joined Creative HQ's management team, before deciding to become a student again.

\section{The research question}

There seems to be widespread agreement that incubation works, but little is currently known about what actually happens to companies during incubation. My research question is, how and why do incubators influence companies' strategy development? The questions in this survey will explore how you make use of the incubator's provisions. There are no questions about strategy development at this stage in the research.

\section{The survey}

The survey is to be completed by just one person in your company, ideally the person in charge of strategy. Participation is entirely voluntary. All data collected will be treated anonymously, with neither your name nor the incubator's name being reported. However, pseudonyms may be used. Note that by completing the questionnaire you acknowledge that we have your consent to use the data from your responses. The due date for completion is 9 August, 2014. Should you wish to withdraw from the research you may do so without question at any time before 9 September, 2014.

\section{Interviews following this survey}

This survey will be followed by interviews with some incubator companies, whose participation will be entirely voluntary. The purpose of the interviews is to explore how their strategies have developed during incubation and the role of the incubator in this process. Interview participants will receive a gift and a summarised report based on the final thesis. At 
the end of this survey you will be asked to indicate if you would consider being involved in the next phase of this research.

\section{Ethics and outcomes of the research}

All data obtained from this research project will remain confidential to me and my supervisors. The research has received approval from the Victoria University Human Ethics Committee. The final thesis will be deposited in the University Library and the research will be submitted for publication in scholarly journals. This research may help incubator companies to get a better understanding of factors which could help with their strategy development.

\section{Contact information}

If you have any further questions please contact myself (jenny.douche@vuw.ac.nz or phone 04479 7599) or my supervisors: Urs Daellenbach (urs.daellenbach@vuw.ac.nz or phone 04 463 5732) and Sally Davenport (sally.davenport@vuw.ac.nz or phone 04463 5144). 
Q1: Which incubator are you in?

The Icehouse

O Soda Inc.

O ecentre

$\mathrm{O}$ BCC

O Creative HQ

$O$ powerHouse

Q2: Where is your company's headquarters primarily physically located?

In the incubator

Separate premises in an office or laboratory

O At the home of the founder/s

O Other

Q3: How often do you use the following facilities at [incubator name inserted]?

\begin{tabular}{|c|c|c|c|c|c|c|c|}
\hline & Never & $\begin{array}{c}\text { Less } \\
\text { than } \\
\text { Once a } \\
\text { Month }\end{array}$ & $\begin{array}{c}\text { Once a } \\
\text { Month }\end{array}$ & $\begin{array}{c}2-3 \\
\text { times a } \\
\text { Month }\end{array}$ & $\begin{array}{c}\text { Once a } \\
\text { week }\end{array}$ & $\begin{array}{c}2-3 \\
\text { Times a } \\
\text { week }\end{array}$ & $\begin{array}{c}\text { Almost } \\
\text { daily }\end{array}$ \\
\hline $\begin{array}{c}\text { Dedicated desks } \\
\text { and/or office space }\end{array}$ & 0 & 0 & 0 & 0 & 0 & 0 & 0 \\
Board rooms or \\
meeting rooms
\end{tabular}

Q4: How often do you engage with the following people at [incubator name inserted]?

\begin{tabular}{|c|c|c|c|c|c|c|c|}
\hline & Never & $\begin{array}{c}\text { Less } \\
\text { than } \\
\text { Once a } \\
\text { Month }\end{array}$ & $\begin{array}{c}\text { Once a } \\
\text { Month }\end{array}$ & $\begin{array}{c}2-3 \\
\text { Times a } \\
\text { Month }\end{array}$ & $\begin{array}{c}\text { Once a } \\
\text { Week }\end{array}$ & $\begin{array}{c}2-3 \\
\text { Times a } \\
\text { Week }\end{array}$ & $\begin{array}{c}\text { Almost } \\
\text { daily }\end{array}$ \\
\hline $\begin{array}{c}\text { Incubator staff } \\
\text { Entrepreneurs in } \\
\text { other incubator } \\
\text { companies }\end{array}$ & 0 & 0 & 0 & 0 & 0 & 0 & 0 \\
\hline
\end{tabular}


Q5: Incubators offer a range of provisions for incubated companies. Which of the following can [incubator name inserted] assist with?

\begin{tabular}{|c|c|c|c|}
\hline General business administration tasks & $\begin{array}{c}\text { Yes, it's } \\
\text { available }\end{array}$ & $\begin{array}{c}\text { Unsure if } \\
\text { available }\end{array}$ & $\begin{array}{c}\text { No, it's not } \\
\text { available }\end{array}$ \\
$\begin{array}{c}\text { Strategy methodologies } \\
\text { Product validation and development }\end{array}$ & 0 & 0 & 0 \\
Pitching development and practice & 0 & 0 & 0 \\
Market validation and development & 0 & 0 & 0 \\
Financial planning and management & 0 & 0 & 0 \\
Growth management & 0 & 0 & 0 \\
Eeveloping a board of directors or advisors & 0 & 0 & 0 \\
Developing a team of people & 0 & 0 & 0 \\
Educational workshops & 0 & 0 & 0 \\
\hline
\end{tabular}

Q6: These are the provisions that you know about. Have you used them at [incubator name inserted]? (Select yes or no for each provision).

Q7: These are the provisions offered by [incubator name inserted] that you have used.

How much have you used them in the last six months? Choose the answer that most closely 
represents your usage level. (Seven point Likert scale ranging from "just once" to "almost daily").

Q8: Assuming they were available at [incubator name inserted], even if they aren't presently, how valuable would the following provisions be to your company? Move the slider to indicate your choice. (100-point sliding scale for each provision).

Q9: Incubators offer a range of connections to people and organisations. Which of the following can [incubator name inserted] connect you to?

\begin{tabular}{|c|c|c|c|}
\hline Government grants & $\begin{array}{c}\text { Yes, its } \\
\text { available }\end{array}$ & $\begin{array}{c}\text { Unsure if } \\
\text { available }\end{array}$ & $\begin{array}{c}\text { No, its not } \\
\text { available }\end{array}$ \\
\hline Angel investors or venture capitalists & 0 & 0 & 0 \\
Professional services, e.g. lawyers, accountants, & 0 & 0 & 0 \\
sales trainers & 0 & 0 & 0 \\
Subject matter experts & 0 & 0 & 0 \\
Potential board members & 0 & 0 & 0 \\
Potential major customers & 0 & 0 & 0 \\
Universities and other tertiary institutions & 0 & 0 & 0 \\
\hline Interns from tertiary institutions & 0 & 0 & 0 \\
\end{tabular}

Q10: These are the connections that you know about. Have you been connected to these people or organisations by [incubator name inserted]? (Respondents select yes or no for each provision).

Q11: These are connections available through [incubator name inserted] that you have used. How often have you used them in the last six months? Choose the answer that most 
closely represents your usage level. (Seven-point Likert scale ranging from "just once" to "almost daily").

Q12: Assuming they were available at [incubator name inserted], even if they aren't presently, how valuable would following connections be to your company? Move the slider to indicate your choice. (100 point sliding scale for each provision.)

Q13: Are there any other provisions or connections available at [incubator name inserted]?

Q14: Here are the extra provisions or connections that you listed. Have you used them? (Provisions listed, select yes or no).

Q15: Think about everything that [incubator name inserted] provides for your company, what is most valuable?

Q16: Are there any other types of support that are currently not available at [incubator name inserted] that you would like to see made available?

Q17: When did your company first join [incubator name inserted]? (Select month and year from drop-down menu.)

Q18: When do you expect to exit [incubator name inserted]? (Select month and year from drop-down menu).

Q19: When did your company form? (Select month and year from drop-down menu.)

Q20: What is your title/position within your company? (Free text entry.)

Q21: How many FTE equivalents who are not shareholders, does your company have?
None
O One
Two to four
F Five or more

Q22: How many shareholders in total, currently work full time in your company?
O None
O One
Two to four
$O$ Five or more 
Q23: In addition to the director/s who work in your company, who else is part of your governance structure?
Nobody
O External director/s
Advisory board member/s
O Other

Q24: Is there anything else that I haven't asked about that you think may be of interest to the wider research project?

Q25: This questionnaire will be followed by a series of interviews with incubator companies to be held later this year. Would you consider being involved in the next part of this research?

Yes, I would like to be involved

I may consider being involved, but am unsure at this stage

No, I would not like to be involved

Q26: Please provide your contact details here.

Your name

Company name

Email address

Mobile phone number

Thank you for taking the time to complete this survey, it is greatly appreciated. If you have any further questions please contact me (jenny.douche@vuw.ac.nz or phone 04479 7599) or my supervisors: Urs Daellenbach (urs.daellenbach@vuw.ac.nz or phone 04463 5732) and Sally Davenport (sally.davenport@vuw.ac.nz or phone 04463 5144). 


\section{Appendix E: Information sheet for firms (Phase Three)}

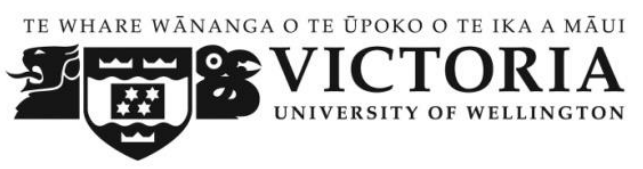

\section{Interviews with incubator businesses}

My name is Jenny Douché and I am a doctoral student in the School of Management at Victoria University of Wellington. I am inviting you, as the main strategist of a current resident incubator business, to participate in my research. You have been selected because you have already completed the survey where you indicated that you would consider participating in an interview.

My thesis will seek to investigate how resident incubator businesses develop their strategies. The research question is, “How may business incubators influence firms' strategy development?" I have long been interested in incubators and their role in helping young high-growth-orientated businesses. I first became involved in incubation in 2002 after founding one of the first businesses to graduate from Wellington's incubator, Creative HQ and, upon selling the business, I joined Creative HQ's management team. I noticed that something unique appeared to happen during incubation, resulting in resident businesses succeeding or failing faster than their non-incubator counterparts. This fascinated me. There seems to be widespread agreement that incubation works, little is currently known about what actually happens to businesses during incubation. This led me to my research question: How may incubators influence firms' strategy development? An anticipated outcome of this research is that it will help incubator residents to get a better understanding of factors that may help with their strategy development.

This stage of my research involves conducting single, in-depth interviews with incubator businesses such as yours. The purpose is to establish if and how you have made use of the incubator's provisions, what changes have been made to your strategies during incubation, and which of these are due to the incubator's influence. The interviews will last 1-1.5 hours and will be conducted at your incubator's premises. Soon after completion of the interview you will receive a full transcript, based on which you may make factual changes. Participation is entirely voluntary; however, I hope you can spare the time. All data collected from the interviews will be treated anonymously; your name and your incubator's name will not be reported. However, pseudonyms may be used. Other characteristics that may identify you or 
your organisation may also be used, but only with your consent. Please be assured that all data will remain confidential to me and my supervisors. Should you wish to withdraw from the project you may do so without question at any time within one month of receipt of the interview transcript. This research project has received approval from the Victoria University Human Ethics Committee.

Interview participants will receive a small gift and a summarised report based on the final thesis. The final thesis will be deposited in the University Library. It is also intended that one or more articles will be submitted for publication in scholarly journals.

If you have any further questions please contact me (jenny.douche@vuw.ac.nz or phone 04 479 7599) or my supervisors: Urs Daellenbach (urs.daellenbach@vuw.ac.nz or phone 04463 5732) and Sally Davenport (sally.davenport@vuw.ac.nz or phone 04463 5144).

Yours sincerely, Jenny Douché 


\section{Appendix F: Interview schedule (Phase Three)}

\begin{tabular}{|c|c|}
\hline Data required & Question \\
\hline \multirow[t]{2}{*}{ Demographics } & $\begin{array}{l}\text { 1. Time in incubator? Ownership status? Position? No. of employees } \\
\text { and shareholders? Governance? Trading status? Industry? }\end{array}$ \\
\hline & 2. Why did you join the incubator? \\
\hline \multirow[t]{5}{*}{$\begin{array}{l}\text { Incubator's } \\
\text { affordances }\end{array}$} & $\begin{array}{l}\text { 3. What services and facilities of the incubator do you use and which } \\
\text { are most important? }\end{array}$ \\
\hline & 4. Tell me about the interactions you have with your advisor? \\
\hline & $\begin{array}{l}\text { 5. Tell me about the incubator's networks, including how you have } \\
\text { used them for your business? }\end{array}$ \\
\hline & $\begin{array}{l}\text { 6. Tell me about the other businesses in the incubator and what it's like } \\
\text { being in a common space? }\end{array}$ \\
\hline & $\begin{array}{l}\text { 7. Tell me about the infrastructure that the incubator provides and } \\
\text { how you use it? }\end{array}$ \\
\hline \multirow{2}{*}{$\begin{array}{l}\text { Strategy dev. - } \\
\text { goal } \\
\text { orientation }\end{array}$} & $\begin{array}{l}\text { 8. Have the goals of your business changed since you joined the } \\
\text { incubator, and if so, in what way? }\end{array}$ \\
\hline & $\begin{array}{l}\text { 9. If your goals have changed what was the main reason for the } \\
\text { change? }\end{array}$ \\
\hline \multirow{4}{*}{$\begin{array}{l}\text { Strategy } \\
\text { development - } \\
\text { process } \\
\text { orientation }\end{array}$} & $\begin{array}{l}\text { 10. Since you have been in the incubator to what extent have you been } \\
\text { focused on planning as opposed to doing, and how has this } \\
\text { changed? }\end{array}$ \\
\hline & $\begin{array}{l}\text { 11. If your approach to planning and doing has changed, what was the } \\
\text { main reason for that change? }\end{array}$ \\
\hline & $\begin{array}{l}\text { 12. In general have your strategy developments become more emergent } \\
\text { or deliberate and why? }\end{array}$ \\
\hline & $\begin{array}{l}\text { 13. If your strategy has become more deliberate or emergent what was } \\
\text { the main reason for the change? }\end{array}$ \\
\hline \multirow{8}{*}{$\begin{array}{l}\text { Strategy } \\
\text { developments } \\
\text { - content } \\
\text { orientation }\end{array}$} & $\begin{array}{l}\text { 14. Have you made any changes to the products and services of your } \\
\text { business since entering the incubator? }\end{array}$ \\
\hline & $\begin{array}{l}\text { 15. If your products and services have changed, what was the main } \\
\text { reason for that change? }\end{array}$ \\
\hline & $\begin{array}{l}\text { 16. Have you made any changes to the people involved in your business } \\
\text { since entering the incubator? }\end{array}$ \\
\hline & 17. If people have changed, what was the main reason for that change? \\
\hline & $\begin{array}{l}\text { 18. Have you made any changes to your marketing strategy since } \\
\text { entering the incubator? }\end{array}$ \\
\hline & $\begin{array}{l}\text { 19. If your marketing strategy has changed, what was the main reason } \\
\text { for that change? }\end{array}$ \\
\hline & $\begin{array}{l}\text { 20. Have you made any changes to the way you and others in your } \\
\text { business spend their time since entering the incubator? }\end{array}$ \\
\hline & $\begin{array}{l}\text { 21. If your time usage has changed, what was the main reason for that } \\
\text { change? }\end{array}$ \\
\hline \multirow{2}{*}{$\begin{array}{l}\text { Strategy } \\
\text { developments } \\
\text { - other }\end{array}$} & $\begin{array}{l}\text { 22. Are there any other significant ways that you have changed your } \\
\text { business's strategy since you joined the incubator? }\end{array}$ \\
\hline & $\begin{array}{l}\text { 23. If your strategy has changed in other ways what was the main reason } \\
\text { for that change? }\end{array}$ \\
\hline
\end{tabular}




\begin{tabular}{|l|l|}
\hline \multirow{4}{*}{$\begin{array}{l}\text { Closing } \\
\text { perspectives }\end{array}$} & $\begin{array}{l}\text { 24. What has been the biggest influence of the incubator on the strategy } \\
\text { development of your business? }\end{array}$ \\
\cline { 2 - 3 } & $\begin{array}{l}\text { 25. Are there any other noteworthy ways that the incubator has helped } \\
\text { or hindered your business's strategy development that we have not } \\
\text { covered? }\end{array}$ \\
\cline { 2 - 2 } & $\begin{array}{l}\text { 26. Is there anything else that you'd like to add that you feel would be of } \\
\text { value to this research? }\end{array}$ \\
\hline
\end{tabular}




\section{Appendix G: Firms' characteristics comparison tables}

Tables 69 to 76 compare the characteristics of the firms to the type of strategy

developments. These tables supplement the analysis in Chapter Six.

The comparison table for the external investment is not included given that the groups of firms closely match those in the governance structure (see Table 69). Similarly, a comparison table for the firms' level of interaction with other firms is not included given that these groups of firms closely match the groups of firms in Table 73 . Only the analysis that is additional to what was included in Chapter Six is presented in these tables to avoid repetition. For example, planning continuum changes are excluded from Table 69. The letter/s in the brackets refers to the provision code that was influential.

Table 69

Type of Product Compared to Types of Strategy Developments

\begin{tabular}{|l|l|l|l|}
\hline & $\begin{array}{l}\text { Physical low tech (4 } \\
\text { firms) }\end{array}$ & $\begin{array}{l}\text { Physical high tech (12 } \\
\text { firms) }\end{array}$ & $\begin{array}{l}\text { Information technology } \\
\text { (17 firms) }\end{array}$ \\
\hline Partnership status cont. & & & \\
\hline Shareholders increased & & $\begin{array}{l}13 \mathrm{E}(\mathrm{C}, \mathrm{K}), 20 \mathrm{E}(\mathrm{J}, \mathrm{K}), \\
33 \mathrm{~A}(\mathrm{E}, \mathrm{R})\end{array}$ & $\begin{array}{l}1 \mathrm{~B}(\mathrm{I}), 4 \mathrm{~B}(\mathrm{~S}), 7 \mathrm{D}(\mathrm{I}), \\
16 \mathrm{C}(\mathrm{B}), 18 \mathrm{C}(\mathrm{K}, \mathrm{O})\end{array}$ \\
\hline Governance increased & & $32 \mathrm{~A}(\mathrm{~K}, \mathrm{R})$ & $6 \mathrm{C}(\mathrm{K}, \mathrm{R})$ \\
\hline $\begin{array}{l}\text { No change attributable } \\
\text { to incubator influence }\end{array}$ & 4 & 8 & 11 \\
\hline Time allocation & & & \\
\hline Switched focus & $8 \mathrm{D}(\mathrm{E})$ & $13 \mathrm{E}(\mathrm{C}), 26 \mathrm{~F}(\mathrm{E}, \mathrm{S})$ & $14 \mathrm{D}(\mathrm{E}), 17 \mathrm{D}(\mathrm{H})$ \\
\hline More efficient & & $2 \mathrm{~F}(\mathrm{E})$ & $4 \mathrm{~B}(\mathrm{E}), 10 \mathrm{C}(\mathrm{E})$ \\
\hline $\begin{array}{l}\text { No change attributable } \\
\text { to incubator influence }\end{array}$ & 3 & 9 & 13 \\
\hline
\end{tabular}


Table 70

Governance Structure Compared to Types of Strategy Developments

\begin{tabular}{|c|c|c|c|}
\hline & $\begin{array}{l}\text { None, just founder (16 } \\
\text { firms) }\end{array}$ & $\begin{array}{l}\text { Advisory board ( } 2 \\
\text { firms) }\end{array}$ & $\begin{array}{l}\text { Board of directors (15 } \\
\text { firms) }\end{array}$ \\
\hline \multicolumn{4}{|l|}{ Goal orientation } \\
\hline Goals increased & $\begin{array}{l}\text { 6C(E), 8D(E, J), 15A(E, } \\
\text { I) }\end{array}$ & $19 \mathrm{D}(\mathrm{H})$ & $\begin{array}{l}\text { 1B(E), 7D(H), 18C(E), } \\
23 \mathrm{E}(\mathrm{E}), 29 \mathrm{~B}(\mathrm{E})\end{array}$ \\
\hline Goals more precise & $26 \mathrm{~F}(\mathrm{I}), 17 \mathrm{D}(\mathrm{H}), 31 \mathrm{D}(\mathrm{E})$ & $5 \mathrm{D}(\mathrm{E})$ & $13 \mathrm{E}(\mathrm{E})$ \\
\hline Goals reduced & $10 \mathrm{C}(\mathrm{E})$ & & $24 \mathrm{~B}(\mathrm{H})$ \\
\hline $\begin{array}{l}\text { No change attributable } \\
\text { to incubator influence }\end{array}$ & 9 & 2 & 8 \\
\hline \multicolumn{4}{|l|}{ Product scope cont. } \\
\hline $\begin{array}{l}\text { Product scope } \\
\text { increased }\end{array}$ & $8 \mathrm{D}(\mathrm{E}), 17 \mathrm{D}(\mathrm{E}, \mathrm{H})$ & & $\begin{array}{l}20 \mathrm{E}(\mathrm{E}), 23 \mathrm{E}(\mathrm{E}), 28 \mathrm{E}(\mathrm{E}, \\
\mathrm{F})\end{array}$ \\
\hline Product more scalable & $3 \mathrm{~F}(\mathrm{~F}), 6 \mathrm{C}(\mathrm{F}), 10 \mathrm{C}(\mathrm{E}, \mathrm{S})$ & & $4 \mathrm{~B}(\mathrm{E}), 21 \mathrm{C}(\mathrm{F}, \mathrm{H}), 29 \mathrm{~B}(\mathrm{E})$ \\
\hline Product evolved & $\begin{array}{l}2 \mathrm{~F}(\mathrm{~S}), 9 \mathrm{~A}(\mathrm{H}), 11 \mathrm{D}(\mathrm{E}, \mathrm{H}) \\
15 \mathrm{~A}(\mathrm{H}), 25 \mathrm{E}(\mathrm{F}, \mathrm{H}) \\
22 \mathrm{D}(\mathrm{E}, \mathrm{H})\end{array}$ & & $\begin{array}{l}\text { 1B(E, H), 7D(H), } \\
14 \mathrm{D}(\mathrm{E}), 33 \mathrm{~A}(\mathrm{~F}), 13 \mathrm{E}(\mathrm{H})\end{array}$ \\
\hline Product was different & $30 \mathrm{C}(\mathrm{E}, \mathrm{I}, \mathrm{S}), 31 \mathrm{D}(\mathrm{E}, \mathrm{H})$ & & 16C(E), 18C(E, O) \\
\hline Product scope reduced & 27F(E, H, P ceased firm) & 19D(E) & \\
\hline $\begin{array}{l}\text { No change attributable } \\
\text { to incubator influence }\end{array}$ & 2 & 1 & 2 \\
\hline \multicolumn{4}{|l|}{ Competitive emphasis } \\
\hline $\begin{array}{l}\text { Competitive emphasis } \\
\text { increased }\end{array}$ & $12 \mathrm{D}(\mathrm{E}), 15 \mathrm{~A}(\mathrm{E}), 22 \mathrm{D}(\mathrm{H})$ & & $\begin{array}{l}\text { 4B(P), 13E(E), 16C(P) } \\
\text { 18C(E), 21C }(\mathrm{H}, \mathrm{Q}, \mathrm{S})\end{array}$ \\
\hline $\begin{array}{l}\text { Competitive emphasis } \\
\text { refined }\end{array}$ & $\begin{array}{l}\text { 8D(E), 10C(E), 11D(U), } \\
\text { 17D(H), 30C(E, I), } \\
\text { 31D(U) }\end{array}$ & & $\begin{array}{l}7 \mathrm{D}(\mathrm{H}, \mathrm{S}), 23 \mathrm{E}(\mathrm{E}) \\
24 \mathrm{~B}(\mathrm{H}), 29 \mathrm{~B}(\mathrm{E})\end{array}$ \\
\hline Market changed & $6 \mathrm{C}(\mathrm{I}), 9 \mathrm{~A}(\mathrm{H})$ & & $32 \mathrm{~A}(\mathrm{~T})$ \\
\hline $\begin{array}{l}\text { No change attributable } \\
\text { to incubator influence }\end{array}$ & 5 & 2 & 5 \\
\hline \multicolumn{4}{|l|}{ Time allocation } \\
\hline Switched focus & 8D(E), 17D(H), 26F(E, S) & & $13 \mathrm{E}(\mathrm{C}), 14 \mathrm{D}(\mathrm{E})$ \\
\hline More efficient & $2 \mathrm{~F}(\mathrm{E}), 10 \mathrm{C}(\mathrm{E})$ & & $4 \mathrm{~B}(\mathrm{E})$ \\
\hline $\begin{array}{l}\text { No change attributable } \\
\text { to incubator influence }\end{array}$ & 11 & 2 & 12 \\
\hline
\end{tabular}


Table 71

Time in Incubator Compared to Types of Strategy Developments

\begin{tabular}{|c|c|c|c|c|}
\hline & $\begin{array}{l}<6 \text { months (9 } \\
\text { firms) }\end{array}$ & $\begin{array}{l}6-12 \text { months (7 } \\
\text { firms) }\end{array}$ & $\begin{array}{l}1-2 \text { years }(4 \\
\text { firms) }\end{array}$ & $>2$ years (13 firms) \\
\hline \multicolumn{5}{|l|}{ Goal orientation } \\
\hline Goals increased & $8 \mathrm{D}(\mathrm{E}, \mathrm{J})$ & $\begin{array}{l}\text { 7D(H), 15A(E, I), } \\
19 \mathrm{D}(\mathrm{H}), 23 \mathrm{E}(\mathrm{E})\end{array}$ & & $\begin{array}{l}\text { 1B(E), 6C(E), 18C(E), } \\
29 \mathrm{~B}(\mathrm{E})\end{array}$ \\
\hline Goals more precise & $\begin{array}{l}\text { 5D(E), 17D }(\mathrm{H}), \\
26 \mathrm{~F}(\mathrm{I}), 31 \mathrm{D}(\mathrm{E})\end{array}$ & & & $13 \mathrm{E}(\mathrm{E})$ \\
\hline Goals reduced & & $10 \mathrm{C}(\mathrm{E})$ & $24 \mathrm{~B}(\mathrm{H})$ & \\
\hline $\begin{array}{l}\text { No change } \\
\text { attributable to } \\
\text { incubator influence }\end{array}$ & 4 & 2 & 3 & 8 \\
\hline \multicolumn{5}{|l|}{$\begin{array}{l}\text { Deliberate \& } \\
\text { emergent }\end{array}$} \\
\hline $\begin{array}{l}\text { Emergent to } \\
\text { deliberate }\end{array}$ & $\begin{array}{l}2 \mathrm{~F}(\mathrm{E}), 8 \mathrm{D}(\mathrm{E}, \mathrm{I}), \\
26 \mathrm{~F}(\mathrm{E})\end{array}$ & & & $13 \mathrm{E}(\mathrm{E}, \mathrm{H})$ \\
\hline $\begin{array}{l}\text { Deliberate to } \\
\text { emergent }\end{array}$ & & 10C(E), 22D(E, H) & & $\begin{array}{l}\text { 4B(H), } 16 \mathrm{C}(\mathrm{E}), 30 \mathrm{C}(\mathrm{H}, \\
\mathrm{I})\end{array}$ \\
\hline $\begin{array}{l}\text { No change } \\
\text { attributable to } \\
\text { incubator influence }\end{array}$ & 5 & 3 & 4 & 8 \\
\hline \multicolumn{5}{|l|}{ Product scope cont. } \\
\hline $\begin{array}{l}\text { Product scope } \\
\text { increased }\end{array}$ & $8 \mathrm{D}(\mathrm{E}), 17 \mathrm{D}(\mathrm{E}, \mathrm{H})$ & $20 \mathrm{E}(\mathrm{E}), 23 \mathrm{E}(\mathrm{E})$ & & $28 \mathrm{E}(\mathrm{E}, \mathrm{F})$ \\
\hline $\begin{array}{l}\text { Product more } \\
\text { scalable }\end{array}$ & & $10 \mathrm{C}(\mathrm{E}, \mathrm{S})$ & & $\begin{array}{l}3 \mathrm{~F}(\mathrm{~F}), 4 \mathrm{~B}(\mathrm{E}), 6 \mathrm{C}(\mathrm{F}) \\
21 \mathrm{C}(\mathrm{F}, \mathrm{H}), 29 \mathrm{~B}(\mathrm{E})\end{array}$ \\
\hline Product evolved & $2 \mathrm{~F}(\mathrm{~S}), 9 \mathrm{~A}(\mathrm{H})$ & $\begin{array}{l}7 \mathrm{D}(\mathrm{H}), 15 \mathrm{~A}(\mathrm{H}), \\
22 \mathrm{D}(\mathrm{E}, \mathrm{H})\end{array}$ & $\begin{array}{l}\text { 14D(E), 25E(F, } \\
\mathrm{H}), 33 \mathrm{~A}(\mathrm{~F})\end{array}$ & $\begin{array}{l}\text { 1B(E,H), 11D(E, H), } \\
13 \mathrm{E}(\mathrm{H})\end{array}$ \\
\hline $\begin{array}{l}\text { Product was } \\
\text { different }\end{array}$ & $31 \mathrm{D}(\mathrm{E}, \mathrm{H})$ & & & $\begin{array}{l}\text { 16C(E), 18C(E, O), } \\
30 \mathrm{C}(\mathrm{E}, \mathrm{I}, \mathrm{S})\end{array}$ \\
\hline $\begin{array}{l}\text { Product scope } \\
\text { reduced }\end{array}$ & $\begin{array}{l}27 \mathrm{~F}(\mathrm{E}, \mathrm{H}, \mathrm{P} \\
\text { ceased firm })\end{array}$ & $19 \mathrm{D}(\mathrm{E})$ & & \\
\hline $\begin{array}{l}\text { No change } \\
\text { attributable to } \\
\text { incubator influence }\end{array}$ & 3 & 0 & 1 & 1 \\
\hline \multicolumn{5}{|l|}{$\begin{array}{l}\text { Competitive } \\
\text { emphasis }\end{array}$} \\
\hline $\begin{array}{l}\text { Competitive } \\
\text { emphasis increased }\end{array}$ & $12 \mathrm{D}(\mathrm{E})$ & $15 \mathrm{~A}(\mathrm{E}), 22 \mathrm{D}(\mathrm{H})$ & & $\begin{array}{l}\text { 4B(P), 13E(E), 16C(P), } \\
18 \mathrm{C}(\mathrm{E}), 21 \mathrm{C}(\mathrm{H}, \mathrm{Q}, \mathrm{S})\end{array}$ \\
\hline $\begin{array}{l}\text { Competitive } \\
\text { emphasis refined }\end{array}$ & $\begin{array}{l}8 \mathrm{D}(\mathrm{E}), 17 \mathrm{D}(\mathrm{H}), \\
31 \mathrm{D}(\mathrm{U})\end{array}$ & $\begin{array}{l}7 \mathrm{D}(\mathrm{H}, \mathrm{S}), 10 \mathrm{C}(\mathrm{E}), \\
23 \mathrm{E}(\mathrm{E})\end{array}$ & $24 \mathrm{~B}(\mathrm{H})$ & $\begin{array}{l}11 \mathrm{D}(\mathrm{U}), 29 \mathrm{~B}(\mathrm{E}) \\
30 \mathrm{C}(\mathrm{E}, \mathrm{I})\end{array}$ \\
\hline Market changed & $9 \mathrm{~A}(\mathrm{H})$ & & & $6 \mathrm{C}(\mathrm{I}), 32 \mathrm{~A}(\mathrm{~T})$ \\
\hline $\begin{array}{l}\text { No change } \\
\text { attributable to } \\
\text { incubator influence }\end{array}$ & 4 & 2 & 3 & 3 \\
\hline \multicolumn{5}{|l|}{ Time allocation } \\
\hline Switched focus & $\begin{array}{l}\text { 8D }(\mathrm{E}), 17 \mathrm{D}(\mathrm{H}), \\
26 \mathrm{~F}(\mathrm{E}, \mathrm{S})\end{array}$ & & $14 \mathrm{D}(\mathrm{E})$ & $13 \mathrm{E}(\mathrm{C})$ \\
\hline More efficient & $2 \mathrm{~F}(\mathrm{E})$ & $10 \mathrm{C}(\mathrm{E})$ & & $4 \mathrm{~B}(\mathrm{E})$ \\
\hline $\begin{array}{l}\text { No change } \\
\text { attributable to } \\
\text { incubator influence }\end{array}$ & 5 & 6 & 3 & 11 \\
\hline
\end{tabular}


Table 72

Age of Firm Before Entering Compared to Types of Strategy Developments

\begin{tabular}{|c|c|c|c|c|}
\hline & $\begin{array}{l}<6 \text { months }(10 \\
\text { firms) }\end{array}$ & $\begin{array}{l}\text { 6-12 months (9 } \\
\text { firms) }\end{array}$ & $1-2$ years (6 firms) & $>2$ years (8 firms) \\
\hline \multicolumn{5}{|l|}{ Goal orientation } \\
\hline Goals increased & $18 \mathrm{C}(\mathrm{E})$ & $\begin{array}{l}6 \mathrm{C}(\mathrm{E}), 7 \mathrm{D}(\mathrm{H}) \\
15 \mathrm{~A}(\mathrm{E}, \mathrm{I}), 29 \mathrm{~B}(\mathrm{E})\end{array}$ & $8 \mathrm{D}(\mathrm{E}, \mathrm{J}), 19 \mathrm{D}(\mathrm{H})$ & $1 \mathrm{~B}(\mathrm{E}), 23 \mathrm{E}(\mathrm{E})$ \\
\hline Goals more precise & $\begin{array}{l}\text { 5D(E), 26F(I), } \\
31 \mathrm{D}(\mathrm{E})\end{array}$ & $13 \mathrm{E}(\mathrm{E})$ & & $17 \mathrm{D}(\mathrm{H})$ \\
\hline Goals reduced & & & $10 \mathrm{C}(\mathrm{E})$ & $24 \mathrm{~B}(\mathrm{H})$ \\
\hline $\begin{array}{l}\text { No change due to } \\
\text { incubator influence }\end{array}$ & 6 & 4 & 3 & 4 \\
\hline \multicolumn{5}{|l|}{$\begin{array}{l}\text { Deliberate \& } \\
\text { emergent }\end{array}$} \\
\hline $\begin{array}{l}\text { Emergent to } \\
\text { deliberate }\end{array}$ & $26 \mathrm{~F}(\mathrm{E})$ & $2 \mathrm{~F}(\mathrm{E}), 13 \mathrm{E}(\mathrm{E}, \mathrm{H})$ & $8 \mathrm{D}(\mathrm{E}, \mathrm{I})$ & \\
\hline $\begin{array}{l}\text { Deliberate to } \\
\text { emergent }\end{array}$ & & $22 \mathrm{D}(\mathrm{E}, \mathrm{H})$ & $10 \mathrm{C}(\mathrm{E}), 30 \mathrm{C}(\mathrm{H}, \mathrm{I})$ & $4 \mathrm{~B}(\mathrm{H}), 16 \mathrm{C}(\mathrm{E})$ \\
\hline $\begin{array}{l}\text { No change due to } \\
\text { incubator influence }\end{array}$ & 9 & 6 & 3 & 6 \\
\hline \multicolumn{5}{|l|}{$\begin{array}{l}\text { Partnership status } \\
\text { cont. }\end{array}$} \\
\hline $\begin{array}{l}\text { Shareholders } \\
\text { increased }\end{array}$ & $\begin{array}{l}\text { 18C(K, O), 20E(J, } \\
\mathrm{K}), 33 \mathrm{~A}(\mathrm{E}, \mathrm{R})\end{array}$ & $7 \mathrm{D}(\mathrm{I}), 13 \mathrm{E}(\mathrm{C}, \mathrm{K})$ & & $\begin{array}{l}\text { 1B(I), 4B(S), } \\
16 \mathrm{C}(\mathrm{B})\end{array}$ \\
\hline $\begin{array}{l}\text { Governance } \\
\text { increased }\end{array}$ & & $6 \mathrm{C}(\mathrm{K}, \mathrm{R})$ & $32 \mathrm{~A}(\mathrm{~K}, \mathrm{R})$ & \\
\hline $\begin{array}{l}\text { No change due to } \\
\text { incubator influence }\end{array}$ & 7 & 6 & 5 & 5 \\
\hline \multicolumn{5}{|l|}{ Product scope cont. } \\
\hline $\begin{array}{l}\text { Product scope } \\
\text { increased }\end{array}$ & $20 \mathrm{E}(\mathrm{E}), 28 \mathrm{E}(\mathrm{E}, \mathrm{F})$ & & $8 \mathrm{D}(\mathrm{E})$ & $17 \mathrm{D}(\mathrm{E}, \mathrm{H}), 23 \mathrm{E}(\mathrm{E})$ \\
\hline $\begin{array}{l}\text { Product more } \\
\text { scalable }\end{array}$ & $21 \mathrm{C}(\mathrm{F}, \mathrm{H})$ & $\begin{array}{l}3 \mathrm{~F}(\mathrm{~F}), 6 \mathrm{C}(\mathrm{F}) \\
29 \mathrm{~B}(\mathrm{E})\end{array}$ & $10 \mathrm{C}(\mathrm{E}, \mathrm{S})$ & $4 \mathrm{~B}(\mathrm{E})$ \\
\hline Product evolved & $9 \mathrm{~A}(\mathrm{H}), 33 \mathrm{~A}(\mathrm{~F})$ & $\begin{array}{l}2 \mathrm{~F}(\mathrm{~S}), 7 \mathrm{D}(\mathrm{H}), \\
13 \mathrm{E}(\mathrm{H}), 15 \mathrm{~A}(\mathrm{H}), \\
22 \mathrm{D}(\mathrm{E}, \mathrm{H})\end{array}$ & $14 \mathrm{D}(\mathrm{E})$ & $\begin{array}{l}1 \mathrm{~B}(\mathrm{E}, \mathrm{H}), 11 \mathrm{D}(\mathrm{E}, \\
\mathrm{H}), 25 \mathrm{E}(\mathrm{F}, \mathrm{H})\end{array}$ \\
\hline $\begin{array}{l}\text { Product was } \\
\text { different }\end{array}$ & $\begin{array}{l}18 \mathrm{C}(\mathrm{E}, \mathrm{O}), 31 \mathrm{D}(\mathrm{E}, \\
\mathrm{H})\end{array}$ & & $30 \mathrm{C}(\mathrm{E}, \mathrm{I}, \mathrm{S})$ & $16 \mathrm{C}(\mathrm{E})$ \\
\hline $\begin{array}{l}\text { Product scope } \\
\text { reduced }\end{array}$ & $\begin{array}{l}27 \mathrm{~F}(\mathrm{E}, \mathrm{H}, \mathrm{P} \text { ceased } \\
\text { firm) }\end{array}$ & & $19 \mathrm{D}(\mathrm{E})$ & \\
\hline $\begin{array}{l}\text { No change due to } \\
\text { incubator influence }\end{array}$ & 2 & 1 & 1 & 1 \\
\hline \multicolumn{5}{|l|}{$\begin{array}{l}\text { Competitive } \\
\text { emphasis }\end{array}$} \\
\hline $\begin{array}{l}\text { Competitive } \\
\text { emphasis increased }\end{array}$ & $\begin{array}{l}18 \mathrm{C}(\mathrm{E}), 21 \mathrm{C}(\mathrm{H}, \mathrm{Q}, \\
\mathrm{S})\end{array}$ & $\begin{array}{l}12 \mathrm{D}(\mathrm{E}), 13 \mathrm{E}(\mathrm{E}), \\
15 \mathrm{~A}(\mathrm{E}), 22 \mathrm{D}(\mathrm{H})\end{array}$ & & $4 \mathrm{~B}(\mathrm{P}), 16 \mathrm{C}(\mathrm{P})$ \\
\hline $\begin{array}{l}\text { Competitive } \\
\text { emphasis refined }\end{array}$ & $31 \mathrm{D}(\mathrm{U})$ & $7 \mathrm{D}(\mathrm{H}, \mathrm{S}), 29 \mathrm{~B}(\mathrm{E})$ & $\begin{array}{l}\text { 8D(E), 10C(E), } \\
30 \mathrm{C}(\mathrm{E}, \mathrm{I})\end{array}$ & $\begin{array}{l}11 \mathrm{D}(\mathrm{U}), 17 \mathrm{D}(\mathrm{H}), \\
23 \mathrm{E}(\mathrm{E}), 24 \mathrm{~B}(\mathrm{H})\end{array}$ \\
\hline Market changed & $9 \mathrm{~A}(\mathrm{H})$ & $6 \mathrm{C}(\mathrm{I})$ & $32 \mathrm{~A}(\mathrm{~T})$ & \\
\hline $\begin{array}{l}\text { No change } \\
\text { attributable to } \\
\text { incubator influence }\end{array}$ & 6 & 2 & 2 & 2 \\
\hline \multicolumn{5}{|l|}{ Time allocation } \\
\hline Switched focus & $26 \mathrm{~F}(\mathrm{E}, \mathrm{S})$ & $13 \mathrm{E}(\mathrm{C})$ & $8 \mathrm{D}(\mathrm{E}), 14 \mathrm{D}(\mathrm{E})$ & $17 \mathrm{D}(\mathrm{H})$ \\
\hline More efficient & & $2 \mathrm{~F}(\mathrm{E})$ & $10 \mathrm{C}(\mathrm{E})$ & $4 \mathrm{~B}(\mathrm{E})$ \\
\hline $\begin{array}{l}\text { No change due to } \\
\text { incubator influence }\end{array}$ & 9 & 7 & 3 & 6 \\
\hline
\end{tabular}


Table 73

Stage of Development on Entry Compared to Types of Strategy Developments

\begin{tabular}{|c|c|c|c|}
\hline & Concept only (13 firms) & $\begin{array}{l}\text { Prototype developed (11 } \\
\text { firms) }\end{array}$ & $\begin{array}{l}\text { Already trading (9 } \\
\text { firms) }\end{array}$ \\
\hline \multicolumn{4}{|l|}{ Goal orientation } \\
\hline Goals increased & $7 \mathrm{D}(\mathrm{H}), 18 \mathrm{C}(\mathrm{E}), 23 \mathrm{E}(\mathrm{E})$ & $1 \mathrm{~B}(\mathrm{E}), 15 \mathrm{~A}(\mathrm{E}, \mathrm{I})$ & $\begin{array}{l}\text { 6C(E), 8D(E, J), } 19 \mathrm{D}(\mathrm{H}), \\
29 \mathrm{~B}(\mathrm{E})\end{array}$ \\
\hline Goals more precise & 5D(E), 17D(H), 26F(I) & $13 \mathrm{E}(\mathrm{E})$ & $31 \mathrm{D}(\mathrm{E})$ \\
\hline Goals reduced & $10 \mathrm{C}(\mathrm{E})$ & $24 \mathrm{~B}(\mathrm{H})$ & \\
\hline $\begin{array}{l}\text { No change attributable } \\
\text { to incubator influence }\end{array}$ & 5 & 7 & 4 \\
\hline \multicolumn{4}{|l|}{ Planning continuum } \\
\hline Planning increased & $2 \mathrm{~F}(\mathrm{E}, \mathrm{I}), 5 \mathrm{D}(\mathrm{E}), 7 \mathrm{D}(\mathrm{E})$ & $15 \mathrm{~A}(\mathrm{E}, \mathrm{I}), 22 \mathrm{D}(\mathrm{E}, \mathrm{H})$ & $12 \mathrm{D}(\mathrm{E}), 31 \mathrm{D}(\mathrm{E})$ \\
\hline Planning more precise & $10 \mathrm{C}(\mathrm{E}, \mathrm{H}, \mathrm{U})$ & $13 \mathrm{E}(\mathrm{I})$ & \\
\hline Planning reduced & $30 \mathrm{C}(\mathrm{E}, \mathrm{H})$ & & 4B(E, H), 6C(E), 16C(E) \\
\hline $\begin{array}{l}\text { No change attributable } \\
\text { to incubator influence }\end{array}$ & 8 & 8 & 4 \\
\hline \multicolumn{4}{|l|}{ Deliberate \& emergent } \\
\hline Emergent to deliberate & $2 \mathrm{~F}(\mathrm{E}), 26 \mathrm{~F}(\mathrm{E})$ & $13 \mathrm{E}(\mathrm{E}, \mathrm{H})$ & $8 \mathrm{D}(\mathrm{E}, \mathrm{I})$ \\
\hline Deliberate to emergent & $10 \mathrm{C}(\mathrm{E}), 30 \mathrm{C}(\mathrm{H}, \mathrm{I})$ & $22 \mathrm{D}(\mathrm{E}, \mathrm{H})$ & $4 \mathrm{~B}(\mathrm{H}), 16 \mathrm{C}(\mathrm{E})$ \\
\hline No change & 9 & 9 & 6 \\
\hline \multicolumn{4}{|l|}{ Partnership status cont. } \\
\hline Shareholders increased & $\begin{array}{l}7 \mathrm{D}(\mathrm{I}), 18 \mathrm{C}(\mathrm{K}, \mathrm{O}), 20 \mathrm{E}(\mathrm{J}, \\
\mathrm{K})\end{array}$ & $\begin{array}{l}\text { 1B(I), 13E(C, K), 33A(E, } \\
\mathrm{R})\end{array}$ & $4 \mathrm{~B}(\mathrm{~S}), 16 \mathrm{C}(\mathrm{B})$ \\
\hline Governance increased & $32 \mathrm{~A}(\mathrm{~K}, \mathrm{R})$ & & $6 \mathrm{C}(\mathrm{K}, \mathrm{R})$ \\
\hline $\begin{array}{l}\text { No change attributable } \\
\text { to incubator influence }\end{array}$ & 11 & 8 & 6 \\
\hline \multicolumn{4}{|l|}{ Product scope cont. } \\
\hline $\begin{array}{l}\text { Product scope } \\
\text { increased }\end{array}$ & $\begin{array}{l}17 \mathrm{D}(\mathrm{E}, \mathrm{H}), 20 \mathrm{E}(\mathrm{E}), \\
28 \mathrm{E}(\mathrm{E}, \mathrm{F}), 23 \mathrm{E}(\mathrm{E})\end{array}$ & & $8 \mathrm{D}(\mathrm{E})$ \\
\hline Product more scalable & $10 \mathrm{C}(\mathrm{E}, \mathrm{S})$ & $21 \mathrm{C}(\mathrm{F}, \mathrm{H})$ & $\begin{array}{l}3 \mathrm{~F}(\mathrm{~F}), 4 \mathrm{~B}(\mathrm{E}), 6 \mathrm{C}(\mathrm{F}), \\
29 \mathrm{~B}(\mathrm{E})\end{array}$ \\
\hline Product evolved & $2 \mathrm{~F}(\mathrm{~S}), 14 \mathrm{D}(\mathrm{E})$ & $\begin{array}{l}\text { 1B(E, H), 7D(H), 9A(H), } \\
\text { 11D(E, H), 13E }(\mathrm{H}), \\
\text { 15A(H), 22D(E, H), } \\
\text { 25E(F, H), 33A(F) }\end{array}$ & \\
\hline Product was different & 18C(E, O), 30C(E, I, S) & & $16 \mathrm{C}(\mathrm{E}), 31 \mathrm{D}(\mathrm{E}, \mathrm{H})$ \\
\hline $\begin{array}{l}\text { Product scope } \\
\text { decreased }\end{array}$ & & 27F(E, H, P ceased firm) & $19 \mathrm{D}(\mathrm{E})$ \\
\hline $\begin{array}{l}\text { No change attributable } \\
\text { to incubator influence }\end{array}$ & 4 & 0 & 1 \\
\hline \multicolumn{4}{|l|}{ Competitive emphasis } \\
\hline $\begin{array}{l}\text { Competitive emphasis } \\
\text { increased }\end{array}$ & $18 \mathrm{C}(\mathrm{E})$ & $\begin{array}{l}13 \mathrm{E}(\mathrm{E}), 15 \mathrm{~A}(\mathrm{E}), 21 \mathrm{C}(\mathrm{H}, \\
\mathrm{Q}, \mathrm{S}), 22 \mathrm{D}(\mathrm{H})\end{array}$ & 4B(P), 12D(E), 16C(P) \\
\hline $\begin{array}{l}\text { Competitive emphasis } \\
\text { refined }\end{array}$ & $\begin{array}{l}7 \mathrm{D}(\mathrm{H}, \mathrm{S}), 10 \mathrm{C}(\mathrm{E}), \\
17 \mathrm{D}(\mathrm{H}), 23 \mathrm{E}(\mathrm{E}), 30 \mathrm{C}(\mathrm{E}, \\
\mathrm{I})\end{array}$ & $11 \mathrm{D}(\mathrm{U}), 24 \mathrm{~B}(\mathrm{H})$ & $8 \mathrm{D}(\mathrm{E}), 29 \mathrm{~B}(\mathrm{E}), 31 \mathrm{D}(\mathrm{U})$ \\
\hline Market changed & $32 \mathrm{~A}(\mathrm{~T})$ & $9 \mathrm{~A}(\mathrm{H})$ & $6 \mathrm{C}(\mathrm{I})$ \\
\hline $\begin{array}{l}\text { No change attributable } \\
\text { to incubator influence }\end{array}$ & 6 & 2 & 2 \\
\hline \multicolumn{4}{|l|}{ Time allocation } \\
\hline Switched focus & $\begin{array}{l}26 \mathrm{~F}(\mathrm{E}, \mathrm{S}) 14 \mathrm{D}(\mathrm{E}), \\
17 \mathrm{D}(\mathrm{H})\end{array}$ & $13 \mathrm{E}(\mathrm{C})$ & $8 \mathrm{D}(\mathrm{E})$ \\
\hline More efficient & $2 \mathrm{~F}(\mathrm{E}), 10 \mathrm{C}(\mathrm{E})$ & & $4 \mathrm{~B}(\mathrm{E})$ \\
\hline $\begin{array}{l}\text { No change attributable } \\
\text { to incubator influence }\end{array}$ & 8 & 10 & 7 \\
\hline
\end{tabular}


Table 74

Level of Interaction with Advisor Compared to Types of Strategy Developments

\begin{tabular}{|c|c|c|c|}
\hline & Almost daily (9 firms) & $\begin{array}{l}\text { Several times a month } \\
\text { (18 firms) }\end{array}$ & $\begin{array}{l}\text { Once a month or less } \\
\text { (6 firms) }\end{array}$ \\
\hline \multicolumn{4}{|l|}{ Goal orientation } \\
\hline Goals increased & 18C(E), 23E(E) & $\begin{array}{l}\text { 1B(E), 7D(H), 8D(E, J), } \\
15 \mathrm{~A}(\mathrm{E}, \mathrm{I}), 29 \mathrm{~B}(\mathrm{E})\end{array}$ & $6 \mathrm{C}(\mathrm{E}), 19 \mathrm{D}(\mathrm{H})$ \\
\hline Goals more precise & & $\begin{array}{l}\text { 5D(E), 13E(E), 17D }(\mathrm{H}), \\
26 \mathrm{~F}(\mathrm{I}), 31 \mathrm{D}(\mathrm{E})\end{array}$ & \\
\hline Goals reduced & & $10 \mathrm{C}(\mathrm{E}), 24 \mathrm{~B}(\mathrm{H})$ & \\
\hline $\begin{array}{l}\text { No change } \\
\text { attributable to } \\
\text { incubator influence }\end{array}$ & 7 & 6 & 2 \\
\hline \multicolumn{4}{|l|}{ Planning continuum } \\
\hline Planning increased & $22 \mathrm{D}(\mathrm{E}, \mathrm{H})$ & $\begin{array}{l}2 \mathrm{~F}(\mathrm{E}, \mathrm{I}), 5 \mathrm{D}(\mathrm{E}), 7 \mathrm{D}(\mathrm{E}), \\
15 \mathrm{~A}(\mathrm{E}, \mathrm{I}), 12 \mathrm{D}(\mathrm{E}), \\
31 \mathrm{D}(\mathrm{E})\end{array}$ & \\
\hline Planning more precise & & $10 \mathrm{C}(\mathrm{E}, \mathrm{H}, \mathrm{U}), 13 \mathrm{E}(\mathrm{I})$ & \\
\hline Planning reduced & 4B(E, H), 30C $(\mathrm{E}, \mathrm{H})$ & $16 \mathrm{C}(\mathrm{E})$ & $6 \mathrm{C}(\mathrm{E})$ \\
\hline $\begin{array}{l}\text { No change } \\
\text { attributable to } \\
\text { incubator influence }\end{array}$ & 6 & 9 & 3 \\
\hline \multicolumn{4}{|l|}{$\begin{array}{l}\text { Deliberate } \& \\
\text { emergent }\end{array}$} \\
\hline $\begin{array}{l}\text { Emergent to } \\
\text { deliberate }\end{array}$ & & $\begin{array}{l}2 \mathrm{~F}(\mathrm{E}), 8 \mathrm{D}(\mathrm{E}, \mathrm{I}), 13 \mathrm{E}(\mathrm{E}, \\
\mathrm{H}), 26 \mathrm{~F}(\mathrm{E})\end{array}$ & \\
\hline $\begin{array}{l}\text { Deliberate to } \\
\text { emergent }\end{array}$ & $\begin{array}{l}4 \mathrm{~B}(\mathrm{H}), 22 \mathrm{D}(\mathrm{E}, \mathrm{H}) \\
30 \mathrm{C}(\mathrm{H}, \mathrm{I})\end{array}$ & $10 \mathrm{C}(\mathrm{E}), 16 \mathrm{C}(\mathrm{E})$ & \\
\hline $\begin{array}{l}\text { No change } \\
\text { attributable to } \\
\text { incubator influence }\end{array}$ & 6 & 12 & 6 \\
\hline \multicolumn{4}{|l|}{$\begin{array}{l}\text { Partnership status } \\
\text { cont. }\end{array}$} \\
\hline $\begin{array}{l}\text { Shareholders } \\
\text { increased }\end{array}$ & $\begin{array}{l}4 \mathrm{~B}(\mathrm{~S}), 18 \mathrm{C}(\mathrm{K}, \mathrm{O}) \\
20 \mathrm{E}(\mathrm{J}, \mathrm{K})\end{array}$ & $\begin{array}{l}\text { 1B(I), 7D(I), 13E(C, K), } \\
16 \mathrm{C}(\mathrm{B}), 33 \mathrm{~A}(\mathrm{E}, \mathrm{R})\end{array}$ & \\
\hline Governance increased & $32 \mathrm{~A}(\mathrm{~K}, \mathrm{R})$ & & $6 \mathrm{C}(\mathrm{K}, \mathrm{R})$ \\
\hline $\begin{array}{l}\text { No change } \\
\text { attributable to } \\
\text { incubator influence }\end{array}$ & 5 & 13 & 5 \\
\hline \multicolumn{4}{|l|}{ Product scope cont. } \\
\hline $\begin{array}{l}\text { Product scope } \\
\text { increased }\end{array}$ & $\begin{array}{l}20 \mathrm{E}(\mathrm{E}), 23 \mathrm{E}(\mathrm{E}), 28 \mathrm{E}(\mathrm{E}, \\
\mathrm{F})\end{array}$ & $8 \mathrm{D}(\mathrm{E}), 17 \mathrm{D}(\mathrm{E}, \mathrm{H})$ & \\
\hline Product more scalable & $4 \mathrm{~B}(\mathrm{E})$ & $\begin{array}{l}\text { 10C(E, S), 21C(F, H), } \\
29 B(E)\end{array}$ & $3 \mathrm{~F}(\mathrm{~F}), 6 \mathrm{C}(\mathrm{F})$ \\
\hline Product evolved & $14 \mathrm{D}(\mathrm{E}), 22 \mathrm{D}(\mathrm{E}, \mathrm{H})$ & $\begin{array}{l}1 \mathrm{~B}(\mathrm{E}, \mathrm{H}), 2 \mathrm{~F}(\mathrm{~S}), 7 \mathrm{D}(\mathrm{H}) \\
13 \mathrm{E}(\mathrm{H}), 15 \mathrm{~A}(\mathrm{H}), 25 \mathrm{E}(\mathrm{F}, \\
\mathrm{H}), 33 \mathrm{~A}(\mathrm{~F})\end{array}$ & $9 \mathrm{~A}(\mathrm{H}), 11 \mathrm{D}(\mathrm{E}, \mathrm{H})$ \\
\hline Product was different & 18C(E, O), 30C(E, I, S) & $16 \mathrm{C}(\mathrm{E}), 31 \mathrm{D}(\mathrm{E}, \mathrm{H})$ & \\
\hline $\begin{array}{l}\text { Product scope } \\
\text { reduced }\end{array}$ & & & $\begin{array}{l}19 \mathrm{D}(\mathrm{E}), 27 \mathrm{~F}(\mathrm{E}, \mathrm{H}, \mathrm{P} \\
\text { ceased firm })\end{array}$ \\
\hline $\begin{array}{l}\text { No change } \\
\text { attributable to } \\
\text { incubator influence }\end{array}$ & 1 & 4 & 0 \\
\hline \multicolumn{4}{|l|}{ Competitive emphasis } \\
\hline $\begin{array}{l}\text { Competitive emphasis } \\
\text { increased }\end{array}$ & $4 \mathrm{~B}(\mathrm{P}), 18 \mathrm{C}(\mathrm{E}), 22 \mathrm{D}(\mathrm{H})$ & $\begin{array}{l}\text { 12D(E), 13E(E), 15A(E), } \\
16 \mathrm{C}(\mathrm{P}), 21 \mathrm{C}(\mathrm{H}, \mathrm{Q}, \mathrm{S})\end{array}$ & \\
\hline $\begin{array}{l}\text { Competitive emphasis } \\
\text { refined }\end{array}$ & $23 \mathrm{E}(\mathrm{E}), 30 \mathrm{C}(\mathrm{E}, \mathrm{I})$ & $\begin{array}{l}7 \mathrm{D}(\mathrm{H}, \mathrm{S}), 8 \mathrm{D}(\mathrm{E}), 10 \mathrm{C}(\mathrm{E}), \\
17 \mathrm{D}(\mathrm{H}), 24 \mathrm{~B}(\mathrm{H}), 29 \mathrm{~B}(\mathrm{E}), \\
31 \mathrm{D}(\mathrm{U})\end{array}$ & $11 \mathrm{D}(\mathrm{U})$ \\
\hline Market changed & $32 \mathrm{~A}(\mathrm{~T})$ & & $6 \mathrm{C}(\mathrm{I}), 9 \mathrm{~A}(\mathrm{H})$ \\
\hline
\end{tabular}




\begin{tabular}{|l|l|l|l|}
\hline $\begin{array}{l}\text { No change } \\
\text { attributable to } \\
\text { incubator influence }\end{array}$ & 3 & 6 & 3 \\
\hline Time allocation & & & \\
\hline Switched focus & $14 \mathrm{D}(\mathrm{E})$ & $8 \mathrm{D}(\mathrm{E}), 13 \mathrm{E}(\mathrm{C}), 17 \mathrm{D}(\mathrm{H})$ & \\
\hline More efficient & $4 \mathrm{~B}(\mathrm{E})$ & $2 \mathrm{~F}(\mathrm{E}), 10 \mathrm{C}(\mathrm{E}), 26 \mathrm{~F}(\mathrm{E}, \mathrm{S})$ & \\
\hline $\begin{array}{l}\text { No change } \\
\text { attributable to } \\
\text { incubator influence }\end{array}$ & 7 & 12 & 6 \\
\hline
\end{tabular}


Table 75

Location of Head Office Compared to Types of Strategy Developments

\begin{tabular}{|c|c|c|c|}
\hline & In incubator (13 firms) & $\begin{array}{l}\text { At home of founder ( } 9 \\
\text { firms) }\end{array}$ & $\begin{array}{l}\text { In separate office (11 } \\
\text { firms) }\end{array}$ \\
\hline \multicolumn{4}{|l|}{ Goal orientation } \\
\hline Goals increased & $1 \mathrm{~B}(\mathrm{E}), 23 \mathrm{E}(\mathrm{E})$ & $\begin{array}{l}\text { 8D(E, J), 15A(E, I), } \\
19 \mathrm{D}(\mathrm{H}), 29 \mathrm{~B}(\mathrm{E})\end{array}$ & $6 \mathrm{C}(\mathrm{E}), 7 \mathrm{D}(\mathrm{H}), 18 \mathrm{C}(\mathrm{E})$ \\
\hline Goals more precise & & $31 \mathrm{D}(\mathrm{E})$ & $\begin{array}{l}\text { 5D(E), 13E(E), 17D(H), } \\
26 \mathrm{~F}(\mathrm{I})\end{array}$ \\
\hline Goals reduced & $10 \mathrm{C}(\mathrm{E}), 24 \mathrm{~B}(\mathrm{H})$ & & \\
\hline $\begin{array}{l}\text { No change attributable } \\
\text { to incubator influence }\end{array}$ & 9 & 4 & 4 \\
\hline \multicolumn{4}{|l|}{ Planning continuum } \\
\hline Planning increased & $22 \mathrm{D}(\mathrm{E}, \mathrm{H})$ & $\begin{array}{l}2 \mathrm{~F}(\mathrm{E}, \mathrm{I}), 15 \mathrm{~A}(\mathrm{E}, \mathrm{I}), \\
31 \mathrm{D}(\mathrm{E})\end{array}$ & 5D(E), 7D(E), 12D(E) \\
\hline Planning more precise & $10 \mathrm{C}(\mathrm{E}, \mathrm{H}, \mathrm{U})$ & & $13 \mathrm{E}(\mathrm{I})$ \\
\hline Planning reduced & 4B(E,H), 30C $(\mathrm{E}, \mathrm{H})$ & & $6 \mathrm{C}(\mathrm{E}), 16 \mathrm{C}(\mathrm{E})$ \\
\hline $\begin{array}{l}\text { No change attributable } \\
\text { to incubator influence }\end{array}$ & 9 & 6 & 5 \\
\hline \multicolumn{4}{|l|}{ Deliberate \& emergent } \\
\hline Emergent to deliberate & & $2 \mathrm{~F}(\mathrm{E}), 8 \mathrm{D}(\mathrm{E}, \mathrm{I})$ & 13E(E, H), 26F(E) \\
\hline Deliberate to emergent & $\begin{array}{l}4 \mathrm{~B}(\mathrm{H}), 10 \mathrm{C}(\mathrm{E}), 22 \mathrm{D}(\mathrm{E}, \\
\mathrm{H}), 30 \mathrm{C}(\mathrm{H}, \mathrm{I})\end{array}$ & & $16 \mathrm{C}(\mathrm{E})$ \\
\hline $\begin{array}{l}\text { No change attributable } \\
\text { to incubator influence }\end{array}$ & 9 & 7 & 8 \\
\hline \multicolumn{4}{|l|}{ Partnership status cont. } \\
\hline Shareholders increased & $\begin{array}{l}\text { 1B(I), 4B(S), 20E(J, K), } \\
33 \mathrm{~A}(\mathrm{E}, \mathrm{R})\end{array}$ & & $\begin{array}{l}7 \mathrm{D}(\mathrm{I}), 13 \mathrm{E}(\mathrm{C}, \mathrm{K}), 16 \mathrm{C}(\mathrm{B}), \\
18 \mathrm{C}(\mathrm{K}, \mathrm{O})\end{array}$ \\
\hline Governance increased & $32 \mathrm{~A}(\mathrm{~K}, \mathrm{R})$ & & $6 \mathrm{C}(\mathrm{K}, \mathrm{R})$ \\
\hline $\begin{array}{l}\text { No change attributable } \\
\text { to incubator influence }\end{array}$ & 8 & 9 & 6 \\
\hline \multicolumn{4}{|l|}{ Product scope cont. } \\
\hline $\begin{array}{l}\text { Product scope } \\
\text { increased }\end{array}$ & $\begin{array}{l}20 \mathrm{E}(\mathrm{E}), 23 \mathrm{E}(\mathrm{E}), 28 \mathrm{E}(\mathrm{E}, \\
\mathrm{F})\end{array}$ & $8 \mathrm{D}(\mathrm{E})$ & $17 \mathrm{D}(\mathrm{E}, \mathrm{H})$ \\
\hline Product more scalable & $\begin{array}{l}4 \mathrm{~B}(\mathrm{E}), 10 \mathrm{C}(\mathrm{E}, \mathrm{S}), 21 \mathrm{C}(\mathrm{F}, \\
\mathrm{H})\end{array}$ & $29 \mathrm{~B}(\mathrm{E})$ & $6 \mathrm{C}(\mathrm{F}), 3 \mathrm{~F}(\mathrm{~F})$ \\
\hline Product evolved & $\begin{array}{l}\text { 1B(E, H), 14D(E), } \\
\text { 22D(E, H), 33A(F) }\end{array}$ & $2 \mathrm{~F}(\mathrm{~S}), 9 \mathrm{~A}(\mathrm{H}), 15 \mathrm{~A}(\mathrm{H})$ & $\begin{array}{l}\text { 7D(H), 11D(E, H }) \\
13 \mathrm{E}(\mathrm{H}), 25 \mathrm{E}(\mathrm{F}, \mathrm{H})\end{array}$ \\
\hline Product was different & $30 \mathrm{C}(\mathrm{E}, \mathrm{I}, \mathrm{S})$ & $31 \mathrm{D}(\mathrm{E}, \mathrm{H})$ & $16 \mathrm{C}(\mathrm{E}), 18 \mathrm{C}(\mathrm{E}, \mathrm{O})$ \\
\hline Product scope reduced & & $\begin{array}{l}\text { 19D }(\mathrm{E}), 27 \mathrm{~F}(\mathrm{E}, \mathrm{H}, \mathrm{P} \\
\text { ceased firm) }\end{array}$ & \\
\hline $\begin{array}{l}\text { No change attributable } \\
\text { to incubator influence }\end{array}$ & 2 & 1 & 2 \\
\hline \multicolumn{4}{|l|}{ Competitive emphasis } \\
\hline $\begin{array}{l}\text { Competitive emphasis } \\
\text { increased }\end{array}$ & $\begin{array}{l}\text { 4B(P), 21C(H, Q, S }) \\
22 \mathrm{D}(\mathrm{H})\end{array}$ & $15 \mathrm{~A}(\mathrm{E})$ & $\begin{array}{l}12 \mathrm{D}(\mathrm{E}), 13 \mathrm{E}(\mathrm{E}), 16 \mathrm{C}(\mathrm{P}) \\
18 \mathrm{C}(\mathrm{E})\end{array}$ \\
\hline $\begin{array}{l}\text { Competitive emphasis } \\
\text { refined }\end{array}$ & $\begin{array}{l}10 \mathrm{C}(\mathrm{E}), 23 \mathrm{E}(\mathrm{E}), 24 \mathrm{~B}(\mathrm{H}), \\
30 \mathrm{C}(\mathrm{E}, \mathrm{I})\end{array}$ & $8 \mathrm{D}(\mathrm{E}), 29 \mathrm{~B}(\mathrm{E}), 31 \mathrm{D}(\mathrm{U})$ & $\begin{array}{l}\text { 7D(H, S }), 11 \mathrm{D}(\mathrm{U}) \\
17 \mathrm{D}(\mathrm{H})\end{array}$ \\
\hline Market changed & $32 \mathrm{~A}(\mathrm{~T})$ & $9 \mathrm{~A}(\mathrm{H})$ & $6 \mathrm{C}(\mathrm{I})$ \\
\hline $\begin{array}{l}\text { No change attributable } \\
\text { to incubator influence }\end{array}$ & 5 & 4 & 3 \\
\hline \multicolumn{4}{|l|}{ Time allocation } \\
\hline Switched focus & $14 \mathrm{D}(\mathrm{E})$ & $8 \mathrm{D}(\mathrm{E})$ & $\begin{array}{l}13 \mathrm{E}(\mathrm{C}), 17 \mathrm{D}(\mathrm{H}), 26 \mathrm{~F}(\mathrm{E}, \\
\text { S) }\end{array}$ \\
\hline More efficient & $4 \mathrm{~B}(\mathrm{E}), 10 \mathrm{C}(\mathrm{E})$ & $2 \mathrm{~F}(\mathrm{E})$ & \\
\hline $\begin{array}{l}\text { No change attributable } \\
\text { to incubator influence }\end{array}$ & 10 & 7 & 8 \\
\hline
\end{tabular}


Table 76

Background of Participant Compared to Types of Strategy Developments

\begin{tabular}{|c|c|c|c|c|}
\hline & $\begin{array}{l}\text { Technical(11 } \\
\text { firms) }\end{array}$ & $\begin{array}{l}\text { Industry(11 } \\
\text { firms) }\end{array}$ & $\begin{array}{l}\text { Business(7 } \\
\text { firms) }\end{array}$ & Other(4 firms) \\
\hline \multicolumn{5}{|l|}{ Goal orientation } \\
\hline Goals increased & $\begin{array}{l}\text { 1B(E), 18C(E), } \\
23 \mathrm{E}(\mathrm{E}), 29 \mathrm{~B}(\mathrm{E})\end{array}$ & $\begin{array}{l}6 \mathrm{C}(\mathrm{E}), 7 \mathrm{D}(\mathrm{H}) \\
15 \mathrm{~A}(\mathrm{E}, \mathrm{I})\end{array}$ & & $8 \mathrm{D}(\mathrm{E}, \mathrm{J})$ \\
\hline Goals more precise & $13 \mathrm{E}(\mathrm{E}), 17 \mathrm{D}(\mathrm{H})$ & $26 \mathrm{~F}(\mathrm{I})$ & $31 \mathrm{D}(\mathrm{E})$ & $5 \mathrm{D}(\mathrm{E})$ \\
\hline Goals reduced & & $10 \mathrm{C}(\mathrm{E})$ & $24 \mathrm{~B}(\mathrm{H})$ & \\
\hline $\begin{array}{l}\text { No change attributable } \\
\text { to incubator influence }\end{array}$ & 5 & 6 & 5 & 2 \\
\hline \multicolumn{5}{|l|}{ Planning continuum } \\
\hline Planning increased & $\begin{array}{l}\text { 12D(E), 22D(E, } \\
\mathrm{H})\end{array}$ & $\begin{array}{l}2 \mathrm{~F}(\mathrm{E}, \mathrm{I}), 7 \mathrm{D}(\mathrm{E}) \\
15 \mathrm{~A}(\mathrm{E}, \mathrm{I})\end{array}$ & $31 \mathrm{D}(\mathrm{E})$ & $5 \mathrm{D}(\mathrm{E})$ \\
\hline Planning more precise & $13 \mathrm{E}(\mathrm{I})$ & $10 \mathrm{C}(\mathrm{E}, \mathrm{H}, \mathrm{U})$ & & \\
\hline Planning reduced & & $6 \mathrm{C}(\mathrm{E}), 30 \mathrm{C}(\mathrm{E}, \mathrm{H})$ & $4 \mathrm{~B}(\mathrm{E}, \mathrm{H}), 16 \mathrm{C}(\mathrm{E})$ & \\
\hline $\begin{array}{l}\text { No change attributable } \\
\text { to incubator influence }\end{array}$ & 8 & 5 & 4 & 3 \\
\hline \multicolumn{5}{|l|}{ Deliberate \& emergent } \\
\hline Emergent to deliberate & $13 \mathrm{E}(\mathrm{E}, \mathrm{H})$ & $2 \mathrm{~F}(\mathrm{E}), 26 \mathrm{~F}(\mathrm{E})$ & & $8 \mathrm{D}(\mathrm{E}, \mathrm{I})$ \\
\hline Deliberate to emergent & $22 \mathrm{D}(\mathrm{E}, \mathrm{H})$ & $10 \mathrm{C}(\mathrm{E}), 30 \mathrm{C}(\mathrm{H}, \mathrm{I})$ & $4 \mathrm{~B}(\mathrm{H}), 16 \mathrm{C}(\mathrm{E})$ & \\
\hline No change & 9 & 7 & 5 & 3 \\
\hline \multicolumn{5}{|l|}{ Partnership status cont. } \\
\hline Shareholders increased & $\begin{array}{l}1 \mathrm{~B}(\mathrm{I}), 13 \mathrm{E}(\mathrm{C}, \mathrm{K}) \\
18 \mathrm{C}(\mathrm{K}, \mathrm{O}), 20 \mathrm{E}(\mathrm{J}, \\
\mathrm{K})\end{array}$ & $7 \mathrm{D}(\mathrm{I}), 16 \mathrm{C}(\mathrm{B})$ & $4 \mathrm{~B}(\mathrm{~S}), 33 \mathrm{~A}(\mathrm{E}, \mathrm{R})$ & \\
\hline Governance increased & & $6 \mathrm{C}(\mathrm{K}, \mathrm{R})$ & $32 \mathrm{~A}(\mathrm{~K}, \mathrm{R})$ & \\
\hline $\begin{array}{l}\text { No change attributable } \\
\text { to incubator influence }\end{array}$ & 7 & 8 & 4 & 4 \\
\hline \multicolumn{5}{|l|}{ Product scope cont. } \\
\hline $\begin{array}{l}\text { Product scope } \\
\text { increased }\end{array}$ & $\begin{array}{l}17 \mathrm{D}(\mathrm{E}, \mathrm{H}) \\
20 \mathrm{E}(\mathrm{E}), 23 \mathrm{E}(\mathrm{E}), \\
28 \mathrm{E}(\mathrm{E}, \mathrm{F})\end{array}$ & & & $8 \mathrm{D}(\mathrm{E})$ \\
\hline Product more scalable & $29 \mathrm{~B}(\mathrm{E})$ & $\begin{array}{l}3 \mathrm{~F}(\mathrm{~F}), 6 \mathrm{C}(\mathrm{F}) \\
10 \mathrm{C}(\mathrm{E}, \mathrm{S})\end{array}$ & $4 \mathrm{~B}(\mathrm{E})$ & $21 \mathrm{C}(\mathrm{F}, \mathrm{H})$ \\
\hline Product evolved & $\begin{array}{l}1 \mathrm{~B}(\mathrm{E}, \mathrm{H}), 13 \mathrm{E}(\mathrm{H}), \\
22 \mathrm{D}(\mathrm{E}, \mathrm{H}), 25 \mathrm{E}(\mathrm{F}, \\
\mathrm{H})\end{array}$ & $\begin{array}{l}2 \mathrm{~F}(\mathrm{~S}), 7 \mathrm{D}(\mathrm{H}), \\
9 \mathrm{~A}(\mathrm{H}), 11 \mathrm{D}(\mathrm{E}, \mathrm{H}), \\
15 \mathrm{~A}(\mathrm{H})\end{array}$ & $33 \mathrm{~A}(\mathrm{~F})$ & $14 \mathrm{D}(\mathrm{E})$ \\
\hline Product was different & $18 \mathrm{C}(\mathrm{E}, \mathrm{O})$ & $30 \mathrm{C}(\mathrm{E}, \mathrm{I}, \mathrm{S})$ & $\begin{array}{l}16 C(E), 31 D(E \\
H)\end{array}$ & \\
\hline Product scope reduced & & $\begin{array}{l}27 \mathrm{~F}(\mathrm{E}, \mathrm{H}, \mathrm{P} \\
\text { ceased firm })\end{array}$ & $19 \mathrm{D}(\mathrm{E})$ & \\
\hline $\begin{array}{l}\text { No change attributable } \\
\text { to incubator influence }\end{array}$ & 2 & 1 & 2 & 1 \\
\hline \multicolumn{5}{|l|}{ Competitive emphasis } \\
\hline $\begin{array}{l}\text { Competitive emphasis } \\
\text { increased }\end{array}$ & $\begin{array}{l}\text { 12D(E), 13E(E), } \\
18 \mathrm{C}(\mathrm{E}), 22 \mathrm{D}(\mathrm{H})\end{array}$ & $15 \mathrm{~A}(\mathrm{E})$ & 4B(P), 16C(P) & $21 \mathrm{C}(\mathrm{H}, \mathrm{Q}, \mathrm{S})$ \\
\hline $\begin{array}{l}\text { Competitive emphasis } \\
\text { refined }\end{array}$ & $\begin{array}{l}17 \mathrm{D}(\mathrm{H}), 23 \mathrm{E}(\mathrm{E}) \\
29 \mathrm{~B}(\mathrm{E})\end{array}$ & $\begin{array}{l}\text { 7D(H, S), 10C(E), } \\
11 \mathrm{D}(\mathrm{U}), 30 \mathrm{C}(\mathrm{E}, \mathrm{I})\end{array}$ & $24 \mathrm{~B}(\mathrm{H}), 31 \mathrm{D}(\mathrm{U})$ & $8 \mathrm{D}(\mathrm{E})$ \\
\hline Market changed & & $6 \mathrm{C}(\mathrm{I}), 9 \mathrm{~A}(\mathrm{H})$ & $32 \mathrm{~A}(\mathrm{~T})$ & \\
\hline $\begin{array}{l}\text { No change attributable } \\
\text { to incubator influence }\end{array}$ & 4 & 4 & 2 & 2 \\
\hline \multicolumn{5}{|l|}{ Time allocation } \\
\hline Switched focus & $13 \mathrm{E}(\mathrm{C}), 17 \mathrm{D}(\mathrm{H})$ & $26 \mathrm{~F}(\mathrm{E}, \mathrm{S})$ & & $8 \mathrm{D}(\mathrm{E}), 14 \mathrm{D}(\mathrm{E})$ \\
\hline More efficient & & $2 \mathrm{~F}(\mathrm{E}), 10 \mathrm{C}(\mathrm{E})$ & $4 \mathrm{~B}(\mathrm{E})$ & \\
\hline $\begin{array}{l}\text { No change attributable } \\
\text { to incubator influence }\end{array}$ & 9 & 8 & 4 & 2 \\
\hline
\end{tabular}




\section{References}

Aaboen, L., Lofsten, H., \& Bengtsson, L. (2011). Nourishment for the piggy bank: Facilitation of external financing in incubators. International Journal of Technology Transfer \& Commercialisation, 10(3-4), 254-374.

Abduh, M., D’Souza, C., Quazi, A., \& Burley, H. T. (2007). Investigating and classifying clients' satisfaction with business incubator services. Managing Service Quality, 17(1), 74 91.

Adkins, D. (2001). A report for the Japan Association of New Business Incubation Organisations (JANBO): Summary of the US Incubator Industry (Report No. EMCIS2010). Athens, $\mathrm{OH}$ : National Business Incubation Association.

Allen, R. S., \& Helms, M. M. (2006). Linking strategic practices and organizational performance to Porter's generic strategies. Business Process Management Journal, 12(4), 433-454.

Al-Mubaraki, H. M., \& Busler, M. (2012). Quantitative and qualitative approaches of incubators as value-added: Best practice model. Journal of American Academy of Business, Cambridge, 18(1), 238-245.

Al-Mubaraki, H. M., \& Busler, M. (2013). Business incubation as an economic development strategy: A literature review. International Journal of Management, 30(1), 362-372.

Al-Mubaraki, H. M., \& Hamad, E. (2013). Business incubation accelerator tool for 21st Century. Journal of American Academy of Business, Cambridge, 18(2), 233-237.

Anderson, P., \& Tushman, M. L. (1990). Technological discontinuities and dominant designs: A cyclical model of technological change. Administrative Science Quarterly, 35(4), 604-633.

Andres, H.P. \& Shipps, B.P. (2010). Team learning in technology-mediated distributed teams. Journal of Information Systems Education, 21(2), 213-221.

Armstrong, J. H., \& Mullin, J. R. (1983). The role of incubator industries in the local Economy: The Westfield, Massachusetts experience. Northeast Journal of Business \& Economics, 11(1), 35-44.

Barney, J. (1991). Firm resources and sustained competitive advantage. Journal of management, 17(1), 99-120.

Batavia Industrial Center. (2013). A place to start. Retrieved from http://www.bic4biz.com/our_approach.html

Bergek, A., \& Norrman, C. (2008). Incubator best practice: A framework. Technovation, 28(12), 20-28.

Bhide, A. 2000, The origin and evolution of new businesses, New York, NY: Oxford University Press.

Bio-Commerce Centre (BCC). (2013). Retrieved from http://www.thebcc.co.nz

Blank, S. G., \& Dorf, B. (2012). The startup owner's manual: The step-by-step guide for building a great company. Pescadero, CA: K \& S Ranch Publishers.

Boccardelli, P., \& Magnusson, M. G. (2006). Dynamic capabilities in early-phase entrepreneurship. Knowledge and Process Management, 13(3), 162-174. 
Bøllingtoft, A. (2012). The bottom-up business incubator: Leverage to networking and cooperation practices in a self-generated, entrepreneurial-enabled environment. Technovation, 32(5). 304-315.

Boschma, R. A. (2005). Proximity and innovation: A critical assessment. Regional Studies, 39(1), 61-74.

Boslaugh, S., \& Watters, P. A. (2008). Statistics in a nutshell: A desktop quick reference. Sebastopol, CA: O'Reilly Media.

Bowman-Upton, N., Seaman, S. L., \& Sexton, D. L. (1989) Innovation evaluation programmes: Do they help the inventors? Journal of Small Business Management 27(3), 23-30.

Bryman, A., \& Bell, E. (2011). Business research methods. Oxford, UK: Oxford University Press.

Bryson, J., Pajo, K., Ward, R. \& Mallon, M. (2006). Learning at work: Organisational affordances and individual engagement. Journal of Workplace Learning, 18(5), 279-297.

Burke, G. I., \& Jarratt, D. G. (2004). The influence of information and advice on competitive strategy definition in small- and medium-sized enterprises. Qualitative Market Research, 7(2), 126-138.

Callaghan Innovation. (2014). Retrieved from http://www.callaghaninnovation.govt.nz/what-we-do/funding-andgrants/incubators

Callaghan Innovation. (2015). Retrieved from https://www.callaghaninnovation.govt.nz/access-experts/incubators-andaccelerators/incubators

Cavana, R. Y., Delahaye, B. L., \& Sekaran, U. (2001). Applied business research: Qualitative and quantitative methods. Milton, Qld: Wiley.

Chandler, A. D., Jr., (1962). Strategy and structure. New York, NY: Doubleday.

Chemero, A. (2003). An outline of a theory of affordances. Ecological Psychology, 15(2), 181 195.

Chia, R., \& MacKay, B. (2007). Post-processual challenges for the emerging strategy-aspractice perspective: Discovering strategy in the logic of practice. Human relations, 60(1), 217-242.

Christie, T., \& Sjoquist, D. L. (2012). New business survival in Georgia: Exploring the determinants of survival using regional level data. Growth and Change, 43(1), 110-142.

Clausen, T., \& Korneliussen, T. (2012). The relationship between entrepreneurial orientation and speed to the market: The case of incubator firms in Norway. Technovation, 32(9), 560-567.

Cohn, D. M. (1981). Strategic business planning: A critical management tool for survival. Managerial Planning, 29(4), 4.

Cooper, A. C. (1981). Strategic management: New ventures and small business. Long Range Planning, 14(5), 39-45. 
Cooper, C. E., Hamel, S. A., \& Connaughton, S. L. (2012). Motivations and obstacles to networking in a university business incubator. Journal of Technology Transfer, 37(4), 433453.

Covin, J. G., \& Slevin, D. P. (1989). Strategic management of small firms in hostile and benign environments. Strategic Management Journal, 10(1), 75-87.

Cowling, M. (2003). Productivity and corporate governance in smaller firms. Small Business Economics, 20(4), 335-344.

Creative HQ. (2013). Retrieved from http://creativehq.co.nz/

Creswell, J., \& Clark, V. (2011). Designing and conducting mixed methods research. Los Angeles, CA: Sage Publications.

Crotty, M. (1998). The foundations of social research: Meaning and perspective in the research process. St Leonards, Australia: Allen \& Unwin.

Davidson, C., \& Tolich, M. (2003). Social science research in New Zealand: Many paths to understanding. Auckland, NZ: Pearson Prentice Hall.

Deligianni, I., \& Voudouris, I. (2011). New venture strategies and performance in a catchingup economy. Management Research Review, 34(7), 732-753.

Denzin, N. K., \& Lincoln, Y. S. (2005). Qualitative research. Thousand Oaks, CA: Sage Publications.

Easterby-Smith, M., Thorpe, R., \& Lowe, A. (2002). Management research methods.London, UK: Sage Publications.

Ecentre. (2013). Retrieved from http://www.ecentre.org.nz/

Economic Commission for Europe. (2001). Best practice in business incubation. New York, NY: United Nations Publications. Erlwine, M. \& Gerl, E. (Eds.). (2004). A comprehensive guide to business incubation (2nd ed.). Athens, Ohio: National Business Incubator Association (NBIA) Publications.

Erlewine, M., \& Gerl, E. (2004). A comprehensive guide to business incubation. National Business Incubation Association.Fayard, A., \& Weeks, J. (2007). Photocopiers and watercoolers: The affordances of informal interaction. Organization Studies, 28(5), 605-634.

Freeman, R. E. (2010). Strategic management: A stakeholder approach. Cambridge University Press.

Fry, F. L. (1987). The role of incubators in small business planning. American Journal of Small Business, 12(1), 51-61.

Gao, P. (2005). Using actor-network theory to analyse strategy formulation. Information Systems Journal, 15(3), 255-275.

Garnsey, E., \& Heffernan, P. (2005). Growth setbacks in new firms. Futures, 37(7), 675-697.

Gaspar, F. C. (2009). The stimulation of entrepreneurship through venture capital and business incubation. International Journal of Entrepreneurship and Innovation Management, 9(9), 396-415.

Gaver, W. (1991). Technology affordances. Retrieved from https://www.lri.fr/ mbl/Stanford/CS477/papers/Gaver-CHI1991.pdf

Gersick, C. J. G. (1994). Pacing strategic change: The case of a new venture. Academy of Management Journal, 37(1), 9-45. 
Gibson, J. J. (1977). The theory of affordances. Hilldale, USA.

Gibson, J. J. (1979) The ecological approach to visual perception. Boston, MA: Houghton Mifflin.

Goel, L., Johnson, N., Junglas, I., \& Ives, B. (2013), Predicting users' return to virtual worlds: A social perspective. Information Systems Journal, 23(1), 35-63.

Gram-Hanssen, K. \& Bech-Danielson, C. (2012). Creating a new home. Somali, Iraqi and Turkish immigrants and their homes in Danish social housing. Journal of Housing and the Built Environment, 27(1), 89-103.

Grimaldi, R., \& Grandi, A. (2005). Business incubators and new venture creation: An assessment of incubating models. Technovation, 25(2), 111-121.

Gstraunthaler, T. (2010). The business of business incubators: An institutional analysis evidence from Lithuania. Baltic Journal of Management, 5(3), 397-421.

Gupta, R., \& Pandit, A. (2012). Strategic entrepreneurial orientation: Development of a multi-dimensional construct based on literature review. South Asian Journal of Management, 19(4), 88-110.

Hackett, S. M., \& Dilts, D. M. (2004a). A real options-driven theory of business incubation. Journal of Technology Transfer, 29(1), 41-54.

Hackett, S. M., \& Dilts, D. M. (2004b). A systematic review of business incubation research. Journal of Technology Transfer, 29(1), 55-82.

Hannon, P. D. (2005). Incubation policy and practice: Building practitioner and professional capability. Journal of Small Business and Enterprise Development, 12(1), 57-75.

Harris, S., Forbes, T., \& Fletcher, M. (2000). Taught and enacted strategic approaches in young enterprises. International Journal of Entrepreneurial Behaviour \& Research, 6(3), 125145.

Hartson, R.(2003). Cognitive, physical, sensory, and strategy functional affordances in interaction design. Behaviour \& Information Technology, 22(5), 315-338.

Hetzner, S., Gartmeier, M., Heid, H., \& Gruber, H. (2009). The interplay between change and learning at the workplace: A qualitative study from retail banking. Journal of Workplace Learning, 21(5), 398-415.

Hsiu-Li, C. (2005). A competence-based strategic management model factoring in key success factors and benchmarking. Benchmarking, 12(4), 364-382.

Hughes, M., Hughes, P., \& Morgan, R. E. (2007). Exploitative learning and entrepreneurial orientation alignment in emerging young firms: Implications for market and response performance. British Journal of Management, 18(4), 359-375.

Hughes, M., Ireland, D., \& Morgan, R. (2007). Stimulating dynamic value: Social capital and business incubation as a pathway to competitive success. Long Range Planning 40(2) 154-177.

Icehouse. (2013). Retrieved from http://www.theicehouse.co.nz/

Incubators New Zealand. (2011a). Invest in the potential. Retrieved from http://www.incubators.org.nz/investors. html

Incubators New Zealand. (2011b). Realise the potential. Retrieved from http:/ /www.incubators.org.nz/entrepreneurs. Html 
Incubators New Zealand. (2011c). New Zealand incubation is world class. Retrieved from http:/ /www.incubators.org.nz/incubation. html

Jack, S. L., \& Anderson, A. R. (2002). The effects of embeddedness on the entrepreneurial process. Journal of Business Venturing, 17(5), 467-487.

Jarzabkowski, P. (2004). Strategy as Practice: Recursiveness, adaptation, and practices-in-use. Organization Studies, 25(4), 529-560.

Jarzabkowski, P., Balogun, J., \& Seidl, D. (2007). Strategizing: The challenges of a practice perspective. Human relations, 60(1), 5-27.

Joyce, S. (2013, October). New technology incubators to speed company start-ups. Retrieved from http://www.beehive.govt.nz/release/new-technology-incubators-speed-companystart-ups

Joyce, S. (2014, July). Company incubator network expands. Retrieved from http://www.beehive.govt.nz/release/company-incubator-network-expands

Kilcrease, K. M. (2011). Multi-factor assessment of service delivery in business Incubators: Perspectives from incubator tenents. Journal of Applied Management and Entrepreneurship, 16(2), 80-95.

Kiss, A. N. (2010). Opportunistic adaptation and new venture growth: Exploring the link between cognition, action and growth. (Unpublished doctoral dissertation). Georgia State University, Atlanta, GA.

Latour, B. (1996). On actor-network theory: a few clarifications. Soziale welt, 369-381.

Letiche, H., \& Lissack, M. (2009). Complexity and philosophy: Making room for affordances. E:CO, 11(3), 61-72.

Lewis, D. A., Harper-Anderson, E., \& Molnar, L. A. (2011). Incubating success. Incubation best practices that lead to successful new ventures. New York, NY: U.S. Department of Commerce, Economic Development Administration (EDA).

Lichtenstein, G. A. (1992). The significance of relationships in entrepreneurship: A case study of the ecology of enterprise in two business incubators. Dissertations available from ProQuest, 1-219.

Machold, S., Huse, M., Minichilli, A., \& Nordqvist, M. (2011). Board leadership and strategy involvement in small firms: A team production approach. Corporate Governance : An International Review, 19(4), 368-383.

Madichie, N. O. (2010). Business incubation in the UAE: Prospects for enterprise development. International Journal of Entrepreneurship and Innovation Management, 12(3/4), 291-310.

Mahto, R. V., \& Khanin, D. (2013). Speed of venture financing for emerging technologybased entrepreneurial firms as a function of founder reputation. Creativity and Innovation Management, 22(1), 84-95.

Maier, J. R. A. (2008). Rethinking design theory. Mechanical Engineering, 130(9), 34-37.

Marcouse, I. (2005). Business start-up: Success or failure? Business Review, 12(1), 32-34.

McAdam, M., \& Marlow, S. (2008). A preliminary investigation into networking activities within the university incubator. International Journal of Entrepreneurial Behaviour \& Research, 14(4), 219-241. 
McAdam, M., \& Marlow, S. (2011). Sense and sensibility: The role of business incubator client advisors in assisting high-technology entrepreneurs to make sense of investment readiness status. Entrepreneurship and Regional Development, 23(7-8). 449-468.

McGrenere, J. \& Ho, W. (2000). Affordances: Clarifying and evolving a concept. Retrieved from http://teaching.polishedsolid.com/spring2006/iti/read/affordances.pdf

Meru, A. K., \& Struwig, M. (2011). An evaluation of the entrepreneurs' perception of business-incubation services in Kenya. International Journal of Business Administration, 2(4). 112-121.

Miles, R., \& Snow, C. (1978). Organizational strategy, structure and process. London, UK: McGraw Hill.

Miller, D. (1983). The correlates of entrepreneurship in three types of firms. Management Science, 29(7), 770-791.

Miller, D., \& Friesen, P. (1983). Strategy-making and environment: The third link. Strategic Management Journal, 4(3), 221-235.

Minichilli, A., \& Hansen, C. (2007). The board advisory tasks in small firms and the event of crises. Journal of Management \& Governance, 11(1), 5-22.

Ministry of Business, Innovation and Employment (2012). Evaluation of the NZTE incubator support programme. Retrieved from http://www.mbie.govt.nz/publicationsresearch/publications/evaluation-of-governmentprogrammes/Evaluation $\% 20$ of $\% 20$ the $\% 20$ NZTE $\% 20$ Incubator $\% 20$ Support $\% 20$ Pro gramme.pdf

Mintzberg, H. (1973). Strategy-making in three modes. California Management Review, 16(2), 4453.

Mintzberg, H., \& Waters, J. A. (1985). Of strategies, deliberate and emergent. Strategic Management Journal, 6(3), 257-272.

Mitra, S.(2013). The problems with incubators, and how to solve them. Harvard Business Review. Retrieved from http://www.sramanamitra.com/2013/08/26/harvardbusiness-review-the-problems-with-incubators-and-how-to-solve-them/

Muniz, N., Morales-Gutiérrez, A. C., \& Ariza-Montes, J. (2013). Networking and business incubation processes. An empirical application of social network analysis. Interdisciplinary Journal of Contemporary Research in Business, 4(10)14-26.

Murphy, P. J., Wu, Z., Welsch, H., Heiser, D. R., Young, S. T., \& Jiang, B. (2012). Small firm entrepreneurial outsourcing: Traditional problems, nontraditional solutions. Strategic Outsourcing: An International Journal, 5(3), 248-275.

Nag, R., Hambrick, D. C., \& Chen, M.-J.(2007). What is strategic management, really? Inductive derivation of a consensus definition of the field. Strategic Management Journal, 28(9), 935-955.

National Business Incubation Association. (2013a). Frequently asked questions. Retrieved from Retrieved from http://nbia.org/resource_library/faq/index.php

National Business Incubation Association. (2013b). Program best practices. Retrieved from http://nbia.org/resource_library/best_practices/index.php 
National Business Incubation Association. (2013c). The history of business incubation. Retrieved from http://nbia.org/resource_library/history/index.php

National Business Incubation Association.(2013d). What is business incubation? Retrieved from http://nbia.org/resource_library/what_is/index.php

New Zealand Trade and Enterprise \& Incubators New Zealand. (2011). Celebrating 10 years of business incubation. Scoop Independent News. Retrieved from

http://www.scoop.co.nz/stories/BU1111/S01035/celebrating-10-years-of-businessincubation.htm

New Zealand Trade and Enterprise. (2013a). CHQ Board Presentation. Wellington, New Zealand.

New Zealand Trade and Enterprise. (2013b). Join a business incubator. Retrieved from http://www.nzte.govt.nz/get-ready-to-export/starting-a-business

New Zealand Trade and Enterprise. (2013c). Fund investment. Retrieved from http://www.nzte.govt.nz/en/invest/sectors-of-opportunity/fund-investment/

Nicholls-Nixon, C. L., Cooper, A. C., \& Woo, C. Y. (2000). Strategic experimentation: Understanding change and performance in new ventures. Journal of Business Venturing, 15(5,6), 493-521.

Norman, D. A. (1999). Affordance, conventions, and design. Interactions, 6(3), 38-43.

Nye, B. (2013). Cognitive modelling of socially transmitted affordances: A computational model of behavioural adoption tested against archival data from the Stanford Prison Experiment. Computational and Mathematical Organization Theory 20(3), 302-337.

O'Donnell, A., Gilmore, A., Cummins, D., \& Carson, D. (2001). The network construct in entrepreneurship research: a review and critique. Management Decision, 39(9), 749-760

O'Leary, Z. (2010). The essential guide to doing your research project. London, UK: Sage Publications.

Oliver, H., \& Garnsey, E. (2005). Problem-solving and competence creation in the early development of new firms. Managerial and Decision Economics, 26(2), 139-148.

Organisation for Economic Co-operation and Development (OECD). (1999). Small business, job creation and growth: Facts, obstacles and best practices. Retrieved from http://www.oecd.org/cfe/smes/2090740.pdf

O’Shaughnessy, N. J. (1986). Tactics for turnaround. Management Decision, 24(3), 3-6.

Oxford Dictionaries. (2013). Retrieved from http://oxforddictionaries.com/definition/english/

Patton, D., \& Marlow, S. (2011). University technology business incubators: helping new entrepreneurial firms to learn to grow. Environment and Planning-Part C, 29(5), 911.

Patton, D., Warren, L., \& Bream, D. (2009). Elements that underpin high-tech business incubation processes. The Journal of Technology Transfer, 34(6), 621-636.

Peters, L., Rice, M., \& Sundararajan, M. (2004). The role of incubators in the entrepreneurial process. Journal of Technology Transfer, 29(1), 83-91.

Pfeffer, J., \& Salancik, G. R. (2003). The external control of organizations: A resource dependence perspective. Stanford University Press. 
Phan, P. H., Siegel, D. S., \& Wright, M. (2005). Science parks and incubators: observations, synthesis and future research. Journal of business venturing, 20(2), 165-182

Porter, M. E. (1985), Competitive advantage: Creating and sustaining superior performance. New York, NY: The Free Press.

powerHouse. (2013). Retrieved from http:/ /www.powerhouse-ventures.co.nz/

Rice, M. P. (2002). Co-production of business assistance in business incubators: An exploratory study. Journal of Business Venturing, 17(2), 163-187.

Ries, E. (2011). The lean startup. New York, NY: Crown Business.

Rubens, A., Jackson, G., \& Andrews, C. (2011). Conducting a feasability analysis and assessing success of a business incubator: An applied study. Journal of Applied Management and Entrepreneurship, 16(2), 42-60.

Sadler, E., \& Given, L. M. (2007). Affordance theory: A framework for graduate students' information behavior. Journal of Documentation, 63(1), 115-141.

Savescu, D. (2010). Some aspects regarding the concept "Research for Business." Journal of Industrial Engineering and Management, 3(2), 337-352.

Scheirer, M. A. (1985). Innovation and Enterprise: A Study of NSF's Innovation Centers Program, Rockville, MD: Westat. Inc. and National Science Foundation.

Schwartz, M. (2011). Incubating an illusion? Long-term incubator firm performance after graduation. Growth and Change, 42(4), 491-516.

Schwartz, M., \& Hornych, C. (2012). Specialisation versus diversification: Perceived benefits of different business incubation models. International Journal of Entrepreneurship and Innovation Management, 15(3), 177-197.

Shahidi, H. (1998). The Impact of Business Incubators on Entrepreneurial Networking: A Comparative Study of Small. High-Technology Firms. George Mason University.

Sherman, H., \& Chappell, D. S. (1998). Methodological challenges in evaluating business incubator outcomes. Economic Development Quarterly, 12(4), 313-321.

Sherman, H. D. (1999). Assessing the intervention effectiveness of business incubation programs on new business start-ups. Journal of Developmental Entrepreneurship, 4(2), 117 133.

Singh, R. K., Garg, S. K. \& Deshmukh, S. G. (2008). Strategy development by SMEs for competitiveness: a review. Benchmarking: An international Journal, 15(5), 525-547.

Snow, C. C., \& Hambrick, D. C. (1980). Measuring organizational strategies: Some theoretical and methodological problems. Academy of Management Review, 5(4), 527-538.

Soda Inc. (2013). Retrieved from http://www.sodainc.com/

Stinchcombe, A.L. (1965), Social structure and organizations. (Ed.), Handbook of organizations, pp. 142-93. Rand McNally, Chicago, IL.

Strotmann, H. (2007). Entrepreneurial survival. Small Business Economics, 28(1), 87-104.

Tornatzky, L., McCrea, N., Lewis, M. (1996). The art \& craft of technology business incubator: Best practices, strategies, and tools from more than 50 programs. Athens, Ohio: National Business Incubation Association. 
Turvey, M. T. (1992). Affordances and prospective control: An outline of the ontology. Ecological Psychology, 4(3), 173-187.

University of Central Florida (UCF). (2013). The incubation process. Retrieved from http:/ /www.incubator.ucf.edu/incubationprogram/index.htmlUpstart. (2013). Retrieved from www.upstart.org.nz

University City Science Center. (2015). Who we are. Retrieved from https://www.sciencecenter.org/about-us

Vaara, E., \& Whittington, R. (2012). Strategy-as-practice: taking social practices seriously. The Academy of Management Annals, 6(1), 285-336.

Van Dijk, S., Berends, H., Jelinek, M., Rommer, A. \& Weggeman, M. (2011). Microinstitutional affordances and strategies of radical innovation. Organisation Studies 32(11), 1485-1513.

Van Gelderen, M. (2012). Perseverance strategies of enterprising individuals. International Journal of Entrepreneurial Behaviour \& Research, 18(6), 630-648.

Van Osch, W. and Mendelson, O. (2011). A typology of affordances: Untangling sociomaterial interactions through video analysis. Paper presented at the Thirty-Second International Conference on Information Systems, Shanghai, China.

Volberda, H. W., \& Lewin, A. Y. (2003). Co-evolutionary dynamics within and between firms: From evolution to co-evolution. Journal of management studies, 40(8), 2111-2136.

Warren, L., Patton, D., \& Bream, D. (2009). Knowledge acquisition processes during the incubation of new high technology firms. International Entrepreneurship and Management Journal, 5(4), 481-495.

Webb, J. (2012). The Current State of Incubation in New Zealand: Observations from an International Perspective for NZTE, CREED A Projects Pty Limited, New South Wales, Australia.

Weihrich, H. (1982). The TOWS matrix-A tool for situational analysis. Long Range Planning, 15(2), 54-66.

Wernerfelt, B. (1984). A resource-based view of the firm. Strategic management journal, 5(2), 171-180.

West, G. P., \& Meyer, G. D. (1997). Temporal dimensions of opportunistic change in technology-based ventures. Entrepreneurship Theory and Practice, 22(2), 31-52.

Whittington, R. (2000). What is strategy-And does it matter? (2nd ed.). Boston, MA: Cengage Learning (EMEA).

Whittington, R. (1996). Strategy as practice. Long range planning, 29(5), 731-735.

Wissema, J. G., van der Pol, H. W., \& Messer, H. M. (1980). Strategic management archetypes. Strategic Management Journal, 1(1) 37-47.

Woo, C. Y., Daellenbach, U., \& Nicholls-Nixon, C. (1994). Theory building in the presence of 'randomness': The case of venture creation and performance. Journal of Management Studies, 31(4), 507-524.

Xu, L. (2010). Business incubation in China: Effectiveness and perceived contributions to tenant enterprises. Management Research Review, 33(1), 90-99. 
Yang, H., Hutchison, S., Zinn, H., \& Watson, A. (2011). Discretionary time of Chinese college students: Activities and impact of SARS-induced constraints on choices. Social Indicators Research, 102(3), 517-535.

Yang, N. (2012). Small businesses and international entrepreneurship in the economic hard time: A global strategic perspective. International Journal of Entrepreneurship, 16, 113-131.

Zahra, S. A., Nash, S., \& Bickford, D. J. (1995). Transforming technological pioneering into competitive advantage. The Academy of Management Executive, 9(1), 17-31.

Zahra, S. A., \& Neubaum, D. O. (1998). Environmental adversity and the entrepreneurial activities of new ventures. Journal of Developmental Entrepreneurship, 3(2), 123-140.

Zhao, Y., Liu, J., Tang, J., \& Zhu, Q. (2013). Conceptualizing perceived affordances in social media interaction design. Aslib Proceedings, 65(3), 289-303.

Ziemer, N., \& Long, S. (2009). Collaborative networks as innovation accelerators. Retrieved from http:/ / citeseerx.ist.psu.edu/viewdoc/download?doi=10.1.1.169.1442\&rep=rep1\&typ $\mathrm{e}=\mathrm{pdf}$ 